جامعة الأزهر

كلية الدعوة الإسلامية بالإهاهرة

قسم الأديان والمذاهب

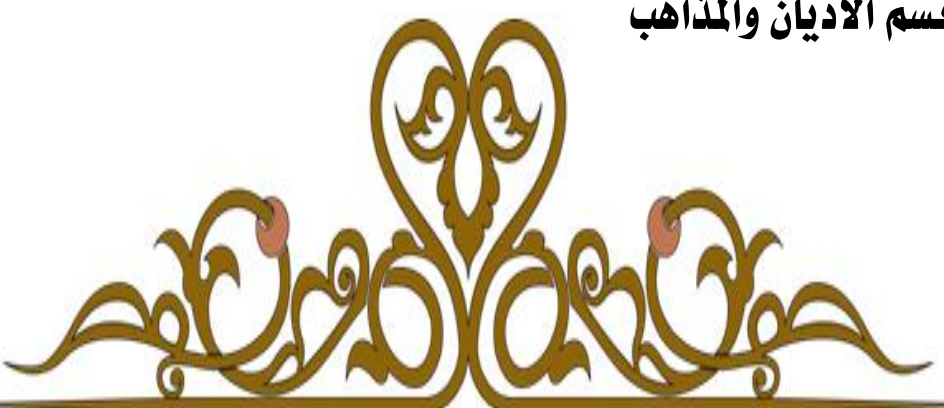

$$
\text { وصلته بأجنحة الاستشراق المكر الأربعة }
$$

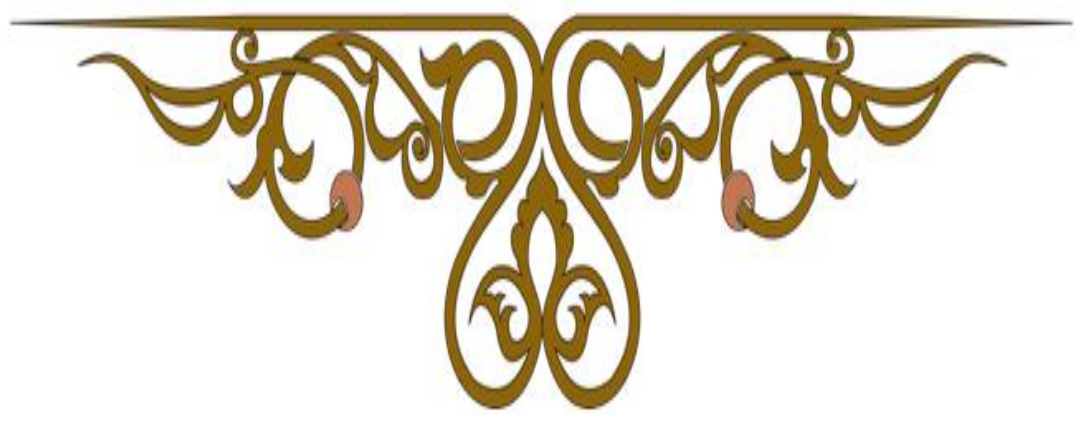

$$
\text { تأليف }
$$

أ • د / محمد محمل محمد إبراهيم كركور

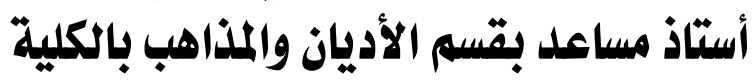

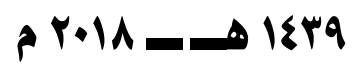

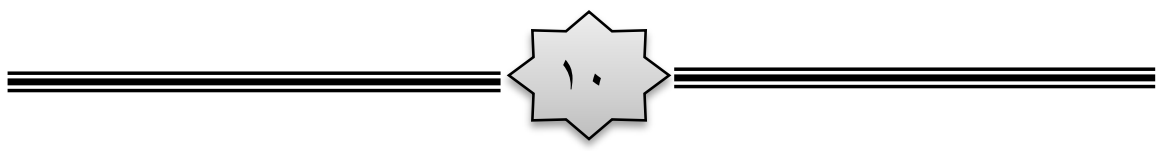




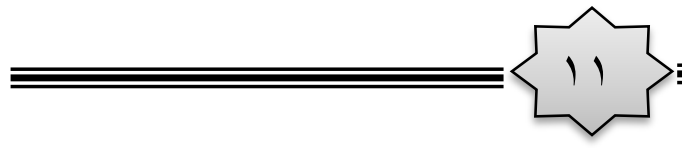




$$
\text { مفهوم الاستشراق }
$$

وصلته بأجنحة المكر الأربعة

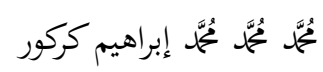

قسم الأديان والمذاهب، كلية الدعوة الإسلامية، جامعة الأزهر، القاهرة، مصر

Mohamedkarkoor.13@azhar.edu.eg البريد الإلكتروني:

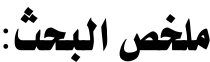

ترجع أهم أسباب اختيار هذا الموضوع إلى بيان مفهوم الاستشراق ، وإلقاء

الضـوه على بدايـة نشـأته، وأهم الأطوار التاريخيـة التي مـر بها، وبيـان أهم الأسباب التي يرمي إليها، والتركيز على بيان أجنحة المكر الأربعة، وتوضيح

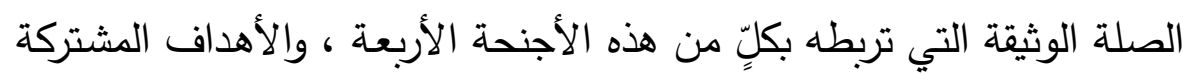
التي تجمعها، ويقوم هذا البحث على المنهج التاريخي الاستدلالي بجناحيه

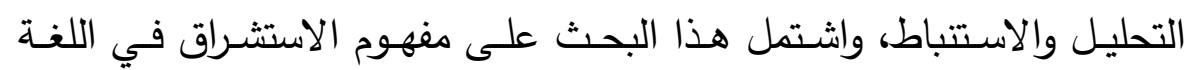

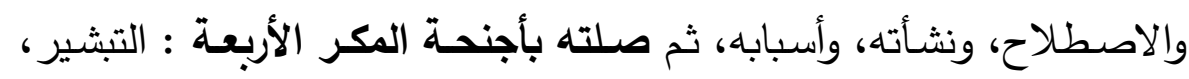

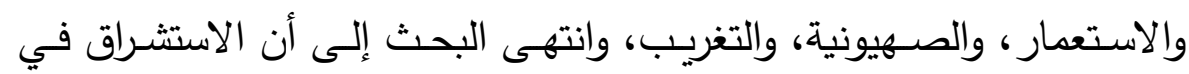

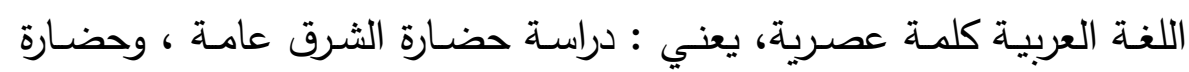

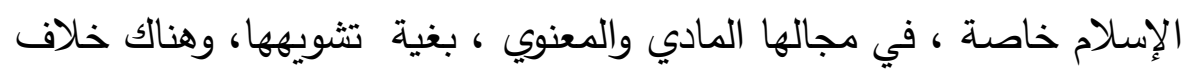

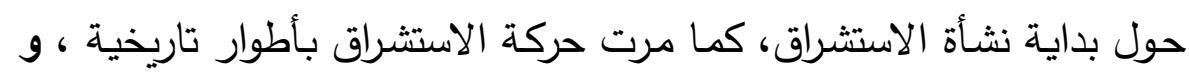
بذل المستشرقون جهودا مضنية في الدراسات الاستشراقية، لأسباب : دينية أو لو

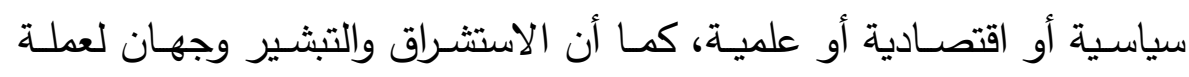

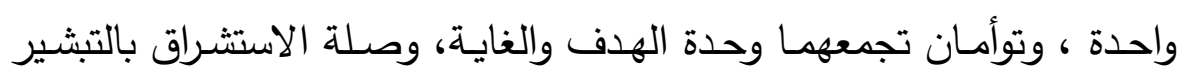
والاستعمار واليهودية الصهيونية والتغربب وثيقة وقديمة.

الكلمـات المفتاحيـة: الاستثـراق، أجنـــة المكـر، التبثـير، الأسـتعمار، الصهيونية، التغريب

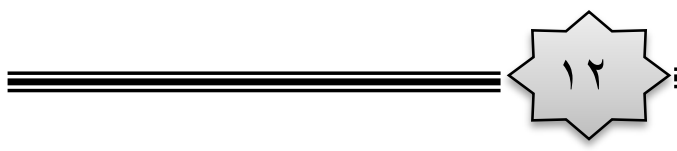




\section{The concept of Separation}

Connected to the Four Wings of Deception

The seeker.

Mohamed Mohamed Mohamed Ibrahim Kurkur

Department of Religions and Sects, Faculty of Islamic

Dawa, Al-Azhar University, Cairo, Egypt

E-Mail: Mohamedkarkoor.13@azhar.edu.eg

Abstract:

The most important reasons for choosing this topic are the statement of the concept of Orientalism, shedding light on the beginning of its origins, the most important historical phases it has gone through, the most important reasons it aims at, focusing on the statement of the four wings of cunning, and clarifying the close link between each of these four wings, and the objectives This research is based on the historical and inferential approach of analysis and deduction. This research includes the concept of Orientalism in language and terminology, its origin, and its causes, and its relation to the four wings of deception: evangelism, colonialism, Zionism and Westernization, The research concluded that Orientalism in Arabic is a modern word, which means: studying the civilization of the East in general, and the civilization of Islam in

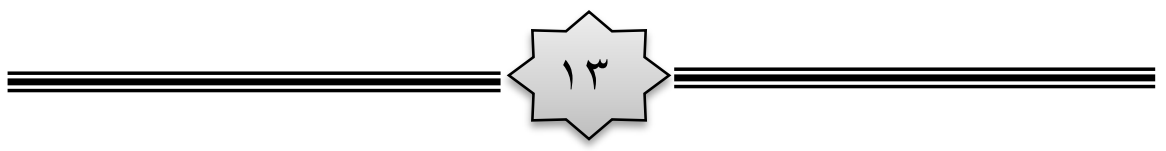


particular, in its physical and moral field, in order to distort it. Orientalist studies, for reasons: religious, political, economic or scientific, and that Orientalism and evangelization are two sides of the same coin, and twins united by the unity of purpose and purpose, and the link of Orientalism with evangelism, colonialism, Jewish Zionism and Westernization close and old.

Keywords: Orientalism, wings of deception, evangelism, colonialism, Zionism, Westernization 


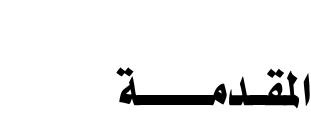

الحمد الله رب العالمين، وأشهد أن لا إله إلا الله ولي الصالحين،

وأثهد أن سيدنا تححا عبد الله ورسوله الأمين، صلِّ اللهح وسلم وزد وبارك على إلى هذا النبي الأمين، وعلى آله وصحبه الغر الميامين، وارحم اللهم مشايخنا

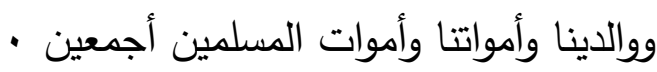

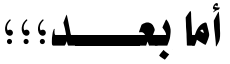

فإن كراهية وحقد اليهود والنصارى وغيرِهم من المشركين على الإسلام

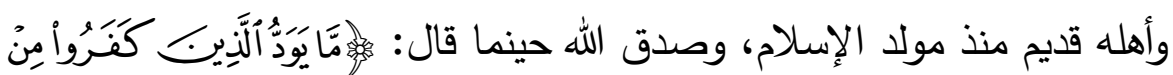

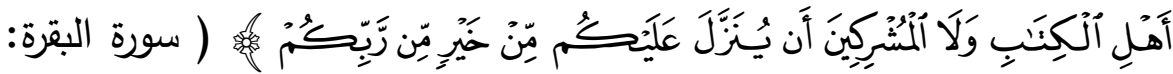

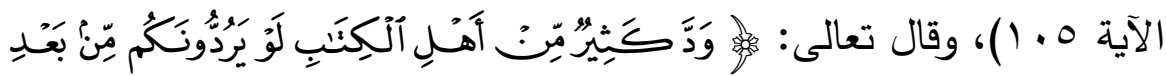

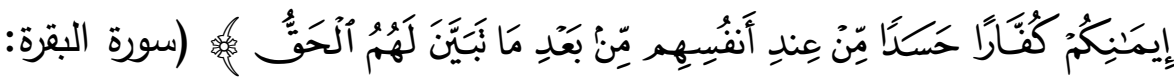

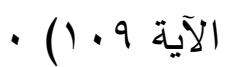

ولقد ورث الغرب المسيحي نصيباً كبيراً من تلك الكراهية وذلك الحقد، خاصة بعد أن طرق الإسلام أبوابهم، ودخل بلادهم، وتسلل إلى نفوس الكثير

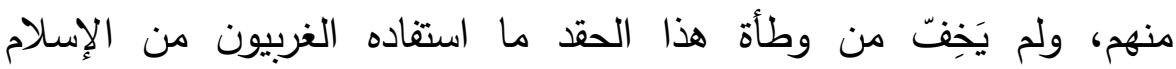
وحضارته، بل تفنَّ هذا الحقد الدفين في صورة حروب عسكرية صليبية حاقدة استمرت قرنين من الزمان (من القرن الحادي عشر إلى القرن الثالث عشر الميلاديين)، واخترقت الكنيسة جدار السياسة، واشترك رجالها مع الملوك والأمراء في هذه الحروب، بل تولى بعضهم القيادة العسكرية، ومنذ أن انتهت

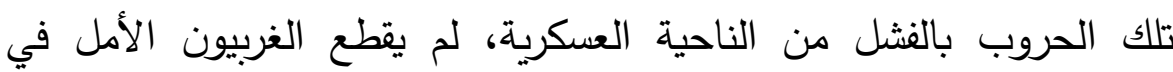
السيطرة على بلاد الشرق الإسلامي التي تفيض لبناً وعسلاً، وكرروا تلك المحاولة في القرن التاسع عشر الميلادي، وسيطروا على عدد كبير من بلاد العالم الإسلامي، لكنهم أُجبروا على الرحيل في هذه المرة كسابقتها .

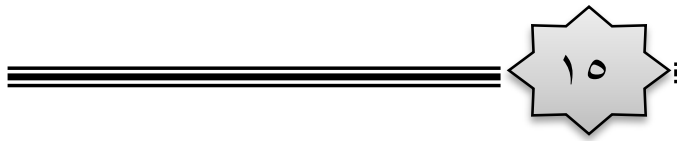


ولم ينقطع تفكير الغرب في الانتقام من الإسلام وأهله بطريقة أخرى

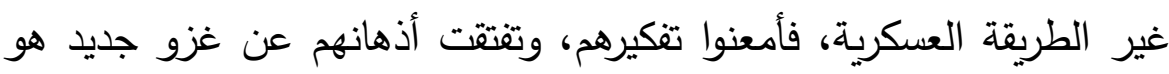
الغزو الفكري والثقافي، يحقق ما لم يحققه الغزو العسكري، وجنَّدوا لهذه الحرب كتائب من المستشرقين يهودا كانوا أو نصارى، قاموا بدراسة التراث الإسلامي ولني من جميع نواحيه الدينية والتاريخية والحضارية، بغرض نقده وإعداد موسوعات من الثبهات حول الإسلام عقيدة وشريعة، لكي يهذموا الإسلام في نفوس أبنائه، ويُبعدوهم عن قيمه وأخلاقه وتشريعاته العظيمة، ويُقصوه عن منصة الإستهاه

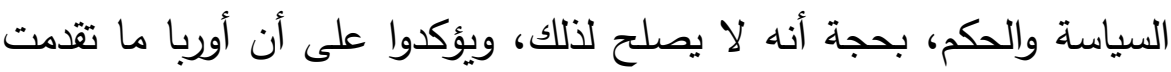

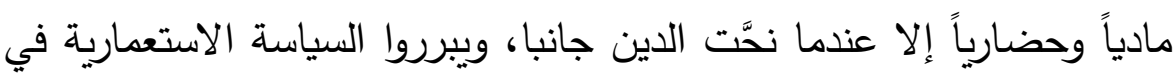

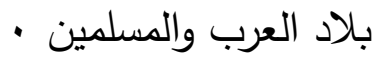

والاستشراق كان ولا يزال جزءا لا يتجزأ من قصة الصراع الحضاري بين العالم الثرقي الإسلامي والعالم الغربي المسيحي، بل يُميّلّ الخلفية الفكرية لهذا الصراع، فقد كان له أكبر الأثر في صياغة التصورات الأوربية عن الإسلام، وفي تشكيل مواقف الغرب عن الإسلام على مدى قرون عديدة، ولا يزال الأوربيون حتى اليوم يستقون معلوماتهم عن الإسلام من كتابات

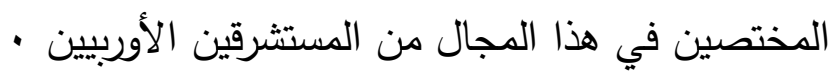

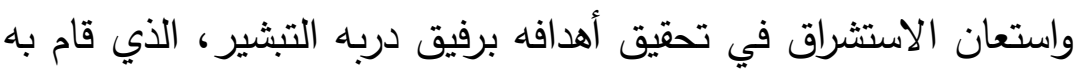
المنصِّرون المسيحيون، الذين كانت مهمتهم توزيح السم المتمثل في الثبهات التي يصنعها المستشرقون • كما استعان بالاستعمار الذي هيأ له أجواء

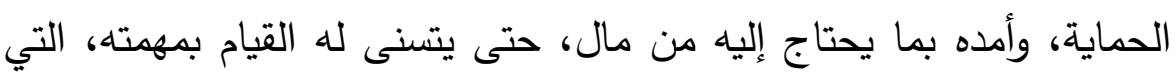
تصب في إطار خضوع واستسلام أبناء الإسلام للمستعدر الغاصب • ولم يَفُتْ الاستشراق في هذا الإطار أن يستعين باليهود الصهاينة، فقد قام الاستشراق على أكتاف عدد كبير من هؤلاء اليهود، الذين روَّجوا لدولة اليهود المزعومة في فلسطين• كما كان للاستشراق دور كبير في تغريب العالم العربي

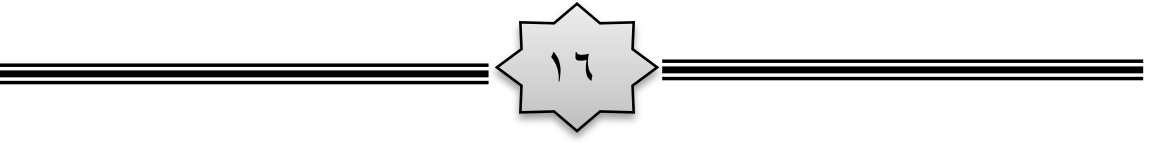


والإسلامي عن مصدر عزته وقوته وبقائه وهو الإسلام .

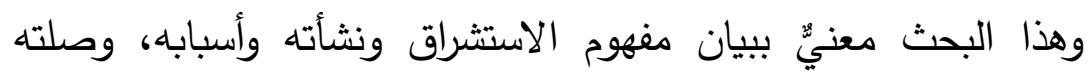

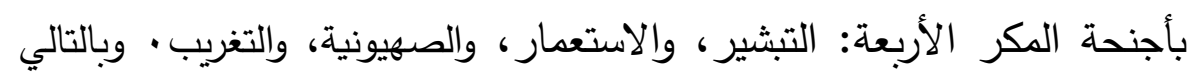

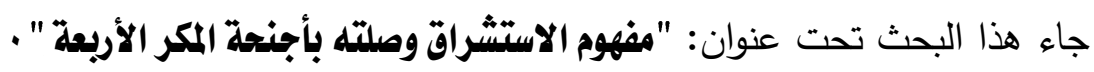
أ . أسباب الاختيار : ترجع أهم أسباب اختيار هذا الموضوع إلى همراف

1 ـ بيان مفهوم الاستشراق، وذلك في إطار كشف اللثام عن

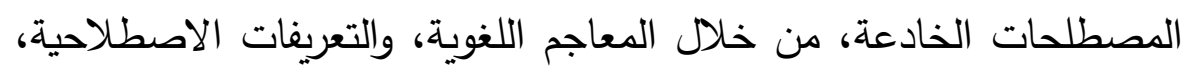
تلك المصطلحات التي يُخفي وراءها أصحابها أهدافهم الخبيثة . r ـ إلقاء الضوء على بداية نشأة الاستشراق، وأهم الأطوار التاريخية

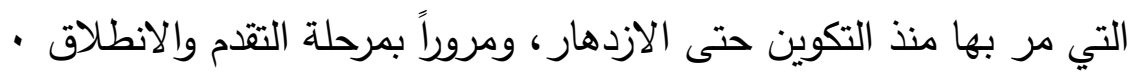

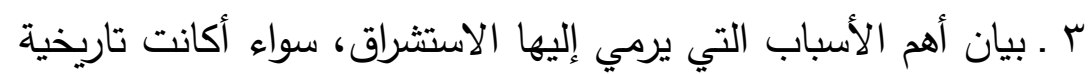

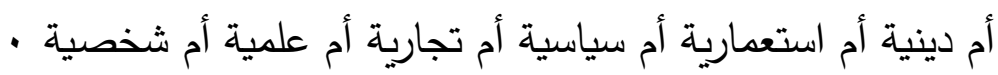

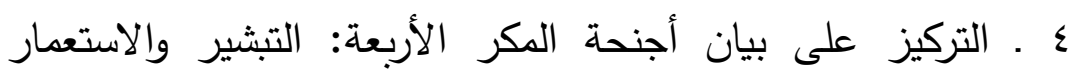
والصهيونية والتغريب، تلك الأجنحة العسكرية والمسلحة بأحدث ما وصل إليه العلم في مجال بث الشبهات وإثارة الفرقة، بهدف السيطرة على بلاد المسلمين،

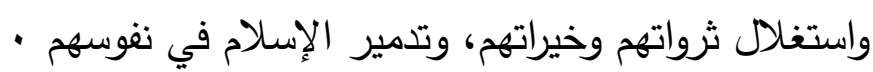

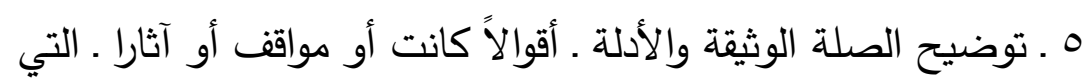
تربط الاستشراق بكلٍ من هذه الأجنحة الأربعة، والأهداف المشتركة التي

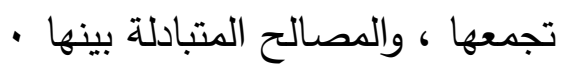
ب ـ ـ الدراسات السابقة:

توجد دراسات علمية سابقة، تحدثت عن جهود بعض العلماء في الرد على اليهود والدفاع عن الإسلام ضد الاستشراق، وأبحاث علمية عرضت

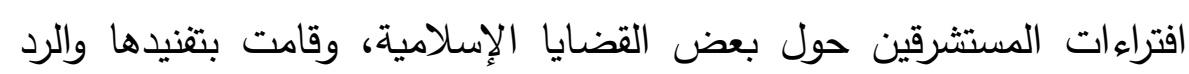

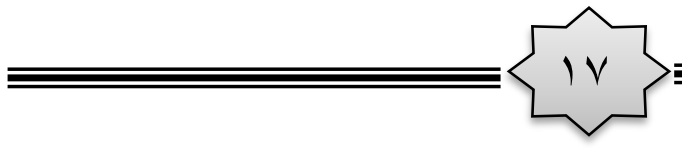


عليها، من تلك القضايا: النبوة والدعوة ، الخلافة الراشدة والفتوحات الإسلامية، التراث الإسلامي، قضايا المرأة المسلمة، وها هي عناوين تلك الدراسات

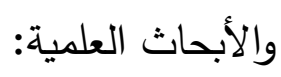

ا ـ ابن القيم وجهوده في الرد على اليهود والنصارى (ماجستير): ححمد

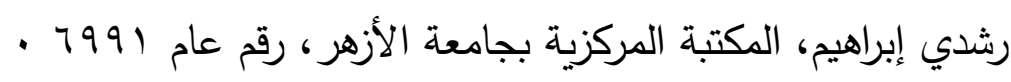

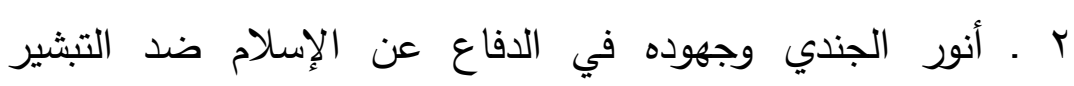
والاستشراق والتغريب (ماجستير): عمر السيد أبو سلامة، المكتبة المركزية

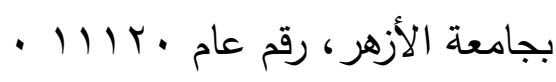

r ـ شبهات المستشرقين حول النبوة والدعوة (ماجستير): محمد زين العابدين حمح، أصول الدين بالقاهرة ـ قسم الدعوة، رقم 1111 ـ

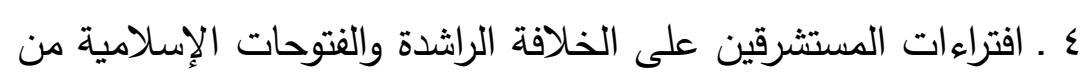

خلال دائرة المعارف: السيد حسين، أصول الدين بالقاهرة ـ قسم الدعوة . ه ـ شبهات المستشرقين حول التراث الإسلامي: إبراهيم عبد الرحمن، أصول الدين بالقاهرة ـ قسم الدعوة . 7 ـ الفكر الاستشراقي في قضايا المرأة المسلمة: محمد علي إسماعيل، أصول الدين بالقاهرة ـ قسم الدعوة • بعض الدراسات السابقة يركز على الدفاع عن الإسلام بصفة عامة لداء

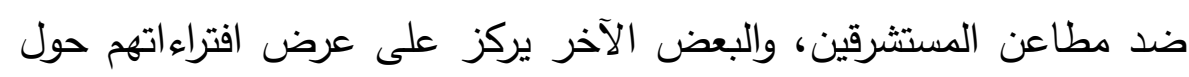
قضايا إسلامية خاصة ويفندها، والحديث عن "مفهوم الاستشراق وصلته

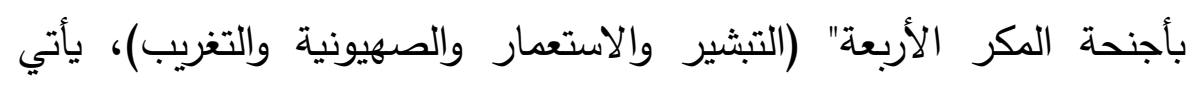
عرضا في تلك الدراسات، وفي سطور وصفحات قليلة متناثرة، وبعضها خلا

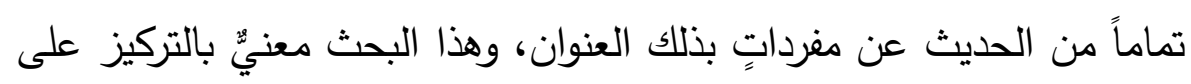

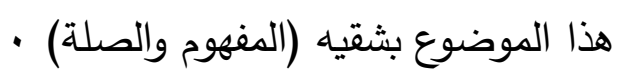
ج . منهج البحث: يقوم هذا البحث على المنهج التاريخي الاستدلالي، $\bar{\equiv}\{11\} \equiv$ 
حيث يعتمد على استرداد آثار الماضي، بجمع المعلومات التاريخية ودراستها للوصول إلى حقائق، وربط ذلك بالعصر الحديث للاستفادة منه، ويسبق ذلك يكان ويعقبه استخدام المنهج الاستدلالي بجناحيه التحليل والاستنباط، بذكر الأدلة

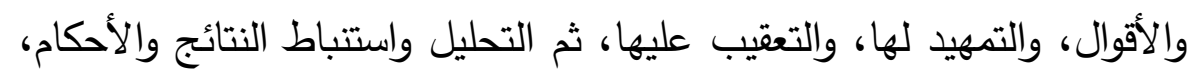
بحيدة وموضوعية، مع عزو النصوص إلى مصادرها، والأقوال إلى قائليها، والترجمة لأهم الأعلام والبلدان والمصطلحات الغامضة الواردة في هذا البحث.

د ـ خطة البحث: اشتمل هذا البحث على: مقدمة، ومطلبين، وخاتمة .

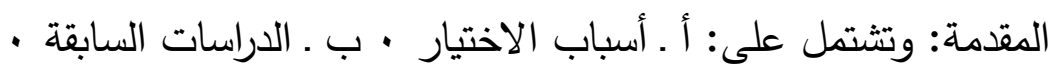
ج · منهج البحث د ـ خطة البحث مثر لبح 


$$
\begin{aligned}
& \text { المطلب الأول: مفهوم الاستشراق: ويشتمل على: } \\
& \text { أولاً: مفهوم الاستشراق في اللغة والاصطلاح . }
\end{aligned}
$$

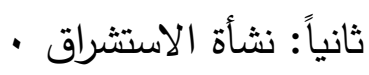

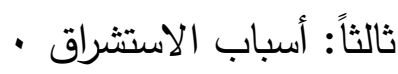

المطلب الثاني: صلة الاستشراق بأجنحة المكر الأربعة: ويشتمل على:

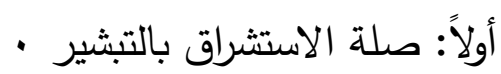

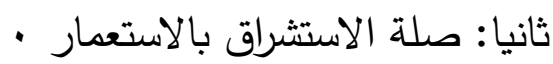

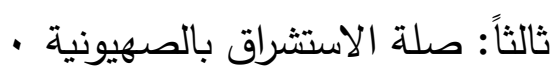

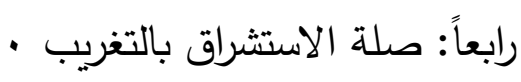

الخاتمة: وتثتمل على: أولاً: أهم النتائج والتوصيات • ثانياً: فهرس

$$
\text { الأعلام والبلدان والمصطلحات المترجم لها ـ المان. }
$$

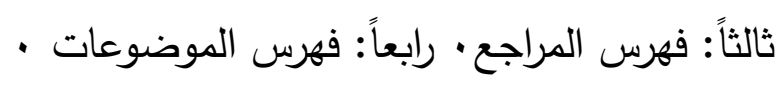

وفي نهاية هذه المقدمة أسأل الله تعالى أن يعلمنا ما ينفعنا، وأن ينفعنا

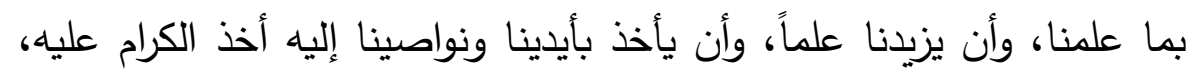
وأن يجنبنا الزَّلل والفواحش والفتن ما ظهر منها وما بطن، وأن يحفظ الإسلام

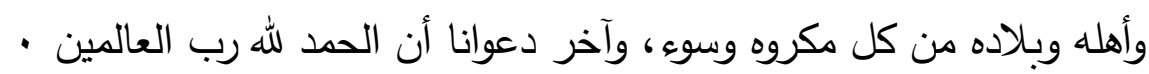

$$
\text { أ •د// حمد حمد حمد إبراهيم كركور }
$$

الأستاذ المساعد بقسم الأديان والمذاهب بالكلية 


\section{المطلب الأول: مفهوم الاستشراق ونشأته وأسبابه أولاً: مفهوم الاستشراق في اللفة والاصطلاح:}

الاستشراق من الكلمات ذات البريق اللامع، والألفاظ التي فيها خداع،

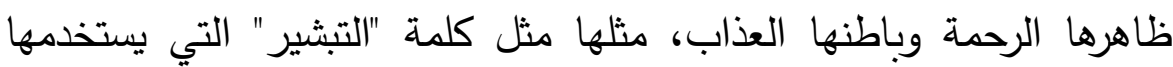

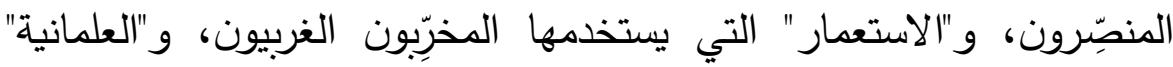

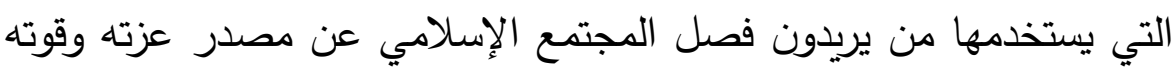

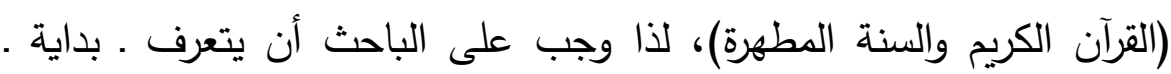

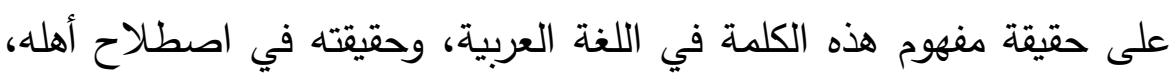

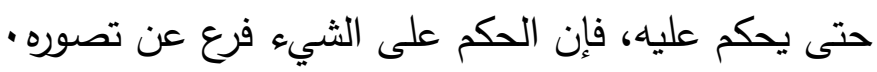
أ ـ مفهوم الاستشراق في اللفة:

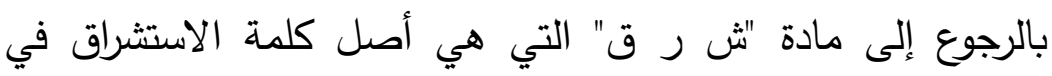

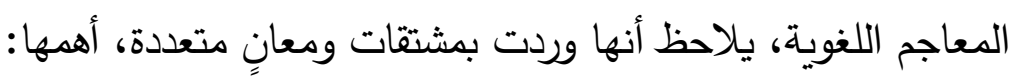

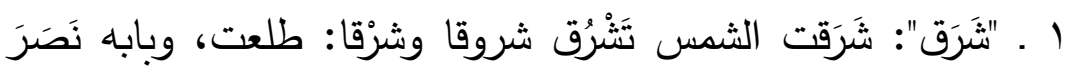

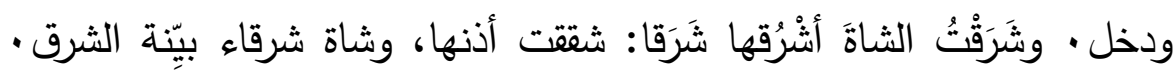

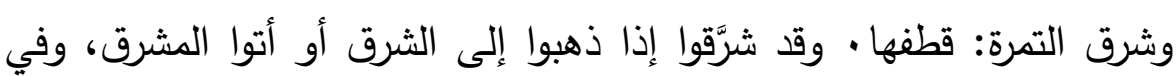

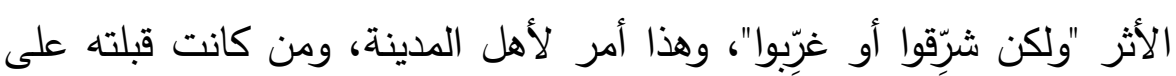

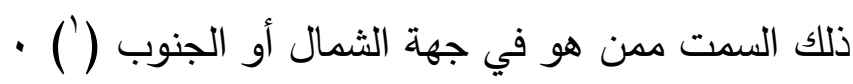

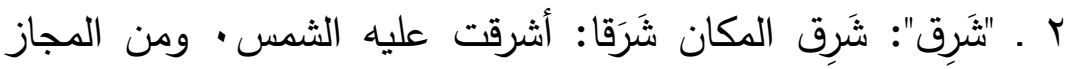

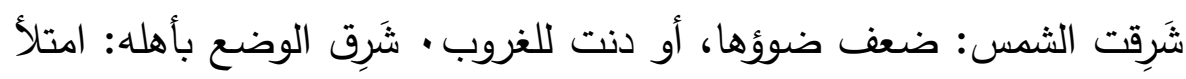

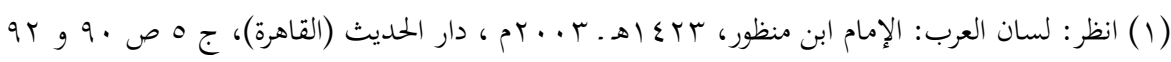

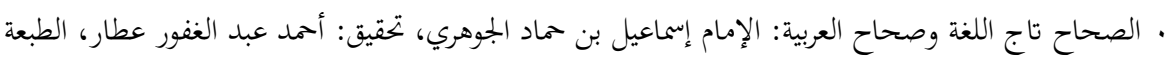

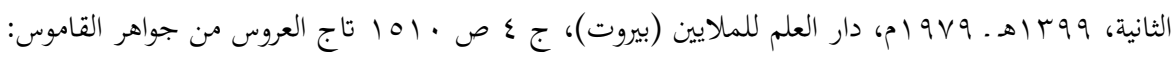

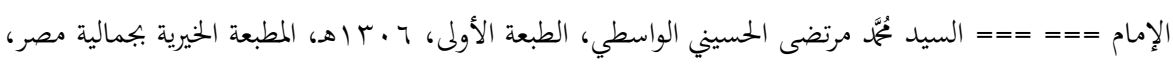

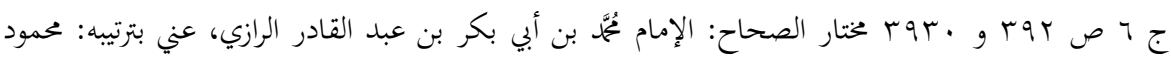

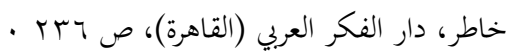

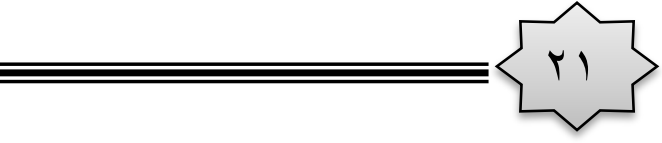


فضاق، وشَرِق وجهه: احمر من الخجل · شَرِق النخل وأشرق وأزهى: لوَّن

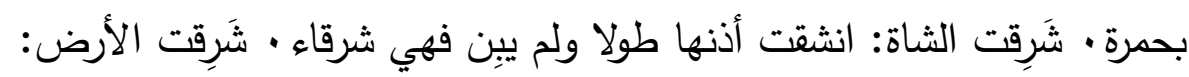

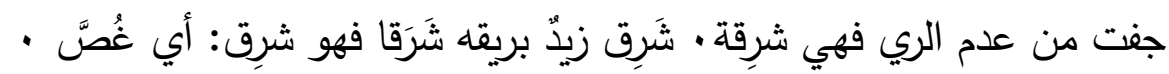

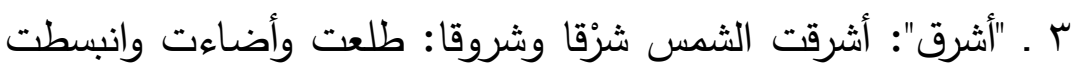
على الأرض، يقال: أشرقت الأرض إشراقا إذا أنارت بإشراق الشمس، قال تعالى:

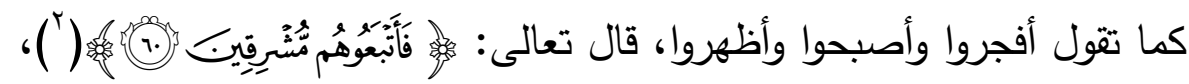
أي لحقوهم وقت دخولهم في شروق الشمس وهو طلوعها · أشرق وجها: أسفر

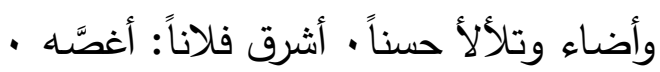
ع ـ "شرَّق": شرَّقوا: ذهبوا إلى الثرق، أو أتوا الشرق، وكل ما

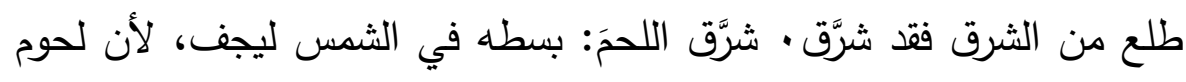
الأضاحي كانت تُشَّقق فيها بمِنى • شرَّق الأرض: منع عنها الماء حتى اشتـ

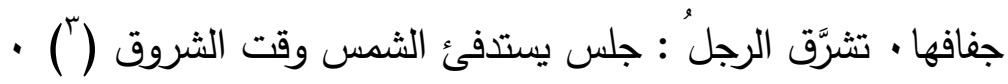
ه ـ "المشرق": اسم الموضع الذي تشرق عليه الثمس، وهو بكسر الراء في الأكثر، وبالفتح وهو القياس لكنه قليل الاستعمال، وفي النسبة

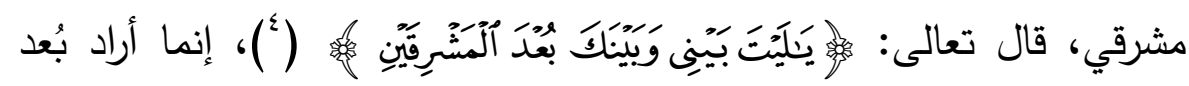

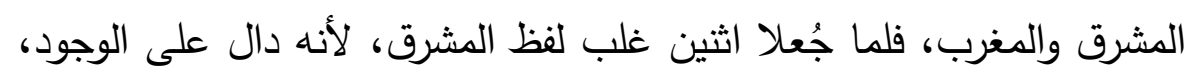

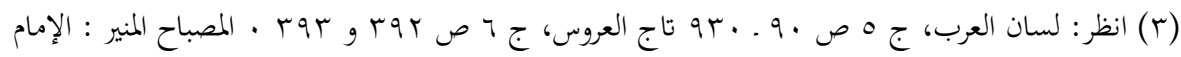

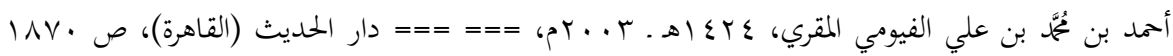

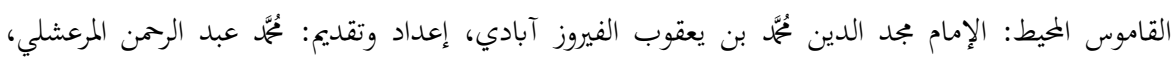

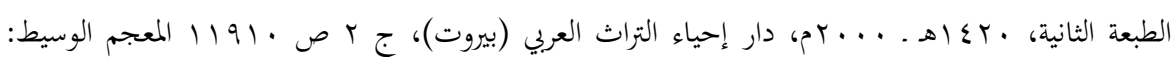

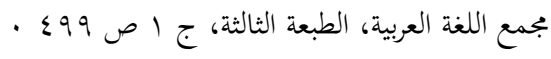

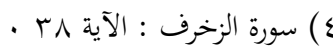

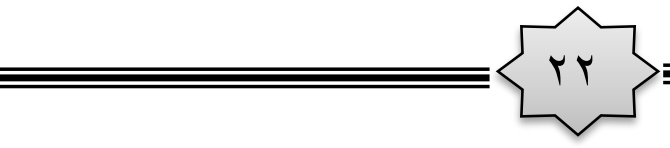


والمغرب دال على العدم، والوجود لا محالة أشرف، والمشرقان: مشرقا الصيف

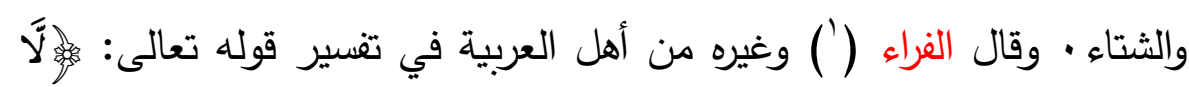

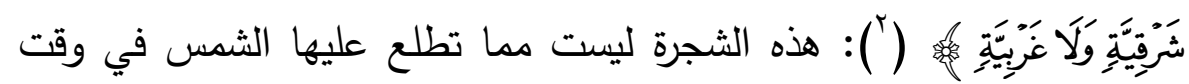
شروقها فقط أو في وقت غروبها فقط، ولكنها شرقية غربية تصيبها الثمس هرب

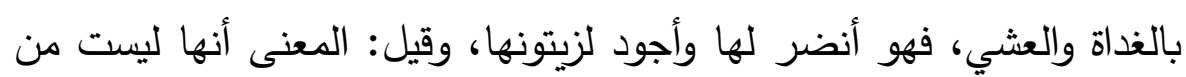

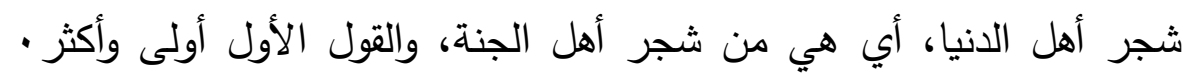

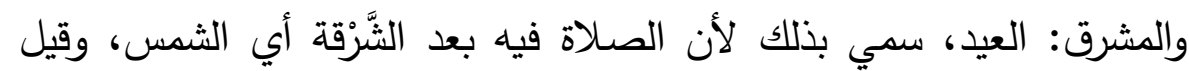
المشرق: مصلى العيد · والمشرق: جهة شروق الشمس، والبلاد الإسلامية في

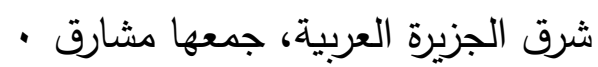

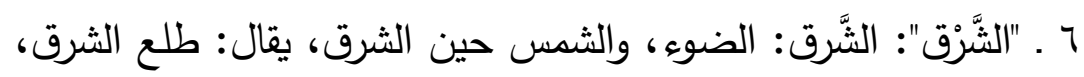

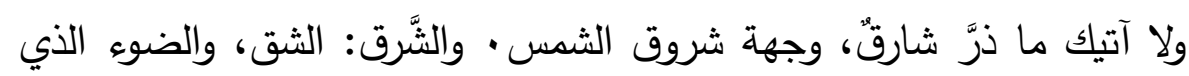
يدخل من شق الباب • والشرقي: الموضع الذي تشرق فيه الشمس من على وجى

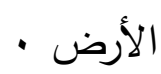

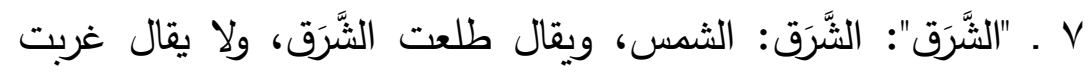
الثَّرَق • الثَّرَقَ: دخول الماء إلى الحلق حتى يُغصَّ به، يقال: شرَق الرجل

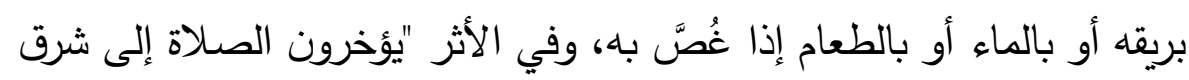

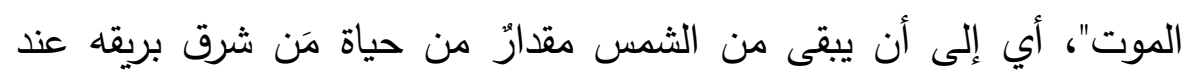
الموت • ولحم شرق: لا دسم عليه .

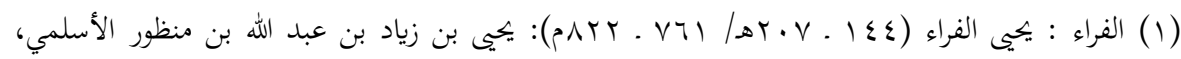

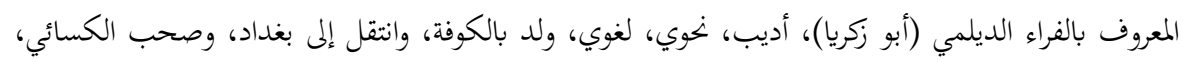

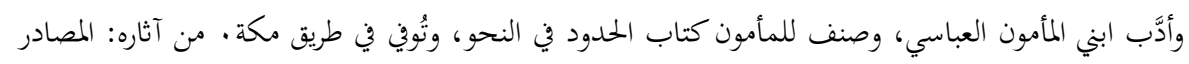

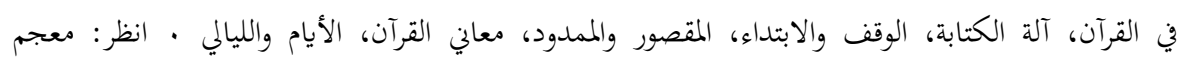

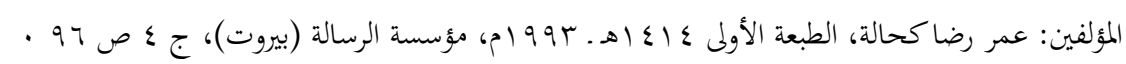

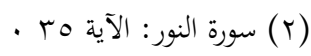

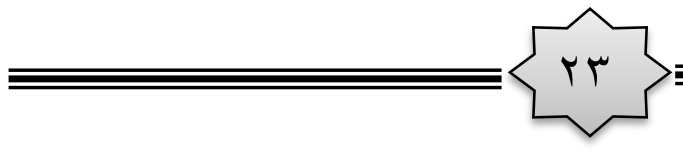


ᄉ . "المشرقة": مشرقة بضم الراء وفتحها، ومشرقة بفتح الثين وتسكين الراء، والمشراق كمحراب: موضع القعود في الثمس حيث تشرق عليه، وخصه

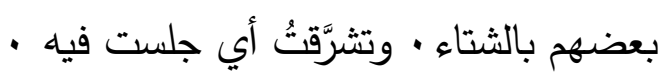

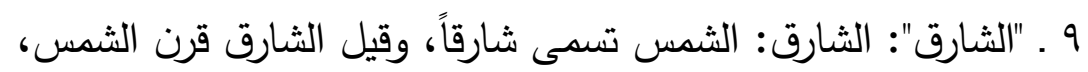
يقال: آتيك كل شارق، أي كل يوم طلعت فيه الثمس، والشارق الجانب الثرقي وهو الذي تشرق عليه الثمس من الأرض، ويقال: أحمرٌ شارق أي

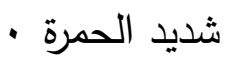

• 1. "التشريق" : تشريق اللحم: تقطيعه وتشريحه وتقديده وبسطه، ومنه سميت أيام التشريق (ثلاثة أيام بعد يوم النحر)، لأن لحوم الأضاحي كانت

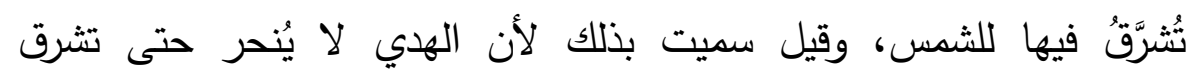
الثمس، وفي الأثر "من ذبح قبل التشريق فليُعد"، أي قبل أن يصلى صلاة العيد، وهو من شروق الشمس وإشراقها، لأن ذلك وقتها • التشريق: الجَمال وإشراق الوجه، والأخذ في ناحية المشرق، يقال شتان بين مشرق ومغرب. الإشراق: ابتعاث نور من العالم غير المحسوس إلى الذهن، تتم به المعرفة.

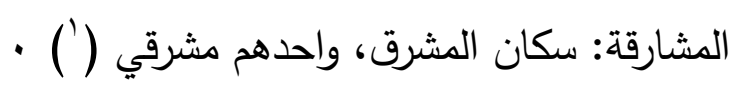
يلاحظ بعد هذا العرض لمشتقات مادة "ش ر ق" ومعانيها في اللغة

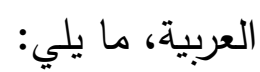
ا ـ من الواضح أن كلمة "استشراق" منحوتة من مادة "ش ر ق قل التي لها

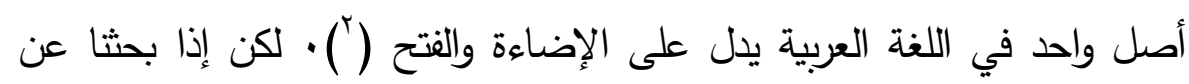

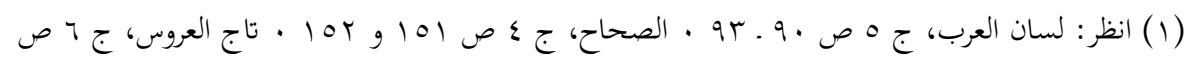

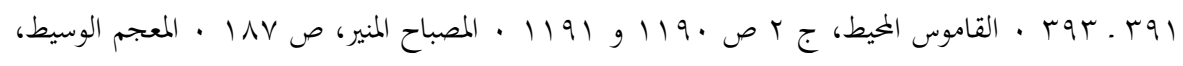
- (r)

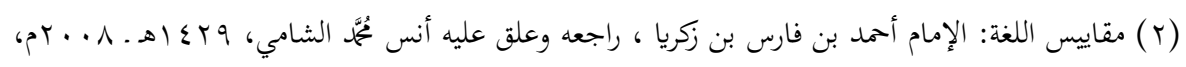

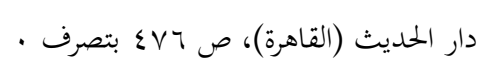
* كما أن كلمة "الاستشراق" مولدة عصرية في اللغة العربية، هي كذلك في اللغات الأجنبية: لم تظهر إلا في $\overline{\overline{ }}\{r \leqslant\}$ 
نفس كلمة "استشراق"، فإننا لا نجد لها ذكراً في المعاجم اللغوية القديمة، مما يدل على أن الكلمة ليست عربية خالصة، بل هي مولدة عصرية *، يقال "استشرق":

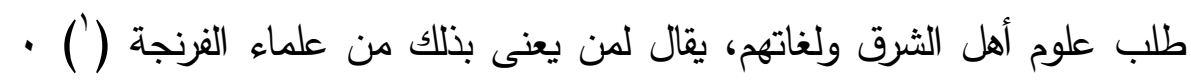

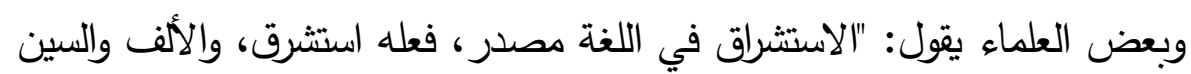

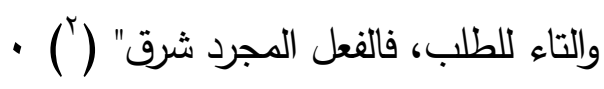
r ـ الفعل من هذه المادة يعني: أضاء، أنار ، أسفر، تلألأ حسناً، أزهى، قطف، امتلأ وفاض، ذهب إلى الثرق، دخل وقت الشروق، بسط اللحم في الشمس ليجف، جلس يستدفئ الشمس إلى ومن معاني المشتقات الأخرى: المشرق: اسم الموضع الذي تشرق عليه الثمس، والبلاد الإسلامية في شرق الجزيرة العربية • الثَّرق: الضوه، والثمس حين تشرق • المشرقة: موضع القعود في الثمس • الثارق: قرن الثمس، أو الجانب الثرقي• التشريق: الجمال وإشراق الوجه . الإشراق: ابتعاث نور من العالم غير المحسوس تتم به المعرفة • المشارقة: سكان المشرق ل

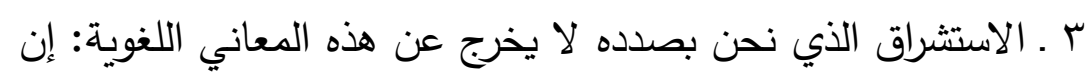
كان المقصود به المكان، فهو المشرق الذي يقابله المغرب، والجانب الشرقي، وبلاد المشرق (البلاد الإسلامية) • وإن كان المقصود به اقتباس الحضارة، فهو

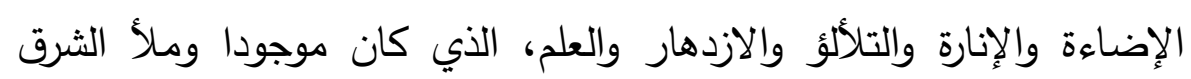

القرن السابع عشر الميلادي، حيث أُطلق هذا اللفظ على أحد أعضاء الكنيسة، ففي سنة 1797 أنس م وجدنا

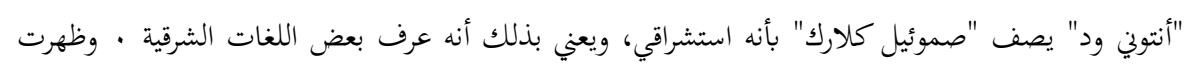

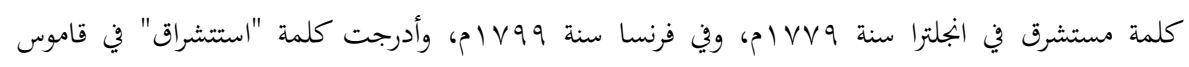

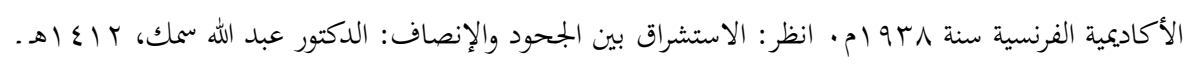

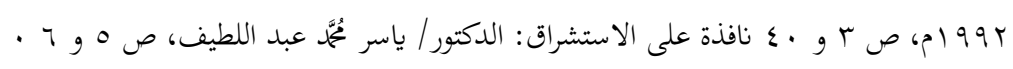

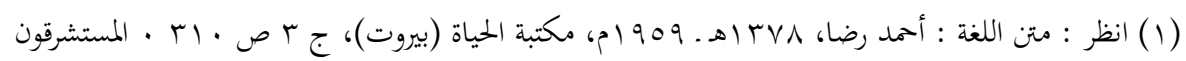

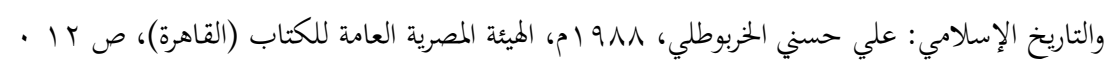

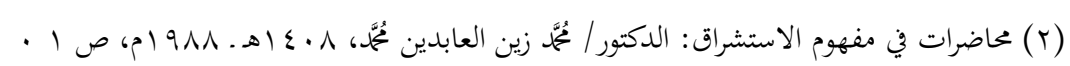

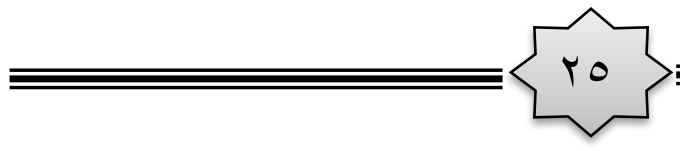


الإسلامي ولا ينبعث إلا منه، يقابله الظلام وغروب الثمس والغُصَّة والجفاف،

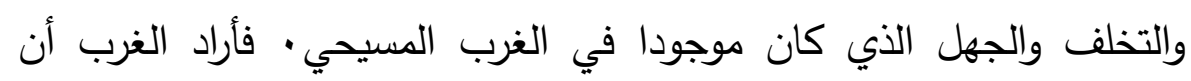
يقتبس ويستقيد من هذا النور ، ويقطف من ثمار هذا العلم، وتشرق عليه شمس المعرفة، فكان الاستشراق وكان الذهاب إلى الشرق للاستدفاء بشمسه، سواء أكان الذهاب بحسن نية بقصد نقل العلم والحضارة والاستفادة منهما، أم كان بسوء نية للتعرف على علوم الثرق الإسلامي، بقصد إثارة الثبهات حولها . ب ـ مفهوم الاستشراق في الاصطلاحح: اختلف الباحثون حول الاستشراق كمفهوم له ضوابط وحدود خاصة،

$$
\text { وها هي أهم تعريفاتهم للاستشراق: }
$$

ا. الاستشراق علم ذو حدود واسعة، وأحياناً غير واضحة، إذ يختلط ميدانه بميادين العلوم الأخرى، لأن المستشرق قد يشارك في أبحاثه علماء الآثار

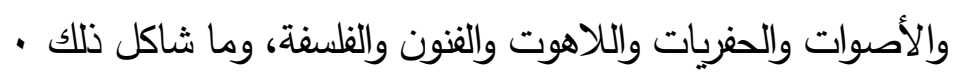

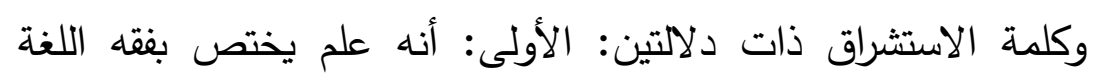
ومتعلقاتها على وجه الخصوص، والثانية: أنه علم الثرق أو علم العالم

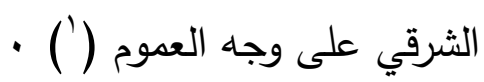

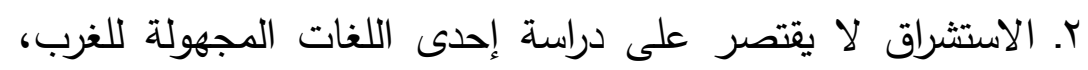
وإنما يُعنى بدراسة الثرق كله: أقصاه ووسطه وأدناه، في لغاته وآدابه وحضارته وأديانه، كما يُعنى بدراسة الأنحاء المختارة من الشرق، والوقوف ولنهاه على قواه الروحية وآدابه العظيمة، التي أسهمت إسهاماً فعالاً في تكوين ثقافة لتهاء - العالم بأسره فواه الموحن والاستشراق هو الوجه الأكاديمي أو المدون للسياسة الاستعمارية في الثرق،

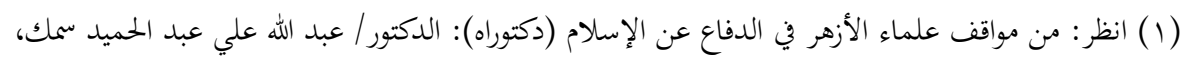

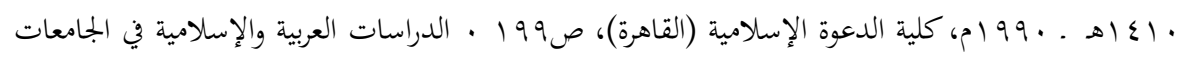

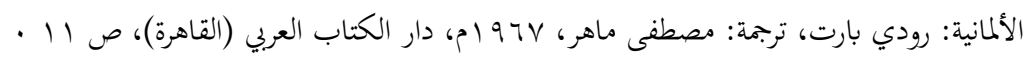
$\overline{\overline{ }}\{r\}$ 
كما أنه يمثل بُعْدا من أبعاد العلاقة المعقدة بين الثرق والغرب (') .

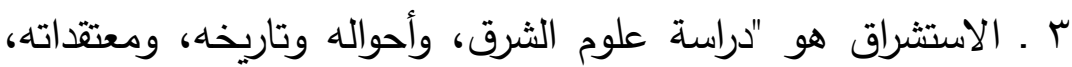

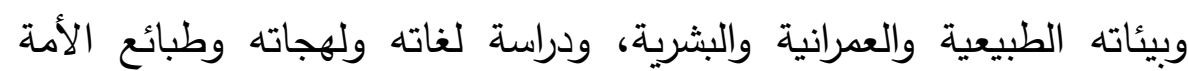
الشخصية في كل مجتمع شرقي، فلكل أمة مشخصاتها، ودراسة الأشخاص ودرسه وله وله

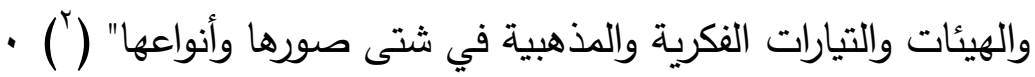
ع ـ الاستشراق هو "علم الأجانب بحياة الشرق وعلومه وآدابه ولغاته وحضاراته ومدنياته" (") ) · أو هو "علم يدرس لغات شعوب الثرق، وتراثهم،

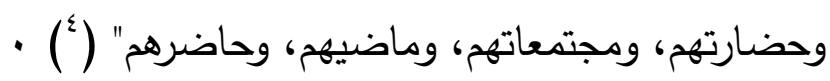

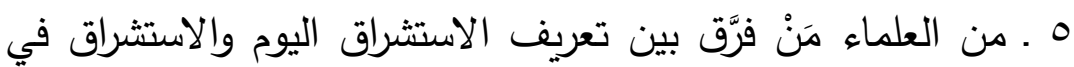
القرون الوسطى ())، فقال: "يراد بالاستشراق اليوم دراسة الغربيين لتاريخ

(1) انظر: الاستشراق والخلفية الفكرية للصراع الحضاري: الدكتور/ محمود حمدي زقزوق، الطبعة الثانية،

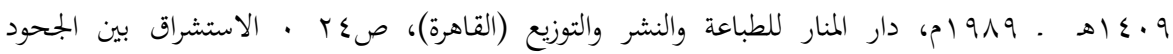
والإنصاف: الدكتور/عبد الله سمك، ص ع و ه ه . مخططات التنصير لغزو العالم الإسلامي من خلال مؤتمر

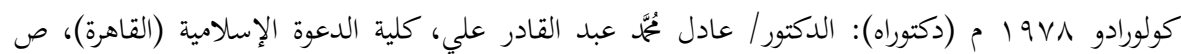

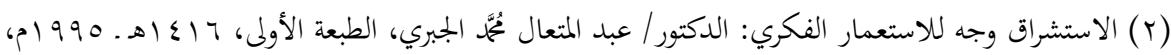

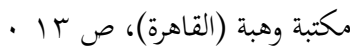

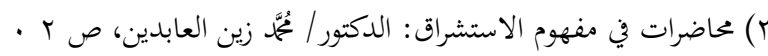

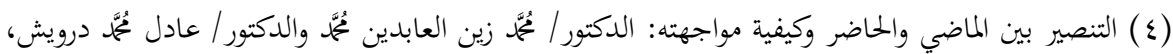

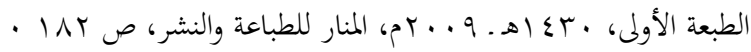
(ه) القرون الوسطى: القرون الوسطى في التاريخ الأوروبي هي التسمية التي تُطلق على الفترة التي امتّدت من عام

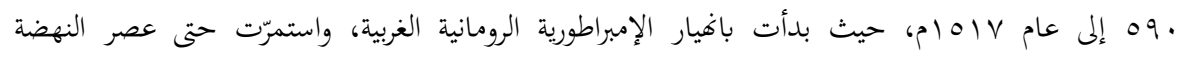

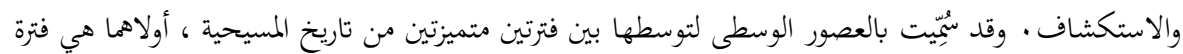

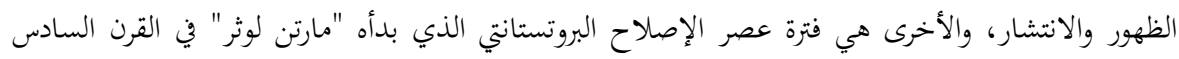

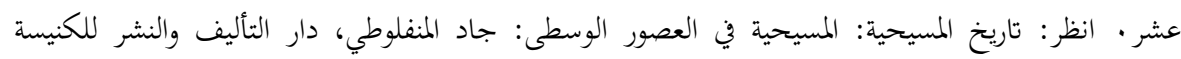

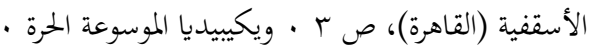


الثرق وأممه ولغاته وآدابه وعلومه وعاداته ومعتقداته وأساطيره · ولكنه في

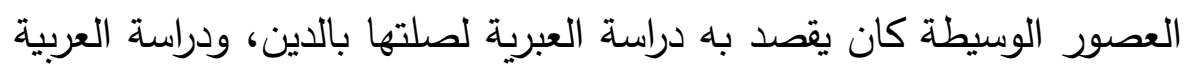

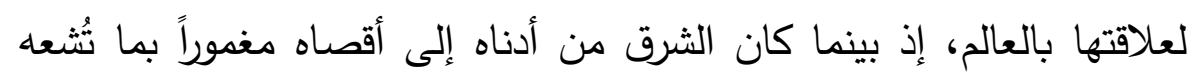

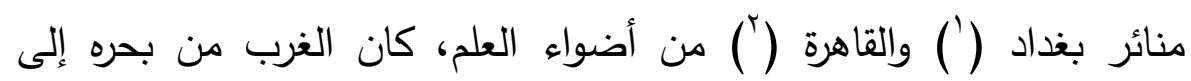

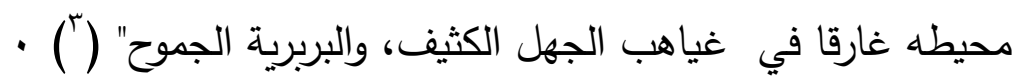
7 ـ ـ الاستشراق "اتجاه فكري يُعنى بدراسة الحياة الحضارية للأمم الثرقية بصفة عامة، ودراسة حضارة الإسلام والعرب بصفة خاصة ، ولقد كان الاستشراق في بداية ظهوره مقتصرا على دراسة الإسلام وحضارته، واللغة العربية وآدابها، ثم بعد ذلك اتسعت مجالات الاستشراق، وأصبحت تشمل

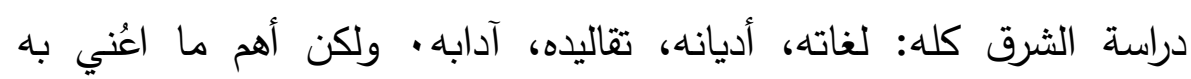
المستشرقون في دراساتهم هو الدين الإسلامي واللغة العربية، لأن ذلك مثار اهتمام المستشرقين الأول، والذي يمثل النزاع الفكري والسياسي والعقائدي الذي يسود

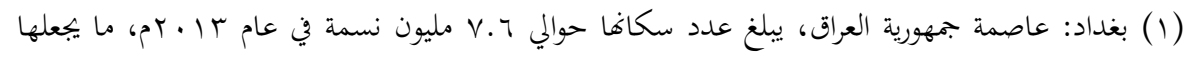

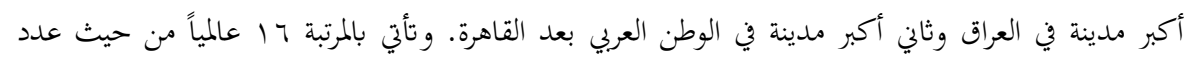

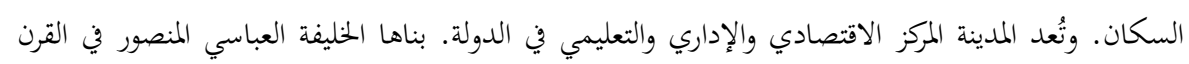

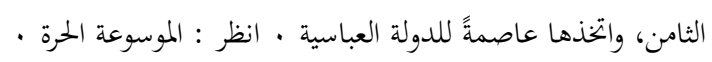

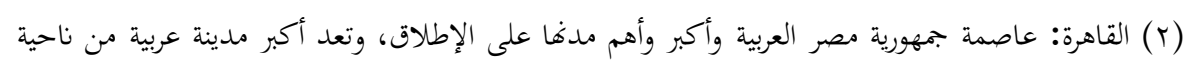

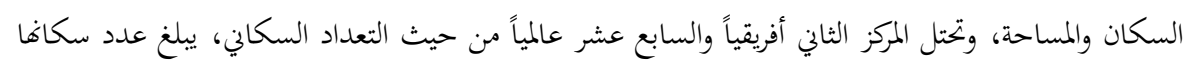

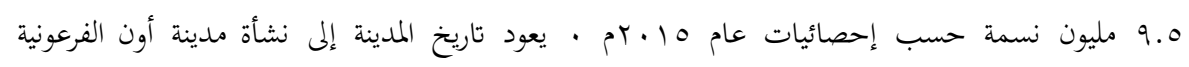

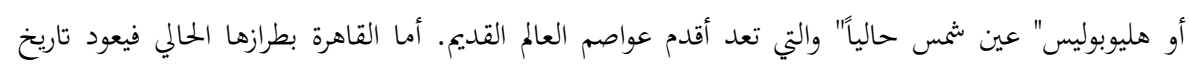

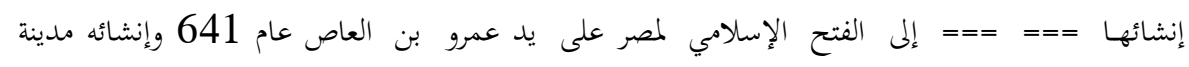

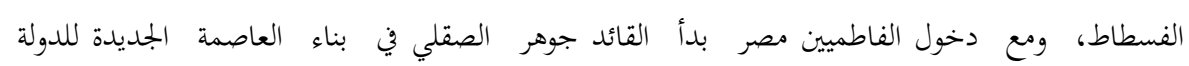

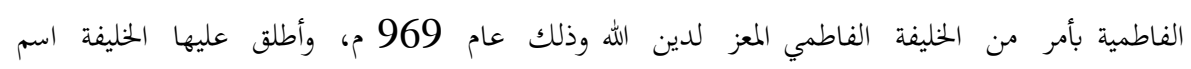

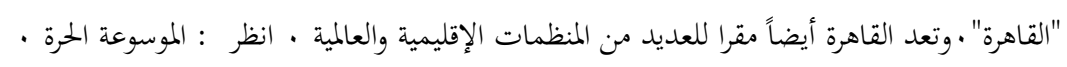

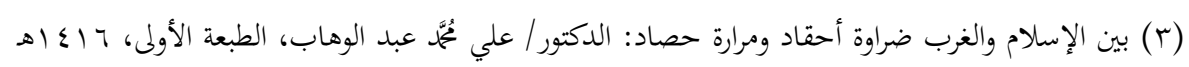

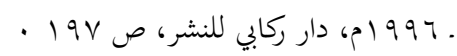

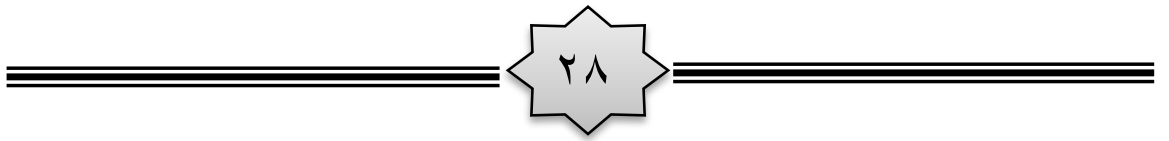




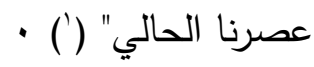

V ـ الاستشراق تعبير أطلقه الغربيون على الدراسات المتعلقة بالشرقيين،

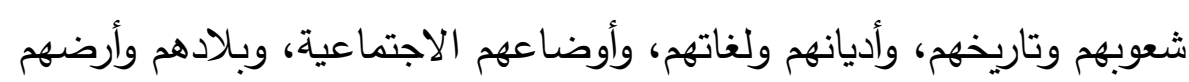

• وحضاراتهم، وكل ما يتعلق بهم (")

^ ـ الاستشراق هو "ذلك التيار الفكري الذي تَمَتَّل في الدراسات المختلفة عن الثرق الإسلامي، والتي شملت حضارته وأديانه وآدابه ولغاته وثقافته،

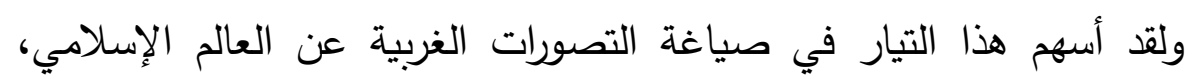

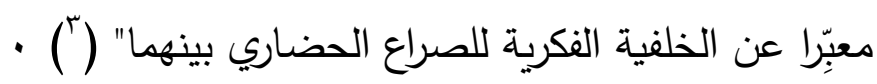

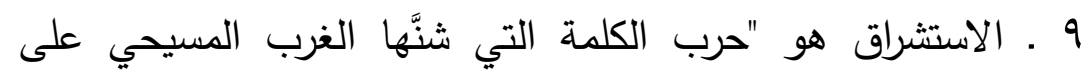
الثرق الإسلامي، منذ القرن الثامن الميلادي، وما زال يستخدمها ضدنا حتى هوب الآن، وإن لبست أثثابا مختلفة على مر العصور ، كي يحقق أهدافه، قام به

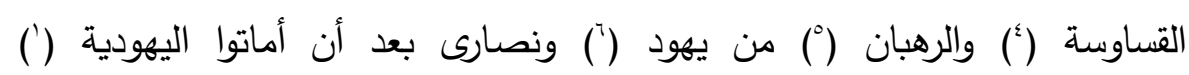

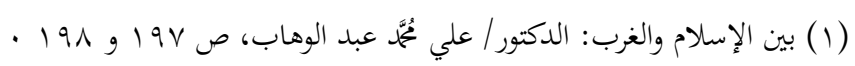

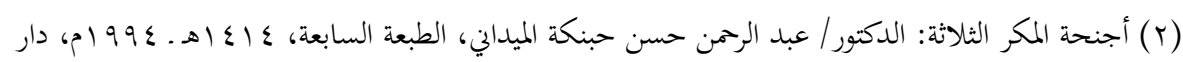

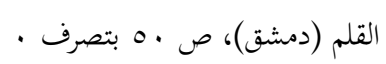

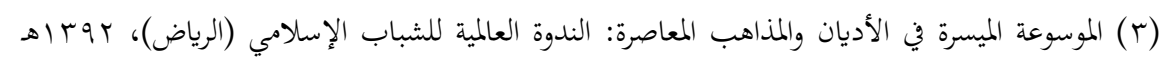

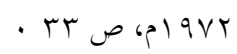
(§) القسيس: كلمة يونانية بمعنى شيخ، وهي معربة من الكلمة السريانية فشيشو، ويبدو أن أصل نشأقتا يرجع إلى مجلس

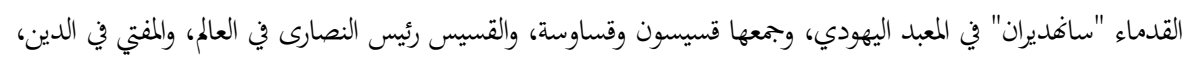

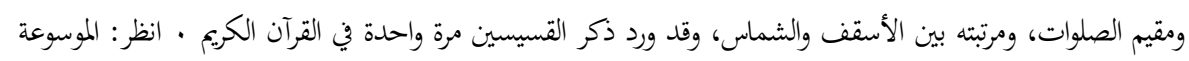

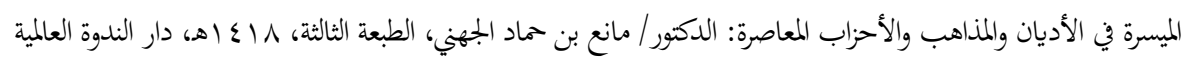

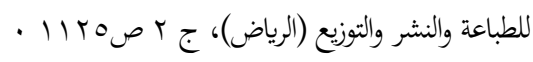
(ه) الراهب: الراهب من النصارى هو ساكن الدير، والجمع رهبان، والرهبانية هي حياة جماعية تُقضى في أديرة

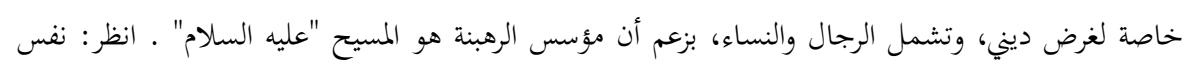

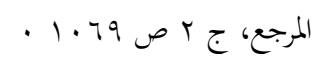
(7) اليهود: المنحدرون من إبراهيم "عليه السلام"، والمعروفون بالأسباط من بني إسرائيل، الذين أرسل الله إليهم

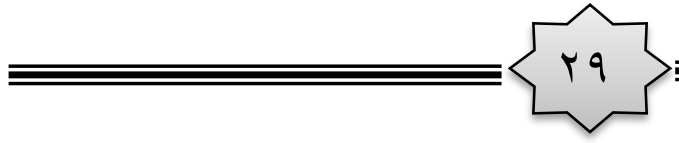


والمسيحية () ) .. . . والاستشراق عبارة عن أيديولوجية خاصة يراد من خلالها ترويج تصورات معينة عن الإسلام، بصرف النظر عما إذا كانت هذه

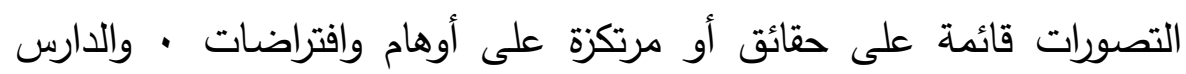

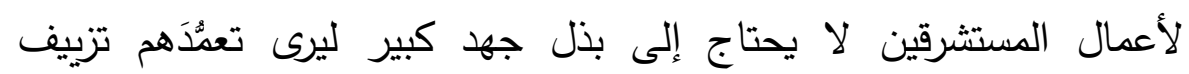
الحقائق، للوصول إلى نتائج تهدف في النهاية إلى رسم صورة مشوهة سقيمة عن الإسلام في نظر الغربيين، وإلى زلزلة عقيدة الإسلام وتمييعها في أعين

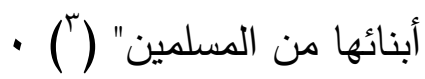
والذي يعنينا هنا هو هذا المعنى الخاص لمفهوم الاستشراق الذي يَعني الدراسات الغربية المتعلقة بالثرق الإسلامي، في لغاته وآدابه وتاريخه وعقائده وتشريعاته وحضارته بوجه عام • وهذا المعنى هو الذي ينصرف إليه الذهن في عالمنا العربي الإسلامي، عندما يُطلق لفظ "استشراق" و"مستشرق"، وهو

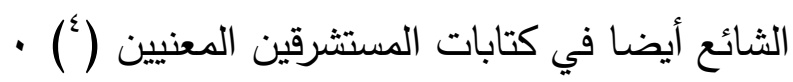

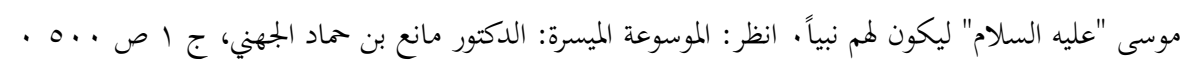

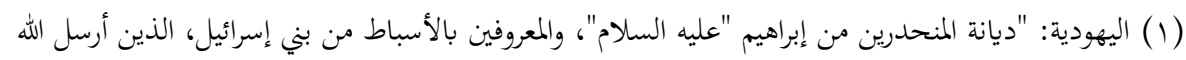

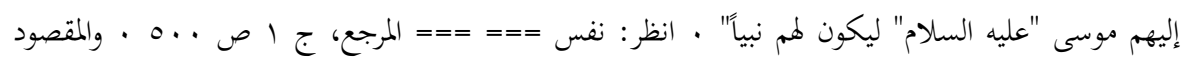
باليهودية هنا ، الديانة المحرفة الموجودة حالياً.

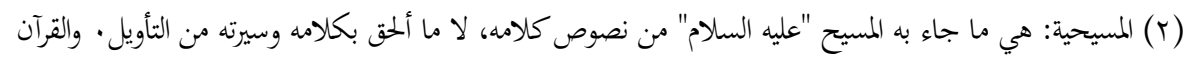

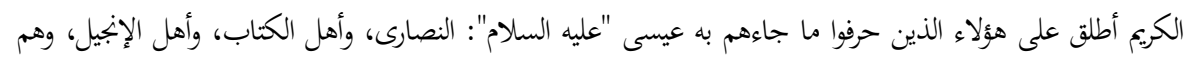

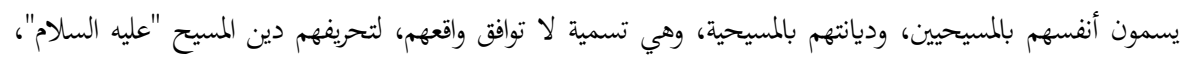

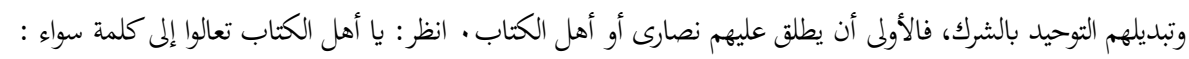

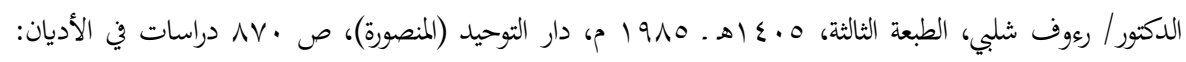

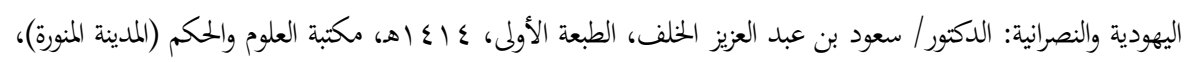

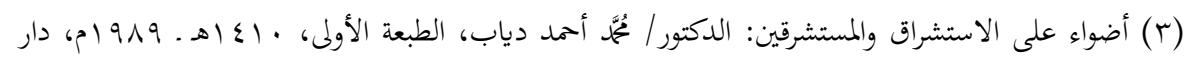

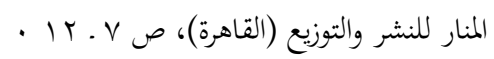

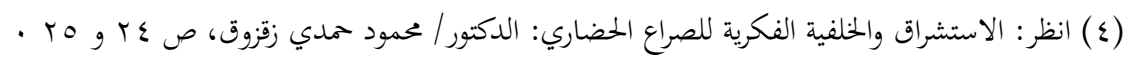

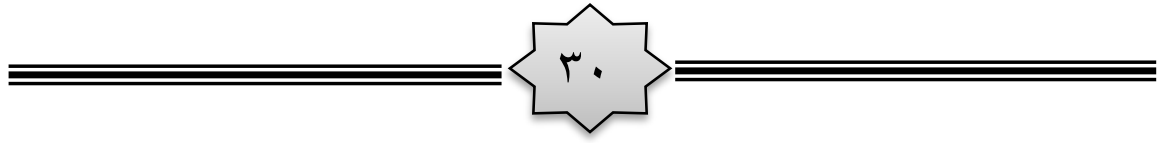


والمستشرق هو أوربي أو أمريكي غير مسلم بصفة خاصة، أو غربي

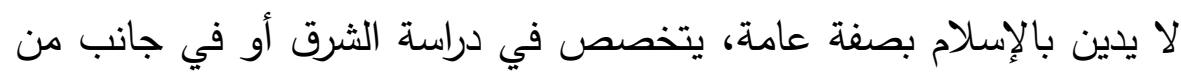

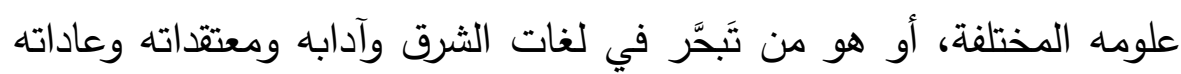
وتقاليده • وقد اختلف العلماء فيمن يسمى مستشرقاً، فمنهم من يخصص لون الكلمة لكل من تخصص في دراسة الثرق سواء أكان غربياً أم شرقياً، ومنهم من يُخرج الثرقي من دائرة المستشرقين، والأصح أن المستشرق هو من يدرس

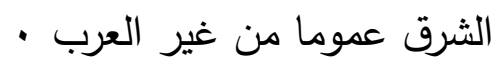

والمستشرقون هم جماعة من الكُتَّب الغربيين غالباً، الذين خَصَّصوا جزءًا من حياتهم في دراسة وتتبُع المواضع التراثية والتاريخية والدينية والاجتماعية للشرق، ويكتبون عن الفكر الإسلامي بصفة خاصة، ولهم طبقات

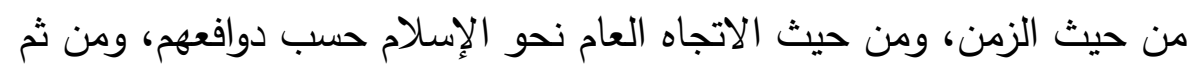

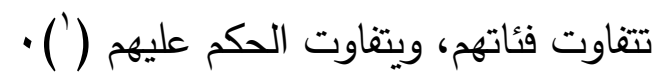
ويلاحظ على هذه التعريفات: أن منها ما هو عام، يُعنى بدراسة ولته حضارة وعلوم الشرق بصفة عامة، ومنها ما هو خاص، يُعنى بدراسة حضارة

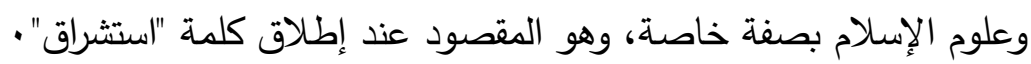

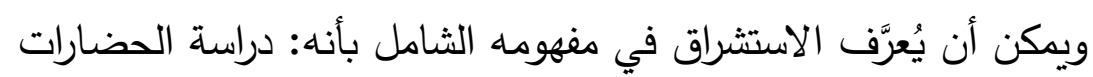
الثرقية بصفة عامة، والحضارة الإسلامية بصفة خاصة، في مجالها المادي والمعنوي، من غربي أو شرقي لا يدين بالإسلام بصفة عامة، أو غربي أوربي

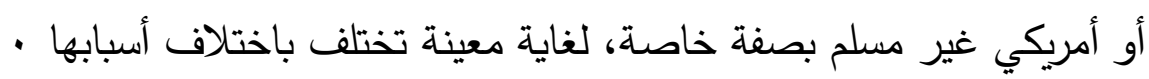
كما أن إطلاق لفظ "عالم" على المستشرق، ووصف الاستشراق بكونه

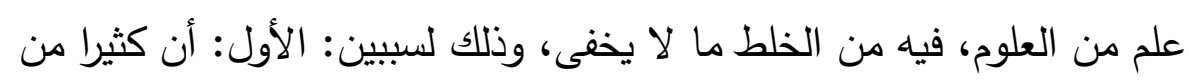

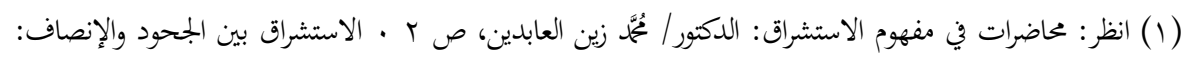

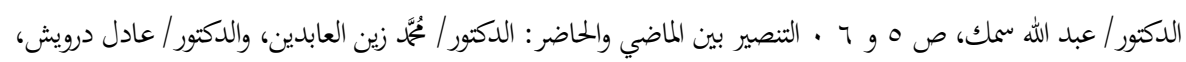


الدراسات الاستشراقية صدرت من قس ورهبان، ولم تصدر جميعها عن علماء وباحثين · الثاني: أن وصف الاستشراق بكونه علم يتتافى مع الحقيقة، لأن العلم بمعناه الدقيق لا بد لله من موضوع وأهداف واضحة يغلب عليها الطابع الإنساني الإيجابي، ولا بد له من منهج ثابت ذي ضوابط محددة، يلتزم

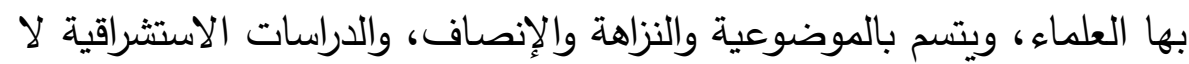

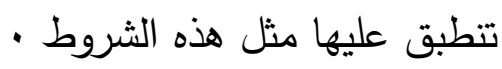
ثانياً: نشأة الاستشراق:

بدأ الاستشراق، ومر بأطوار تاريخية عدة، بداية بالتكوين، وانتهاء

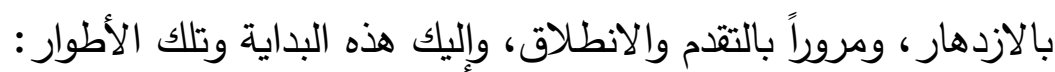

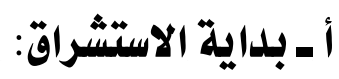

اختلف الباحثون حول تحديد بداية الاستشراق، على النحو التالي: الرأي الأول: يرى أصحاب هذا الرأي أن الاستشراق بدأ في القرن

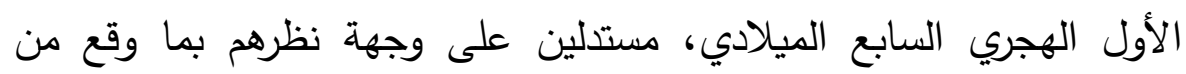

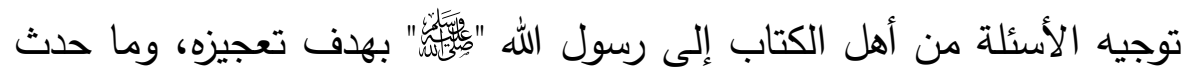
من جدل وحوار بين أهل الكتاب والمسلمين، ومحاولة اليهود التشكيك في عقيدة المسلمين بإثارة الثبهات، والقذّح في السمعيات، بل وصل الأمر بهم إلى حد أنهح كانوا يدخلون الإسلام نفاقا أول النهار ويكفرون آخره، ليردوا

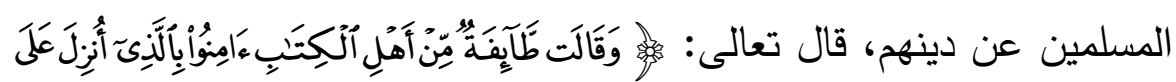

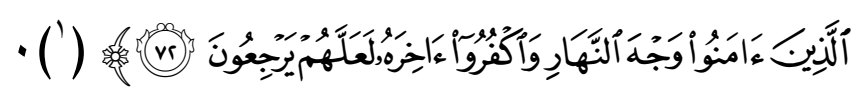

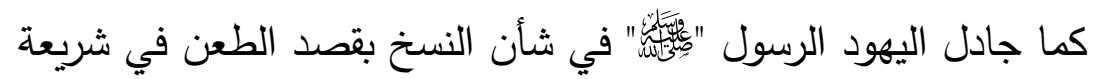
الإسلام، وقالوا: ألا ترون أن ححما يأمر أصحابه بأمر ثم ينهاهم عنه ويأمرهم

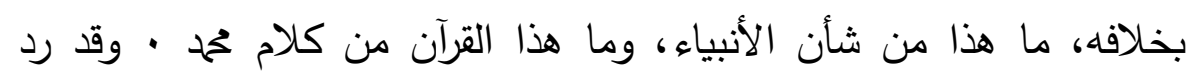

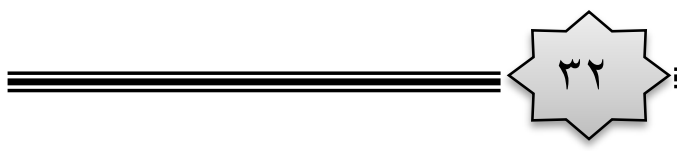


القرآن الكريم على تلك الثبهة مبينا الحكمة من النسخ، كي يزداد المؤمنون إيماناً، بقوله تعالى :

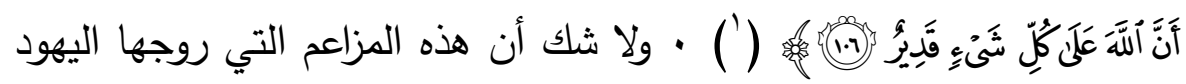
حول شريعة الإسلام، وإن لم تكن في حقيقة الأمر استشراقا بما تعنيه الكلمة

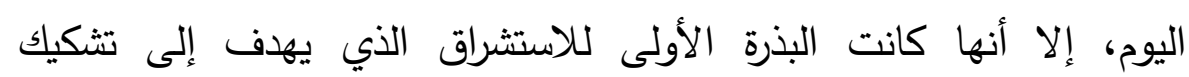

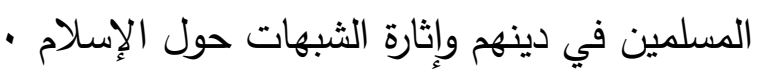
وفي الوقت الذي قامت فيه دولة الإسلام بالمدينة المنورة تستمد حياتها من القرآن الكريم والسنة النبوية، ترَصَّد أعداؤها للدعوة الإسلامية، ووصل لإسل دائل الأمر بهم إلى أن دخل البعض منهم في الإسلام، لترويج الأفكار المريضة، وبث الثبهات، ومن هؤلاء عبد الله بن سبأ اليهودي (†) الذي أبطن اليهودية وأظهر الإسلام، وحرص على الكيد للدعوة الإسلامية، فزرع فكرة ألوهية الإمام

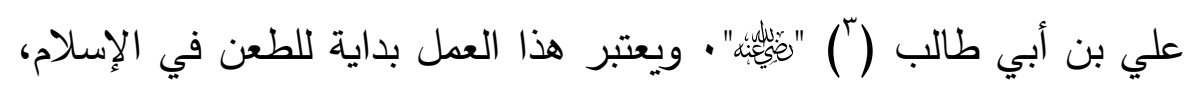

(r) عبد الله بن سبأ اليهودي: يقول المؤرخون إن هذه الشخصية من صنعاء باليمن، ولأنه من أم حبشية فكنيراً ما يطلق عليه

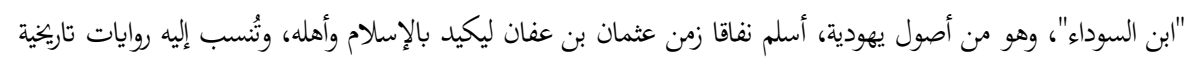

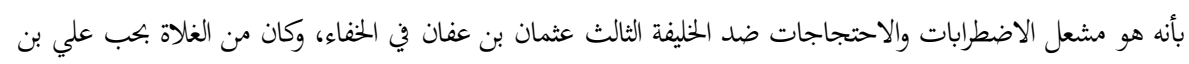

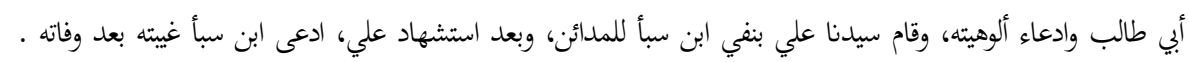

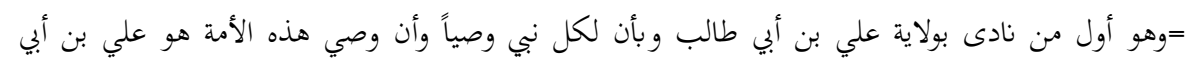

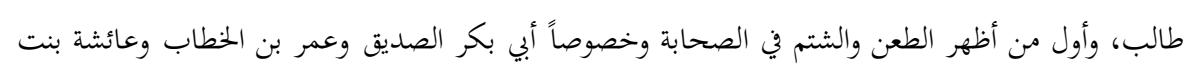

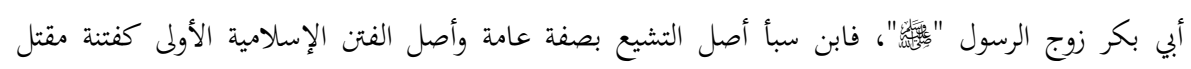

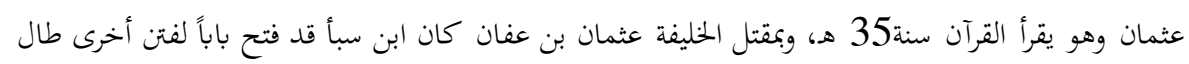

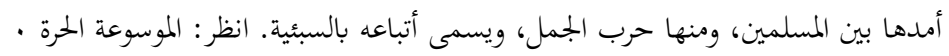

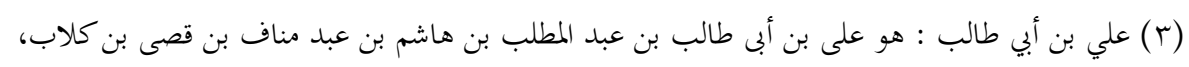

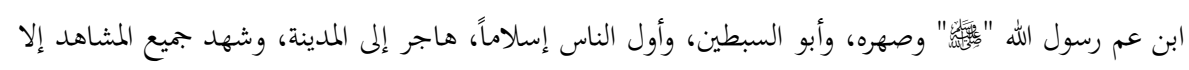

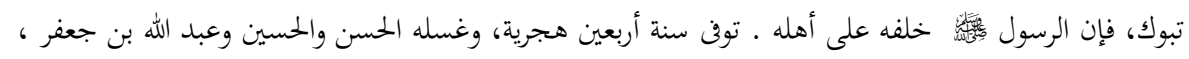

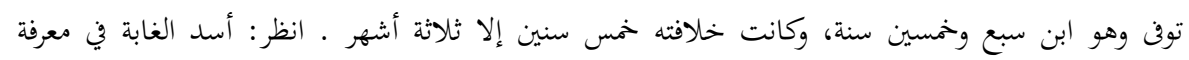

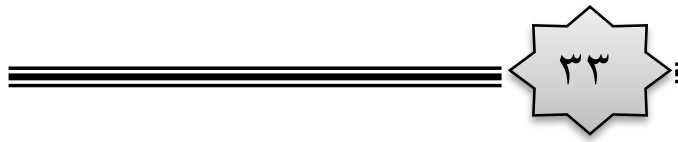


ونواة لعدائه، جاءت مع القرن الأول الهجري، مما يؤكد أن الاستشراق بدأ مع

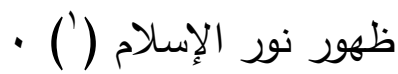

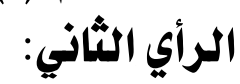

يؤرخ بعض الباحثين لحركة الاستشراق بالقرن الثاني الهجري الثامن الميلادي، ويستدلون على ذلك بما قام به بعض العلماء من أهل الديانات الأخرى من طعن في الإسلام، وعلى سبيل المثال ؤجد في القرن الثاني الهجري يوحنا الدمشقي (') المعروف بآثاره في الدراسات الاستشراقية، حيث الإسي ألف كتابا سماه "حياة ححد"، قدَّم الإسلام فيه على أنه فرقة مسيحية مارقة،

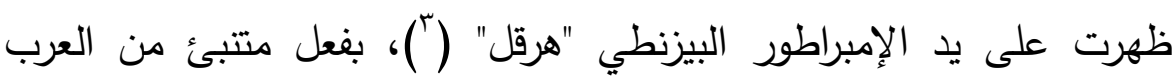

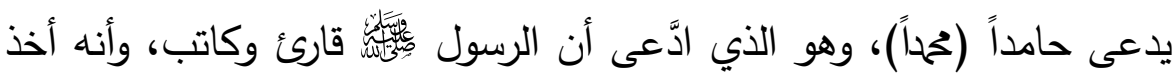

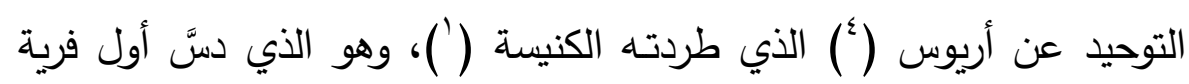

الصحابة: الإمام على بن مُحَّم الجزرى "ابن الأثير"، دار الفكر للطباعة والنشر والتوزيع (بيروت)، ج ج صییهـ .7199

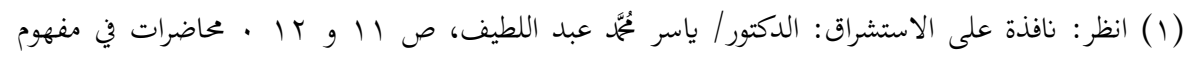

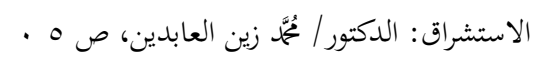

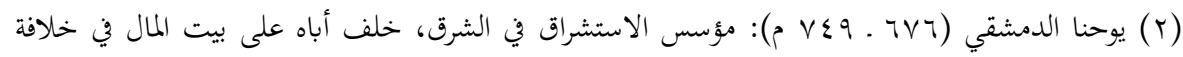

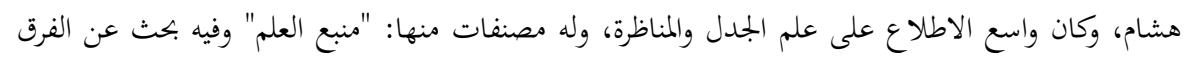

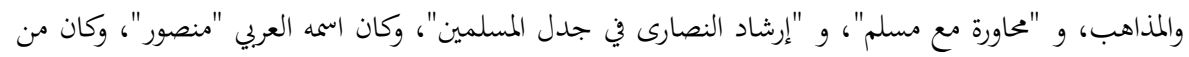

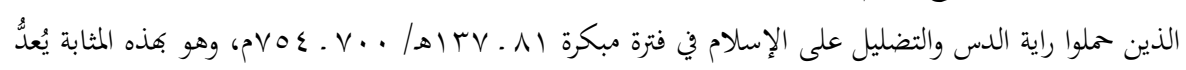

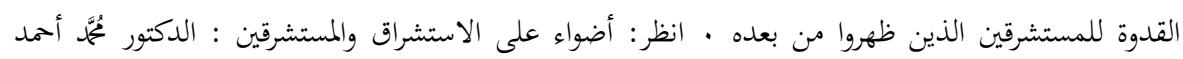

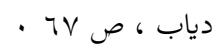

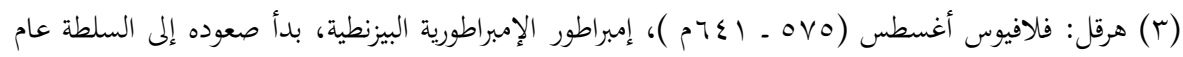

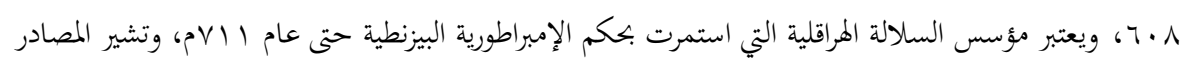

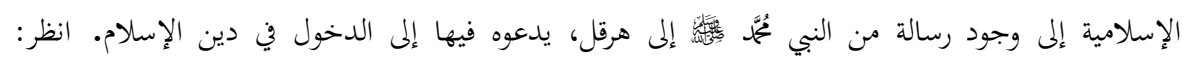

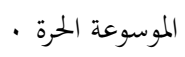
(ع ) أريوس: هو أريوس المصري، مؤسس أكبر الطوائف النصرانية الموحدة ، ظهر في القرن الرابع الميلادي، وأخذ 
تناقلها الناس بعده من أن النبي بـ أباطيل هذا الرجل ومن نحا نحوه من رجال بيزنطة إلى غرب أوربا، فكانت

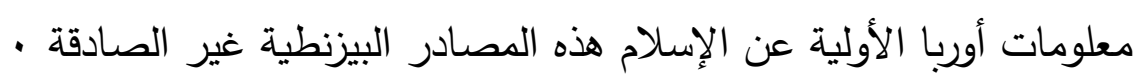

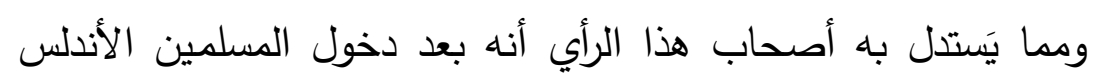

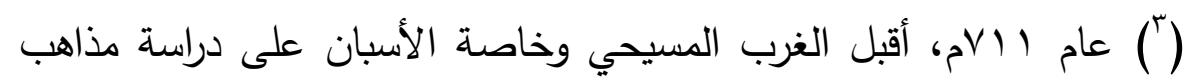

على نفسه مقاومة كنيسة الإسكندرية فيما تبثه بين المسيحيين من ألوهية المسيح، منكراً ما جاء في الأناجيل منا

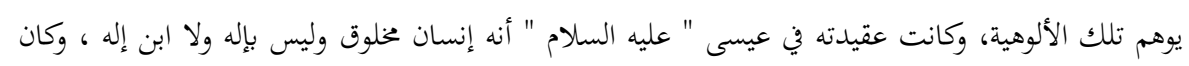

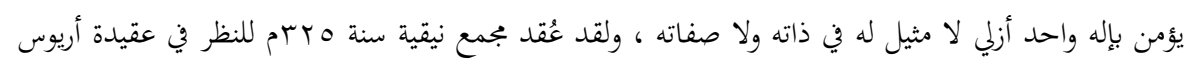

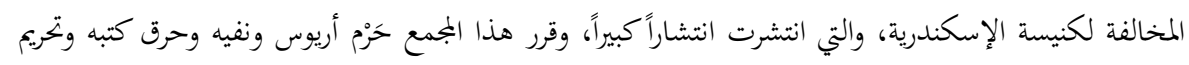

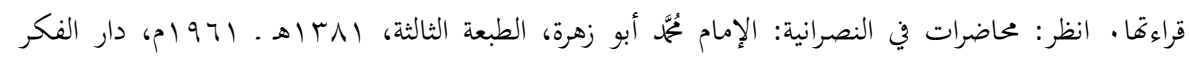

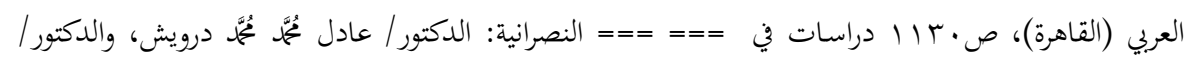

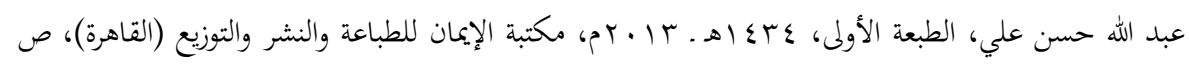
. .

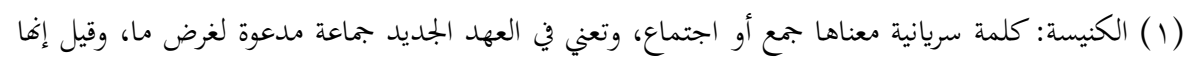

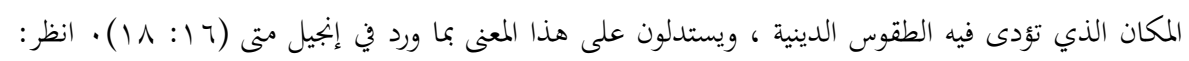

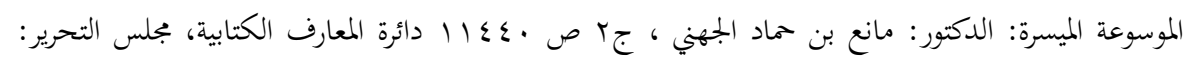

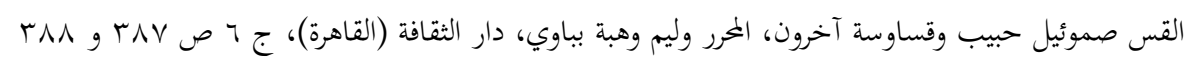

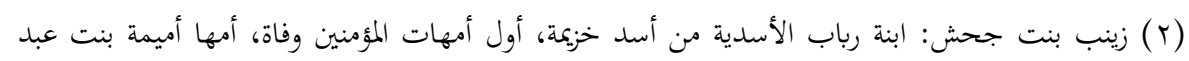

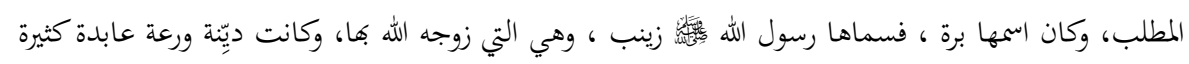

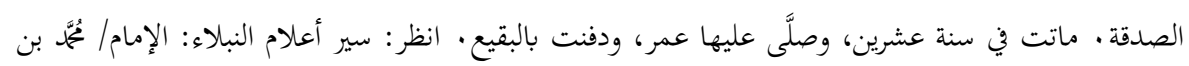

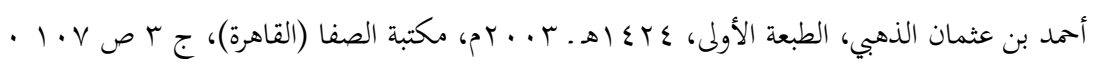

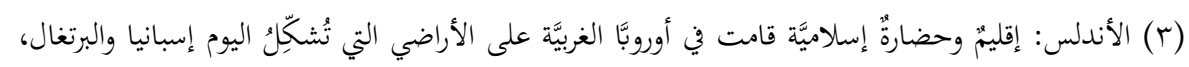

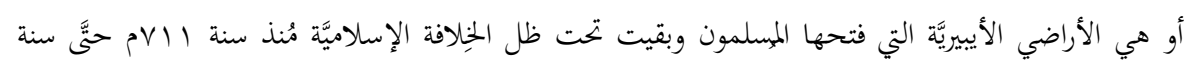

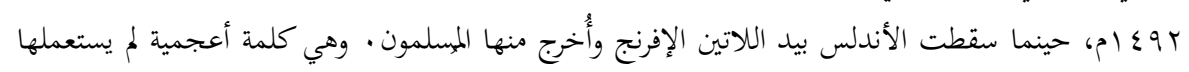

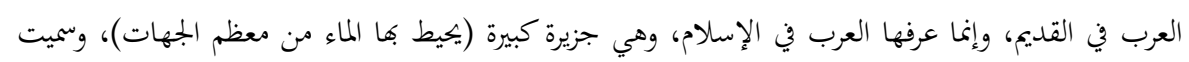

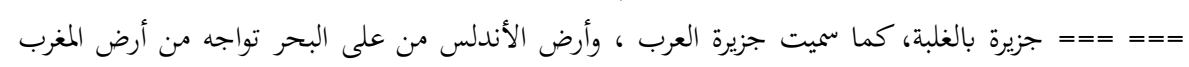

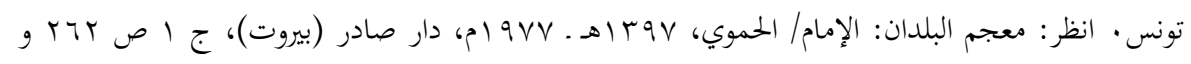
كآب • الموسوعة الحرة . 
أهل الدين والفلاسفة المسلمين، ودراسة اللغة العربية وآدابها، وأنفقا في سبيل

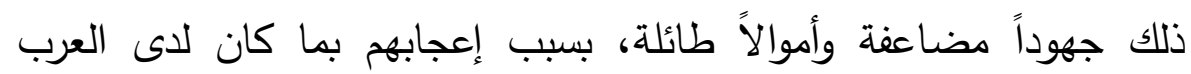

• (') والمسلمين من حضارة (')

الرأي الثالث: يرى أصحاب هذا الرأي أن حركة الاستشراق بدأت في القرن السادس الهجري الثاني عشر الميلادي، حيث ازدهرت حركة الاستشراق وانتشرت المراكز العلمية في العالم الإسلامي، وبدأ الأوربيون يتوافدون عليها،

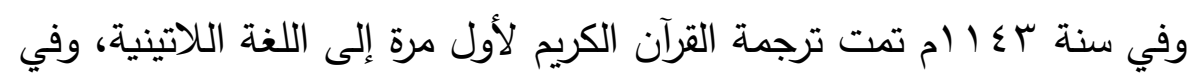

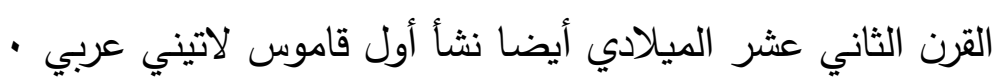
الرأي الرابع: يذهب بعض الباحثين إلى أن القرن السابع الهجري الثالث

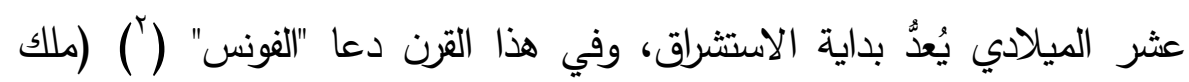
قشتالة) "ميشيل سكوت" (") ليقوم بالبحث في علوم المسلمين وحضارتهم،

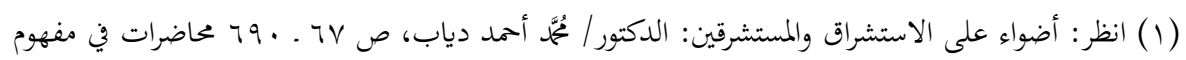

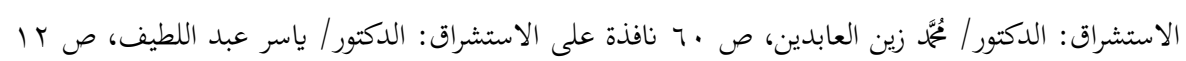

(r) الفونس: الفنس بن شنجه أو ألفونسو الساد (1109 - 1040) ، ملك ليون من سنة ه7 • ام إلى 9 • 11 م وملك قشتالة منذ سنة 1072 م بعد وفاة أخيه. ألفونسو السادس هو الابن الثاني للملك فرناندو

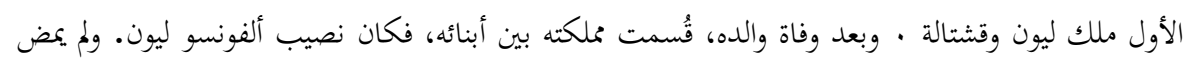

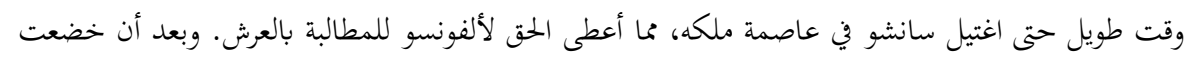

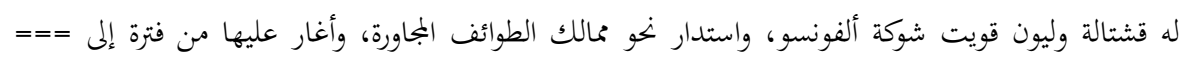

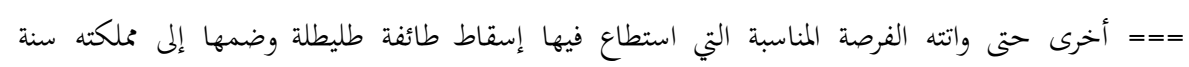

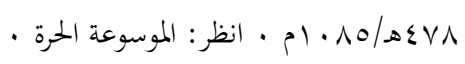

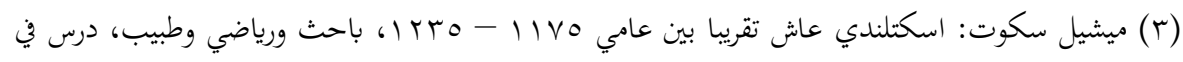
أكسفورد حيث تعلم الفلسفة والرياضيات، ويظهر أنه درس الدين حيث طلب البابا هونوريوس الثالث من كبير أساقفة كانتربري أن يمنح مركزا دينيا لسكوت في إنكلترا عام بr ب أو أو 1224 ـ ـ وذهب إلى طليطلة وكان

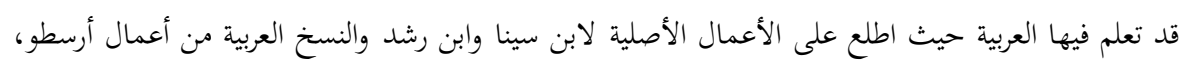

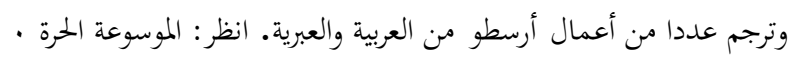

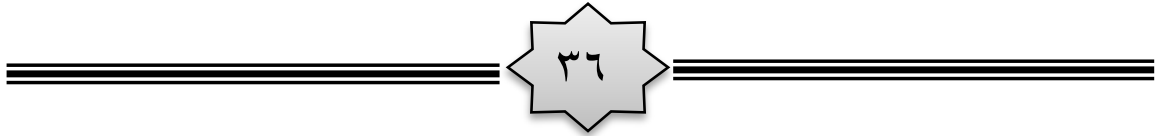


فجمع "سكوت" طائفة من الرهبان في بعض الأديرة (') بالقرب من مدينة

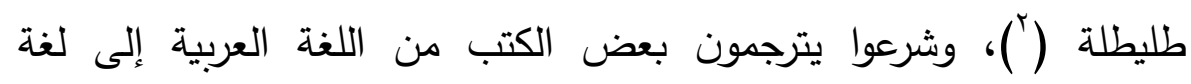
الفرنجة، ثم قََّمها "سكوت" لملك صقلية (") الذي أمر باستنساخ نسخ منها، وبعث بها هدية إلى جامعة باريس (') · وكذلك قام "ريموند لول" (') (رئيس

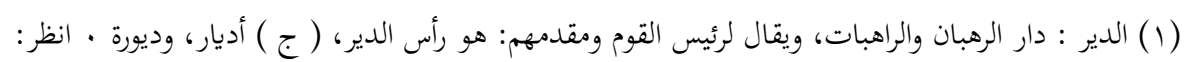

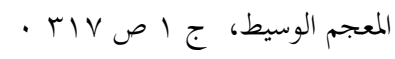

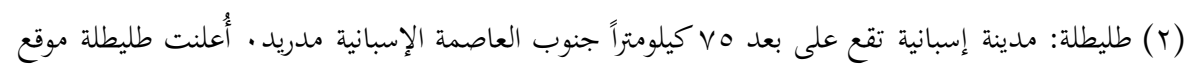
تراث ثقافي عالمي من قبل اليونسكو في 1986 بوصفها واحدة من العواصم السابقة للإمبراطورية الإسبانية

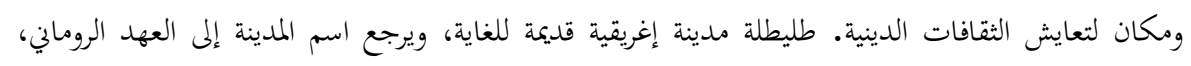

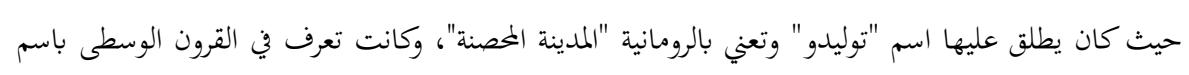

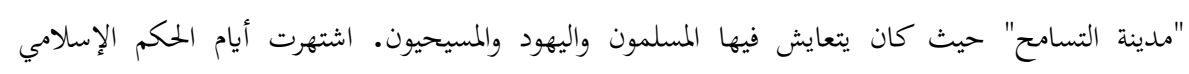

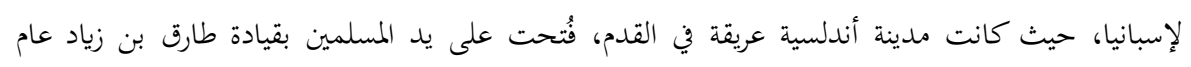

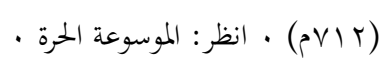

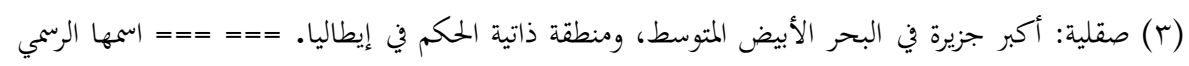

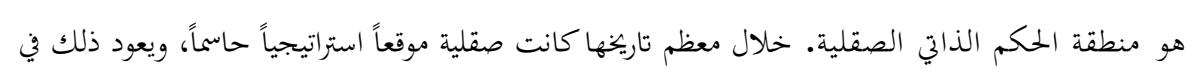

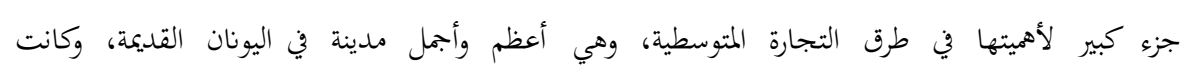

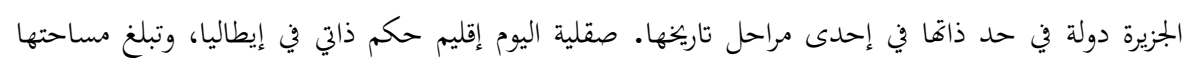

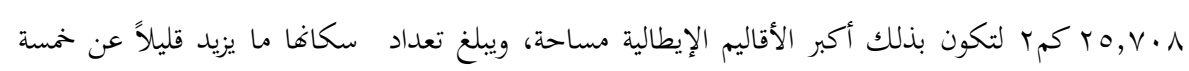

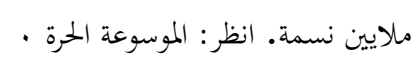

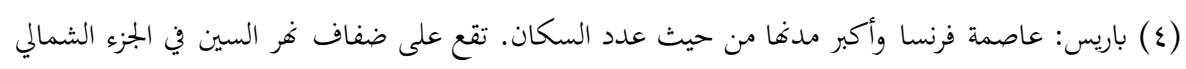

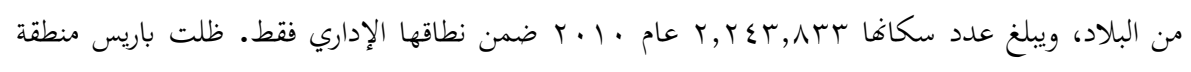

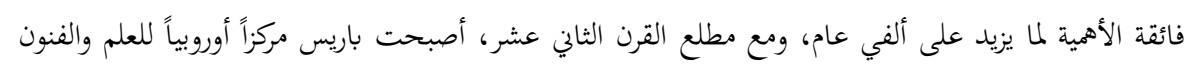

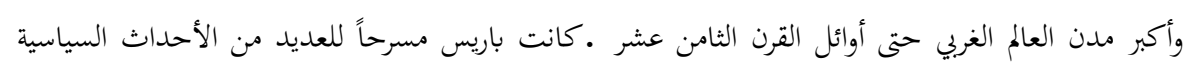

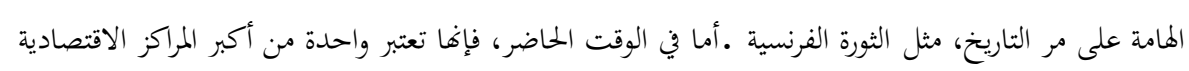

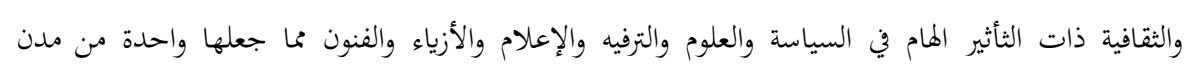

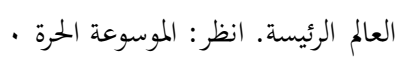

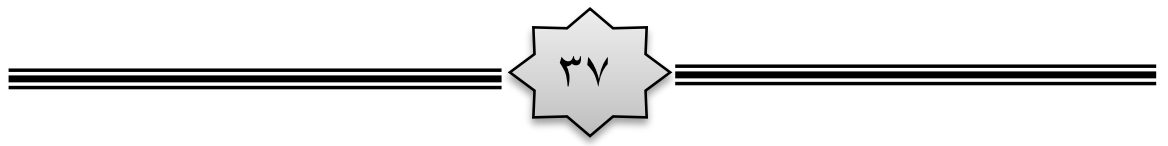


أساقفة طليطلة) بنشاط كبير في الترجمة، ومع مرور الزمن توسع الأوربيون

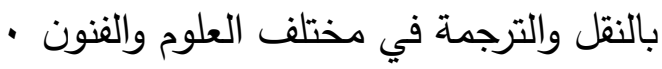
وبذل مبشرون آخرون جهوداً كبيرة لإنشاء كراسي لتدريس اللغة العربية،

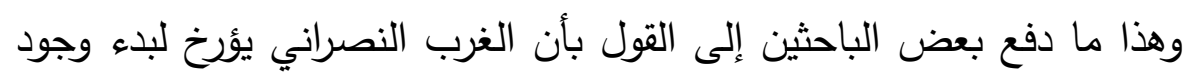

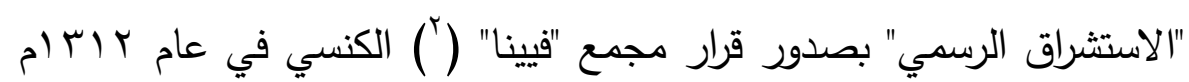
(القرن الرابع عشر الميلادي) بإنشاء عدد من كراسي اللغة العربية في عدد من الجامعات الأوربية، ولكن الإشارة هنا إلى الاستشراق الرسمي تدل على أنه

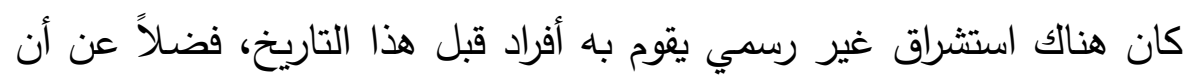

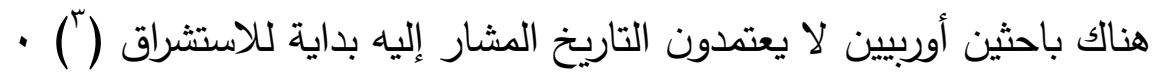

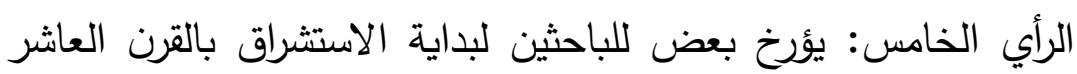

(1) ريموند لول: أسباني فيلسوف، ومن أسرة ميسورة الحال. أُولع بالشعر، ثم انضم إلى رهبنة الفرنسيسكان . انكب على دراسة اللغة العبية والثقافة الإسلامية، قاصداً دعوة المسلمين إلى المسيحية. سافر من أجل ذلك إلى شمال إفريقية غير مرة، ولقي حتفه هناك. حاول في مؤلفاته، وخاصة \الفن الأكبره، أن يدافع عن المسيحية

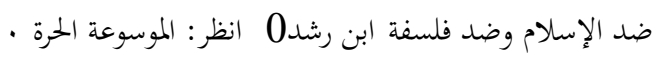
(Y) فينا: عاصمة النمسا، وأكبر مدها من حيث عدد السكان، وسميت بهذا تطويراً عن اسمها اللاتيني القديم (فيندوبونا)،

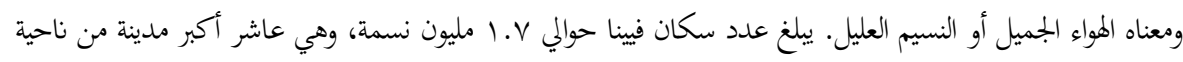

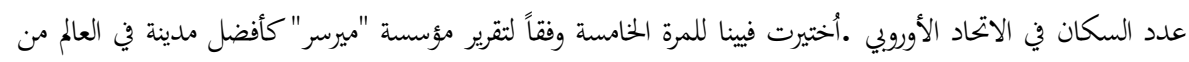

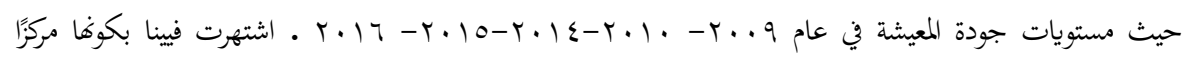
عالميًا للتعليم والأدب والموسيقى والعلوم •وبعد انتهاء الحرب العالمية الثانية في سنة 1945 أصبحت فيينا مركزاً عالمياً للمؤتمرات والوكالات، وتستضيف العديد من المنظمات الدولية الكبرى مثل منظمة الأمم المتحدة ومنظمة أوبك. انظر:

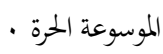

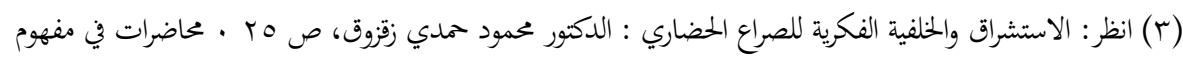

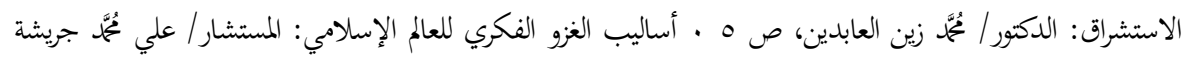

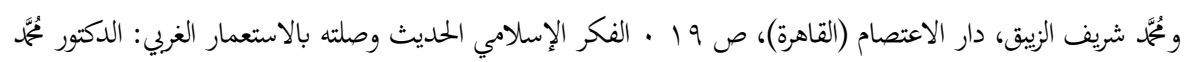

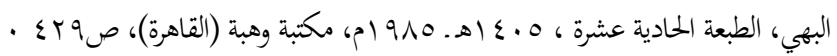

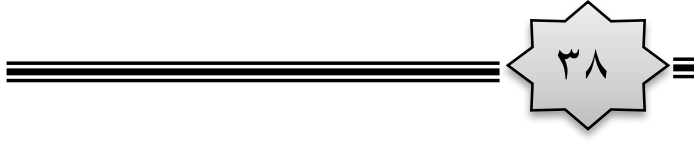


الهجري السادس عشر الميلادي، وذلك بعد فترة الإصلاح الديني (') التي ظهرت في أوربا، واتصل في ذلك الوقت الغرب المسيحي بالثرق الإسلامي

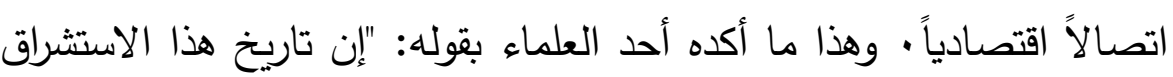
قديم، يرجع إلى القرن السادس عشر الميلادي" ( ) ) .

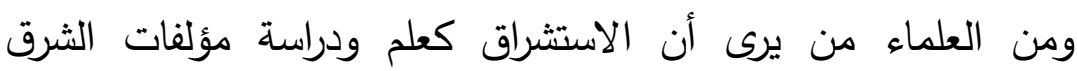
الإسلامي بدأ في القرن الثاني عشر الهجري الثامن عشر الميلادي، وهو العصر الذي بدأ فيه الغرب في استعمار العالم الإسلامي والاستيلاء على ممتلكاته، فإذا بعدد من علماء الغرب ينبغون في الاستشراق، ويُصْدِرون لذلك المجلات في جميع الممالك الغربية، ويُغِيرون على المخطوطات في البلاد العربية والإسلامية، فيشترونها من أصحابها الجهلة، أو يسرقونها من المكتبات العامة التي كانت في نهاية الفوضى، وينقلونها إلى بلادهم ومكتباتهم، وإذا بأعداد هائلة من نوادر المخطوطات العربية تنتقل إلى مكتبات أوربا، وقد بلغت في أوائل القرن التاسع عشر مائتين وخمسين ألف مجلد، وما زال هذا

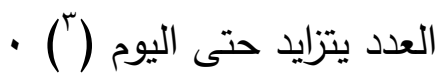
وبعد هذا العرض لهذه الآراء، لا يمكن للباحث أن يجزم أن واحدا

(1) الإصلاح الديني: ظهر الإصلاح الديني في النصرانية بسبب شدة سلطان الكنيسة === ==== على الناس

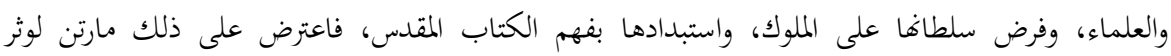

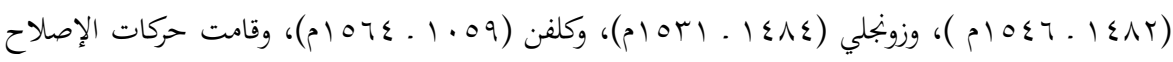

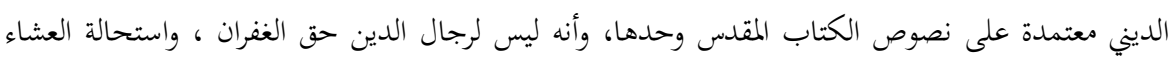

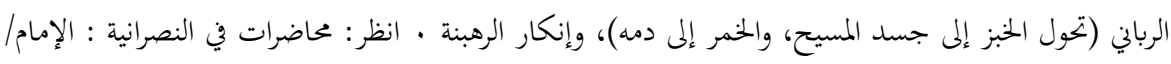

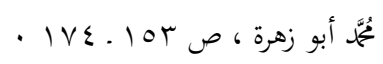

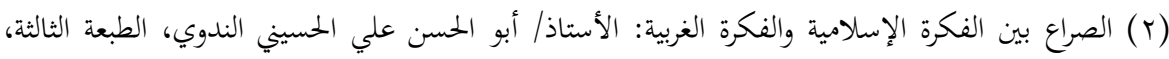
ا

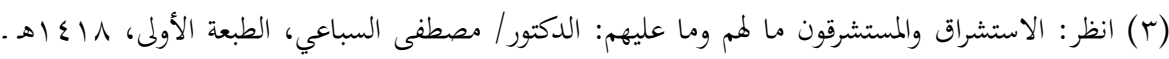

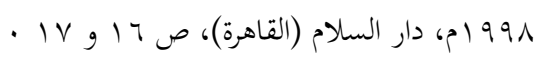


منها يُمبثِل البداية الحقيقية للاستشراق، وإنما يمكن التوفيق بينها بأن الاستشراق بدأ بجهود فردية غير منظمة مع انتشار دعوة الإسلام، وكانت الدوافع المحركة له بالدرجة الأولى دينية، هدفها الكيد للإسلام، ثم اتسع وتبلور بالدراسة والبحث مستفيدا من العلوم الإسلامية، وذلك في العصور الوسطى والحروب الصليبية، ثم وصل إلى جهود جماعية منظمة باجتماع العوامل المكوِنة له في بداية القرن السابع عشر والثامن عشر الميلادي أو أن هذه الآراء وتلك المحاولات لا تتجه إلى تحديد سنة معينة لبداية الاستشراق، وإنما إلى تحديد فترة زمنية على وجه التقريب، يمكن أن تُعدَّ بداية

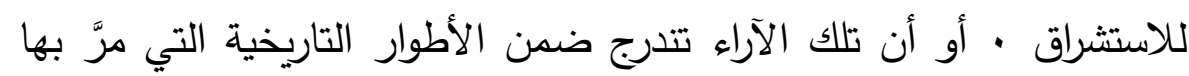

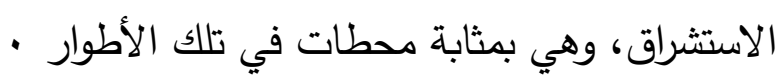

\section{ب ـ الأطوار التاريخية للاستشراق:}

لقد مر الاستشراق عبر تاريخه الطويل بعدة أطوار ، يمكن إجمالها

$$
\text { فيما يلي : } 1 \text { ـ طور التكوين: }
$$

يبدأ هذا الطور في القرن الثامن الميلادي، عندما دخل المسلمون الأندلس، وأسسوا في هذه البلاد أسمى حضارة عرفتها البشرية، واتَّم هذا

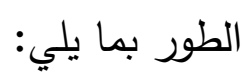

ضعف الحياة العلمية في الغرب: كانت أوربا في العصور الوسطى لونى تعيش في ظلام دامس، وتخلُف لا مثيل له في شتى ميادين الحياة، فبينما كان

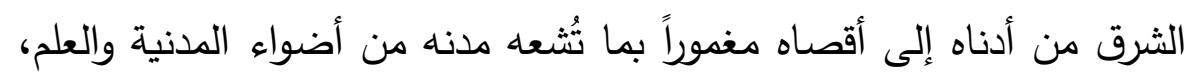

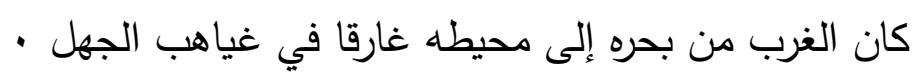

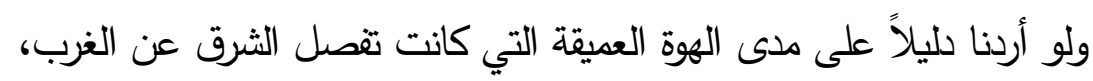
لكفانا أن نعرف أن نسبة 90\% من سكان الغرب في القرن التاسع والعاشر والحادي عشر والثاني عشر الميلادي، كانوا لا يستطيعون القراءة والكتابة، وفي الأديرة يندر

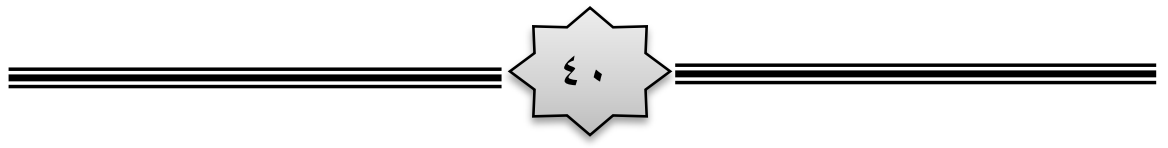


بين الكهنة (') من يستطيع إمساك القلم، وبينما كان هذا يحدث في الغرب، كانت آلاف مؤلفة من المدارس في القرى والمدن تستقبل ملايين البنين والبنات في بلاد

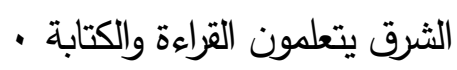
نشأة الاستشراق في كنف الكنيسة: كان رجال الدين يؤلفون الطبقة المتعلمة في أوربا، ولا سبيل لهم إلى إرساء نهضتها إلا على أساس من التراث

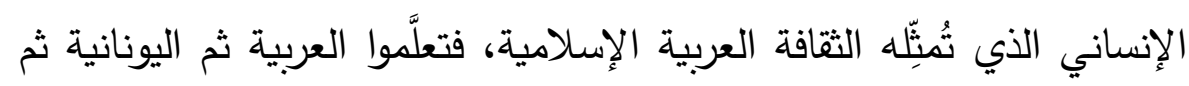
اللغات الثرقية، وبرز الرهبان في نقل الثقافة الإسلامية إلى بلاد أوربا

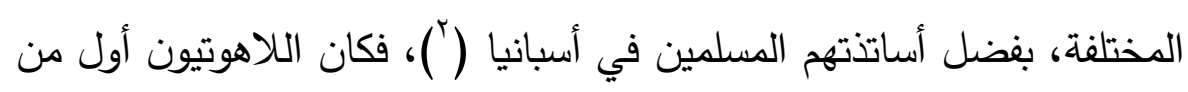
أقبل على دراسة الحضارة الإسلامية، فدرسوها من خلال مدارس المسلمين ومجامعهم، ثم قبعوا في أديرتهم يترجمون هذا التراث، ويذيعونه بين الرهبان

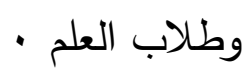

ومن أهم هؤلاء المستشرقين الكنسيين "جرب دي أورالياك" (ربه . . ب. . (م)، الذي قصد الأندلس، وأخذ عن أساتذتها في مدارسها، حتى أصبح أوسع علماء عصره ثقافة بالعربية والرياضيات والفلك، وانتُخب حبرا أعظم

(1) الكاهن ـ الكهنوت: الكاهن هو خادم الدين أو الشخص المخصص لتأدية الحذدمات الكهنوتية، التي تشمل

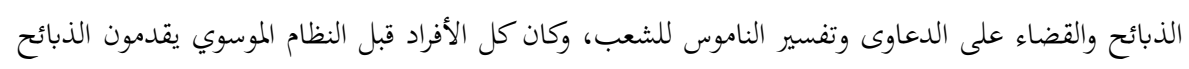

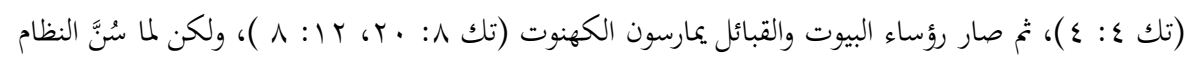

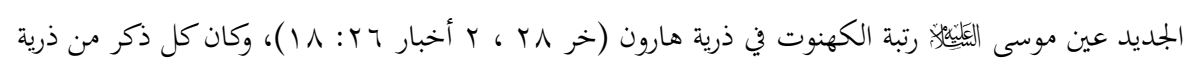

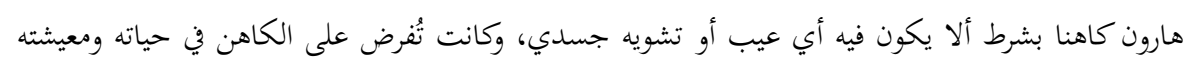

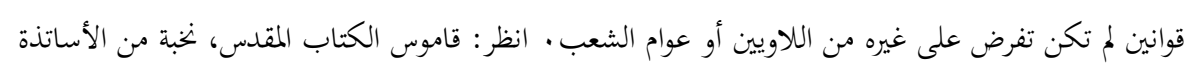

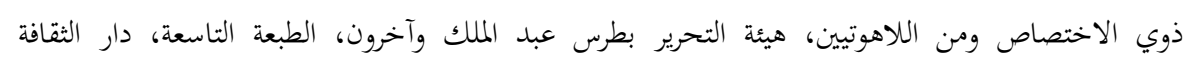

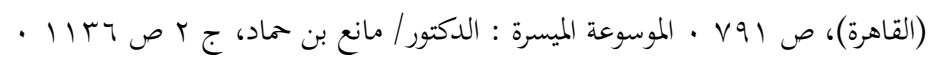

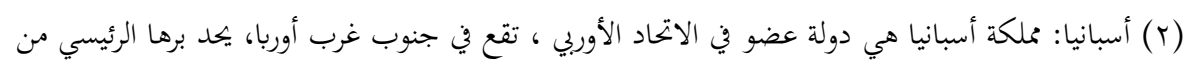

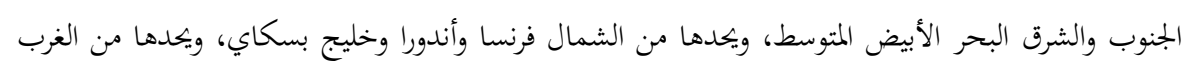

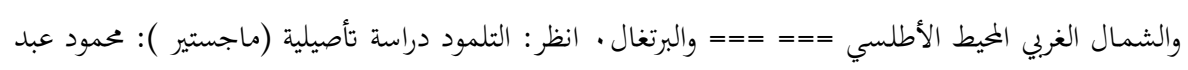

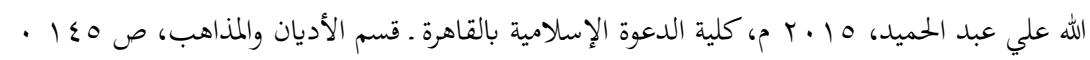
$\overline{\bar{\equiv}}\{1\}$ 
باسم "سلفستر الثاني" (999 ـ س... (م)، فكان أول بابا فرنسي، وقد أمر بإنشاء مدرستين عربيتين، الأولى في روما (') مقر خلافته، والأخرى في دايمس (وطنه)، وتَرجم بعض الكتب الرياضية والفلكية .

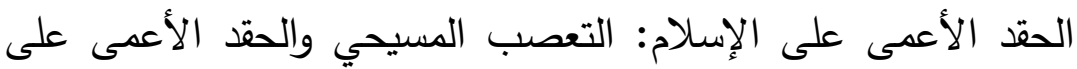
الإسلام بوجه عام صاحب العالم الغربي آنذالك، رغم الأيادي البيضاء للإسلام عليه، فلقد كان موقف الغرب المسيحي في هذا الطور من الإسلام هو موقف الدفع والمشاحنة • وقد عمد عدد من رجال الدين في هذه الفترة إلى التعلم للرد على المسلمين، وتشويه الإسلام بنشر الافتراءات والأكاذيب حوله، وزعموا

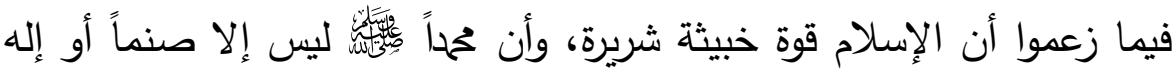
قبيلة أو شيطاناً، وغزت الأساطير الثعبية والخرافات خيال الكُتَّب اللاتينيين

وفي مقابل تلك الصورة البغيضة للإسلام، كانت هناك جهود أخرى للوصول إلى معرفةٍ موضوعيةٍ في مجال العلوم العربية مثل الفلسفة والطب والعلوم الطبيعية، وكان لرئيس أساقفة طليطلة وغيره الفضل في إخراج ترجمات مبكرة لبعض الكتب العلمية العربية، وهذه الحركة التي قامت في أوربا لترجمة العلوم العربية إلى اللاتينية تثبه تلك الحركة التي قامت في العالم الإسلامي في عهد المأمون(r) ومن سبقه لترجمة العلوم اليونانية وغيرها إلى لى

(1) روما: الرواية التاريخية التي تناقلها مؤرخو الرومان القدامى، تتلخص في أن مدينة روما قد تأسست سنة

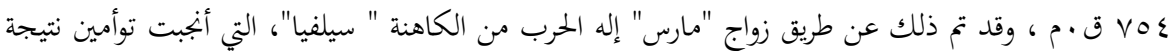

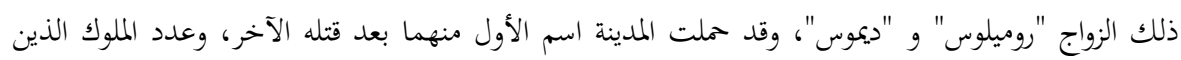

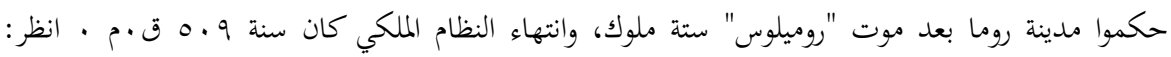

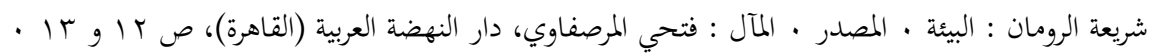
(r) المأمون: هو عبد الله بن هارون الرشيد سابع خلفاء بني العباس، ولد عام • Vاهـ Tدحم، وتوفي غازيا في 19 رجب عام218 هـ 10أغسطس سنة 833 بطرسوس، شهد عهده ازدهاراً بالنهضة العلمية والفكرية وذلك لأنه شارك فيها بنفسه، وتفرد عهد المأمون بتشجيع مطلق للعلوم من فلسفة وطب ورياضيات وفلك واهتمام خاص بعلوم اليونان،

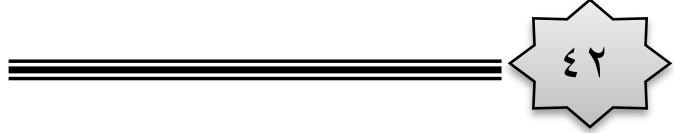


العربية، وقد كانت هنالك بعض المحاولات للتعرف على الإسلام بقدرٍ من الموضوعية، ومما يؤكد هذا أنه كان يوجد اعتراف من بعض المستشرقين بأن الإسلام ترك للنصارى وغيرهم حرية الدين، بل إن المسلمين الفاتحين استعانوا باليهود فولَّوهم كبرى المدن، وفرض التسامحُ الإسلامي وجوده في البلاد المفتوحة، ومنح المواطنين في تلك البلاد حرية وثقافة لم ينالوا مثلها من قبل. ويمكن القول بصفة عامة بأنه قد كان هناك في هذه الفترة المبكرة للاستشراق لهن اتجاهان مختلفان فيما يتعلق بالأهداف والمواقف إزاء الإسلام: الاتجاه الأول كان فئ هان اتجاهاً لاهوتياً متطرفاً، ناظراً إلى الإسلام من خلال ضباب كثلف فيف من الخرافات

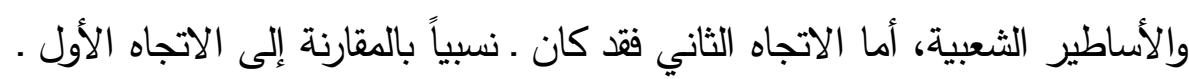
أقرب إلى الموضوعية والعلمية، ونظر إلى الإسلام بوصفه مهذ العلوم الطبيعية والطب والفلسفة، ولكن الاتجاه اللاهوتي الخرافي ظل حيا حتى القرن السابع عشر وما بعده، ولا يزال حيا في العصر الحاضر في كتابات بعض المستشرقين عن

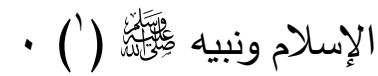

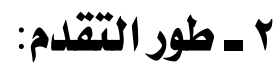

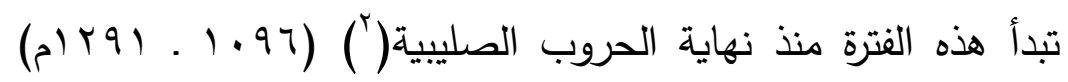
وقد أسس الخليفة عام830 م جامعة بيت الحكمة في بغداد والتي كانت من كبريات جامعات عصرها، وقد

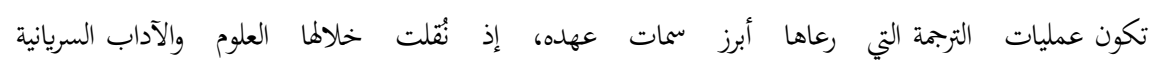

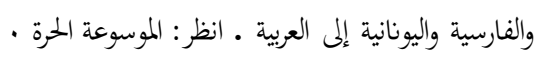

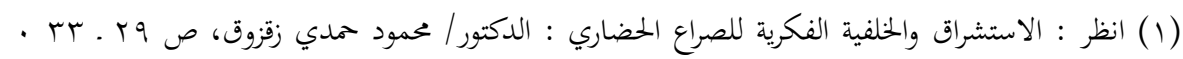

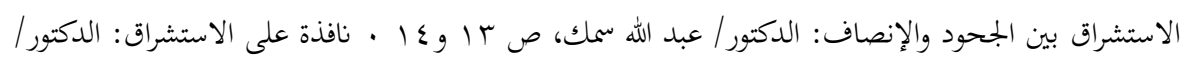

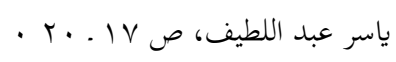

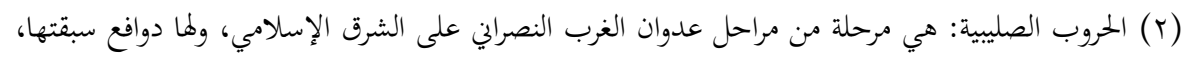

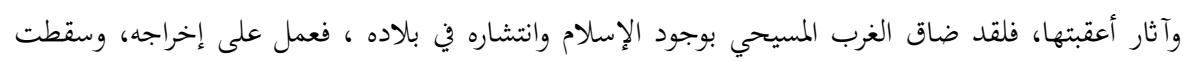

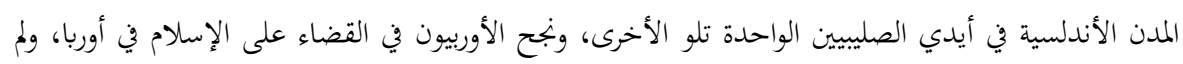

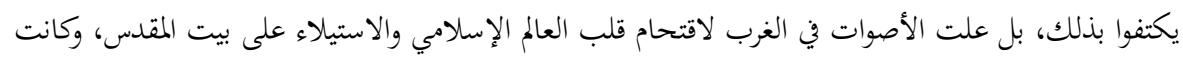

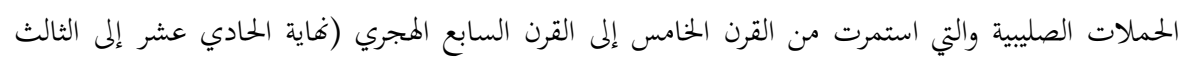

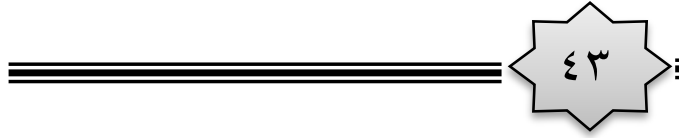


حتى القرن السادس عشر الميلادي . فلقد بذلت الكنيسة في أوربا كل ما استطاعت من جهود في سبيل الحيلولة بين الأوبيين والوقوف على تعاليم الإسلام وآدابه، ولما لم تتمكن من مقاومة المد الإسلامي فكرياً وحضارياً، حرَّضت على حملات مسلحة تَعْبُر البحر المتوسط لمهاجمة المسلمين في الثرق تحت ستار حماية الصليب وإنقاذ القبر المقدس من أيدي البرابرة المتوحشين (المسلمين)، ووعدهم بابا الكنيسة بأن تكون رحلتهم إلى الثرق

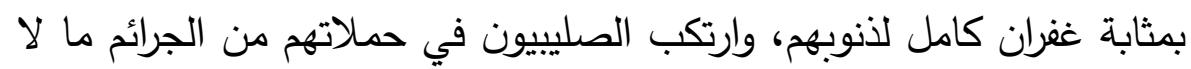
يصدقه عقل، إذ قُتل نحو سبعين ألفا من المسلمين في المسجد الأقصى، حتى وارى خاضت الخيل في دماء الشهداء، فكانوا من أشد الوحوش حماقة، وكانوا لا لانين يُعْرِقون بين المحاربين والأهليين العَُّلَ من الثيوخ والنساء والأطفال، ومكث

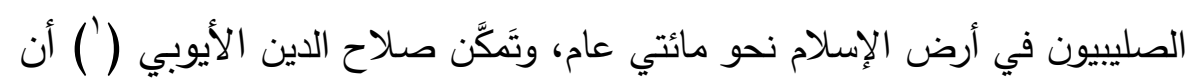

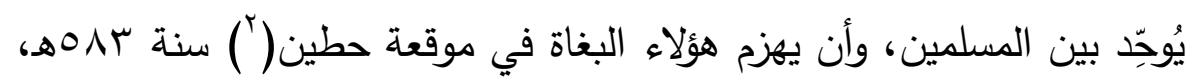

عشر الميلادي)، وانتهت بهزيمة تلك الحملات هزيمة منكرة، فحول الغرب تلك الحروب العسكرية إلى حرب

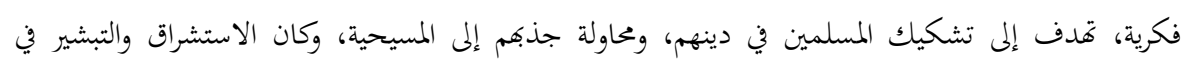

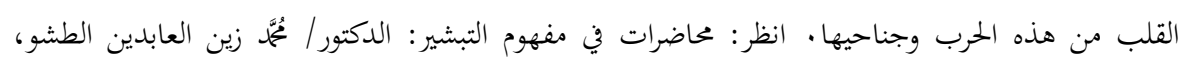

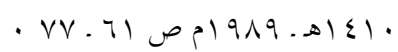

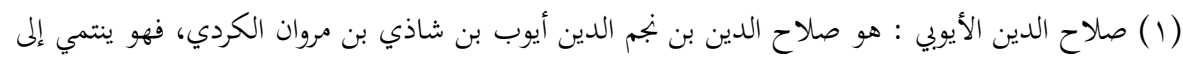

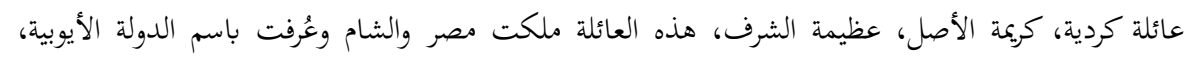

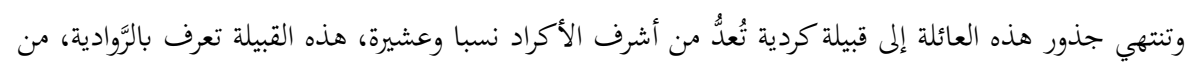

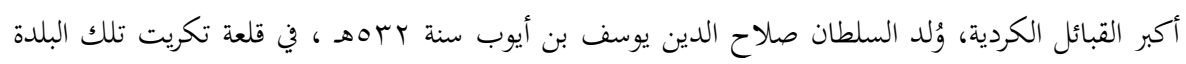

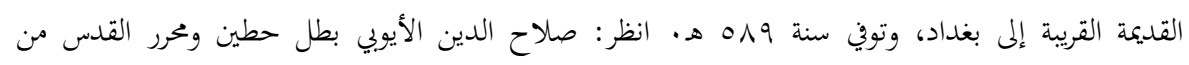

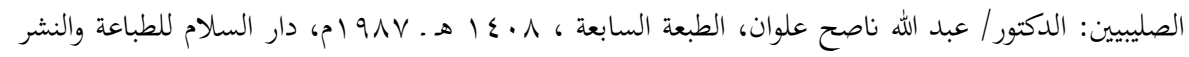

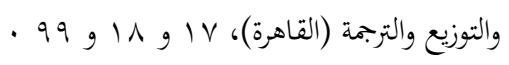

(r) موقعة حطين: أخذ السلطان صلاح الدين الأيوبي يُعدُّ العدة ويجمع الجيوش، لمواجهة الصليبين واسترداد

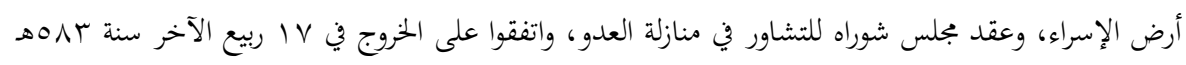

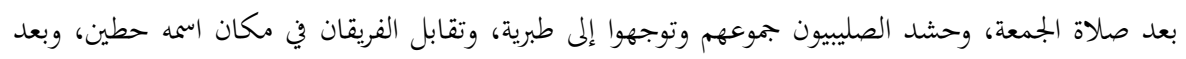

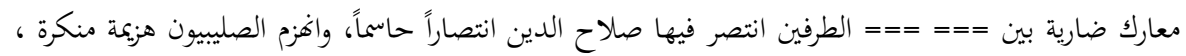

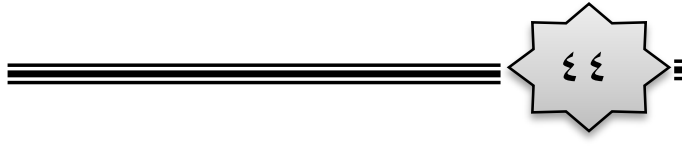


وكانت هذه الهزيمة بداية نهايتهم وطردهم من ديار الإسلام .

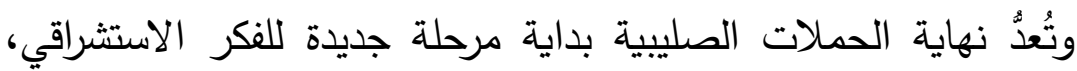
وذلك أن لويس التاسع (') بعد هزيمته في المنصورة (') ووقوعه في الأسر، رسم الخطة الجديدة التي تُمكِنهم من مواجهة الإسلام، وتقوم هذه الخطة على: تحويل المواجهة العسكرية إلى مواجهة فكرية، تستهدف الدسَّ بين المسلمين، وإثارة الخلافات، وإذكاء نارها بين الأوساط الإسلامية، وتجنيد المبشرين الغربيين لمحاربة تعاليم الإسلام، ووقف انتشاره، والقضاء عليه معنوياً، واستخدام من يمكن إغراؤهم من مسيحي الثرق في تتفيذ سياسة الغرب . ومنذ ذلك الوقت الذي فُرضت فيه هذه الخطة على عالمنا الإسلامي والصراغُ على أشده، مما جعل البعض يؤكد على أن تلك الحروب الصليبية كانت البداية للغزو الاستشراقي، وأدت إلى انتعاشه، خلال الاتصال الحضاري

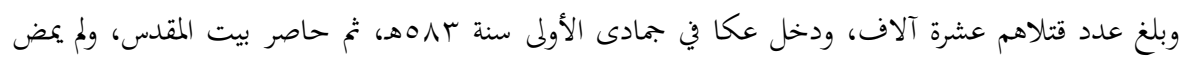

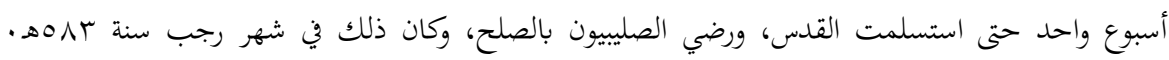

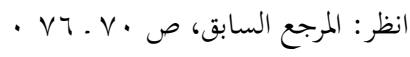
(1) لويس التاسع: لويس التاسع أو لويس القديس كان ملك فرنسا، وهو ابن لويس الثامن. استلم لويس

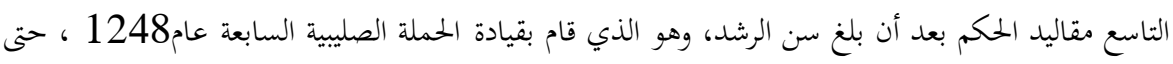

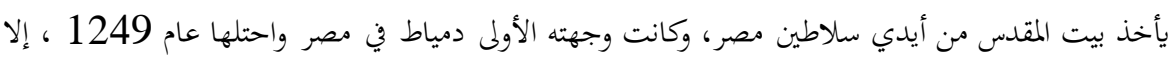

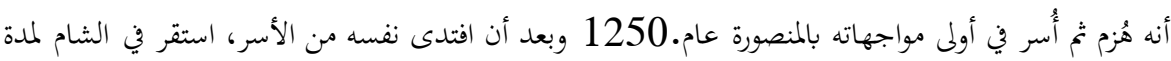
أربع سنوات1254-1250 ، ليعود بعدها إلى فرنسا حيث قام بإعادة تنظيم أجهزة الدولة ووطد دعائم السلطة الملكية، وهو الملك الفرنسي الوحيد الذي رضع رضاعة طبيعية. انظر : الموسوعة الحرة •

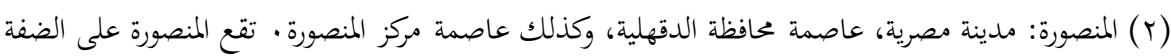
الشرقية لنهر النيل - فرع دمياط ـ ويقابلها على الضفة الغربية مدينة طلخا ـ وتبعد . با كم إلى شمال

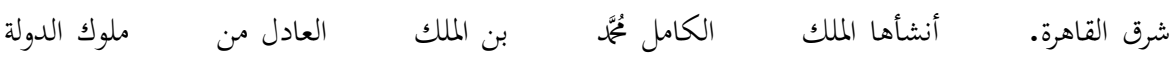
الأيوبية عام616 هـ .1219 م 0وكان يطلق عليها اسم "جزيرة الورد" لأفا كانت محاطة بالمياه من ثلاث جهات وكانت بها أكبر حدائق ورد في مصر. وقد سميت بالمنصورة بعد النصر في معركة المنصورة الذي حققه الشعب المصري على الحملة الصليبية السابعة بقيادة لويس التاسع الفرنسي. انظر : الموسوعة الحرة . $\bar{\equiv} \leq 10$ 
الواسع بين الثرق الإسلامي والغرب النصراني، بغية تحطيم الإسلام من

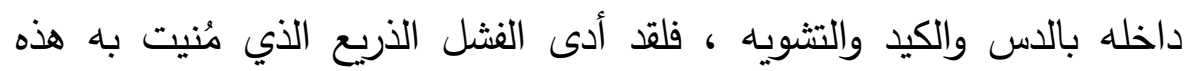
الحروب إلى ازدياد روح التعصب ضد الإسلام والمسلمين، فبدأ الجاحدون للإسلام يتعلمون اللغة العربية لا حبا فيها، ولكن ليتخذوها وسيلة إلى فهم القرآن، وسلاحاً في مناقثته والهجوم على الإسلام وتشويه صورته، فعمل ولان الصليبيون العائدون من الثرق على إظهار الإسلام بصورة مزرية، لذلك وجدنا

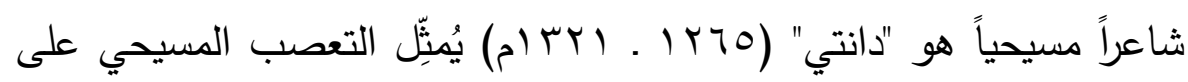

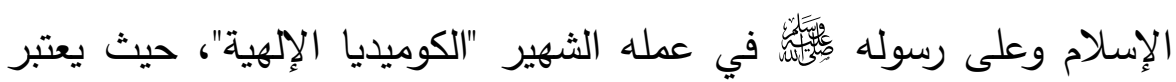

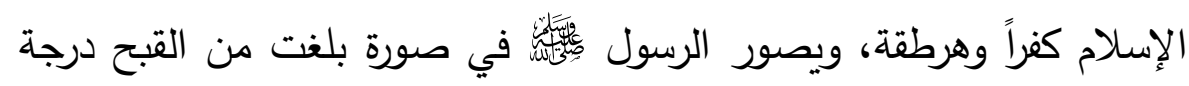
- معف اللسان عن ذكرها

وتميز طور التقدم هذا بعدة سمات، أهمها:

زيادة سلطة البابوات ورجال الدين: لقد كان البابا ذا نفوذ على الملوك، لهده فلا يجلسون على عروشهح إلا بإذن البابا ومباركته، وإذا غضب البابا عليهح

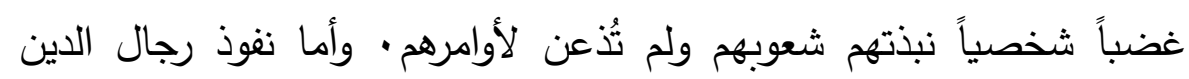

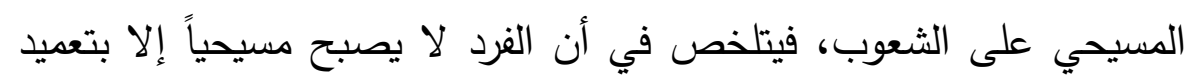
الكاهن، وليس لله صلاة إلا بحضوره في الكنيسة، ولا يموت موتا صحيحا إلا

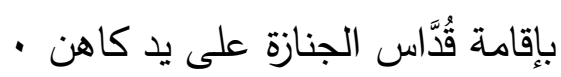
وكانت زيادة سلطة البابوات وفساد رجال الدين الأخلاقي والمالي . مع لع احتكاك الغربيين بالمسلمين إبان الحروب الصليبية . عاملاً من أهم العوامل التي أدت إلى نهضة أوروبا، في الوقت الذي زاد فيه التعصب المسيحي ضد إند الإسلام وأهله، رغم ما جناه الغرب من فوائد علمية واقتصادية وسياسية

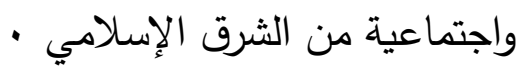

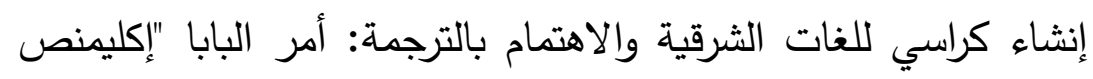

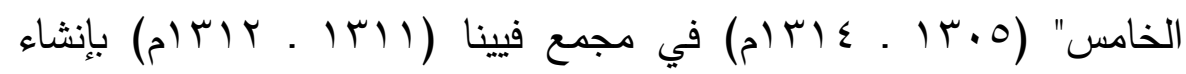

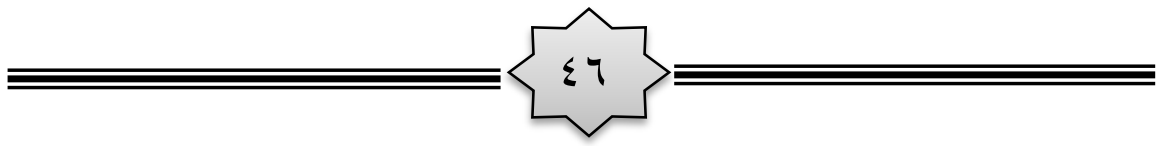


كراسي للعبرية والعربية والسريانية في جامعات روما على نفقـة الفاتيكان (')،

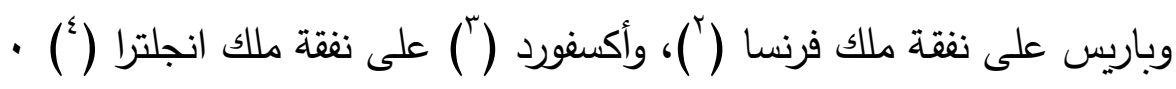

(1) الفاتيكان: دولة مدينة الفاتيكان، هي أصغر دولة من حيث المساحة والسكان في العالم، وتقع في قلب مدينة روما عاصمة إيطاليا التي تحيط بها من جميع الاتجاهات ويفصلها عنها أسوار خاصة . وبرغم كوغا أصغر دول العالم مساحةً وسكانا فهي تستقي دورها وأهميتها من كوها مركز القيادة الروحية للكنيسة الكاثوليكية في

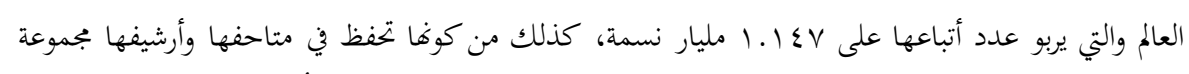

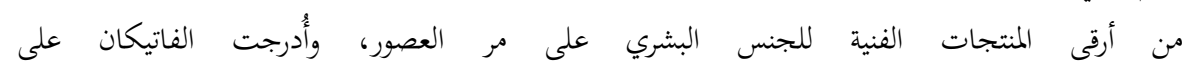

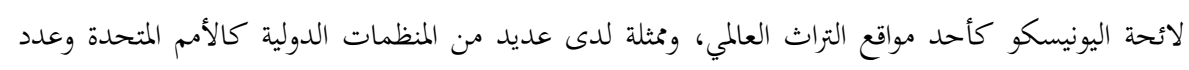

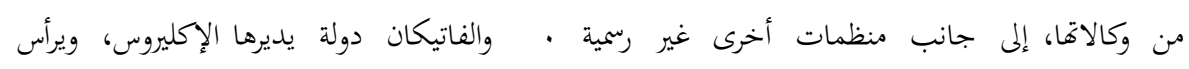

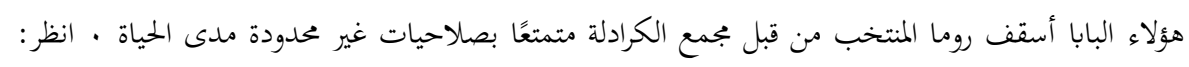

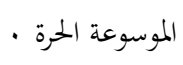

(r) فرنسا: جمهورية دستورية ذات نظام مركزي وبرماني ذي نزعة رئاسية، ويبلغ ======= عدد سكاها حوالي

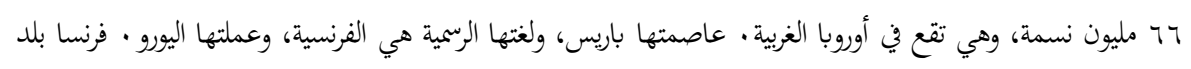

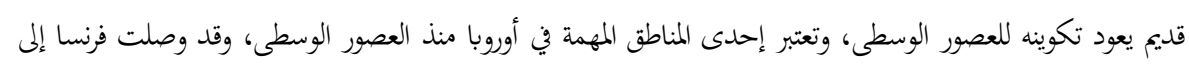

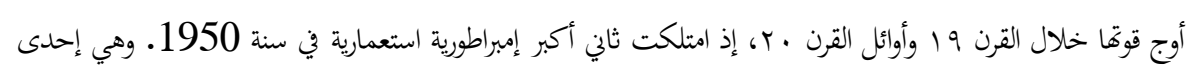

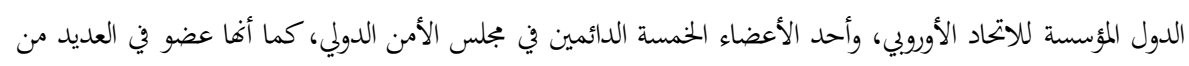

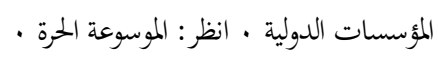

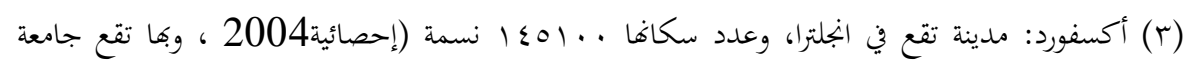
أكسفورد، أعرق جامعات البلدان الناطقة بالإنكليزية. وهي مدينة صغيرة المساحة بالنسبة لتعداد سكاها وتحتفظ بمساحات خضراء عديدة، ولديها قاعدة اقتصادية متنوعة، ومن الأنشطة ذات الأهمية فيها صناعة السيارات، والتعليم بكل مراحله، بجانب جامعتين يتوافد إليهما الطلاب للخضور دورات صيفية لتعلم الإنجليزية

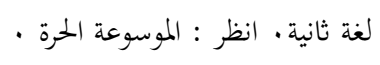
(ع) انجلترا: هي أكبر دولة في المملكة المتحدة، وتشترك في الحدود البرية مع اسكتلندا في الشمال وويلز في الغرب والبحر الأيرلندي في الشمال الغربي وبحر الكلت في الجنوب الغربي وبحر الشمال في الشرق،

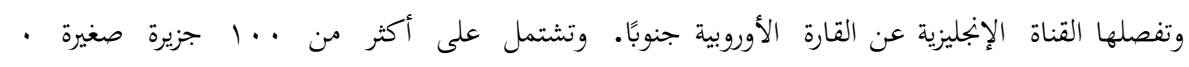

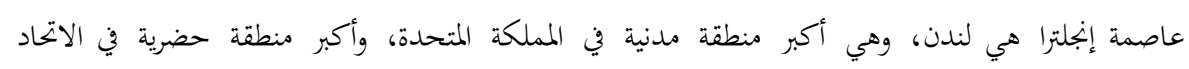

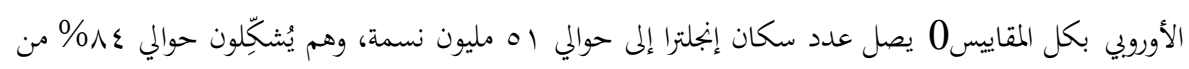

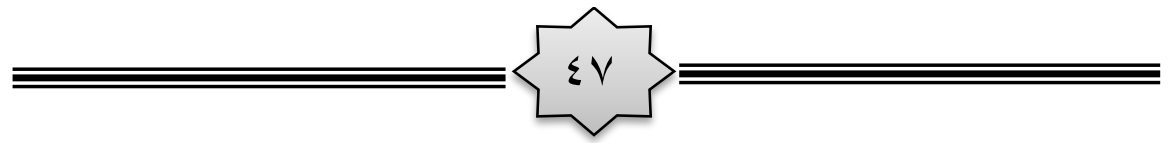


ولقد بدأت الترجمة من العربية إلى اللاتينية منذ القرن الثاني عشر

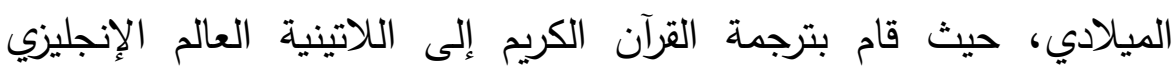

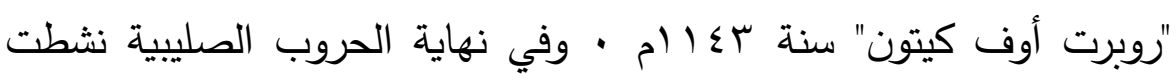

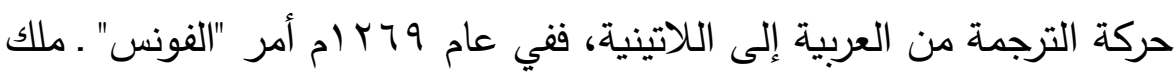
قتشالة ـ بإنشاء معهد للدراسات العليا في مرسليا (')، واختار لله أعلامَ اليهود

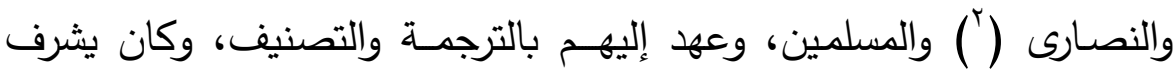
بنفسـه على التوجيه والتحرير والتلخيص، فترجم إلى الأسبانية التلمود (") سكان المملكة المتحدة بشكل عام انظر : الموسوعة الحرة ·

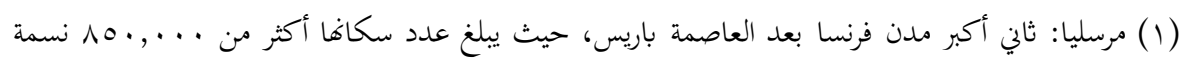

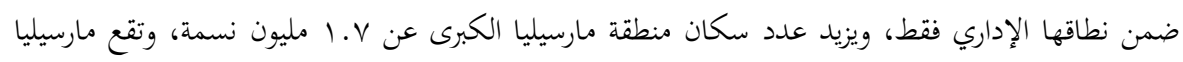

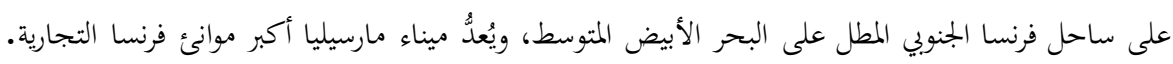

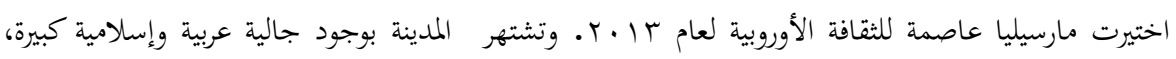

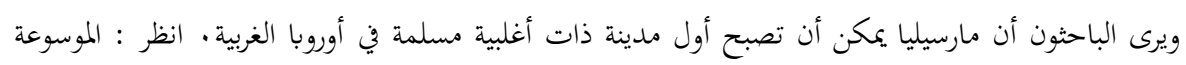
الحرة الحرى

(r) النصارى: القوم الذين يزعمون أفم أتباع عيسى الئليّلة وكتابهم الإنجيل، والنصرانية هي الملة التي يزعم أهلها

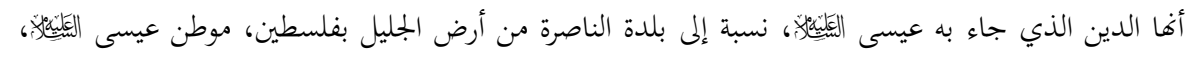

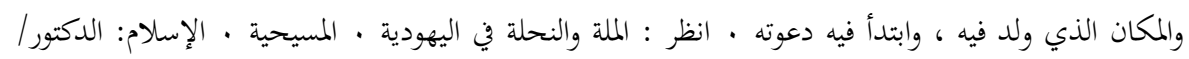

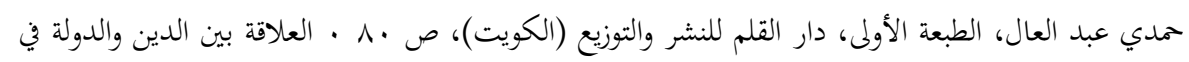

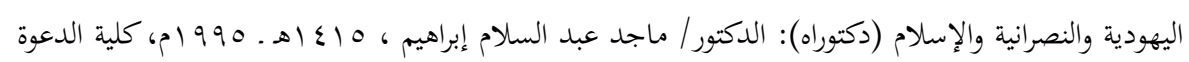

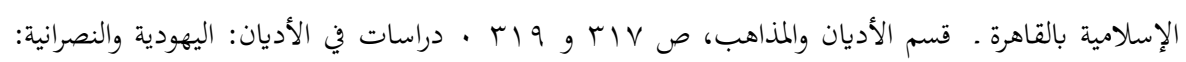

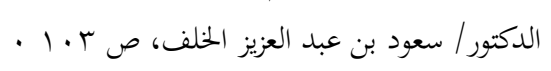

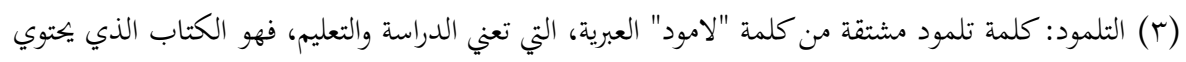

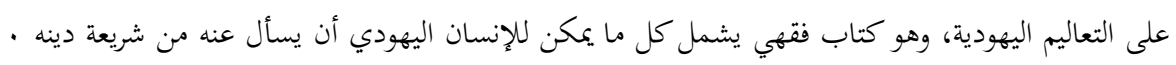

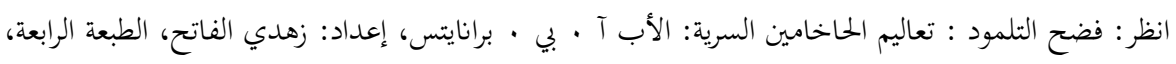

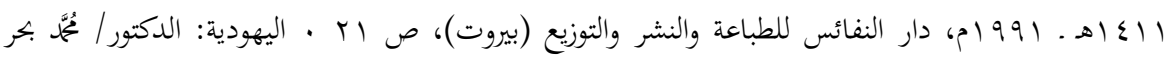

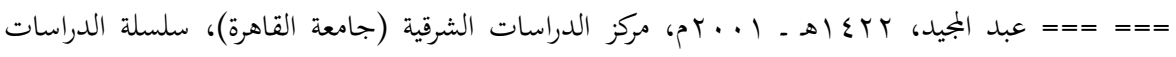

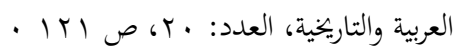

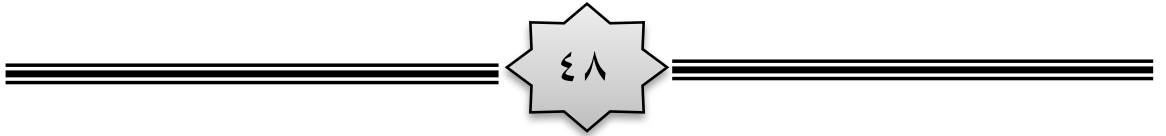


• والإنجيل (') والقرآن

تنوُع الدراسات الاستشراقية: تعاظم دور الاستشراق، ونمت جهود

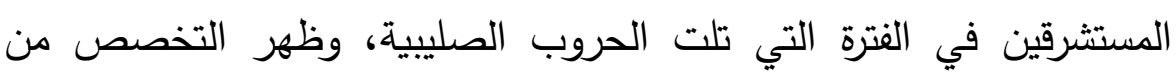

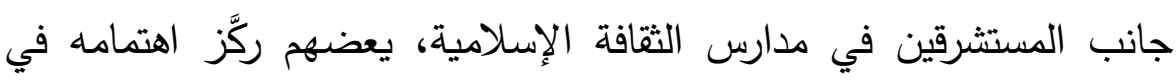

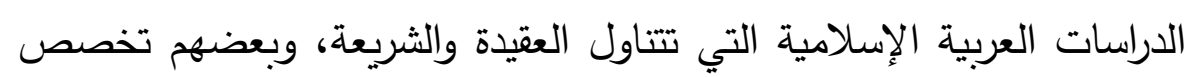

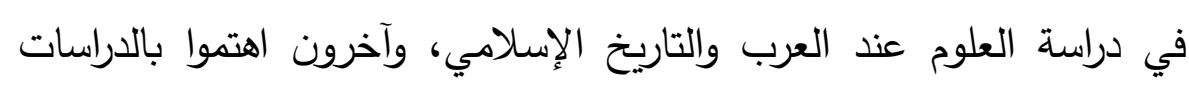

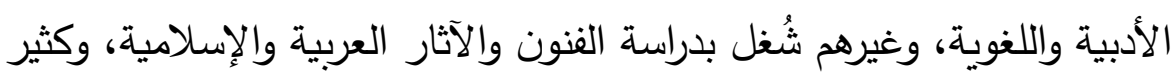

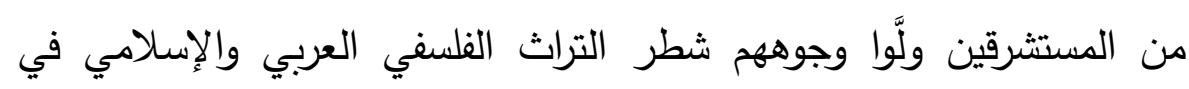

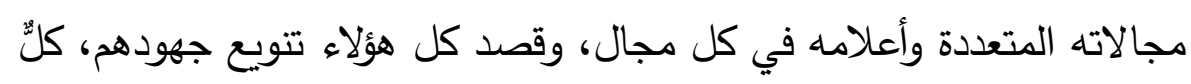

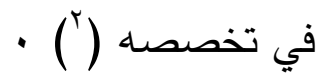 \\ r ـ طور الانطلاق:}

أخذ الاستشراق في الانطلاق بعد ظهور الطباعة العربية في القرن

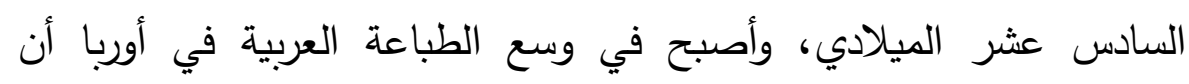

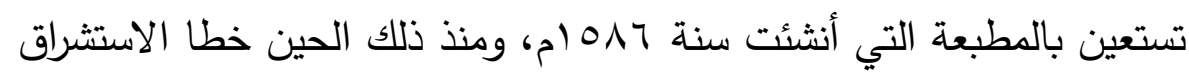
خطوة جديدة نحو الانطلاق ، فانتشرت المدارس لتعليم العربية في أوربا كلها،

(1) الإنجيل: كلمة يونانية معناها "الحلوان"، وهو ما تعطيه من أتاك ببشرى، ثم أريد بالبشرى الكلمة عينها، وما

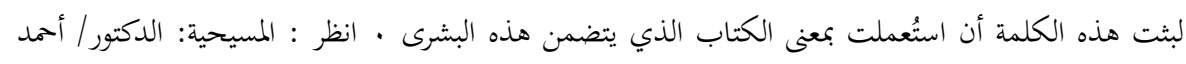

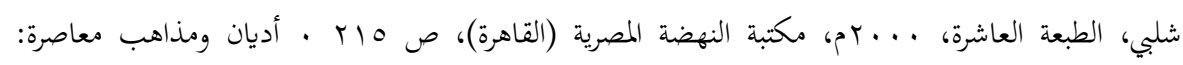

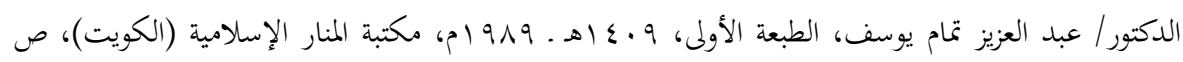

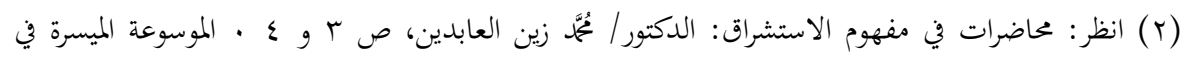

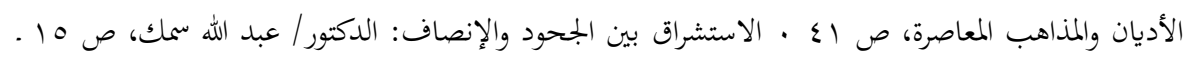

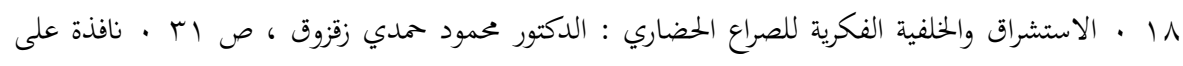

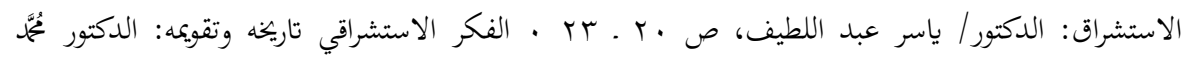

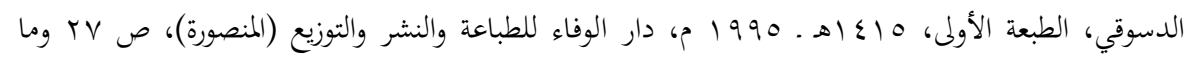


وأقيمت المطابع لإصدار نفائس العرب، وأخذ العلماء والرهبان يتسابقون في دراستها

وفي القرن السابع عشر الميلادي اهتم أباطرة الغرب بالمخطوطات

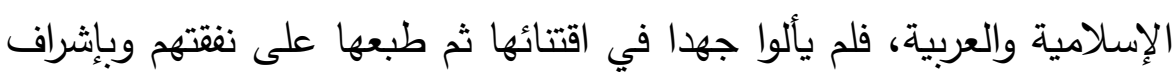

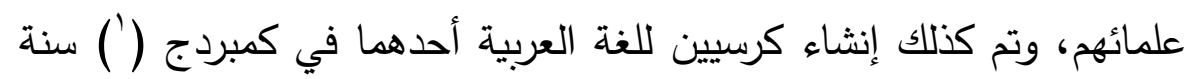

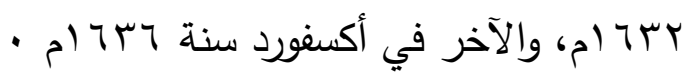
وفي نهاية القرن الثامن عشر الميلادي تأثرت حركة الاستشراق تأثراً كبيراً

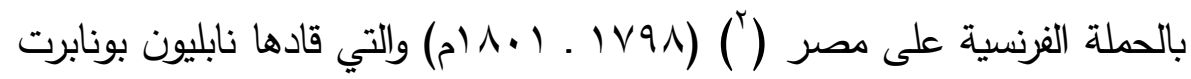

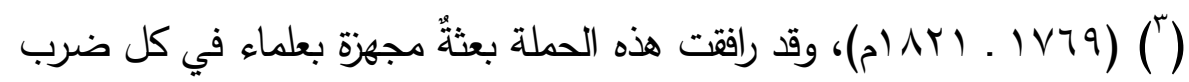

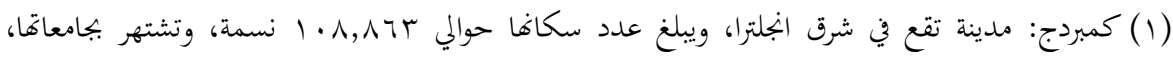
ومنها جامعة كامبريدج التي تعد إحدى أعرق وأفضل الجامعات على مستوى العالم. ويوجد بها جامع متوسط

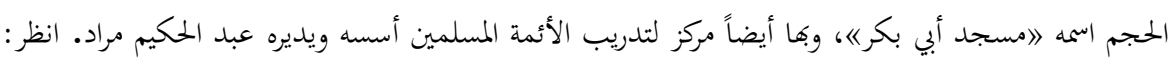

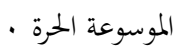

(r) مِصْرَ: جُمهورِيةُ مِصرَ العَبيةِ هي دولة عربية تقع في الركن الشمالي الشرقي من قارة أفريقيا، ولديها امتداد

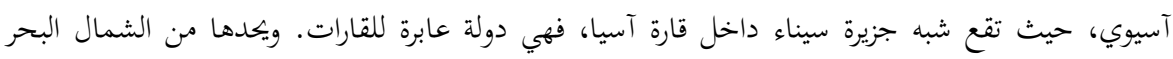

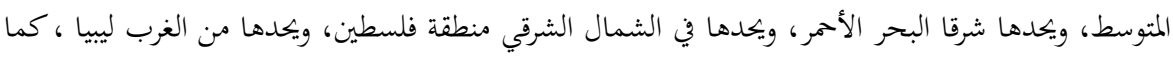

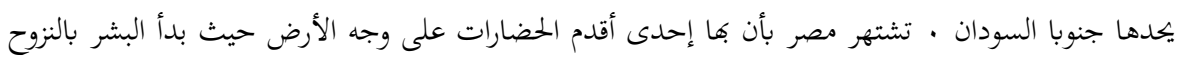

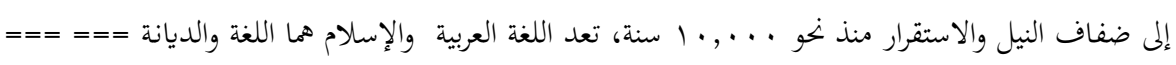

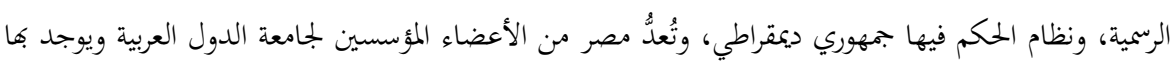

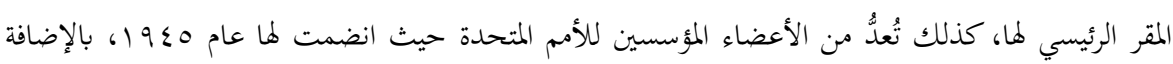

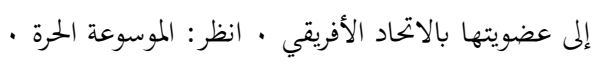

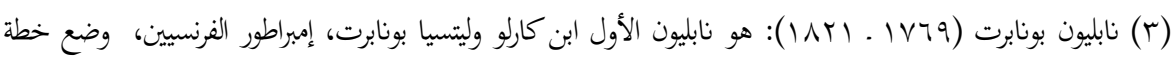

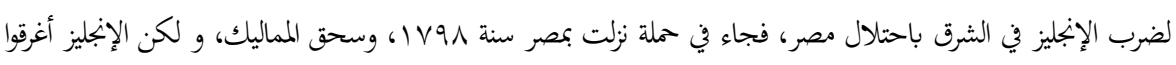

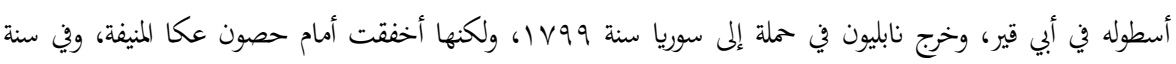

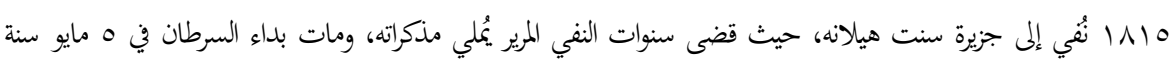

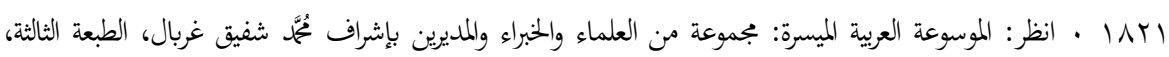

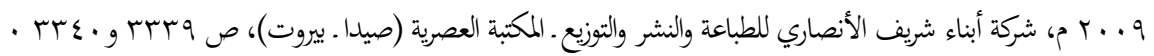

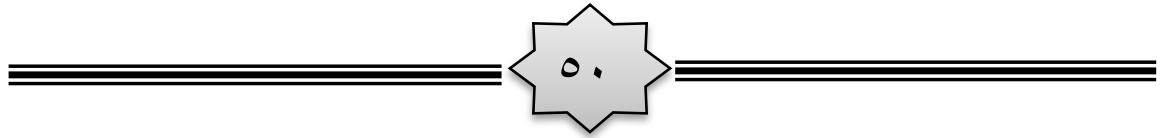


من ضروب ثقافة ذلك العصر، منهم الأثريون والمهندسون والأطباء والمؤرخون والمستشرقون والمترجمون، وقد أمر نابليون بتأليف المجمع العلمي المصري، وتأسيس مطبعة عربية تطبع تصريحاته ومنشوراته، كما عمل على إصدار ثلاث صحف منها واحدة بالعربية، وقد أدى كل ذلك إلى توسيع دائرة الاستشراق، وعناية

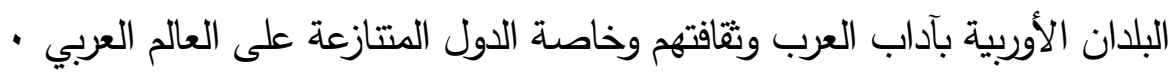

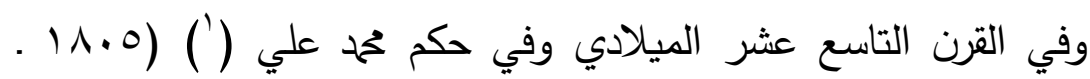
م) I A VV

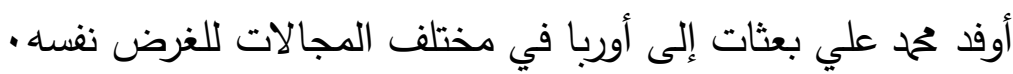
وفي نهاية هذا القرن رغب علماء أوربا المهتمون بأحوال الثرق أن يجتمعوا حيناً بعد حين في مؤتمر شرقي عام لتبادل الأفكار، وانعقد أول مؤتمر في مدينة باريس سنة شN ام بحضور مستشرقي أوربا، وبعد ذلك تتابعت هذه المؤتمرات الدولية، ويضم المؤتمر مئات من أعلام المستشرقين، هينه

$$
\begin{aligned}
& \text { ويعقد مرة كل أربع أو ثلاث سنوات أو سنتين (') . } \\
& \text { ع ـ طور الازدهار: }
\end{aligned}
$$

يُعدُّ القرن العشرون عصر الازدهار الحقيقي للاستشراق ، وخاصة بعد استغلال الاستعمار للاستشراق على أوسع نطاق إبان الاحتلال الغربي

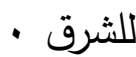

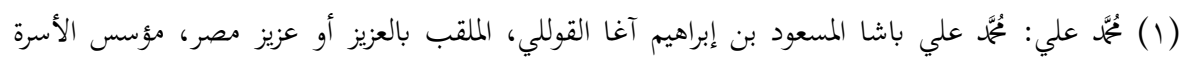

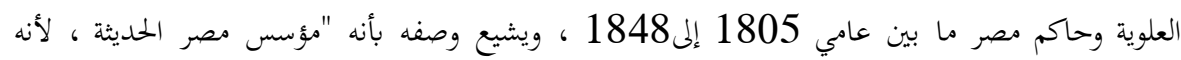

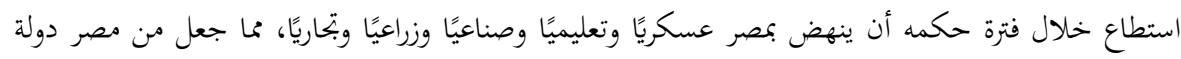

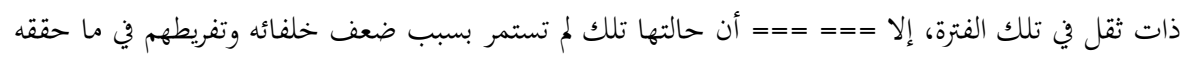

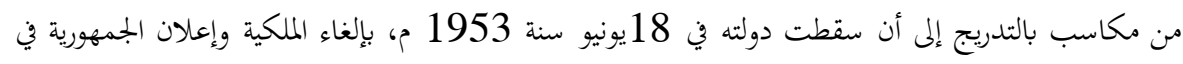

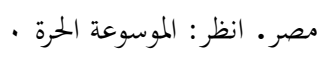

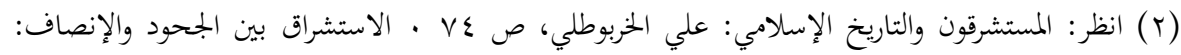

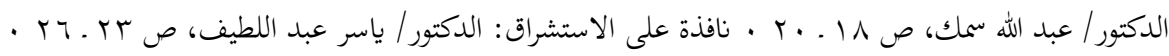


فلقد سيطرت بريطانيا وفرنسا على الثرق والاستشراق حتى الحرب العالمية الثانية، وبعد تلك الحرب وفي النصف الثاني من القرن العشرين هيمنت الولايات المتحدة الأمريكية على الثرق، وحل نفوذها السياسي والثقافي

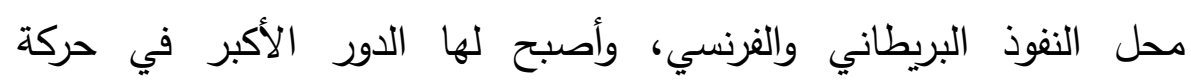
الاستشراق • ولليهود دور خطير في هذه الحركة، حيث تقوم وسائل الإعلام الصهيونية في الغرب خاصة في الولايات المتحدة برسم صورة مشرقة لإسرائيل

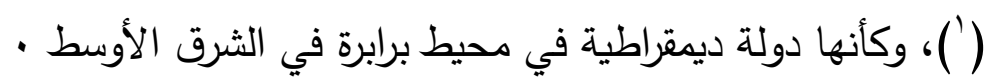
وفي هذه الفترة تحرر الاستشراق من سيطرة الكنيسة، وظهر الاستشراق كعِّم متكامل قائم على دراسة آثار الحضارة الثرقية المادية والروحية، وتوارِيْ الاستشراق الكلاسيكي (التقليدي) لا يعني أن هناك حيدة علمية أو تغييرا

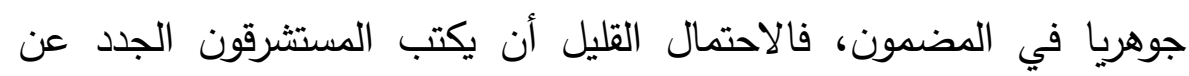
الشرق دون الرجوع إلى ما كتبه المستشرقون السابقون، الذين لا تخلو كتاباتهر - من حقد على الإسلام وتهتم الدول الغربية في العصر الحاضر بالدراسات الاستشراقية في

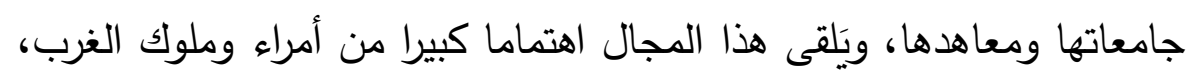
ويحظى الباحثون في مجال الاستشراق بالدعم الكبير من جانب الحكومات

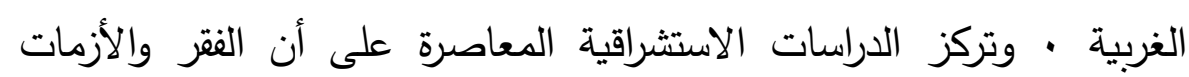

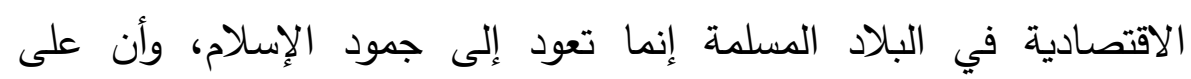
المسلمين أن يستفيدوا من التشريعات الغربية في الأنظمة السياسية والمالية والاجتماعية · وكَثُتُ الدراسات الاستشراقية الأكاديمية في الدول الغربية في

(1) إسرائيل: اسم أطلق على الأسباط الاثني عشر، والأرض التي سكتنها، أو على الأسباط الشمالية وأراضيها

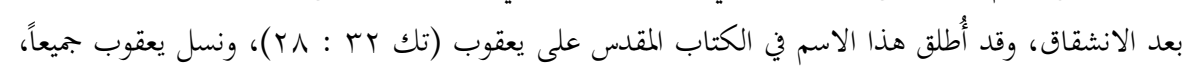

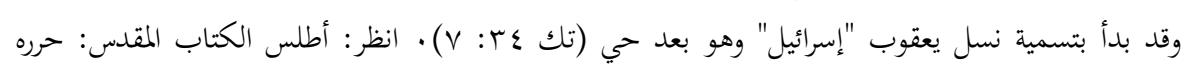

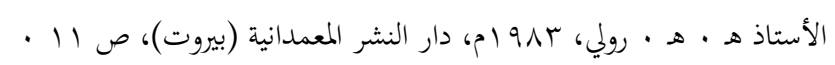
$\overline{\overline{\text { or }}}$ $\}$ 
أواخر القرن العشرين، والتي تحذر من خطر عودة المسلمين إلى دينهم • كما

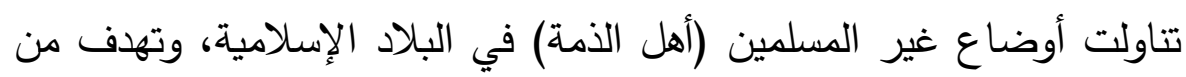
وراء ذلك إلى التدخل السافر للدول الغربية في شئون البلاد الإسلامية تحت دعوى حماية حقوق الأقليات (') ') والخلاصة أن الحركة الاستشراقية مرت عبر تاريخها الطويل بأطوار، الاتهات بداية بطور التكوين والولادة، وتوسطا يطور التقدم والانطلاق، وختاما بطور

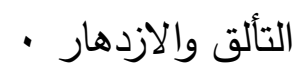

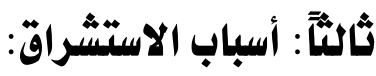

ما الذي يدعو الباحث الغربي إلى بذل كل هذا الجهد والعدر والمال في دراسة عالم غريب عنه؟ يدرس لغاته التي تختلف تماماً عن لغته، ويحاول بلإل جاهداً فهم آدابها وعقائد أهلها وتاريخهم • من المؤكد أنه لم يبذل المستشرقون جهودهم المضنية من أجل سواد عيون الشرق أو حبا فيه أو دفاعا عنه، وإنما بذلوا تلك الجهود لأسباب معينة، أهمها :

1 ـ الكراهية للإسلام: كثف القرآن الكريم عن هذه الكراهية التي يكنّها أهل

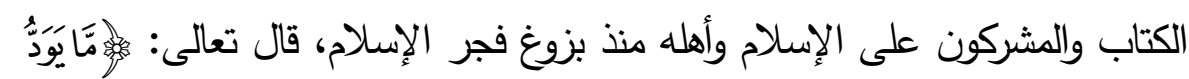

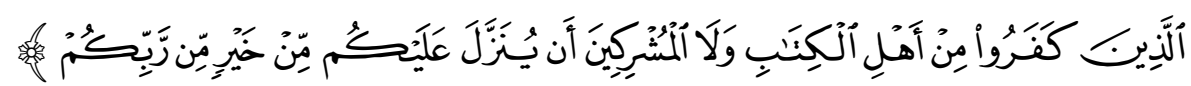

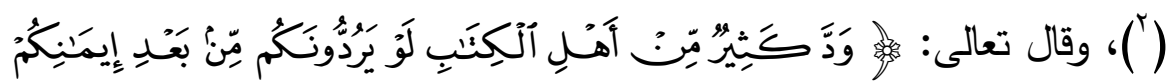

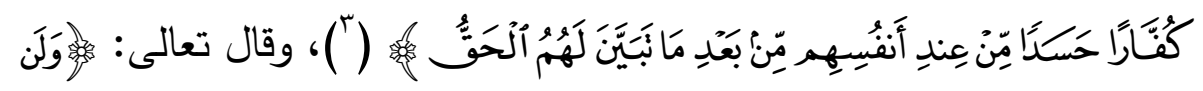

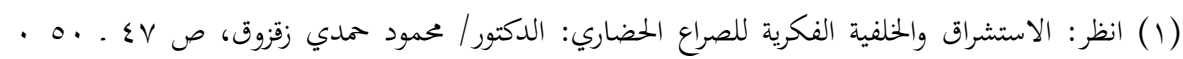

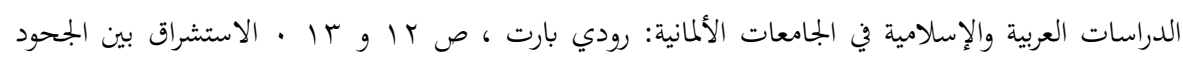

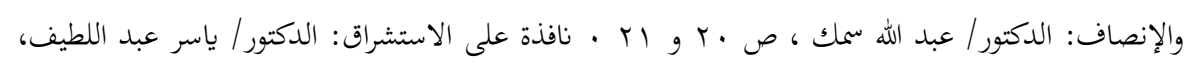
. ro. ro

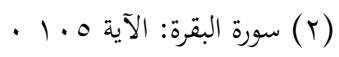

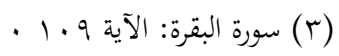

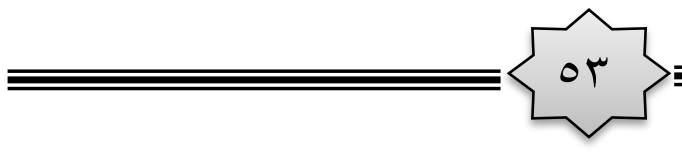




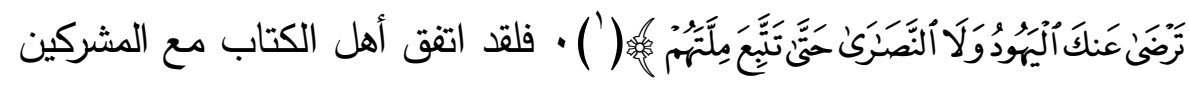
على أنهم لا يحبون الخير للمسلمين، وانفرد أهل الكتاب بأنهم يودون ردة المسلمين، وأنهم لن يرضوا عن رسول الله بـ عليه أن رضاءهم غاية لن تدرك، والمشركون نفَّسوا عن هذه الكراهية حين حاولوا

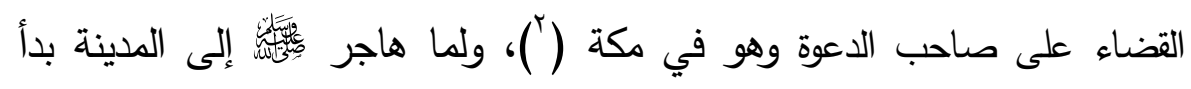
التثكيك وإثارة الثبهات حول الدعوة نفسها من جانب اليهود، وحين بسط الإسلام نفوذه في بلاد الأنلس عمد أهل الكتاب من اليهود والنصارى إلى دراسة الإسلام

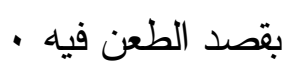

r. التتفيس عن الحروب الصليبية ومواجهة حركة إصلاح الصسيحية: تركت هزيمة الغربيين في الحروب الصلييية آثارا مرة عميقة في نفوس الأوربيين، فأرادوا

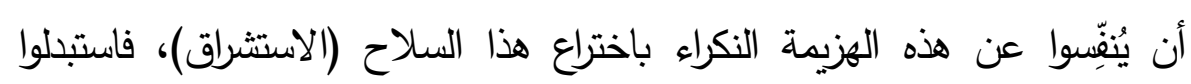

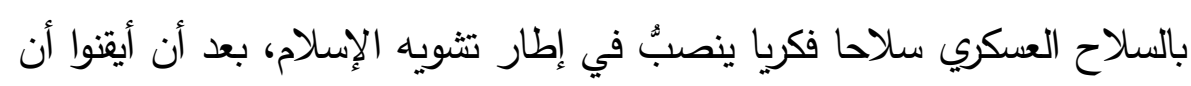

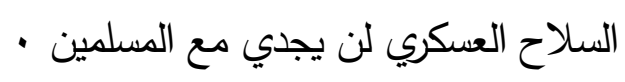
ومن جهة أخرى لعبت الحروب الصليبية دوراً في حمل بعض الغربيين

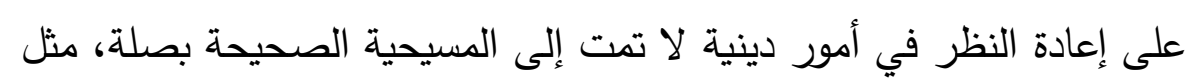
صكوك الغفران، والادعاء بأنه لا اتصال بين الإنسان وربه إلان لمات بواسطة

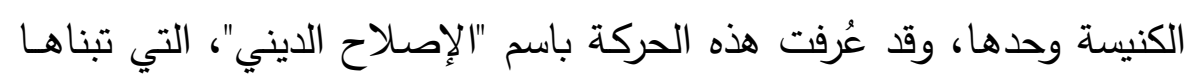

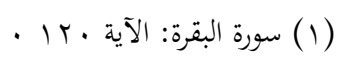

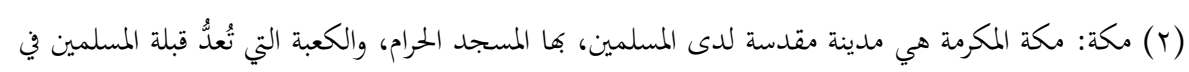

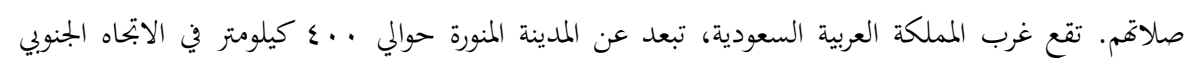

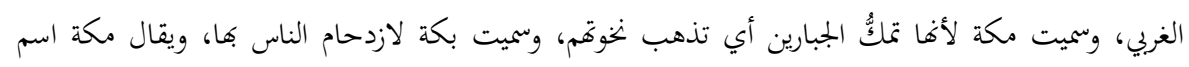

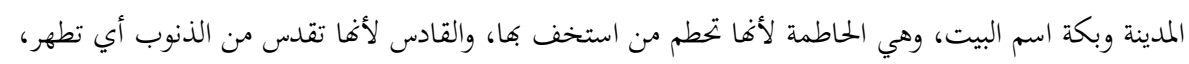

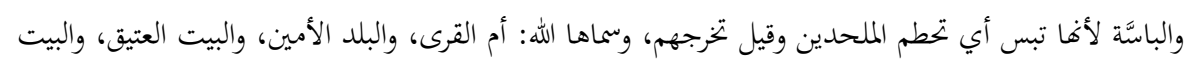

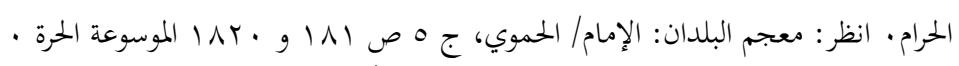
$\overline{\bar{\equiv}}\{0 \leq\}$ 


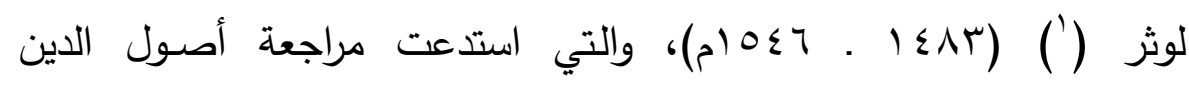

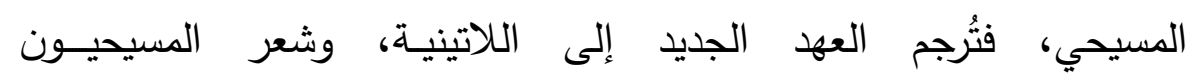
بروتستانت(r) وكاثوليك(r) ) بحاجات ضاغطة لإعادة النظر في شروح كتبهم الدينية، لمحاولة تفههها على أساس التطورات الجديدة التي تمخضت عنها حركة الإصلاح، ومن هنا اتجهوا إلى الدراسات العبرانية، وهذه أدت بهم إلى الى الدراسات العربية فالإسلامية، لأن الأخيرة كانت ضرورية لفهم الأولى، وخاصة الإهن ما كان منها متعلقا بالجانب اللغوي، وبمرور الزمن اتسع نطاق الدراسات

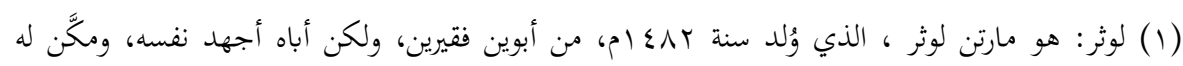

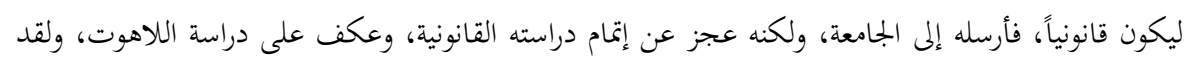

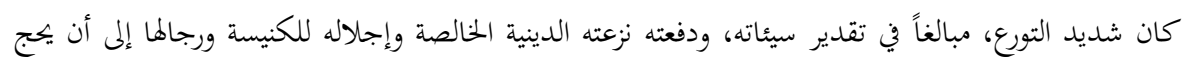

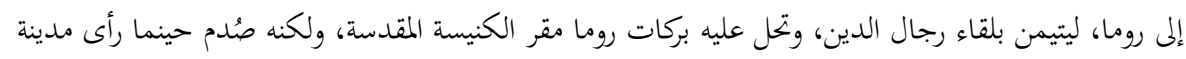

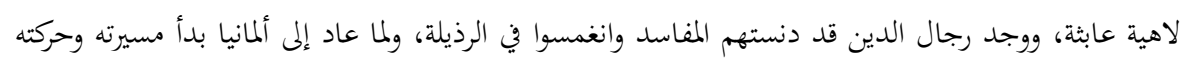

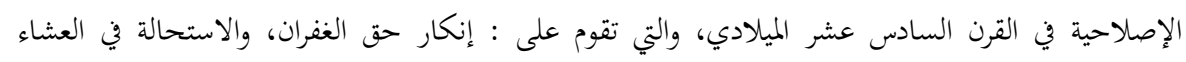

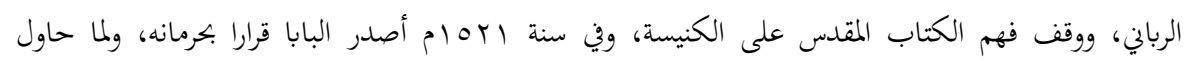

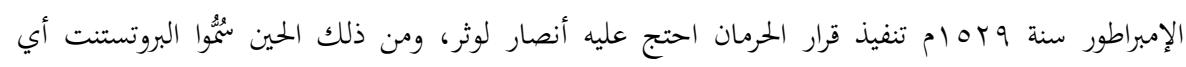

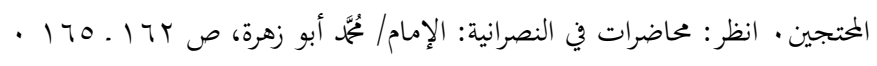

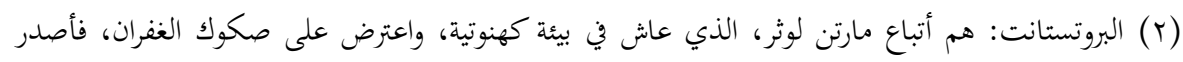

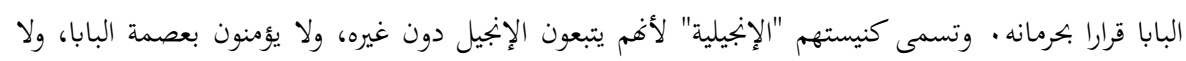

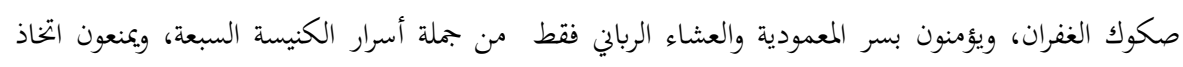

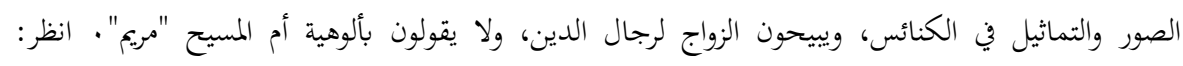

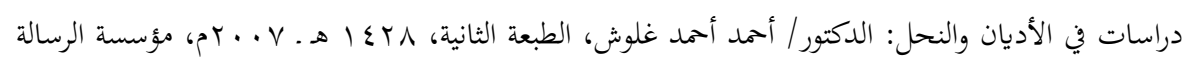

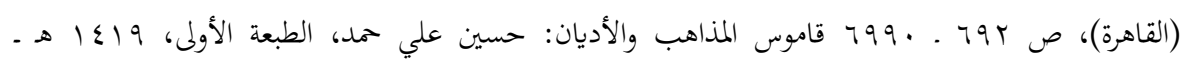

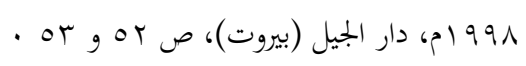

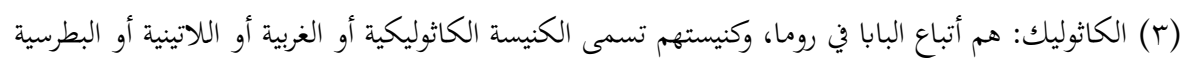

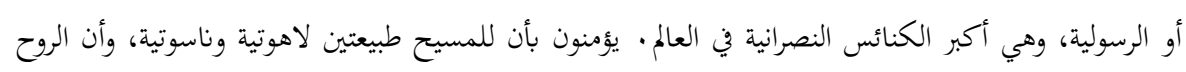

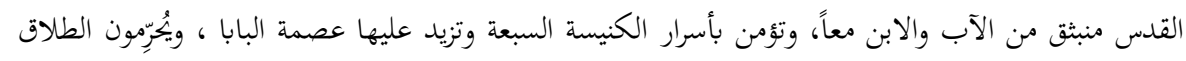

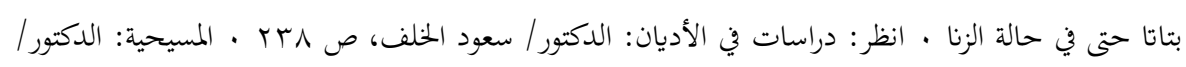

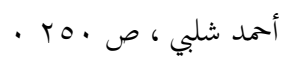

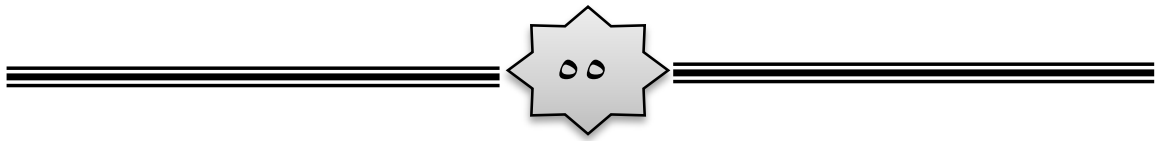


الشرقية حتى شملت أديانا ولغات وثقافات غير الإسلام وغير اللغة العربية . ب ـ الحيلولة دون دخول المسيحيين في الإسلام والتبشيرُ بالمسيحية: كان لتفوق المسلمين أبلغ الأثر في دخول كثير من الأمم في الإسلام، فقد أعجبوا بحضارة المسلمين وقوتهم العسكرية والعلمية التي كانت مضرب الأمثال، لذا تحرك المستشرقون لعرقلة الإسلام، ووقْف تيار التحول من

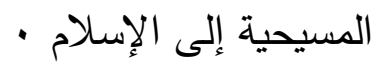

والاستشراق أنشئ خصيصاً لصد المد الإسلامي الذي توغل داخل أوربا في العقد الأول من القرن الأول الهجري الثامن الميلادي، الذي تمت فيه سيطرة المسلمين على أسبانيا كلها، واستولوا على معظم فرنسا، وفي القرن التاسع حاصروا روما نفسها وألزموا البابا دفع جزية قدرها خمسة وعشرون ألف الف رطل فضة لمدة عامين متتاليين · وبذلك أصبح مركز الكنيسة مهدداً، وكانت صاحبة السلطان في ذلك العصر الذي يطلق عليه اسم العصور المظلمة، ومن هنا لجأ رجالها إلى إرسال البعوث من القساوسة والرهبان يهود ونصارى لتَلَِّي علوم الإسلام · في جامعة أسبانيا ــ وترجمتها إلى اللغة اللاتينية، ولكن بصورة مشوهة حتى يحجز ذلك الأوربيين عن الإقبال على الإسلام، وحتى تتمكن الكنيسة ورجالها من استعادة ما فقدت من مجد وسلطان، ومن أجل التحل تحقيق هذا الهدف استخدمت كل وسائل الهدم والتدمير والافتراء والدس والتضليل في ثوب الاستشراق

فهولاء المستشرقون كان يهمهم أن يطعنوا في الإسلام ويشوهوا محاسنه ويحرفوا حقائقه، ليثبتوا لجماهيرهم التي تخضع لزعامتهم الدينية أن الإسلام دين لا يستحق الانتشار، ولا يصلح نظامَ حياة، وأن المسلمين قوم همج لصوص سفاكو دماء، يحثهم دينهم على الملذات الجسدية، ويُبعدهم عن كل سمو روحي وخلقي، ولم يققوا عند هذا الحد بل شككوا في صحة رسالة النبي

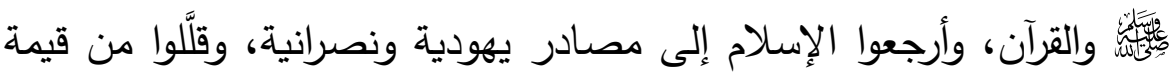

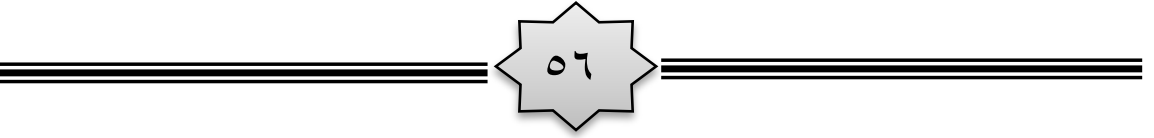


الفقه الإسلامي، ونالوا من اللغة العربية، واعتمدوا على الأحاديث الضعيفة والأخبار الموضوعة، وتطاولوا على تعاليم الإسلام ومؤلفاته في محاولة دائبة ومستمرة لتشكيك المسلمين في دينهم وتراثهم وحضارتهم، وزعزعتهم في • عقيدتهم وقيمهم العليا

ومن جهة أخرى رغب المسيحيون في التبثير (التتصير) بدينهم بين المسلمين، فأقبلوا على الاستشراق ليتسنى لهم تجهيز الدعاة وإرسالهم للعالم

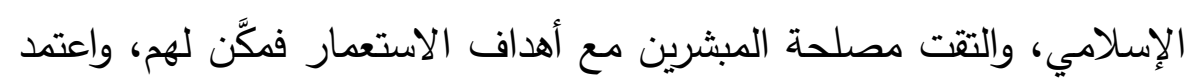

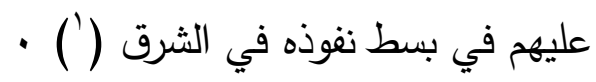
ـ ـ تأييد الغزو الاستعماري: لما انتهت الحروب الصليبية بهزيمة الصليبيين، وهي في ظاهرها حروب دينية وفي حقيتتها حروب استعمارية، لم ييأس الغربيون من العودة إلى احتلال بلاد العرب والمسلمين، فاتجهوا إلى دراسة هذه البلاد في كل

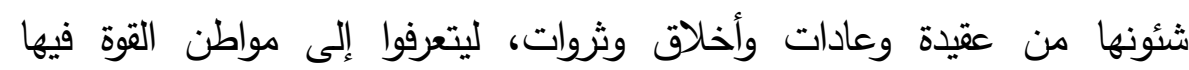
فيضعفوها، وإلى مواطن الضعف فيها فيغتتموها • ولما تم لهم الاستيلاء العسكري لماني في القرنين التاسع عشر والعشرين كان من دوافع الاستشراق إضعاف المقاومة الروحية والمعنوية في نفوسنا، بتأويل الجهاد وصرف أنظار المسلمين إلى الدعة والقعود عن الجهاد في سبيل الله، ومدافعة الغزاة بالاشتغال بالعبادة والزهد وتسميتها بالجهاد الأكبر، وتحطيم وحدة المسلمين وتمزيق الدولة الإسلامية، وعزل الثريعة الإسلامية عن التطبيق في المجتمع الإسلامي، وإحلال الأنظمة القانونية

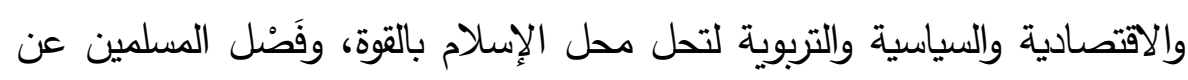

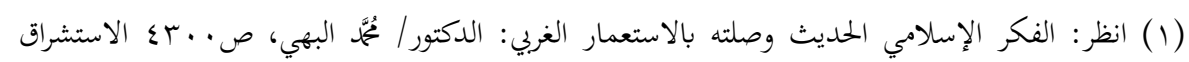

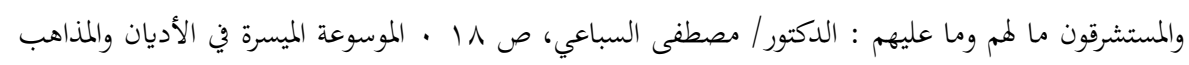

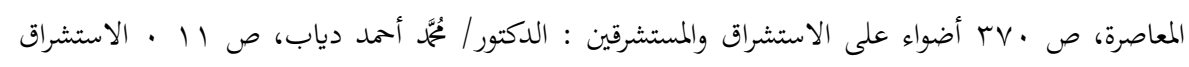

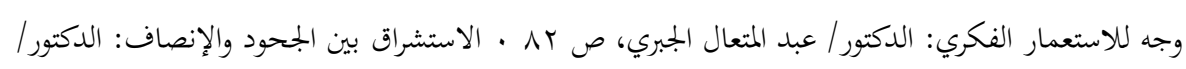

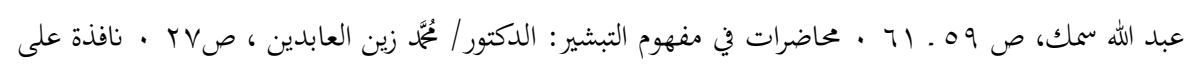

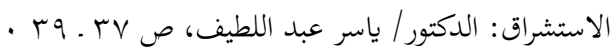


جذورهم الثابتة الأصيلة، وهدم المقومات الأساسية للكيان الفردي والاجتماعي والنفسي والعقلي للمسلمين · ومن شأن هذا أن يفتح الباب إلى الاستسلام أمام الاستعمار وثقافته وفكره، وبث الوهن والارتباك في تفكيرنا ونلك عن طريق التشكيك

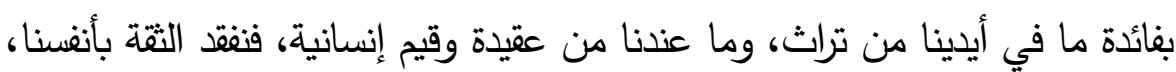
ونرتمي في أحضان الغرب نستجدي منه المقاييس الأخلاقية والمبادئ العقائدية، وبذلك يتم لهم ما يريدون من خضوعنا لحضارتهم وثقافتهم خضوعاً لا تقوم لنا من بعده قائمة. انظر إليهم كيف يشجعون في بلانا القوميات التاريخية التي عفا عليها الزمن، واندثرت منذ حمل العرب رسالة الإسلام، ليتسنى لهم تشتيت شملنا كأمة واحدة، وليعوّقوا قوة الاندفاع التحررية عن عملها في قوتتا وتحررنا، وسيادتتا على أرضنا وثرواتتا، وعودتتا من جديد إلى قيادة ركب الحضارة • ه ـ الدافع السياسي والتجاري: يتجلى الدافع السياسي في عصرنا الحاضر بعد استقلال أكثر الدول العربية والإسلامية، ففي كل سفارة من سفارات الدول الغربية لدى الدول العربية والإسلامية سكرتير أو ملحق ثقافي يحسن اللغة العربية، ليتمكن من الاتصال برجال الفكر والصحافة والسياسة فيتعرف إلى أفكارهم، ويبث فيهم من الاتجاهات السياسية ما تربده دولته، وكثيرا ما كان لهذا الاتصال أثره الخطير في بث الدسائس للتقرقة بين الدول العربية بعضها مع بعض، وبين الدول العربية والدول الإسلامية ل والدول الغربية لا ترسم سياستها الاستعمارية إلا بعد مشورة المستشرقين والاستفادة من آرائهم، وهناك كثير من المستشرقين بدأوا طريقهم في مجال الاستشراق مترجمين أو قناصل لدولهم في الشرق الأوسط، مثل "جوزيف فون هامر" مؤسس أول مجلة استشراقية متخصصة في أوربا، وهي مجلة "ينابيع

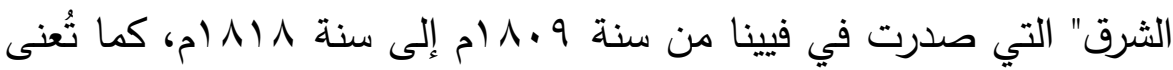
الدول الغربية اليوم وعلى رأسها الولايات المتحدة الأمريكية بتوجيه وزراء خارجيتها ومبعوثيها إلى الثرق الأوسط لدراسة اللغة العربية . 
وفي هذا الإطار حرص المستشرقون على إضعاف روح الإخاء بين المسلمين وتفرقتهم لإحكام السيطرة عليهج، وكذلك عُنوا باللهجات العامية ودراسة العادات السائدة، وكان الاستعمار يوجِهه المستشرقين إلى البلاد التي

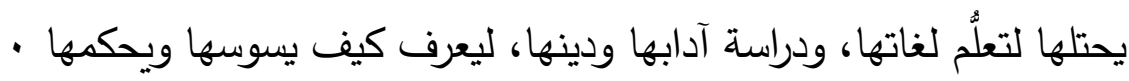
ومن الأهداف التي دفعت بعضاً من المستشرقين لخوض مجال الاستشراق رغبتهم في غزو البلاد الإسلامية غزواً اقتصادياً، يهدفون من ورائه إلى الاستيلاء على الأسواق التجارية، والمؤسسات المالية المختلفة، والاستيلاء

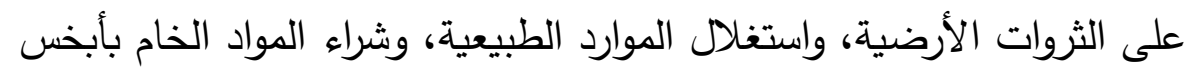
الأثمان، وإماتة الصناعات المحلية القديمة، لتكون بلاد المسلمين بلاد استهلاك لما تُصدّره المصانع الغربية. . وقبل الاستعمار الغربي للعالم الإسلامي في القرنين التاسع عشر والعشرين، كانت المؤسسات والثركات الكبرى والملوك يدفعون المال الوفير للباحثين المستشرقين، من أجل معرفة

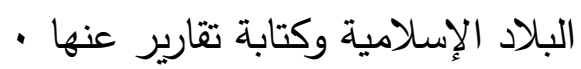
7 ـ الدافع العلمي والشخصي: دراسة المستشرقين للإسلام قامت أولانلا بوحي من الكنيسة الكاثوليكية خاصة، للانتقاص من تعاليم الإسلام والتشكيك

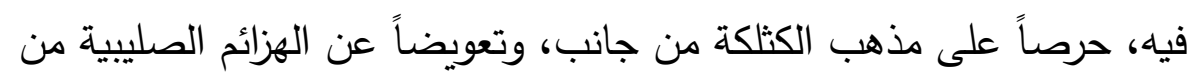
جانب آخر

ولتحقيق هذا الهدف العلمي عمل المستشرقون على: التشكيك بصحة

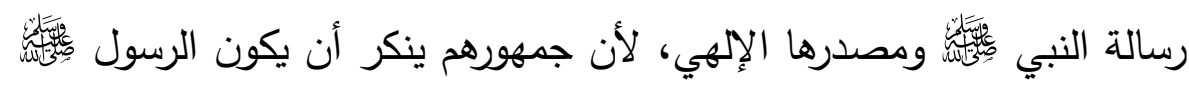

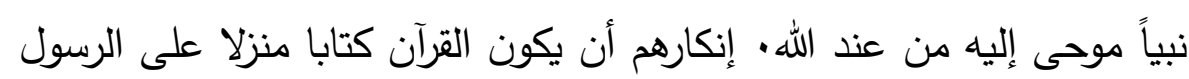

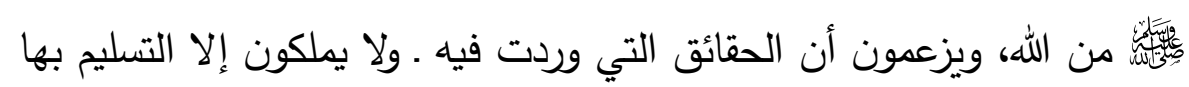

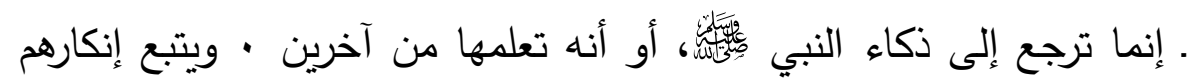

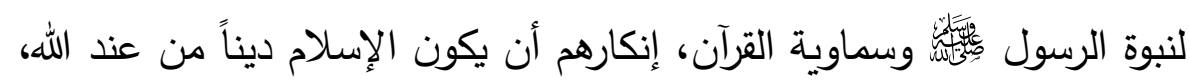

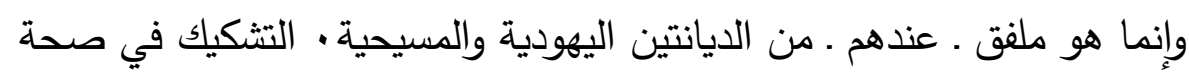

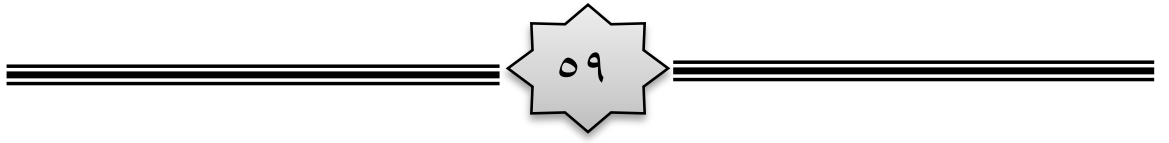


الحديث النبوي الثريف الذي اعتمده علماؤنا المحققون، ويتذرع هؤلاء المستشرقون بما دخل على الحديث النبوي من وضع ودس، متجاهلين تلك الجهود التي بذلها علماؤنا لتنقية الحديث الصحيح من غيره، مستتدين إلى قواعد بالغة الدقة في التثبُّت والتحرِيِ، مما لم يعهد في ديانتهم عُشْر معشاره في التأكد من صحة الكتب المقدسة عندهم ، التشكيك بقيمة الفقه الإسلامي الذاتية، ذلك التشريع الهائل الذي لـ يجتمع مثله لجميع الأمم في جميع العصور ، والزعم بأن هذه الثروة الفقهية العظيمة مستمدة من الفقه الروماني، في الوقت الذي قرر فيه مؤتمر القانون المقارن المنعقد بلاهاي (') أن الفقه الإسلامي فقه مستقل بذاته وليس مستمداً من أي فقه آخر • التشكيك في قدرة اللغة العربية على مسايرة التطور العلمي، وتثكيكه في غنى الأدب العربي، وإظهاره مجدبا لنتجه إلى آدابهم، وذلك هو الاستعمار الأدبي الذي يبغونه مع

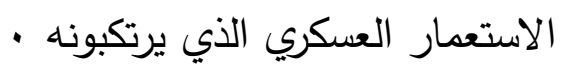

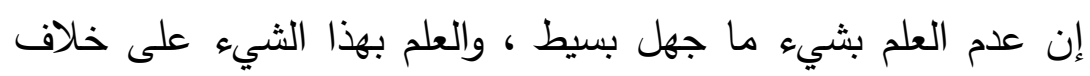
الواقع جهل مركب، وللجهل المركب مضاعفات وخيمة الأثر شديدة الخطر،

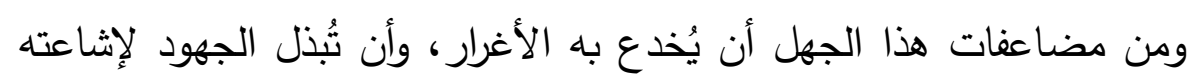

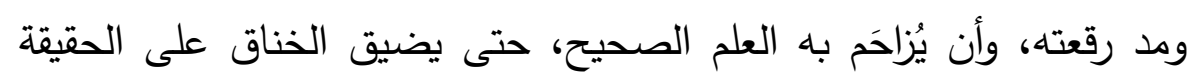
فُزَهق، وينفسح المجال أمام الباطل فيخلو الجو لتضليله، وتضطرب لئه الحياة بوساوسه • هذا الجهل المركب عنوان صادق للبحوث التي كتبها عن الإسلام

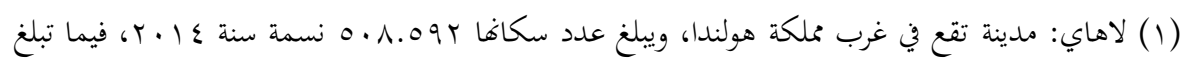

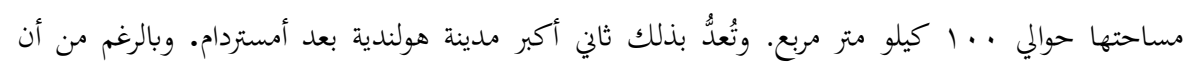

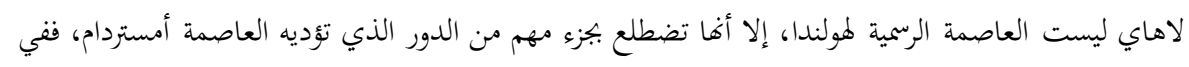

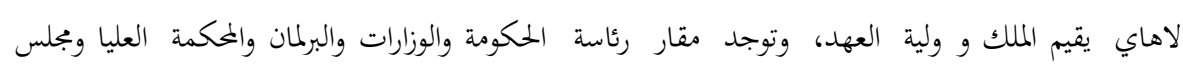

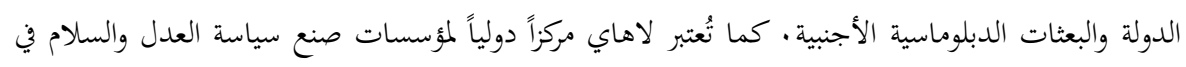
العالم، حيث توجد فيها مقار عدد كبير من المنظمات الدولية العاملة في هذا المجال • انظر: الموسوعة الحرة .

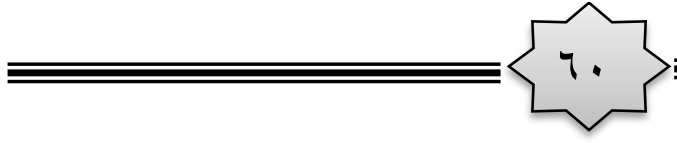


كثير من المستشرقين، ولا تنتظر من المستشرقين بحثا يخلو من العيوب، فذلك شيء يتنافى مع وظيفة الاستشراق الذي يمهد الطريق أمام الاستعمار الغربي والثرقي، كما تمهد الدبابات الطريق أمام زحف المشاة في فنون الحرب . الاستشراق كهانة جديدة تلبس مسوح العلم والرهبانية في البحث، وهي أبعد ما تكون عن بيئة العلم والتجرد، وجمهرة المستشرقين مستأجَرون لإهانة للإنة

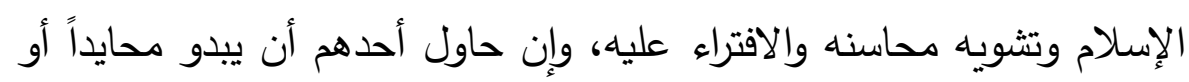
يتخفف من أثقال التعصب، تجد بقية المستشرقين يهيُون في وجهه يطالبونه

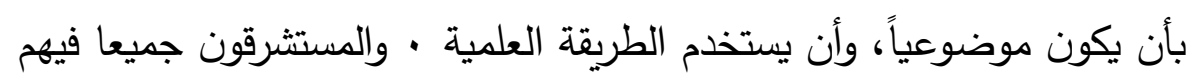

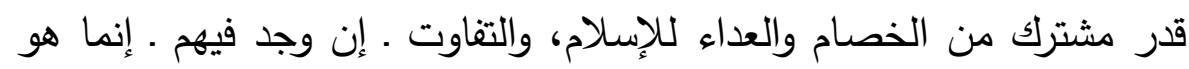

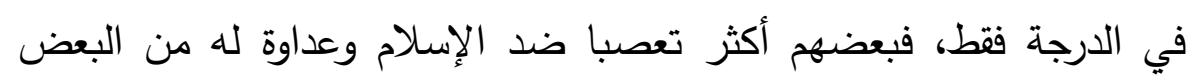
الآخر

وفي بداية الأمر رأت أوربا أنها لا تستطيع أن تتهض وتتخلص من

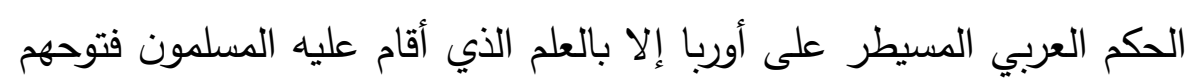

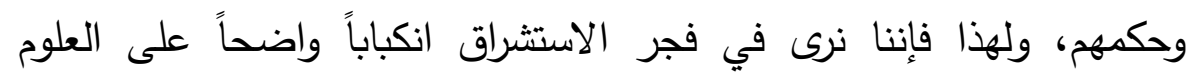
الإنسانية والرياضية والفلسفية من رواد الاستشراق وكبار الرهبان · ولكن

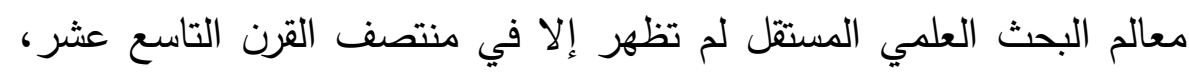

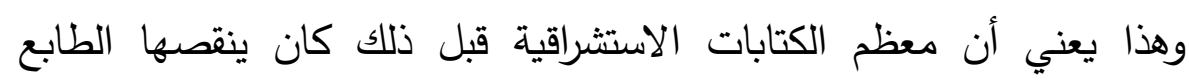
العلمي، وأن الهدف الديني كان وراء نشأة الاستشراق، وقد صاحب الاستشراق

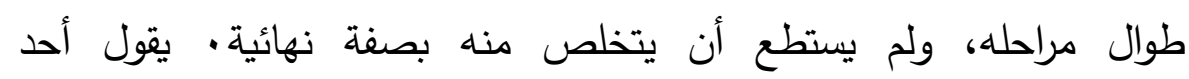
المستشرقين: "لا تزال آثار التعصب الديني الغربي ظاهرة في مؤلفات عدد من العلماء المعاصرين، ومستقرة في الغالب وراء الحواشي المرصوصة في الأبحاث العالمية"، ويقول آخر: "على الرغم من المحاولات الجدية المخلصة ولئية التي بذلها بعض الباحثين في العصور الحديثة للتحرر من المواقف التقليدية

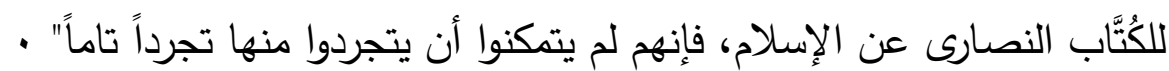

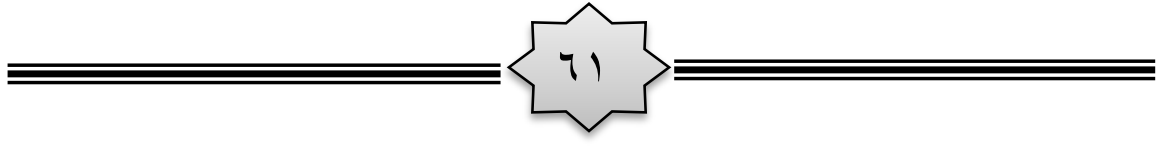


وظهر من المسترقين نفر قليل جدا أقبلوا على الاستشراق بدافع من حب الاطلاع على حضارات الأمم وأديانها وثقافاتها ولغاتها، وهؤلاء كانوا أقل

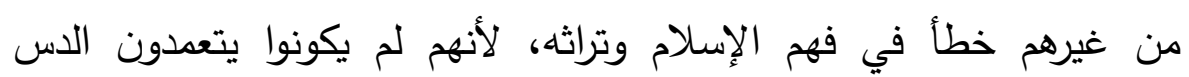
والتحريف، فجاءت أبحاثهم أقرب إلى الحق وإلى المنهج العلمي السليم من

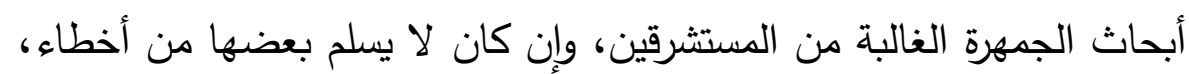
لجهلهم بأساليب اللغة العربية والأجواء الإسلامية، ومن هؤلاء من اتُّهر

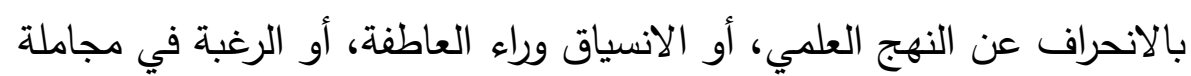
المسلمين، وهذا ما حدث مع "توماس أرنولد"(') حين أنصف المسلمين في الي كتابه العظيم "الدعوة إلى الإسلام" الذي برهن فيه على تسامح المسلمين في جميع العصور مع مخالفيهم في الدين، على عكس مخالفيهم معهم، ولم يذكر إلى في الكتاب حادثة إلا أرجعها إلى مصدرها، بل إن من هؤلاء المستشرقين مَنْ

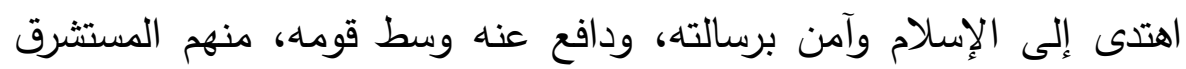

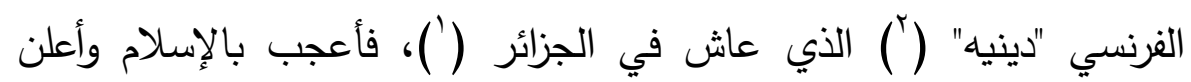

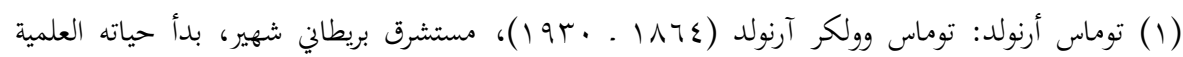

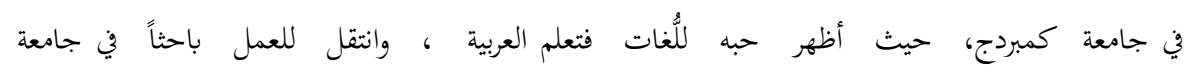

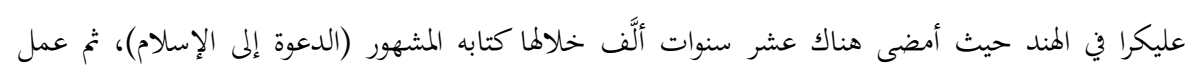

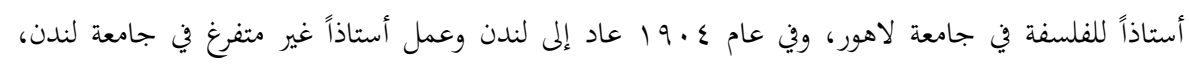
وكان عضو هيئة تحرير دائرة المعارف الإسلامية التي صدرت في ليدن بهولندا في طبعتها الأولى عمل أستاذاً زائراً

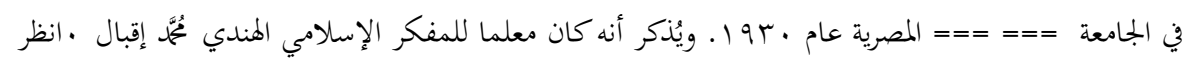

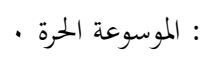

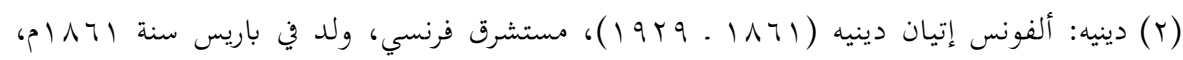

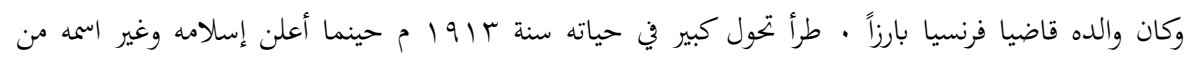

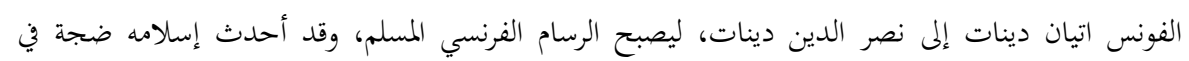

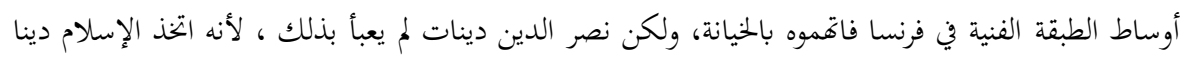

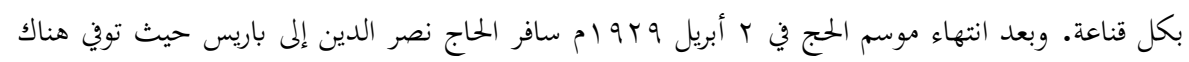

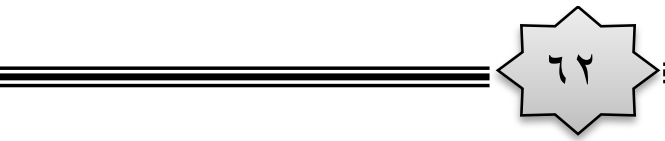


إسلامه، وتسمى باسم "ناصر الدين دينيه" وله كتاب" أشعة خاصة بنور الإسلام" بيَّن فيه تحامل قومه على الإسلام ورسوله، ومات في فرنسا ، ونقل جثمانه إلى الجزائر ودفن فيها - جإن وهؤلاء لا يوجدون إلا حين يكون لهم من الموارد المالية الخاصة ما يُمكِنهم من الانصراف إلى الاستشراق بأمانة وإخلاص، لأن أبحاثهم المجردة

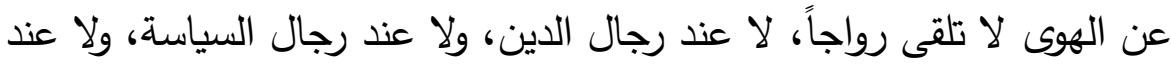

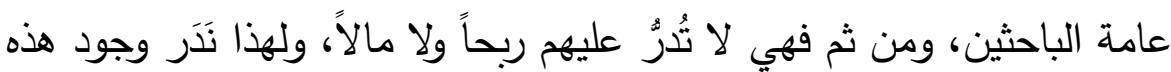
• الفئة في أوساط المستشرقين وهناك أسباب شخصية عند بعض الناس الذين تهيأ لهم الفراغ والمال، واتخذوا الاستشراق وسيلة لإشباع رغباتهم الخاصة في السفر أو في الاطلاع

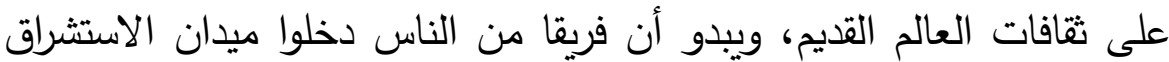
من باب البحث عن الرزق عندما ضاقت بهم سبل العيش المادية، أو دخلوه تخلصا من مسئولياتهم الدينية أمام إخوانهم في الدين، وتغطية لعجزهم الفكري (') · تلك كانت أهم الأسباب التي دعت إلى الاستشراق، وهي تتنوع بين أن

$$
\text { بعد أشهر قليلة في } 24 \text { ديسمبر } 1929 \text { م م انظر: الموسوعة الحرة . }
$$

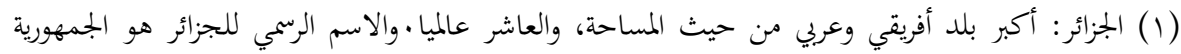

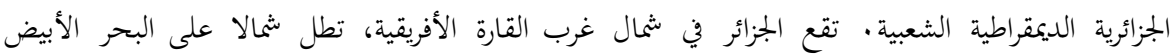

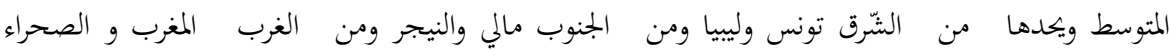
الغربية وموريتانيا الجزائر عضو مؤسس في اتحاد المغرب العربي، وعضو في جامعة الدول العربية و الاتحاد الإفريقي ومنظمة الأمم المتحدة منذ استقلالها، والأوبك والعديد من المؤسسات العالمية والإقليمية. تلقب بلديلد

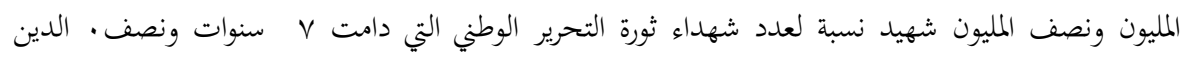

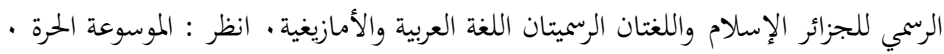
(Y) من وسائل المستشرقين لنشر أبحاثهم وبث أفكارهم : تأليف الكتب في موضوعات عختلفة عن الإسلام

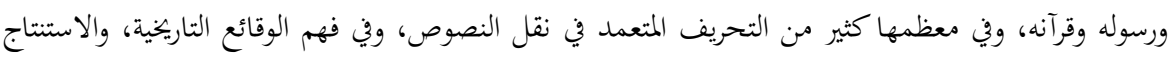

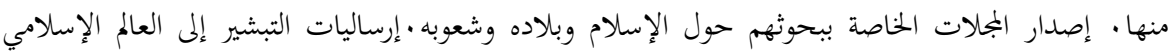

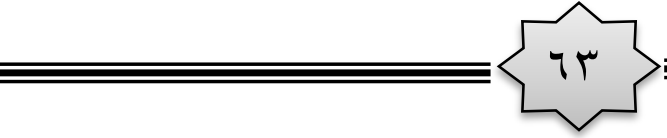


تكون أسبابا دينية أو استعمارية أو سياسية أو تجارية أو علمية أو شخصية .

\section{صلة الاستشراق بأجنحة المكر الأربعة}

المطلب الثاذي المون

\section{أولاً: صلة الاستشراق بالتبشير:}

الاستشراق ما هو إلا لون من ألوان التبشير لاءم نفسه مع ظروف

الحياة، ودراسة كل واحد منهما تعطي صورة كاملة عن الآخر · وهناك صلة وثثية بين الاستشراق والتبشير، وإن بدت حركة التبشير أولاً وتلتها حركة

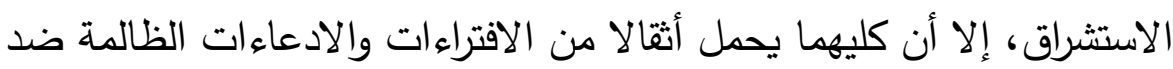

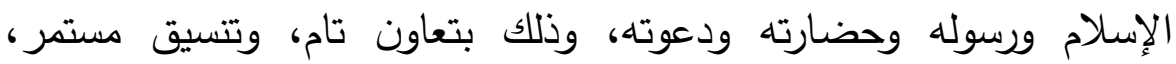
• وتخطيط منظَّم

فعلاقة الاستشراق بالتبشير أو بالأحرى علاقة المستشرقين بالمبشرين

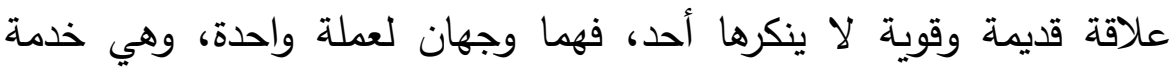
الاستعمار بصورة أو بأخرى، بل كان الاستشراق والتبشير في أول الأمر شيئاً واحداً، فالمستشرق الذي يبحث في علوم الشرق الإسلامي بقصد نقدها بإنيا وتشويهها، إنما هو بعينه يدعو إلى تتصير المسلمين، وبمرور الزمن تم الفصل بين المستشرقين والمبشرين حتى تسهل المهمة ويزيد الإنتاج، مع وجود · الصلة القوية بين الفريقين والاستشراق والتبشير توأمان تجمعهما وحدة الهدف والغاية، وهي

لتزاول أعمالا إنسانية في الظاهر كالمستشفيات والجمعيات والمدارس والملاجئ ودور الضيافة . إلقاء المحاضرات في

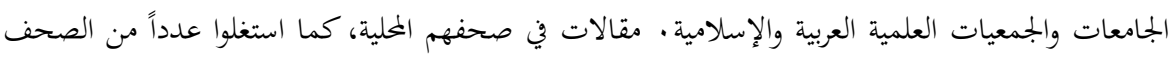

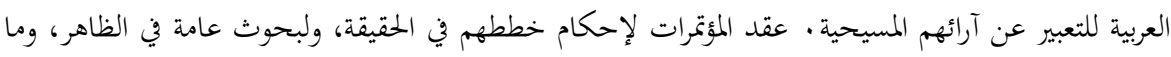

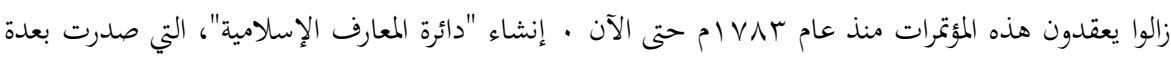

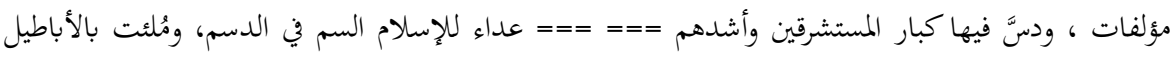

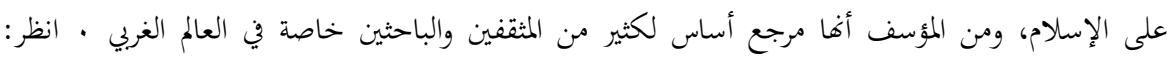

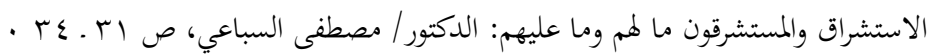

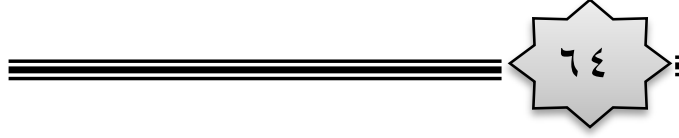


توهين القيم الإسلامية، وتفتيت وحدة المسلمين، والسيطرة على مقدراتهم وثرواتهم، ثم صرفهم في نهاية المطاف عن إسلامهم، وحملهم على الارتماء

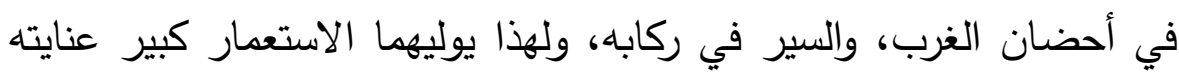
وبالغ تأييده، باعتبارهما الجسر الذي يعبر عليه لتتفيذ مخططاته وتحقيق

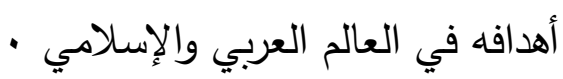
يقول صاحب كتاب "الفكر الإسلامي الحديث": "إن التبشير والاستشراق كلاهما دعامة الاستعمار في مصر والشرق الإسلامي، فكلاهما دعوة إلى توهين القيم الإسلامية، والغض من اللغة العربية الفصحى، وتقطيع أواصر القربى بين الشعوب العربية، وكذا بين الشعوب الإسلامية، والتتديد بحال الشعوب الإسلامية الحاضرة، والازدراء بها في المجالات الدولية العالمية" (')

ويقول اللورد "بلفور" وزير خارجية بريطانيا، وصاحب الوعد المشئوم بجعل فلسطين(r) العربية المسلمة وطناً قومياً لليهود، ورئيس شرفي إحدى لرئي الجمعيات التبشيرية: "إن المبشرين هم ساعد جميع الحكومات المستعمرة،

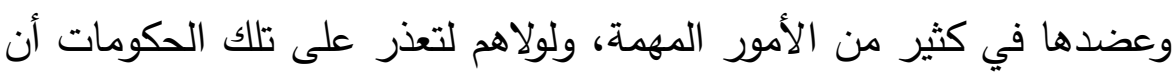
تذلل كثيراً من العقبات، ولذلك فإننا في حاجة إلى لجنة دائمة تعمل لما فيه

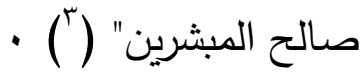

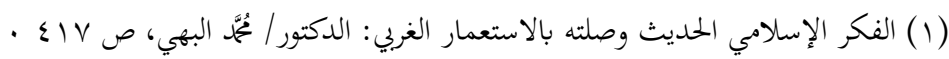

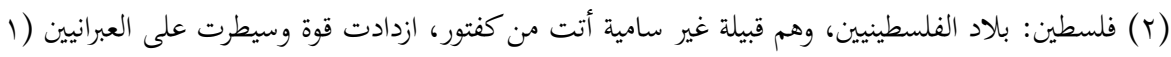

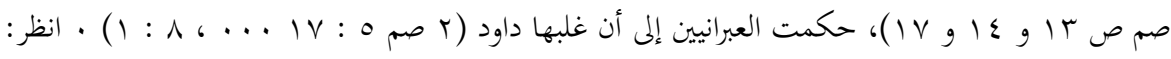

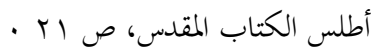

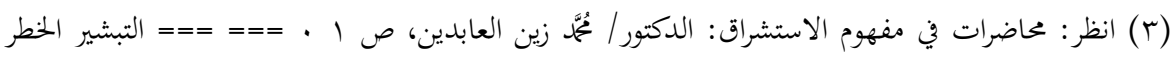

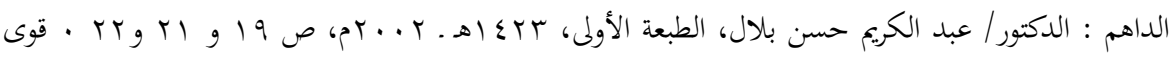

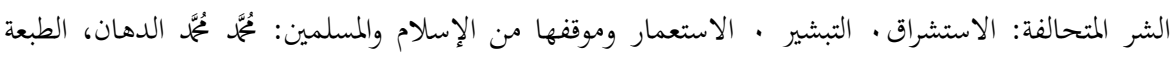

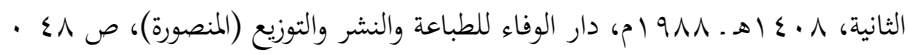
$\overline{0}\left\{\begin{array}{l}70 \\ 70\end{array}\right.$ 
فمعركة الاستشراق التي قادها المستشرقون، لا تختلف كثيراً عن معركة التبثير التي قادها المبشرون، لأن أهداف الفريقين من حيث النتيجة واحدة، تتلخص في محاربة الإسلام من داخله، وزرع الثك في نفوس المسلمين، والطعن على نبي الإسلام، والحط من قيمة الفكر الإسلامي، وتثويه التاريخ الإسلامي، وإثارة الفتن بين الطوائف الإسلامية، ومحاربة اللغة العربية، وتلقين

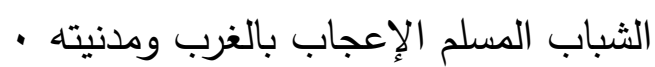
كما أن الاستشراق يتقق مع التبشير في العداء للإسلام، وشاركهما هذا لإناء العداء الاستعمار، ولا تستطيع أن تُرِّقِ بين المستشرق والمبشر والمستعمر، فكلهم وجوه لعملة واحدة، تهدف إلى أمرين: القضاء المبرم على الإسلام والمسلمين أينما

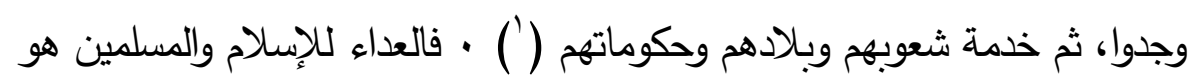
الركيزة الأساسية في عمل المبشرين والمستشرقين، وهو نقطة الانطلاق لكل منهما . كما يُعتبر الاستشراق والتبشير أداتين هامتين في تتبيت قوائم التغريب والغزو الثقافي

ومن نقاط الاتفاق بين الاستشراق والتبشير أنه إذا كان الاستشراق لا

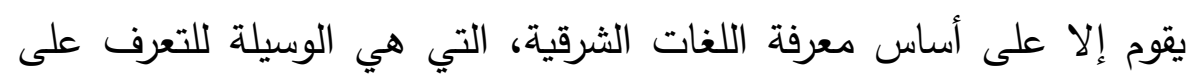
عقائد وحضارات الثرق، فإن التبشير (التنصير) يتفق مع الاستشراق في هذا الصدد، وكان هناك اقتناع تام لدى دعاة التتصير في القرن الثالث عشر الميلادي بضرورة تعلُّم لغات المسلمين، إذا أريد لمحاولات تتصير المسلمين

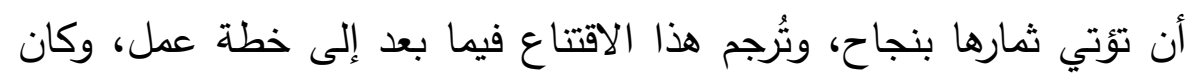

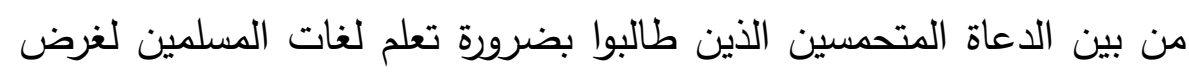

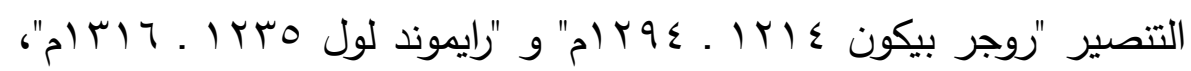
وصادق مجمع "فيينا" الكنسي سنة باس ام على أفكار "بيكون" و "لول"،

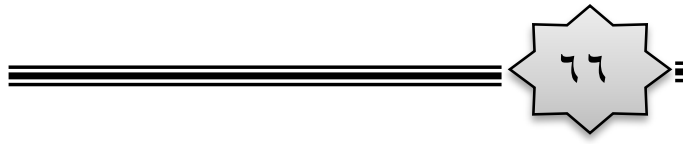


وتمت الموافقة على تعلُّم اللغة العربية في خمس جامعات أوربية، وفي القرن السادس عشر والسابع عشر الميلادي شجعت البابوية الرومانية على دراسة لغات الشرق من أجل مصلحة التتصير، وأنشئت كراسي للغة العربية في

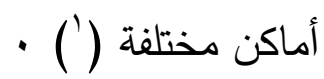

وهناك إعداد متثابه يتضح في المؤهلات الضرورية التي يُشترط توافرها في كل مستشرق ومبثِّر، من أهمها: أولاً: الدراسة اللاهوتية والتاريخية

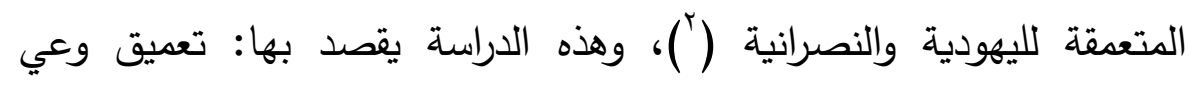
المستشرق والمنصِّر بدينه لمواجهة عقائد الدين الآخر وهو الإسلام، ومحاولة تدعيم الزعم الذي يردده جميع المستشرقين والمنصِّرين، وهو أن الإسلام مأخوذ

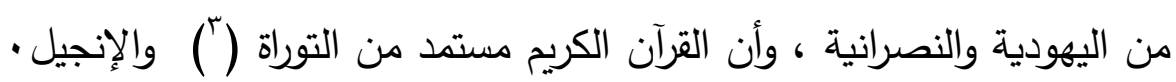
ثانياً: دراسة الإسلام واللغة العربية، واتخاذ هذه الدراسات وسائل لإثارة

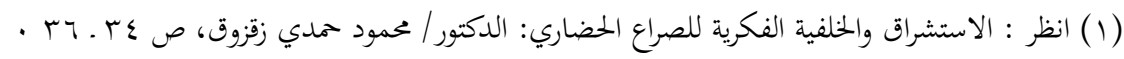

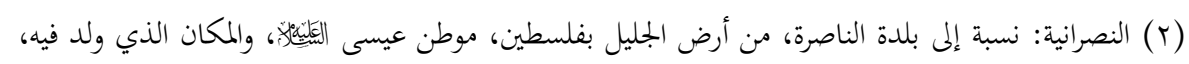

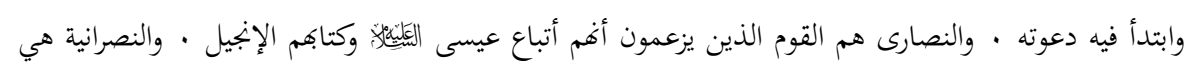

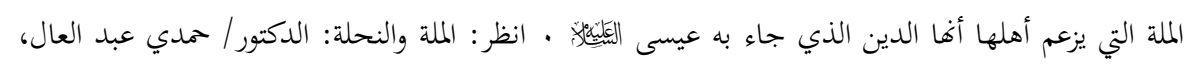

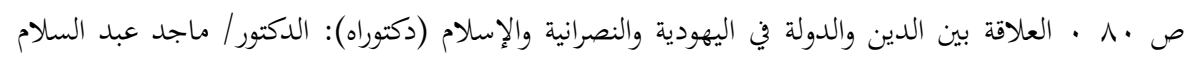

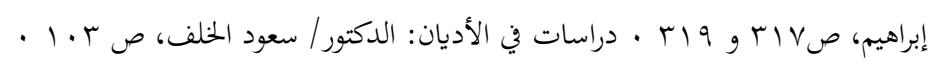

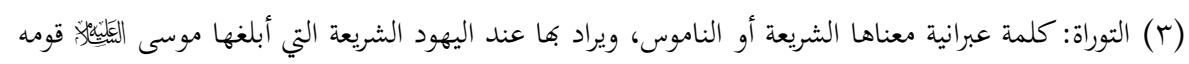

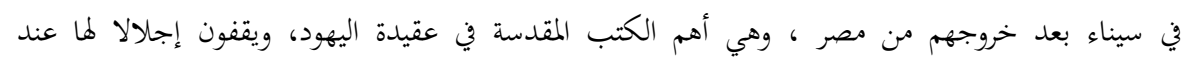

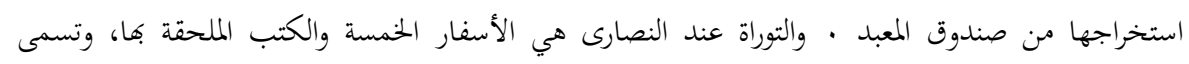

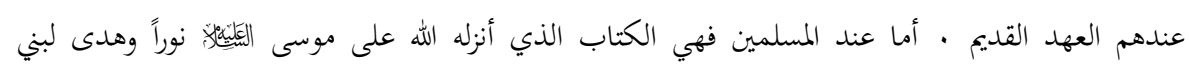

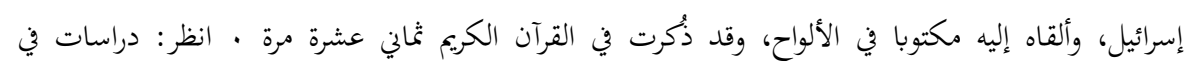

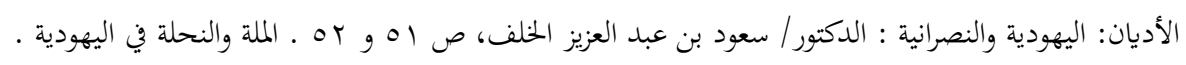

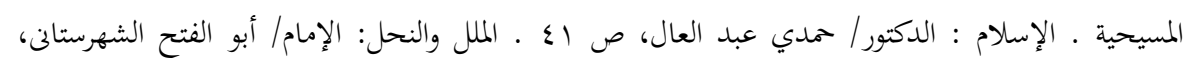

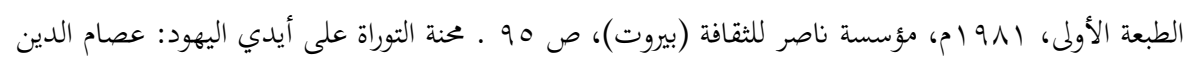

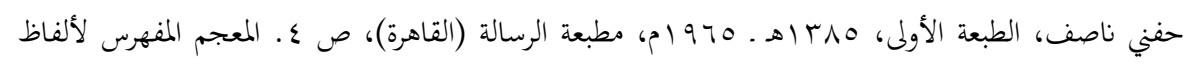

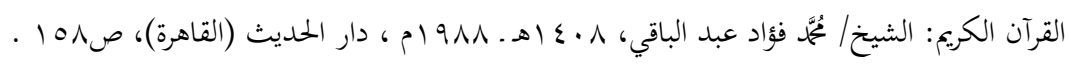

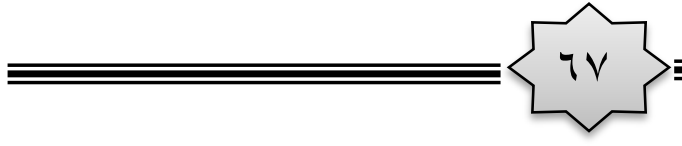




$$
\text { • الشبهات والتشكيك في الإسلام (') }
$$

والتعاون والتتسيق بين الاستشراق والتبشير كان ولايزال قائما ومستمراً، فلم يكن عمل المستشرقين منفصلا عن عمل المبشرين، لأن الاستشراق ما هو إلا أداة من أدوات التبشير، ثم استُخل في مرحلة لاحقة لتحقيق مطامع الدول الاستعمارية، وقد نزل كثير من أساقفة الكنيسة الكاثوليكية إلى ميدان الاستشراق، بقصد التبشير وتدريب المبشرين على العمل في بلاد الثرق • والمستشرق يُفني عمره في القراءة الدائبة لعلوم المسلمين، من أجل تصيُّد خطأ كاتب من كُتَّب المسلمين، ثم يتجاوز حدوده حين يُحمِّل المسئولية عن هذه الهفوة للإسلام ورسوله، ويصب جامَّ غضبه على الإسلام مباشرة، فينسج حوله الأكاذيب والأباطيل والخرافات، ويُحمِله مسئولية تأخر المسلمين وتخلفهم في هذا

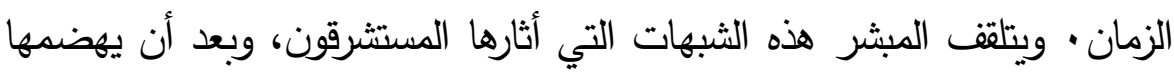
يأتي إلى بلاد المسلمين في ثوب الناصح الأمين الحريص على مصالح المسلمين، فينفث سمومه، ويضع السم في العسل وسط هذه الثبهات، ويثير الفتن والقلاقل في البلاد الإسلامية، حتى تكون مدعاةً لتدخل المستعمر الأثيم، أي أن الاستثراق

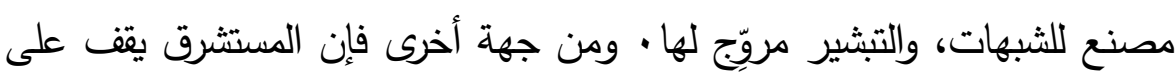
العوائق والصعوبات التي تواجه المبشر أثناء عمله ، فيضعها موضع البحث

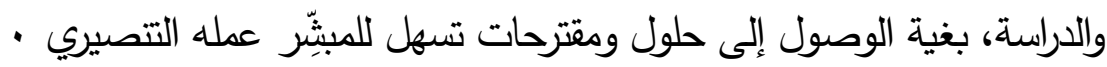
فالاستشراق تغذية للتبشير وإمداد له بما يعاونه في مهمته، والمستشرقون

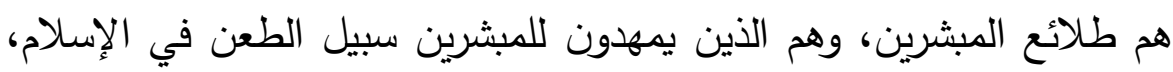
ويزودونهم بأنواع شتى من الشعوذة العلمية باسم الاستتاج التحليلي، ووَجد إنتاج المستشرقين رواجا على أيدي المبشرين ومعاهدهم وإرسالياتهم وجامعاتهم، في صورة مناهج تتنقص القيم الإسلامية في العقيدة والثريعة

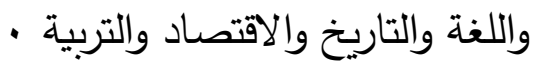

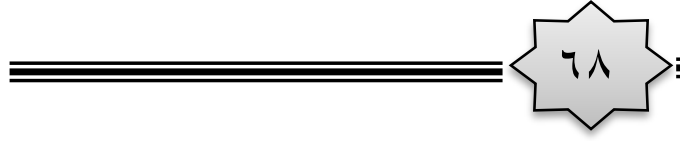


ولايزال الاستشراق يلعب دوراً هاماً في خدمة التتصير ، يكمن في إمداده

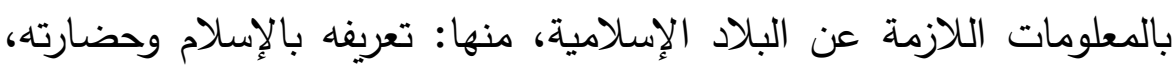
ولغاته ومجتمعاته، وعمل الدراسات العلمية التي تكثف للمنصِّر مواطن الضعف في المجتمعات الإسلامية، ودراسة الاحتياجات اللازمة في بعض هوله بلاد المسلمين التي تعاني من الفقر والمرض، وسد هذه الاحتياجات عن

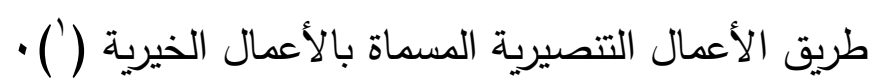
فالفصل بين الاستشراق والتبشير عسير ، لأن كثيراً من المبشرين انتقلوا إلى ميدان الاستشراق بعد فترة من عملهم، وبابا الفاتيكان وغيره من

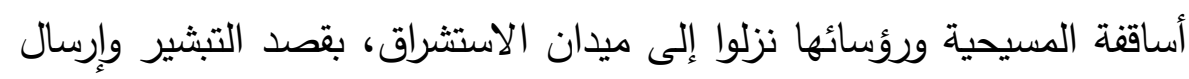

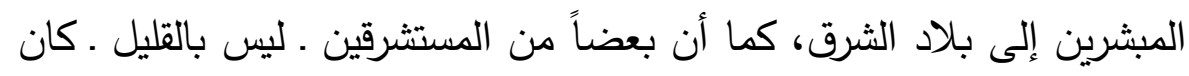

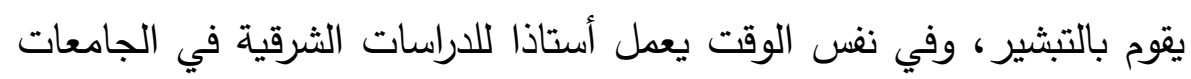

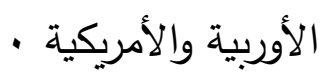

وكان المبشرون والمستشرقون يعملون في حقل واحد، ولكن لكلٍ وجهته،

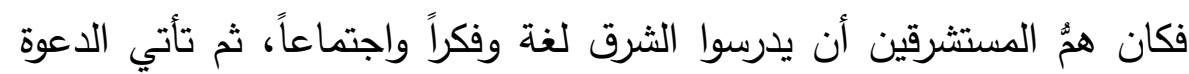
إلى الديانة المسيحية عرضاً، وهم أسبق في دراستهم من المبشرين · وكان هٌُ

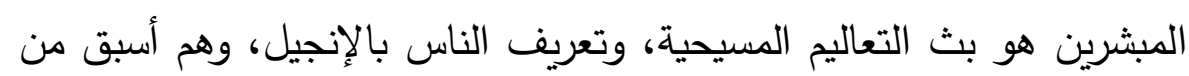

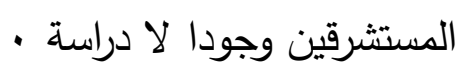
ثانياً: صلة الاستشراق بالاستعمار: أ - ـ مفهوم الاستثمار:

بمراجعة بعض المعاجم اللغوية للتعرف على مفهوم كلمة "الاستعمار"،

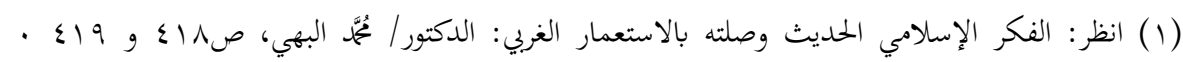

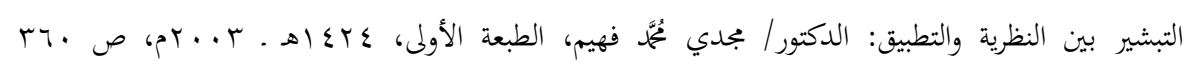

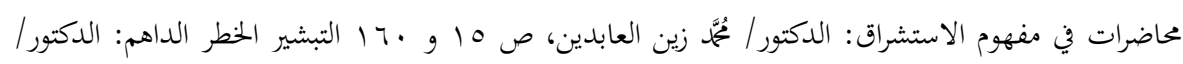

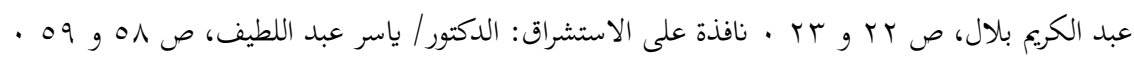
$\overline{\overline{ }}\{79\}$ 
تبين أنها مأخوذة من مادة "ع م ر"، ولها اشتقاقات ومعان متعددة، أهمها:

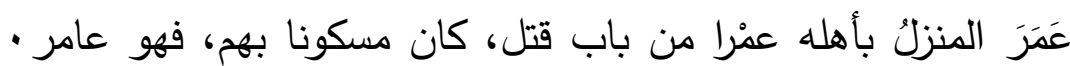

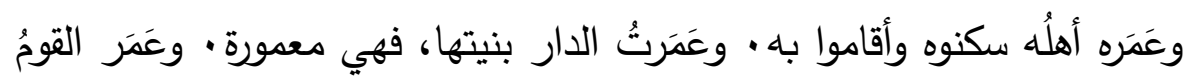

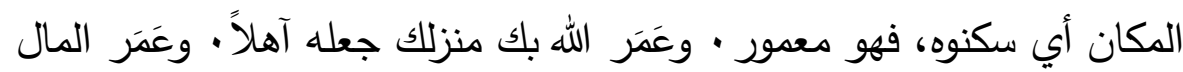

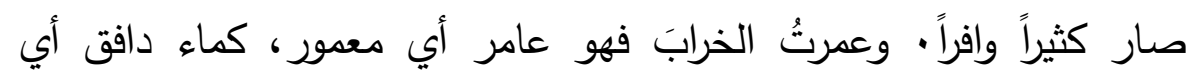

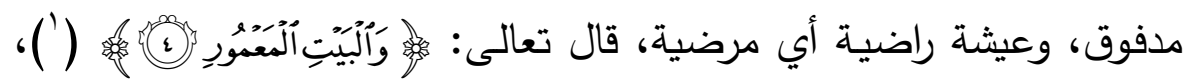
وهو بيت في السماء السابعة بإزاء الكعبة، يدخله كل يوم سبعون ألف ملك،

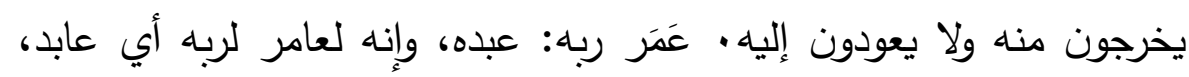

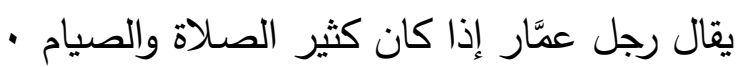

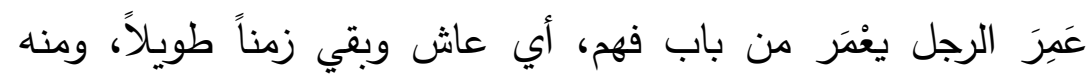
قولهم: أطال الله عمرك بضم العين وفتحها • ويقال: عَمِر فلان يعمَر إذا لها

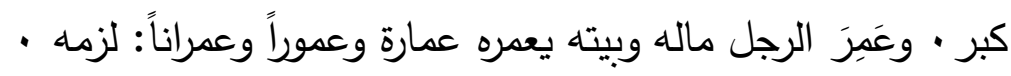

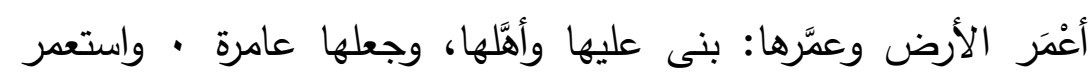

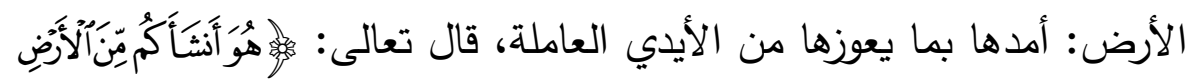

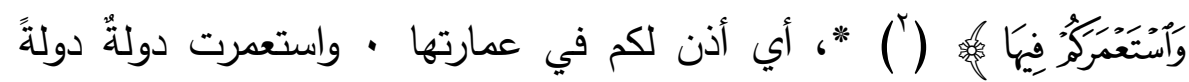
أخرى: فرضت عليها سياستها واستغلتها · اعتمر الثيءَ: أمَّه وقصده وزاره،

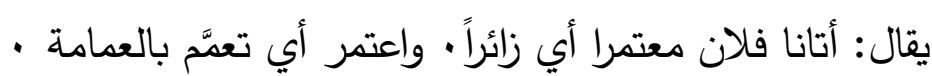

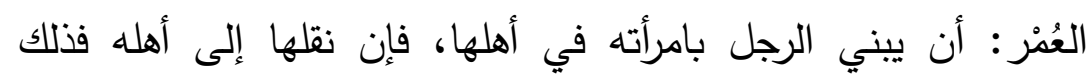

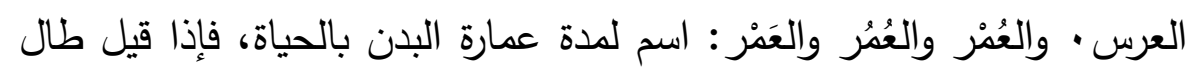

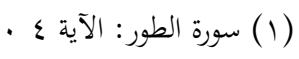

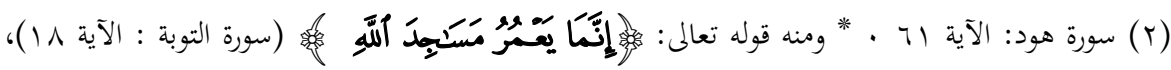

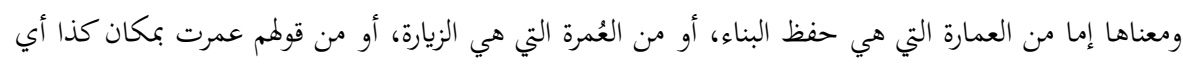

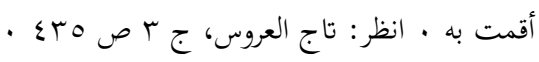

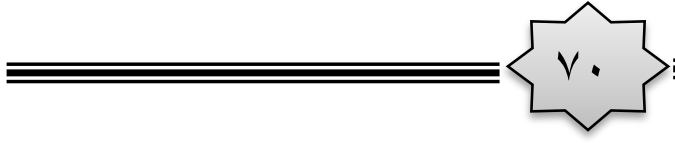




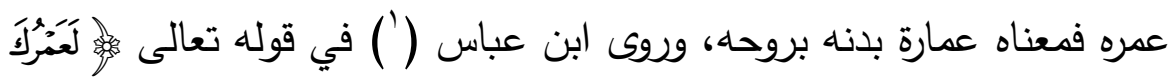

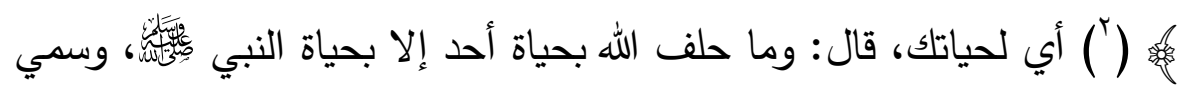
الرجل عَمْرا تفاؤلا أن يبقى • قال الجوهري (َّ): معنى لعمر الله أحلف بيقاء - الله ودوامه النه

العُمْريُّ: ما تجعله للرجل طوال عمرك أو عمره، وهو أن يدفع الرجل

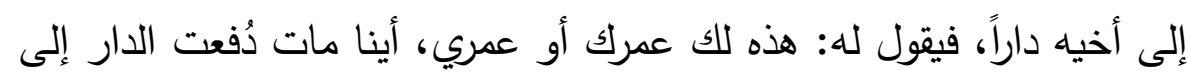
أهله، وكذلك كان فعلهم في الجاهلية، فأبطل الإسلام هذه الثروط وأمضى

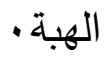

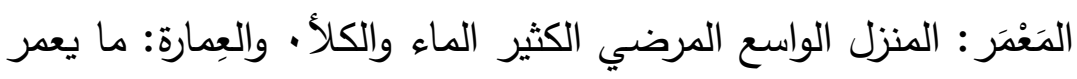
باه المكان · والعُمارة : أجرها أي أجر العِمارة · والعَمارة : كل شيء جعلته

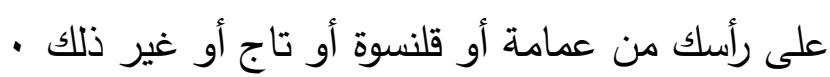
العُمرة: مأخوذة من الاعتمار، وهو الزيارة والقصد، وخُصَّ بهذا لأنه أنه

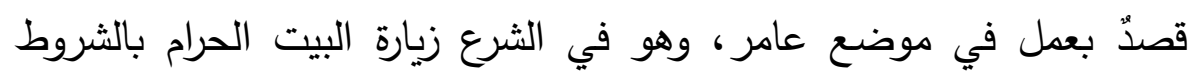

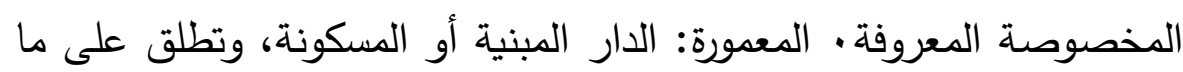

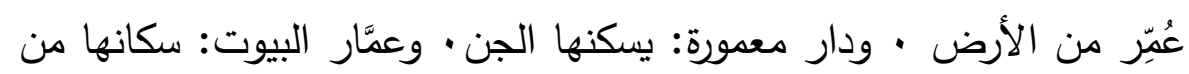

(1) عبد الله بن عباس: هو عبد الله بن عباس بن عبد المطلب بن هاشم بن عبد مناف بن قصي ، أبو العباس

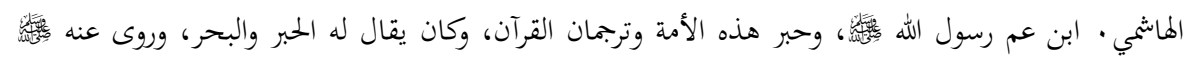

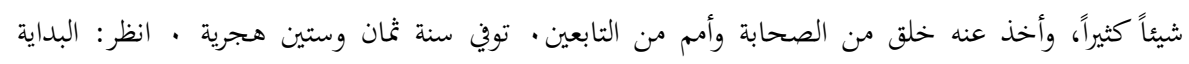

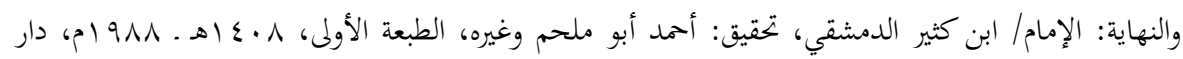

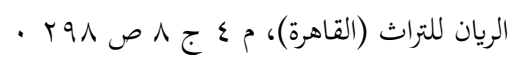

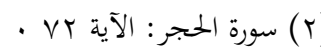

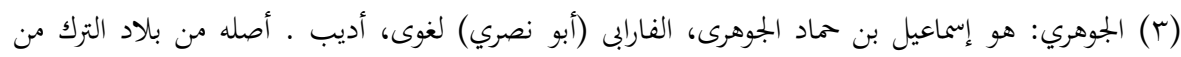

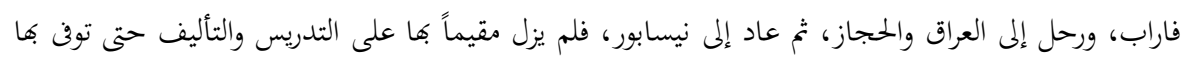

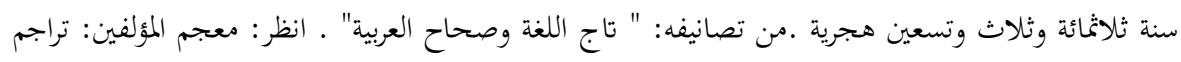

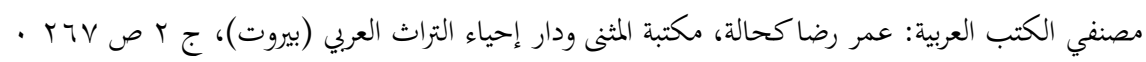

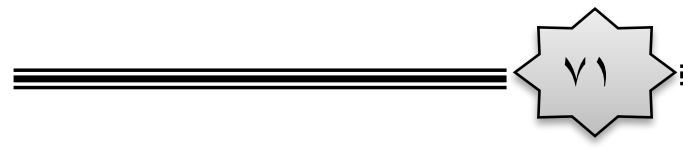


الجن · العوامر: الحيات التي تكون في البيوت، وقيل سميت عوامر لطول

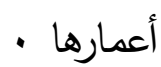

العمران: البنيان، وما يعمر به البلد ويحسن حاله بوساطة الفلاحة

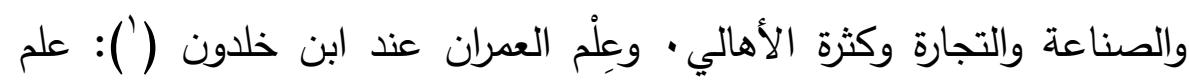
الاجتماع · والمستعمر: إقليم يحكمه أجنبي يتوطنه، أو يكتفي باستغلاله اقتصادياً أو عسكرياً ( (†) · فمادة "ع م رد" تدور في اللغة حول معان إيجابية وصفات حسنة تدور حول العمارة بشقيها المادي والمعنوي، مثل: البناء

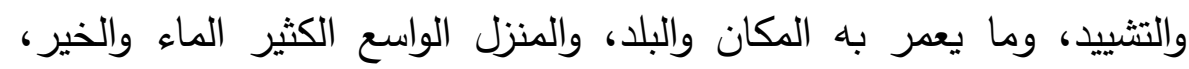
والإقامة فيه، وكثرة المال، والعبادة، والعيش زمناً طويلاً، والقصد إلى شيء ولى وليء

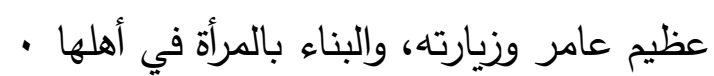

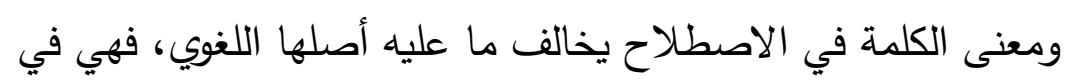
الاصطلاح تعني: استيلاء شعب بالقوة العسكرية على شعب آخر، لنهب ثرواته، واستغلال أرضه، وتسخير طاقات أفراده لمصالح المستعدرين، ويرافق

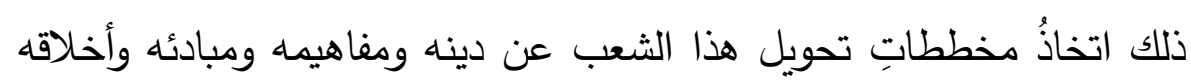
وسلوكه الفردي والاجتماعي إلى ما هو عليه الثعب المستعمِر، من مبادئ

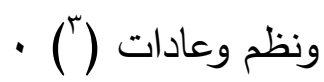

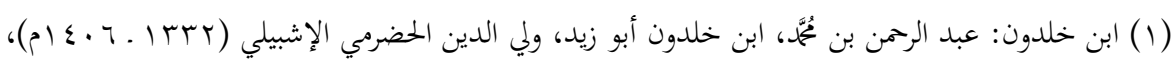

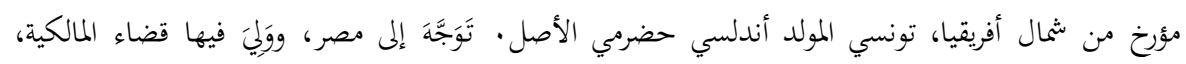

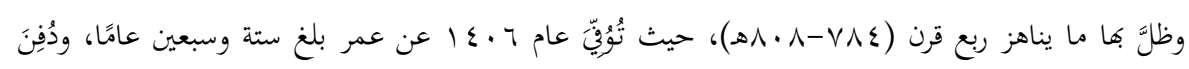

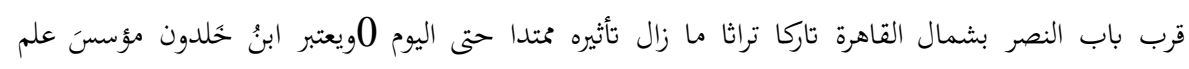

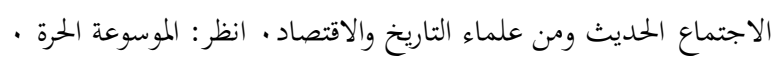

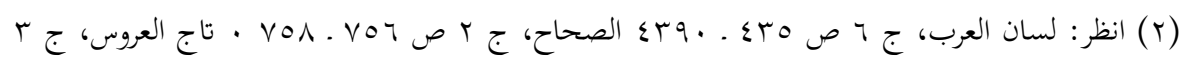

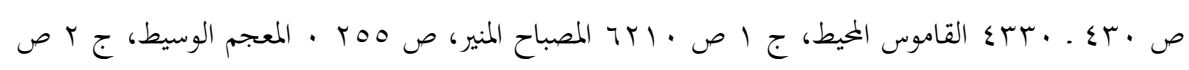
(ץ) التنصير بين الماضي والحاضر وكيفية مواجهته: الدكتور / مُحمّم زين العابدين، والدكتور عادل درويش، ص $\overline{\overline{ }}\{\mathrm{Vr}\}$ 
أو هو حصول دولة أجنبية مستغِلّة على مجهودات وموارد دولة أخرى مستغَلَّة، دون أن تقوم الأولى بإضافة شيء لمجتمع الثانية إلا ما يخدم مصالحها الاستعمارية: من تعليمٍ بدائي للأيدي العاملة، وتحسينٍ محدود لهاء للصحة، وإقامة طرق ومواصلات، وبعض صناعات بسيطة كلها تخدم المستعمر (') * * فالكلمة من الألفاظ البراقة التي استخدمها أعداؤنا في خداع شعوبنا، وأوهمونا أنهم أتوا للبناء والعمار، والحقيقة والواقع يؤكد أنهخ أتوا

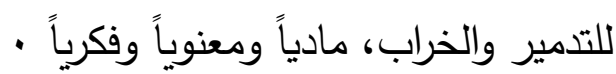
هذا الاستعمار الغربي الذي هاجم العالم الإسلامي كان مزدوبا الهدف، فهو طامع في خيرات الثرق الكثيرة، يراها ميراثاً لا صاحب له، وهو الهاني في الوقت نفسه مثقل بضغائن قديمة ***، يريد التنفيس عنها، وقد كانت هذه الضغائن وراء الحروب الصليبية في العصور الوسطى، وهي كذلك وراء الحروب الاستعمارية في العصر الحديث. فلما واتته الفرصة ووضع يده على أقطار الإسلام، شرع يضرب الإسلام

(1) انظر: بين الإسلام والغرب ضراوة أحقاد ومرارة حصاد: الدكتور / علي عبد الوهاب، ص • ل11 ـ ل

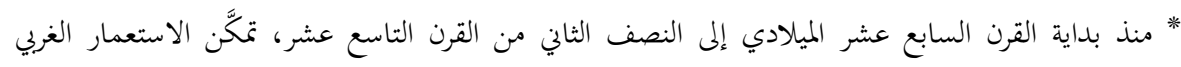

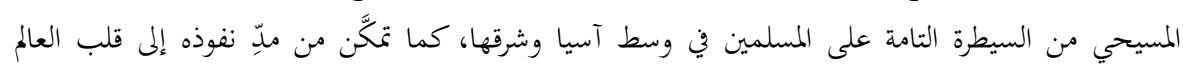

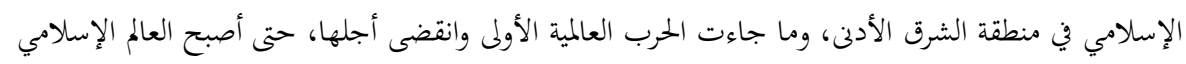

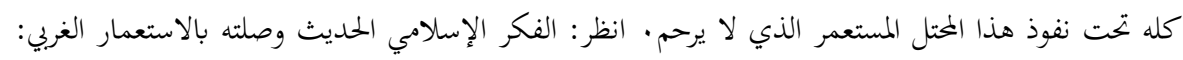

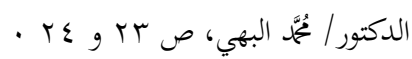

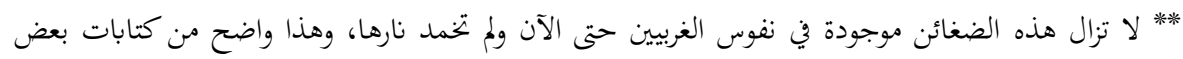

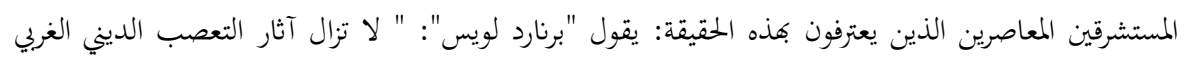

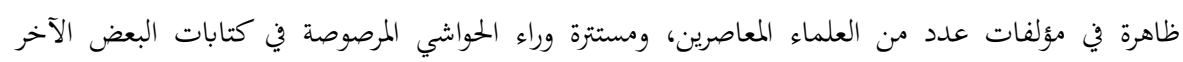

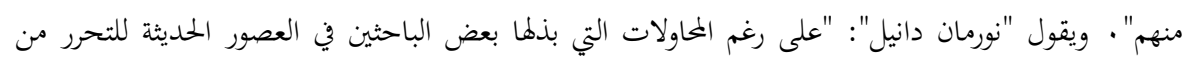

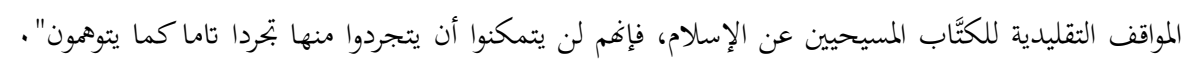

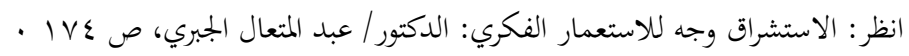

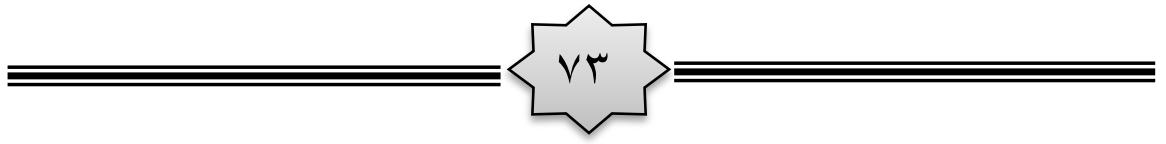


بقوة ومكر، وانطلتت طلائع الغزو الثقافي تطارد هذا الدين في ميادين التربية

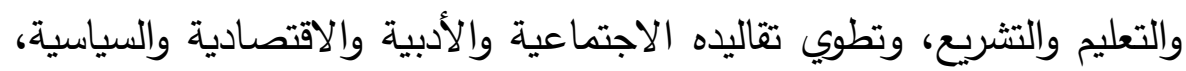

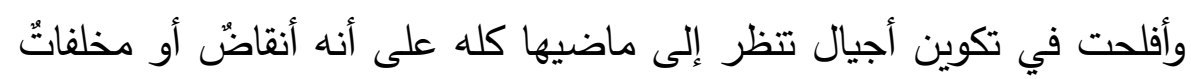
ينبغي أن تختفي، ليحل محلها البناء الجديد الذي وضع الغرين الغرب حقيقته

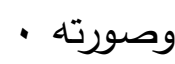

واتخذ الاستعمار لتحقيق هذا الهدف وسيلتين: الأولى: قيام بعض مفكري المسلمين بحركة تقدمية، تبغي تقرير سلطة المستعمر، وعدم تحديه ومعارضته • الثانية: قيام بعض الغربيين المسيحيين بصبغ حياة المسلمين

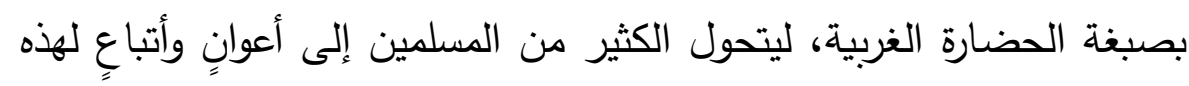
الحضارة وأهلها، كما قاموا بتشجيع الدعوات القومية، وإبراز الخلافات المذهبية بين طوائف المسلمين وشعوبهح ، مع شرح كثيرٍ من مبادئ الإسلام شرحا يثوهها وينحرف بها عن أهدافها الأصلية، مع تمجيد القيم المسيحية، كنية كنية والحضارة الغربية، والنظام السياسي، والسلوك الفردي للشعوب الغربية (').

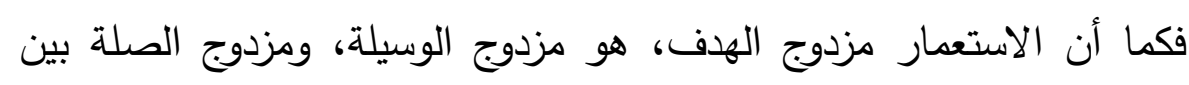

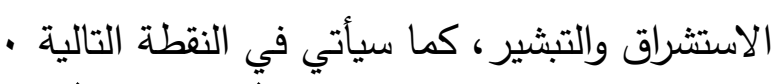

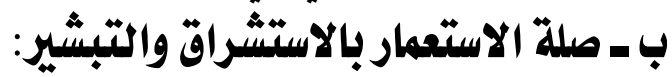
ا ـ صلة الاستعمار بالاستشراق:

هناك صلة وثيقة، وهدف مشترك، ومصلحة متبادلة بين كل من

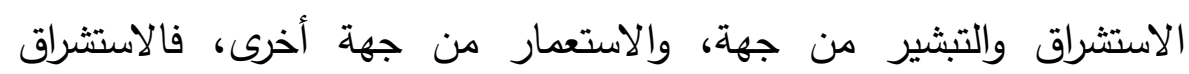
والتبشير كلاهما دعامة الاستعمار في العالم الإسلامي، وكلاهما دعوة إلى ونى

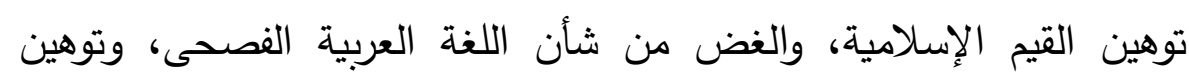

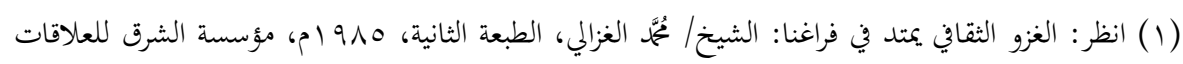

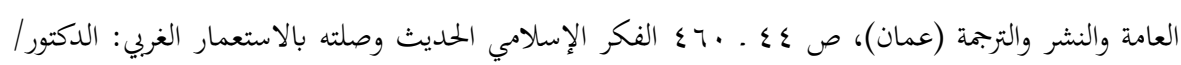

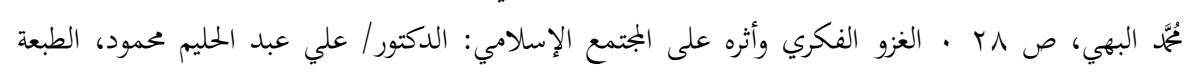

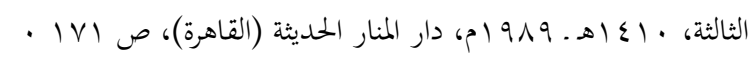

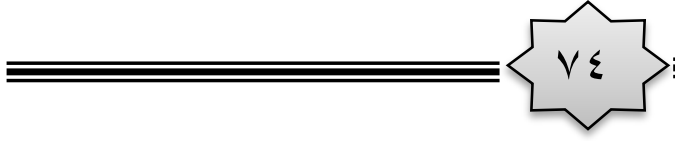


أواصر القربى بين الشعوب الإسلامية، لتقتيت وحدتهم، وكسر شوكتهم،

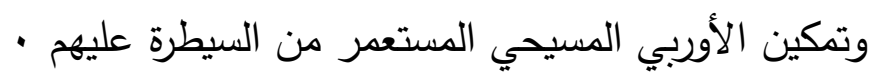
ولقد كان للاستشراق دور كبير في خدمة الاستعمار الأجنبي الذي مني اجتاح العالم الإسلامي منذ منتصف القرن التاسع عشر الميلادي، وكان للاستعمار دور مهم في تعزيز موقف الاستشراق الذي مارس عمله على أعلى

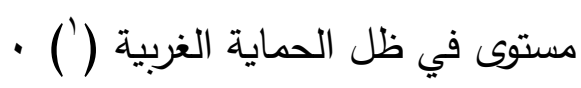

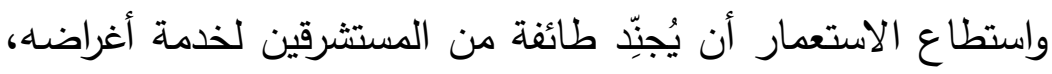
وتحقيق أهدافه، وتمكين سلطانه في بلاد المسلمين، وانساق في هذا التيار عدد

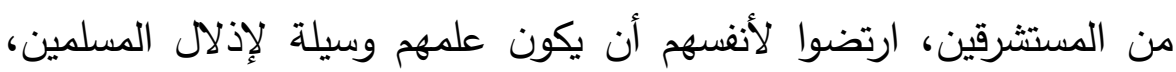
وإضعاف شأن الإسلام وقيمه: ففي فرنسا كان هناك عدد من المستشرقين يعملون مستشارين لوزارة المستعمرات الفرنسية في شئون شمال أفريقيا • وكانت الحكومة البريطانية ـ. من هن أجل تحقيق أهدافها الاستعمارية ـ ترسم سياستها في مستعمراتها بعد التنسيق تئيق

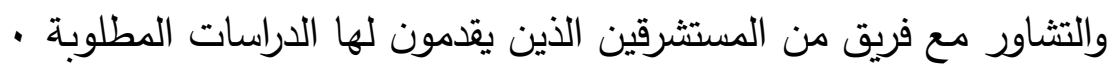
وكان التراث الاستشراقي بمثابة دليل للاستعمار في شعاب الثرق وأوديته من أجل السيطرة عليه، وإخضاع شعوبه وإذلالها، لأن المعرفة بالأجناس المحكومة أو الشرقيين هي التي تجعل حكمه سهلاً ومجدياً . كما استخدم الاستشراق الكتب والمجلات والمقالات ودوائر المعارف وكراسي التدريس والمؤتمرات العلمية والمحاضرات العامة وغيرها من الوسائل التي تقذف بالأكاذيب والمغالطات والثبهات على الإسلام وأهله، استخدمها لخدمة الاستعمار في أغلب الأحيان·هذا إلى جانب التبرير الاستشراقي للسيطرة الاستعمارية على بلاد العالم الإسلامي، وذلك بإضعاف المقاومة

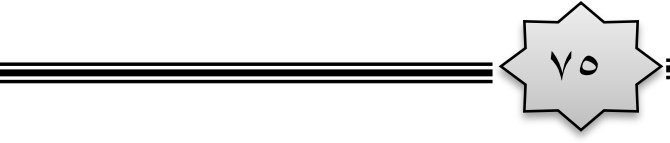


الروحية والمعنوية في نفوس المسلمين، وتثكيكهم في معتقداتهم وتراثهم، حتى

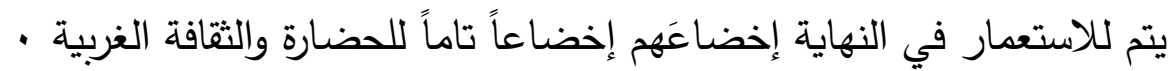

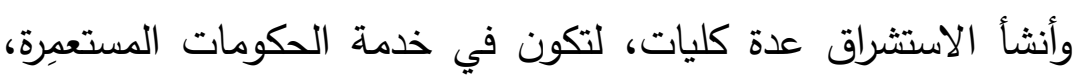
وكان رجال السياسة على صلة وثيقة بأساتذة تلك الكليات، وإلى آرائهح يرجعون قبل البت في المسائل السياسية المتعلقة بالأمم العربية والإسلامية، وأكبر شاهد على ذلك أن السيد "أنتوني إيدن" رئيس وزراء انجلترا السابق الذي شغل من قَبْل منصب وزير الخارجية، وأسهم فيما بعد في العدوان الثالثي على مصر سنة 907 (م، هذا الرجل لم يكن ليضع قراراً سياسياً في شئون الثرق الأوسط، قبل أن يجتمع وأساتذة من المستشرقين في جامعة أكسفورد • وكلية العلوم الثرقية

ويقوم منهج الاستشراق في خدمة الاستعمار على: تكوين الدراسات الاستشراقية عن البلاد الإسلامية قبل احتلالها بفترة، فقد مهدت فرنسا لاحتلالها للجزائر سنة . بام بفترة دراساتٍ سبقت ذلك الاحتلال بنحو عشرين عاماً، وكذلك سبقت الاحتلال البريطاني لمصر وغيرها من أجزاء العالم الإسلامي دراساتُ استشراقية، قام بها المستشرقون البريطانيون، ولم يغب عن الحملة الفرنسية أن تستغل الاستشراق لتحقيق مآربها في الاستيلاء على مصر · وتتسم تلك الدراسات الاستشراقية الممهِدة للاستعمار بالإلمام بكل صغيرة وكبيرة في المجتمع الإسلامي، وتصويره بصورة تُسهِّل على الاستعمار الغربي الاستيلاء عليه، كما اتسمت بطابع العنصرية لأنها قامت على نظرية ولية العرق، التي أكدت تفوق الإنسان الغربي الآري على الإنسان السامي، الذي .

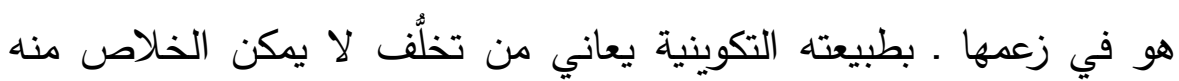
مطلقاً

وجميع المستشرقين هم تبع لوزارات الخارجية في كل البلاد القائمة على الاستعمار، مما يدل على أن مهمتهم سياسية وليست ثقافية، فإذا هم خُدَّام

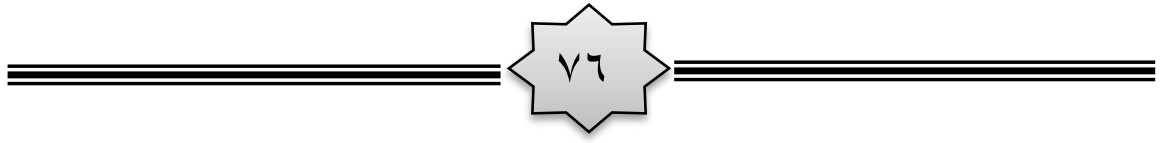


الاستعمار، عن طريق تشكيك العالم الإسلامي في عقيدة أهله (') · وفي المقابل أنثأ الاستعمار عدة مؤسسات في البلاد العربية والإسلامية لخدمة - الاستشراق والدراسات الاستشراقية

وينطوي عمل الدارسين للإسلام من المستشرقين على نزعتين رئيستين:

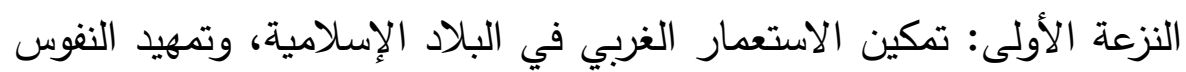
بين سكان هذه البلاد لقبول النفوذ الأوربي والرضا بولايته · النزعة الثانية: الروح الصليبية في دراسة الإسلام، تلك النزعة التي لبست ثثب البحث العلمي.

ويتجلى مظهر النزعة الأولى في إضعاف القيم الإسلامية، عن طريق شرح

تعاليم الإسلام ومبادئه شرحاً يُضعف في المسلم تمسكه بالإسلام، ويُقِِّي في نفسه الثكَّ فيه كدين، أو على الأقل كمنهج سلوك يتقق وطبيعة الحياة القائمة، فيشرح

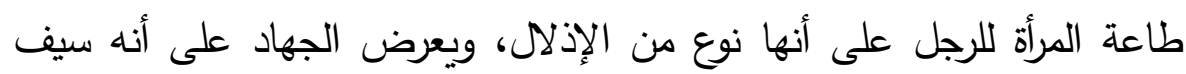
الإسلام الذي لم ينتشر إلا به، ويفسر فكرة العودة إلى القرآن الكريم على أنها تعني

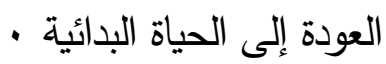
كما يتجلى مظهر تلك النزعة في تمجيد القيم الغربية المسيحية، من خلال إبراز التفوق الغربي في الصناعة وزيادة الدخل، والاستدلال بهذا التفوق على سمو المقاييس الغربية في السلوك الفردي والعادات الاجتماعية، وعلى

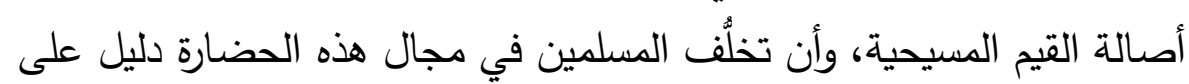
تخلف الإسلام في قيمه ومبادئه، وعلى الثرق الإسلامي ـ إذا أراد أن يرتقي

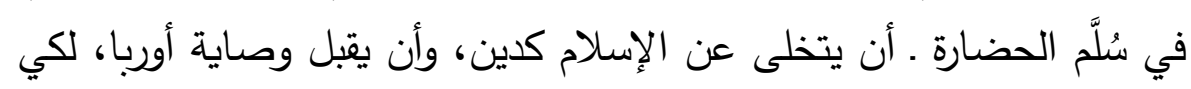

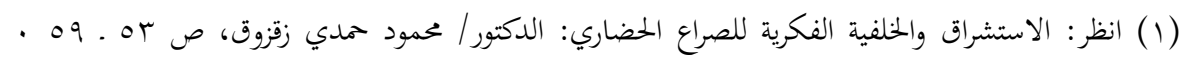

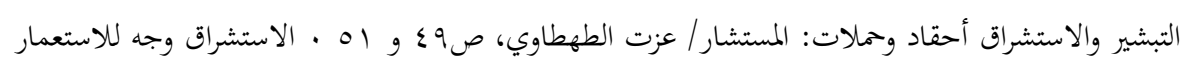

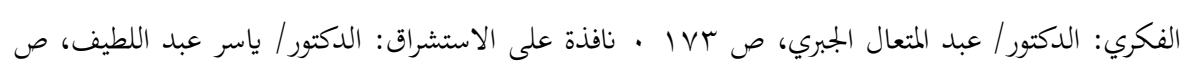

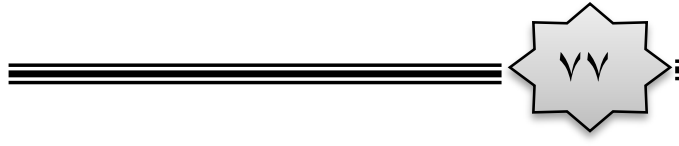


يسهل عليه إدارة أموره الفكرية وسياسة حكمه (') (1) فالمستعمرون يُسخِّرون قواهم المادية لسحق هذه الأمة، والمستشرقون يقدمون الأسباب العلمية والتاريخية لهذا العدوان، بإظهار الإسلام في شكلٍ منكرَ، ويغلِّفون أصوله وفروعه بحشد لا آخر له من الأكاذيب، حتى تبدو

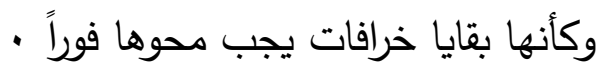

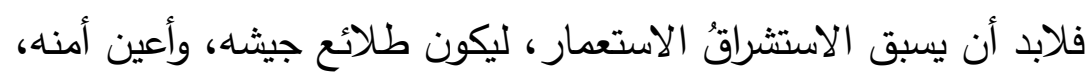

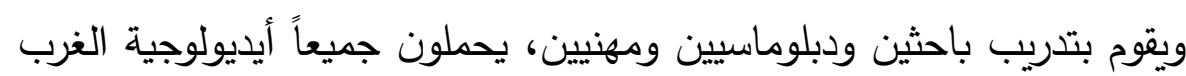
وعقليته تجاه الشرق وحضارته . والدول الغربية قبل أن تغزو الثرق الإسلامي لباي

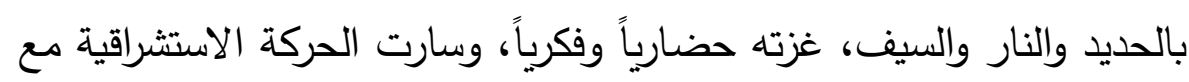

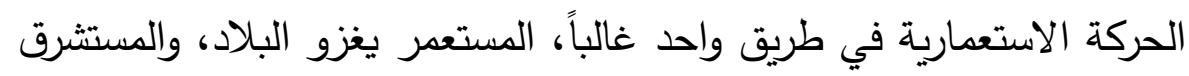

\section{يغزو الفكر والتراث الإسلامي

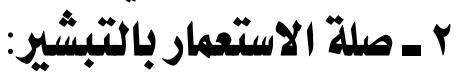

الصلة وثيقة بين الاستعمار والتبشير، فكلاهما أصحاب هدف واحد، يتعاونان في تحقيقه، ويخدم كل منهما الآخر في الوصول إليه، ويشترك رجال السياسة في المؤتمرات التبشيرية، كما يشترك قادة التبثير في المؤتمرات الاستعمارية السياسية • وليس لأحد ممن يتعاطى النظر في أمور الناس في البلاد التي وقعت تحت السيطرة الغربية أن يغفل دور التبشير، ولا أن يتجاهل آثاره، ولا أن يغض النظر عن وسائله، لأنه أقوى العوامل التي مكنت

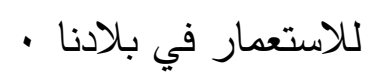
لقد ظهر التبشير وترعرع وانتشر مع الحروب الصليبية ، ولم يزل إلى في

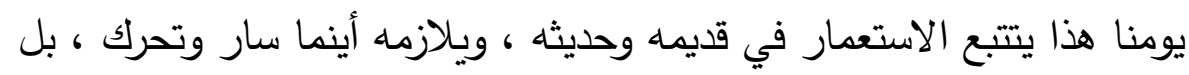

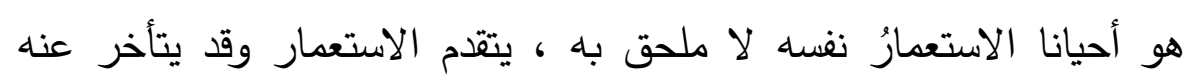

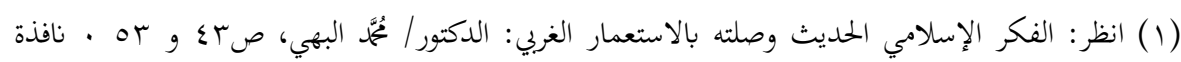

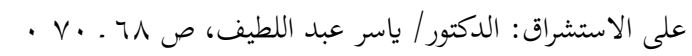

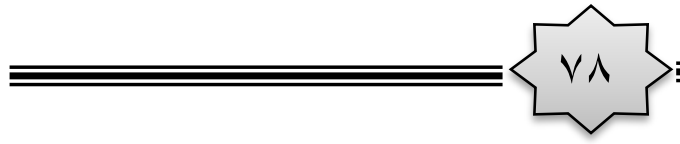


ويبقى بعد أن يرحل ، وهو لا يقل عن الحروب ، لأنه حرب مستمرة هادئة ،

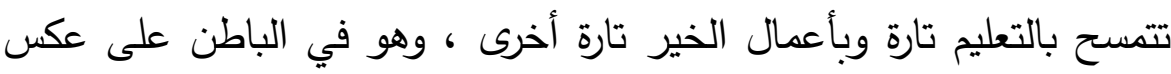
ذلك تماما

ولم يعد ثمة شك في ارتباط التبشير المسيحي بالاستعمار ، بعد ما تكثَّف من وثائق ونشرات صدرت عن المبشرين والمستعمرين ، وما سجله المفكرون والأحرار في بلاد الاستعمار : يقول أحد المبشرين الأمريكان : " لقد تمت محاولات نشيطة لاستئعمال المبشرين لا لمصلحة المسيحية ، وإنما لخدمة الاستعمار والعبودية " . وقال " نابليون الأول " في جلسة مجلس الدولة في بr مايو سنة ؟ •11 م : " إن في نيتي إنثاء مؤسسة الإرساليات الأجنبية ، فهؤلاء الرجال المتدينون سيكونون عونا كبيرا لي في آسيا وأفريقيا وأمريكا ، سأرسلهم لجمع الأحساء المعلومات عن الأقطار ، إن ملابسهم تحميهم وتُخفي أية نوايا اقتصادية أو سياسية " . وتُعتبر أفريقيا خير مثال لدراسة ارتباط التبشير بالاستعمار ، وذلك

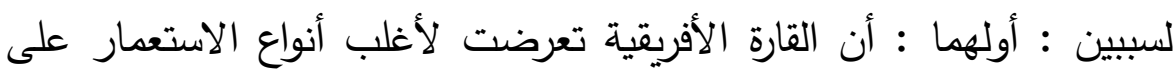
مدى قرون عديدة · ثانيهما : أن أفريقيا . كما يقول جاك مندلسون . " تعتبر

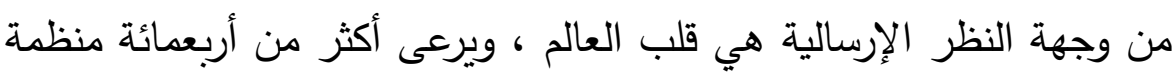

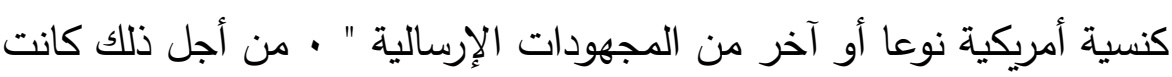
شهادات الأفريقيين في قضية التبشير والاستعمار ، تمثل حججا قوية لا يمكن تجاهلها · وبعد أن اكتشف الأفريقيون العلاقة الوثيقة بين التبشير والاستعمار ، ولمسوا الخديعة التي لحقت بهم ، أدانوا التبشير والمبشرين ، بل والمسيحية كذلك :

يقول " جالك مندلسون " : " حينما تكون حالة الشباب الأفريقيين سعيدة ، فإنهم لا يتعبون من ترديد القصة القديمة : إن المبشرين جاءوا إلينا ، وقالوا

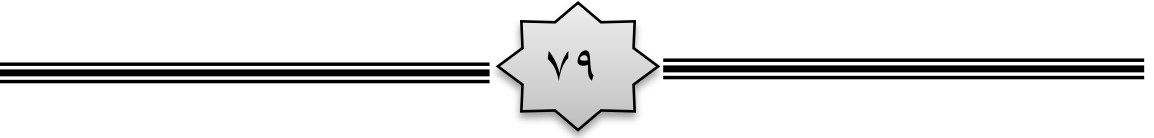


إننا نريد أن نعلمكم العبادة ، وقلنا حسنا ، إننا نريد أن نتعلم العبادة ، وطالب المبشرون منا أن نغلق أعيننا ، وفعلنا ذلك وتعلمنا التعبد ، وحينما فتحنا أعيننا ، وجدنا الإنجيل في يدنا ، ووجدنا أراضينا قد اغتصبت " · وهناك كلمات تكررت بلا توقف في أفريقيا كلها : " إن حركة التبشير المسيحية كانت

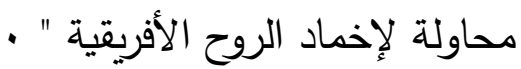

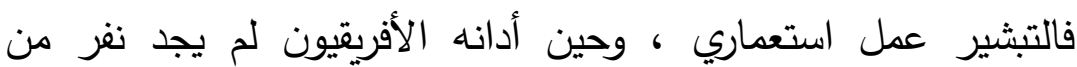
المبشرين سوى التسليم بتلك الإدانة ، وقالوا : " إن المبشر مهما اعتقد أن هدفه مختلف عن المكتشف والمستوطن والوكيل التجاري والموظف الإداري ،

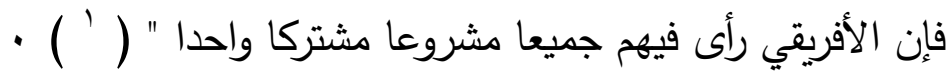
وللمبشرين غرض آخر خفي خلاف هدفهم الظاهري ، وقد يكون هذا

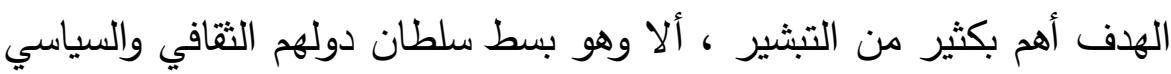
والاقتصادي على البلاد التي يذهبون إليها ، وبالتالي عملوا على تأييد الدول التي وفدوا منها واحتضان سياستها ، وتجسسوا على الثعوب التي يعملون بالتبشير فيها لحساب الدول التي يتبعونها سياسيا وعسكريا : فإيطاليا ( 'r ) كانت تبني جميع سياستها الاستعمارية على جهود

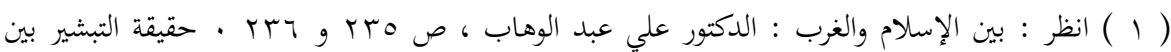

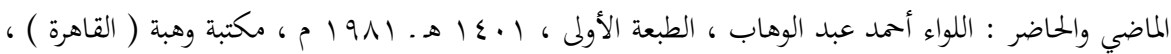
- IT\&. I I ص ( ) ( r إيطاليا : دولة تقع في جنوب أوروبا في شبه الجزيرة الإيطالية على أكبر جزيرتين في البحر الأبيض

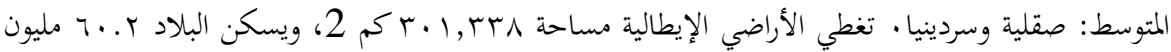

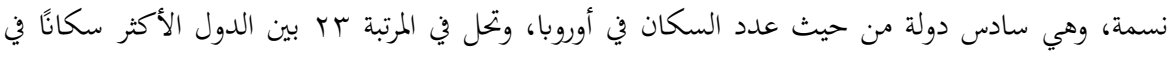
العالم. كانت الأراضي المعروفة اليوم باسم إيطاليا مهد الثقافات والشعوب الأوروبية، كما كانت العاصمة تهربة الإيطالية روما لقرون عديدة المركز السياسي للحضارة الغربية باعتبارها عاصمة للإمبراطورية الرومانية. إيطاليا الحديثة جمهورية ديمقراطية. تُصنف في المرتبة 11 عالميًا من بين الدول الأكثر تقدمًا، حيث يحتل معدل جودة الحياة فيها إحدى المراكز العشرة الأولى في العالم. انظر : الموسوعة الحرة .

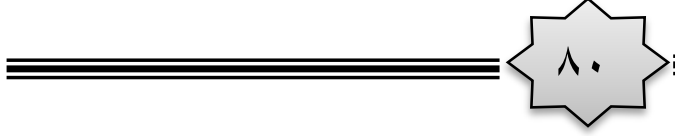


الرهبان والمبشرين ، وكانت ترمي إلى بلوغ أغراضها السياسية في الشرق من خلال زرع البلاد بمدارسها الدينية ، مع أنها كانت قد صادرت أمرات أمرال الأديرة في إيطاليا نفسها • كما أن فرنسا كانت تستند إلى اليسوعيين ( ' ) في مستعمراتها ، وقام اليسوعيون بتحبيب الانتداب الفرنسي إلى النفوس ، وكانت

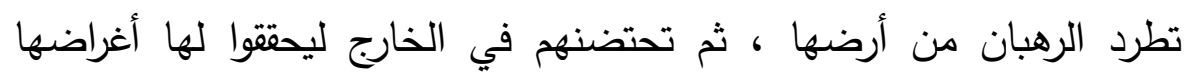
- الاستعمارية

وقد نصح العسكريون انجلترا ببث مبشريها في العالم ، حتى إن أحد جنرالاتها طلب من الحكومة البربطانية أن ترسل مبشريها إلى شبه الجزيرة

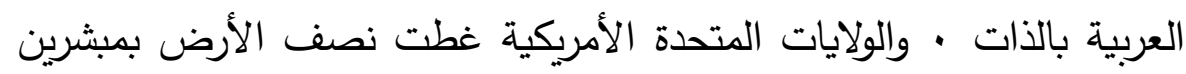
يزعمون أنهم يدعون إلى السلام والسمو الروحاني ، مع أنه تغلب على حياتهر

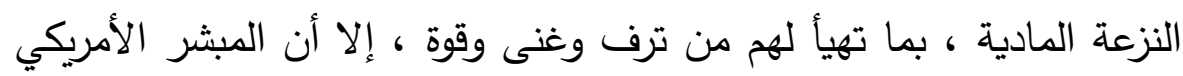

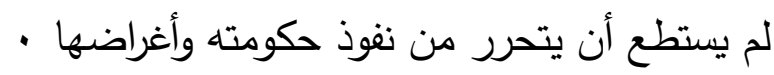

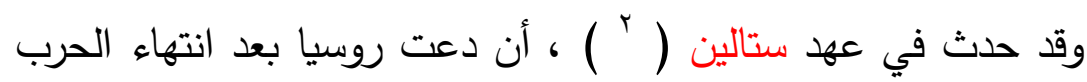
العالمية الثانية إلى عقد مجمع مسكوني في العاصمة الروسية ، وحملت إليه

( 1 ) اليسوعيون : الرهبنة اليسوعية هي واحدة من أهم الرهبنيات الفاعلة في الكنيسة الكاثوليكية. تأسست

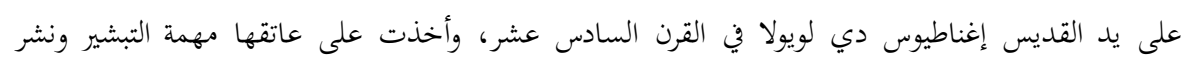

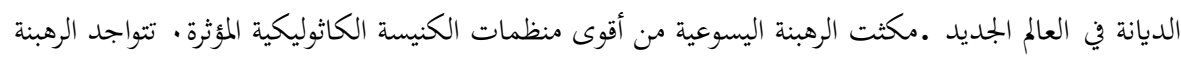

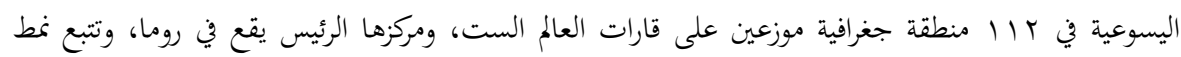

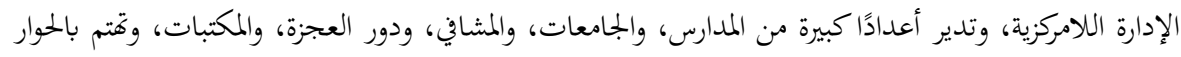

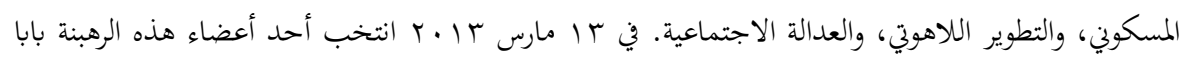

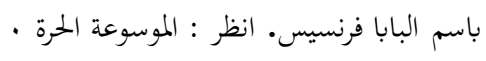

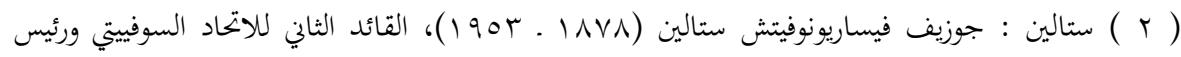

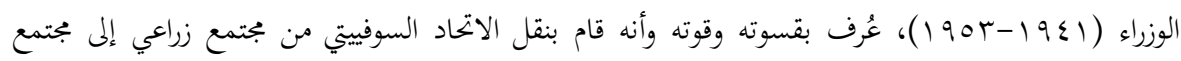

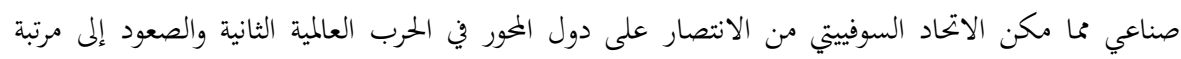
القوى العظمى. انظر : الموسوعة الحرة ·

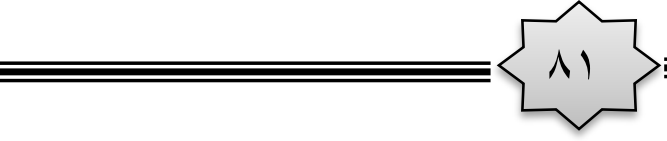


المشتركين بطائرات روسية ، ولم يفت ستالين أن يتقابل معهم ، ولا شك أن

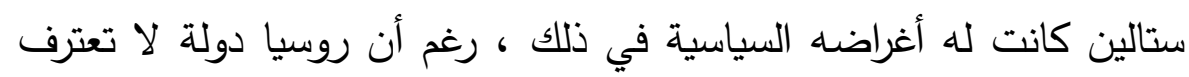

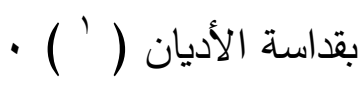

ومما يدل على التعاون الوثيق والرابطة الحميمة بين قوى الاستعمار

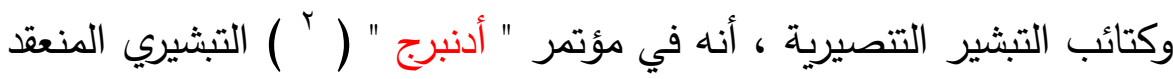
سنة • 191 م إشادة واضحة بدور كتائب التصير في تذليل العقبات التي

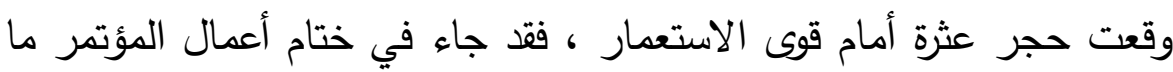

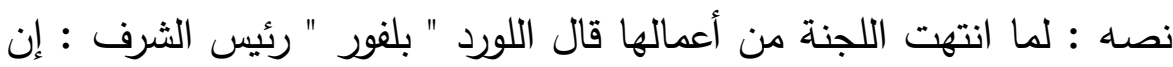
المنصِّرين هم الساعد الأيمن لكل الحكومات في الأمور الهامة ، ولولاهم لتعذر عليها أن تقاوم كثيرا من العقبات ، وعلى هذا فنحن في حاجة إلى لجنة

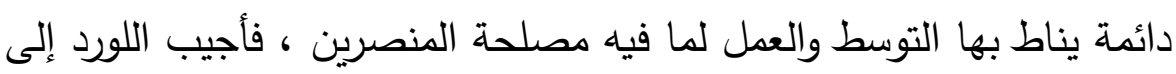
- اقتراحه

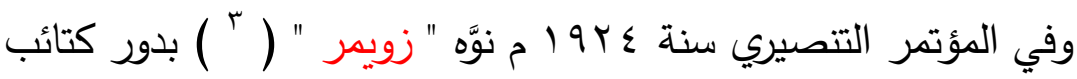

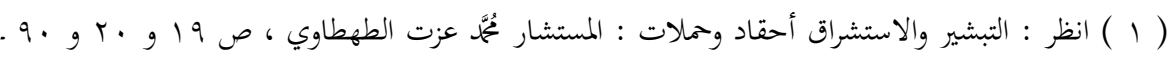

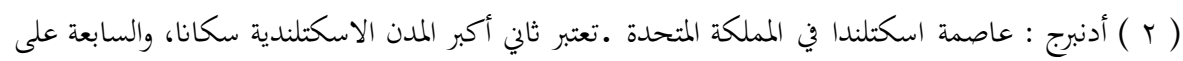

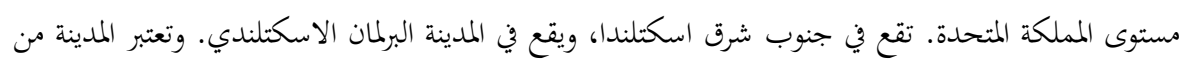

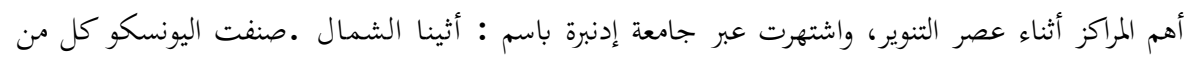

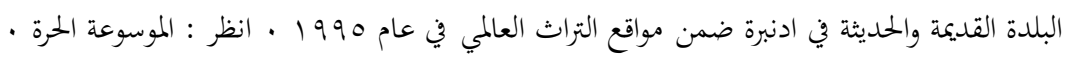

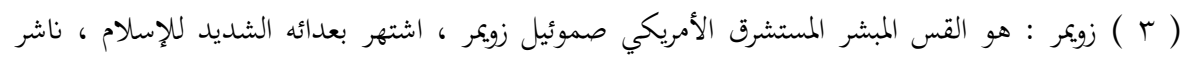

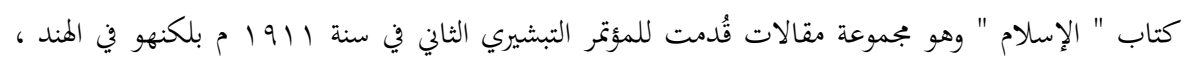

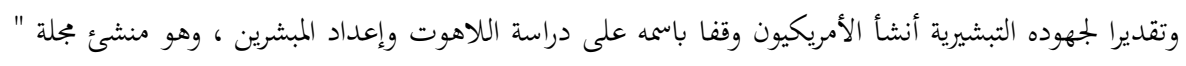

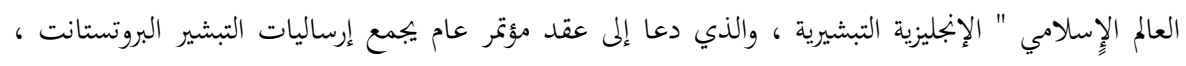

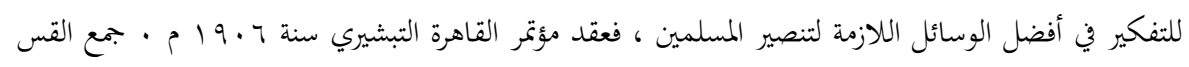

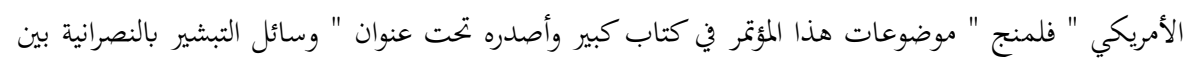

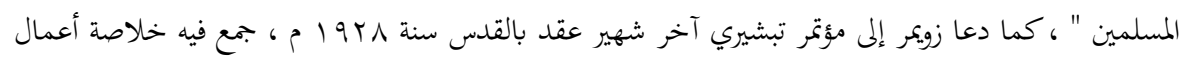

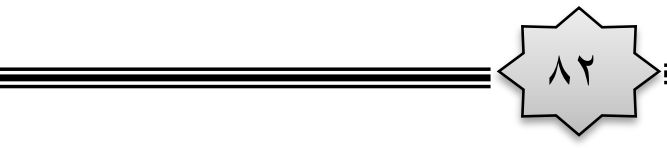


التتصير في التمهيد لقوات الاحتلال ومساعدتها ، وأثاد بذكرهم ، ووجه

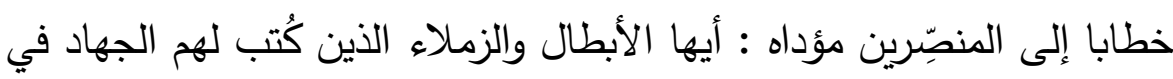
سبيل المسيحية واستعمارها لبلاد الإسلام ، فأحاطتهم عناية الرب بالتوفيق

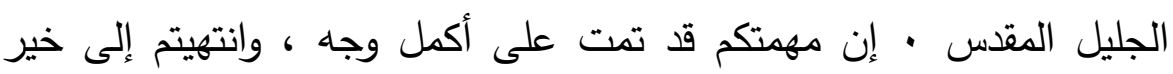
النتائج ، وباركتكم المسيحية ، ورضي عنكم الاستعمار ، فاستمِروا فقد

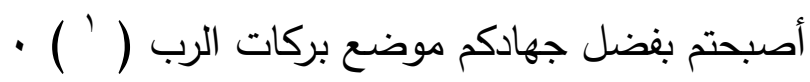

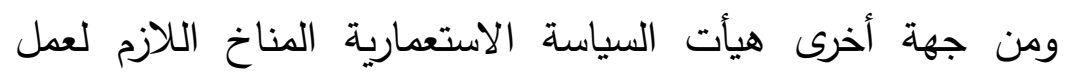
المبشرين في أرجاء العالم الإسلامي وخاصة أيام الاحتلال ، إذ كانت الدول الاستعمارية تبسط حمايتها على مبشريها في بلاد الشرق ، لأنها تَعدُّهم حملة الإديأ

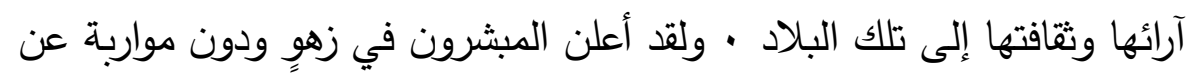
هذه الامتيازات والحمايات التي أفسحت لهم المجال للتبشير بين المسلمين : يقول أحد القساوسة اليسوعيين في معرض حديثه عن سياسة فرنسا الدينية في الشرق الأوسط : إن الحروب الصليبية الهادئة التي بدأها مبشرون في القرن السابع عشر الميلادي ، لا تزال مستمرة إلى أيامنا هذه ، ولقد احتفظت فرنسا طويلا بروح الحروب الصليبية ، والحنين إلى تلك الحروب

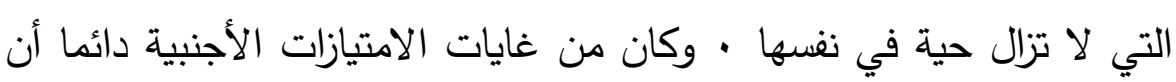
تحتفظ فرنسا بالدور الذي يلعبه رهبانها ، وقد اعتُرف لقناصلنا وسفرائنا

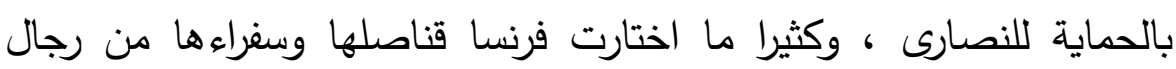
- الدين

ومن هنا فإن المبشرين قد نالوا الدعم المادي والمعنوي من السياسة

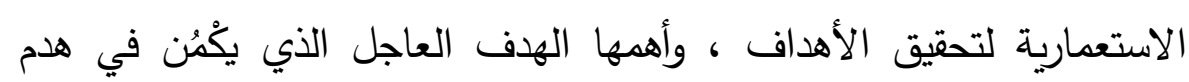

المبشرين في العالم الإسلامي · انظر : حقيقة التبشير بين الماضي والحاضر : اللواء أحمد عبد الوهاب ، ص 101 المابر

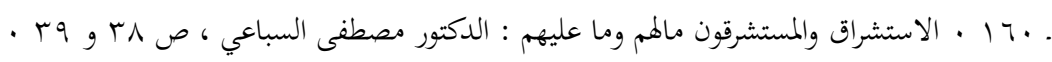

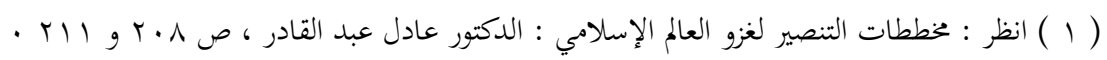

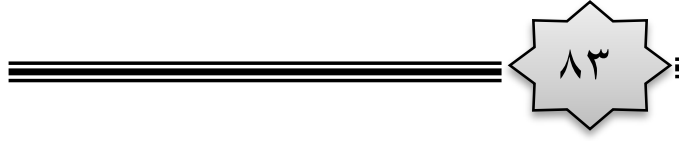


الإسلام في قلوب المسلمين ، وإضعاف تلك الصلة التي تربط المسلم بهذا الدين ، وهذا ما أعلنه المبشرون في تحدٍ صارخ ومواجهة مستكبرة ، التبشير يمثل الركيزة الصلبة التي يعتمد عليها الاستعمار في بسط نفوذه

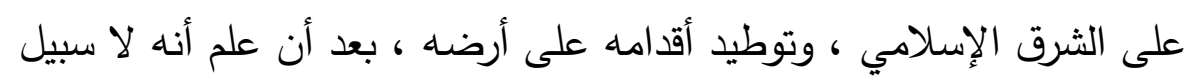

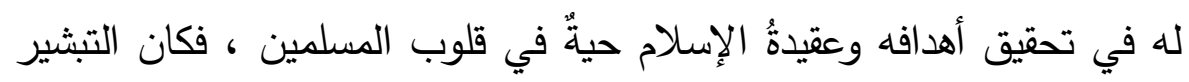

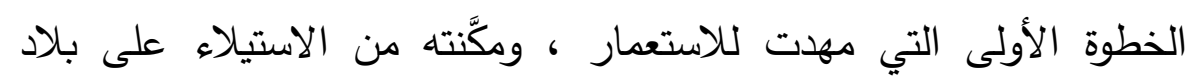

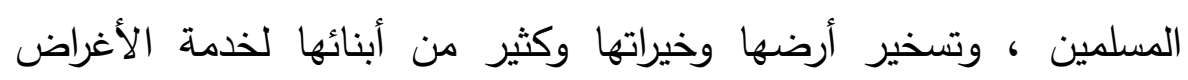
- الاستعمارية

والاستعمار لم يمانع في استغلال الكنيسة لتحقيق مآربه ، والكنيسة

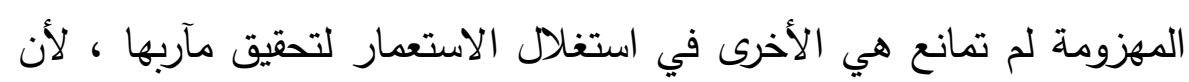

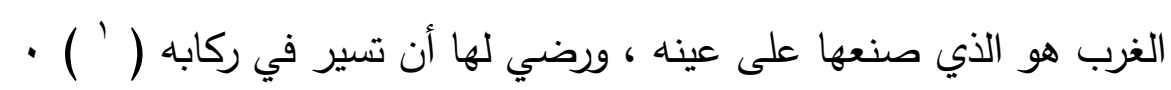
ويعجب الباحث عندما يرى الكنيسة وكبار رجالها يتناسون مبادئ المسيحية الأصلية ، ويُجنِّون أنفسهم لخدمة الاستعمار وتحقيق أهدافه ، لكن ئن الواقع أن الاستعمار تحالف مع الاستشراق والتبشير ، للوصول إلى أهدافه ،

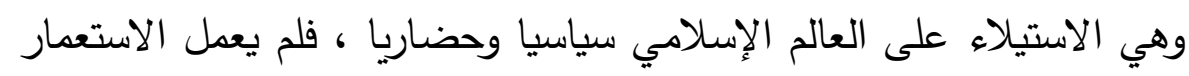

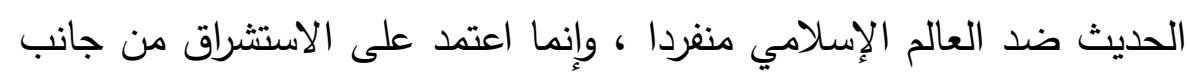
، وعلى التبشير من جانب آخر ، وقام هو بجهوده الخاصة من جانب ثالث .

$$
\begin{aligned}
& \text { ثالثا : صلة الاستشراق بالصهيونية : } \\
& \text { أ ـ تعريفت بالصهيونية : }
\end{aligned}
$$

الصهيونية حركة سياسية عنصرية متطرفة ، ترمي إلى إقامة دولة

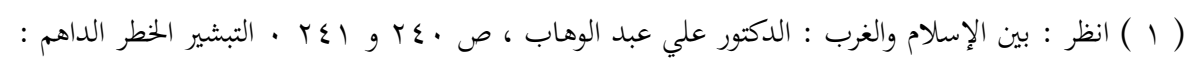

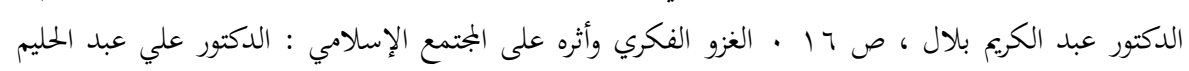

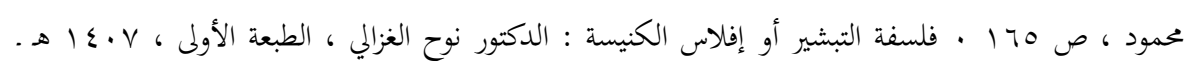
. r.人 gr.V ص. 19AV 
لليهود في فلسطين ، تحكم من خلالها العالم كله ، وتتخذ من الدين سبيلا

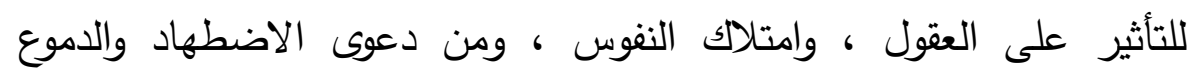
سراديب تسلكها إلى العطف العالمي ، شأن المذاهب الخبيثة التي تعطف إليها القلوب بأساليب تبدو طاهرة بريئة ، ثم تتفلت في صمت إلى أغراضها المدمرة

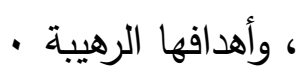

واشتُقت الصهيونية من اسم جبل في القدس ( ' ) يسمى " صهيون " ، حيث تطمع الصهيونية أن تثيد في هذا المكان الهيكل المزعوم ، وتقيم مملكة لها تكون القدس عاصمتها · وترتبط هذه الحركة بشخصية اليهودي النمساوي

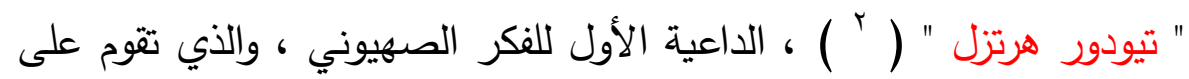
• آرائه الحركة الصهيونية في العالم لردن

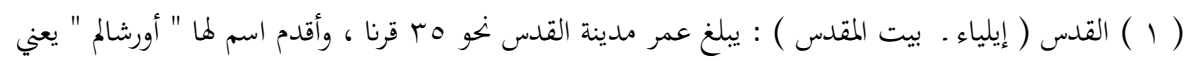

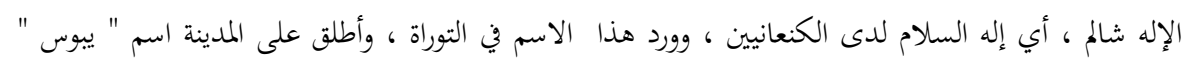

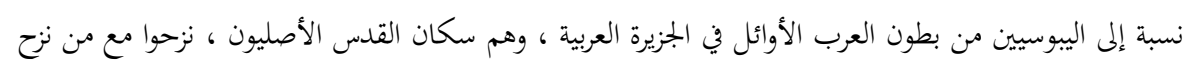

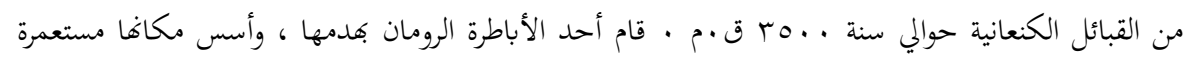

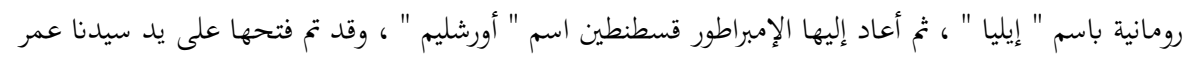

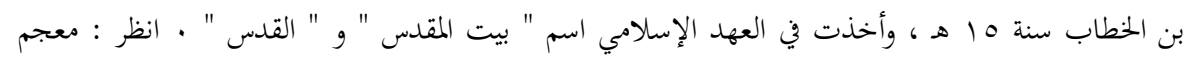

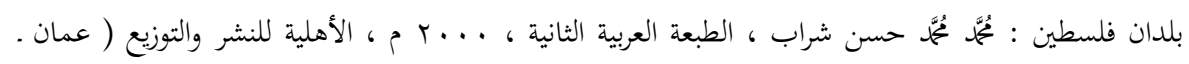

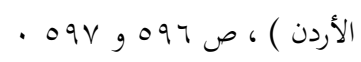

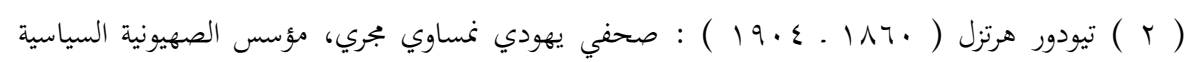

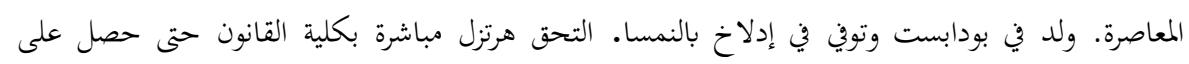

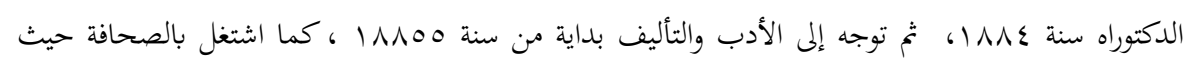

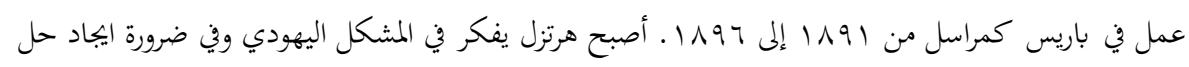

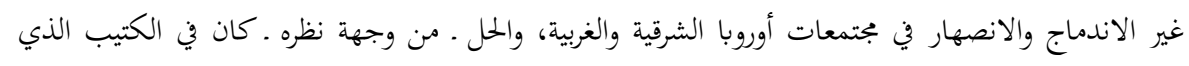

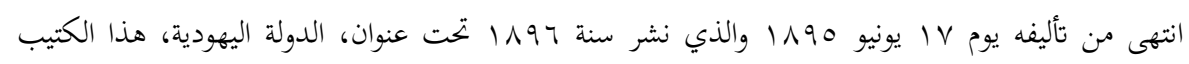

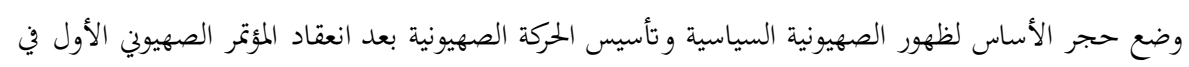

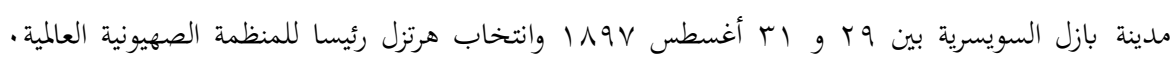
انظر : الموسوعة الحرة .

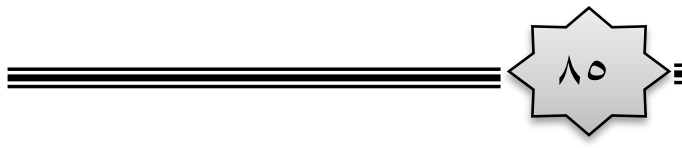


والصهيونية قديمة قدم التوراة نفسها ، وهي التي أججت الروح القومية عند اليهود منذ أيامها الأولى ، وحركة " هرتزل " إنما هي تجديد وتتظيم للصهيونية القديمة، التي قامت واستمدت فكرها ومعتقداتها من تعاليم التوراة المحرفة والتلمود • فلمسهيونية جذور تاريخية قديمة وحركات تبنَّت أفكارها وسياستها

منها : حركة " المكابيين " (') التي أعقبت العودة من السبي البابلي ( ج^ه . . ماه ق م ) ، وأول أهدافها العودة إلى صهيون وبناء الهيكل • حركة هذا

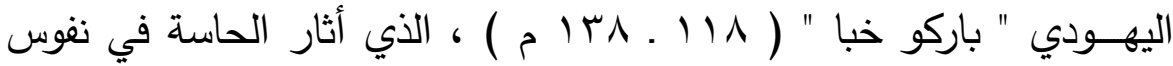
اليهود ، وحثَّهم على التجمع في فلسطين وتأسيس دولة يهودية فيها حركة

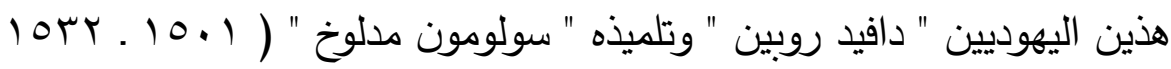
م ) ، اللذين حثا اليهود على ضرورة العودة لتأسيس ملك إسرائيل في فلسطين • حركة صهيونية عنيفة قامت إثر مذابح اليهود في روسيا سنة رAN ا م ، وفي هذه الفترة ألَّف " هيكلر " الجرماني كتابا بعنوان " إرجاع اليهود إلى فلسطين حسب أقوال الأنبياء " . الحركة الصهيونية الحديثة المنسوبة إلى

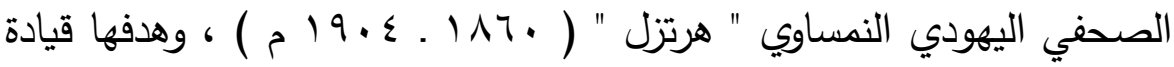
اليهود إلى حكم العالم ، بداية بإقامة دولة لهم في فلسطين ، ونجح في عقد أول مؤتمر صهيوني عالمي سنة IAVV م ، جمع فيه يهود العالم حوله ، وصدرت عنه أخطر قرارات في تاريخ العالم وهـي " بروتوكولات حكماء صهيون " ، المستمدة من كتب اليهود المحرفة التي يقدسونها .

( ) ( المكابيون : هي حركة سياسية دينية يهودية ، قادها في القرن الثاني قبل الميلاد

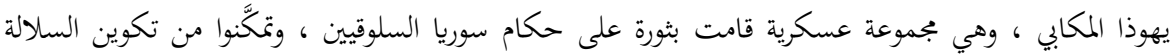

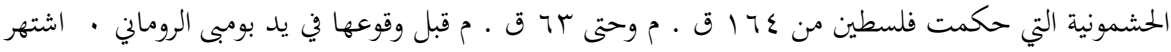

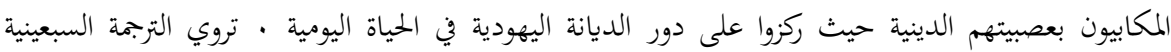

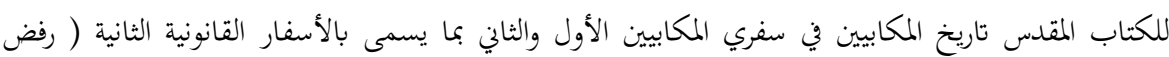
اعتمادها معظم اليهود وجميع البروتستانت) · انظر : الموسوعة الحرة •

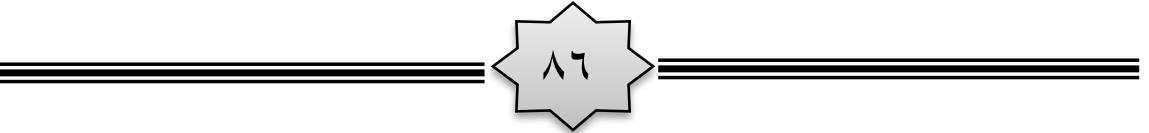


ومن أفكار ومعتقدات هذه الحركة : تعتبر الصهيونية جميع يهود العالم أعضاء في جنسية واحدة هي الجنسية الإسرائيلية ، وهم العنصر الممتاز الذي يجب أن يسود ، وكل الثعوب الأخرى خدم لله ، تهدف الصهيونية إلى سيطرة اليهود على العالم كما دعاهم إلههم يهوه ، وتعتبر المنطلق لذلك هو إقامة حكومتهم على أرض الميعاد ، التي تمتذ من نهر

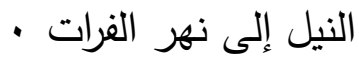

ومن وسائلهم للوصول إلى هدفهم : إغراق الأممين في الرذائل واستخدام الرشوة والخديعة والخيانة ، والمناداة بشعارات " الحرية والمساواة والإخاء " ، لينخدع بها الناس ، وينساقوا وراء ما يريدون ، والسيطرة على المال والإعلام ، تلك القوة الفعالة التي تُوجّه العالم نحو ما يريدون ، وكذلك السيطرة على الحكَّام ، وتوسيع الثقة بينهم وبين شعوبهم ، وافتعال الأزمات الاقتصادية ، والسيطرة على الصناعة والتجارة وكل دور النشر ،والإكثار من

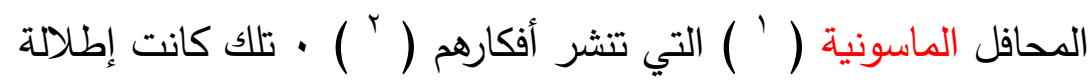

( 1 ( الماسونية : أخطر الجمعيات السرية في العالم ، ويطلقون عليها " البناءون الأحرار " ، ولا أعرف جمعية

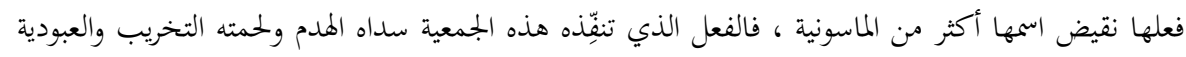

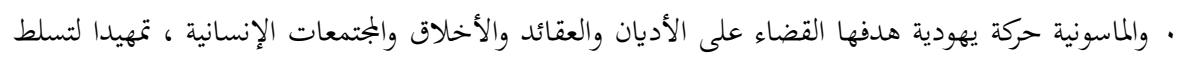

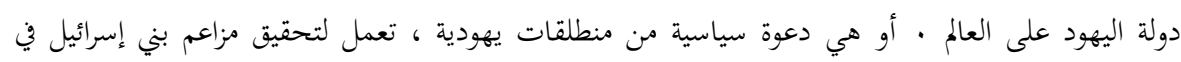

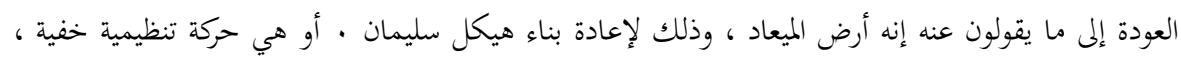

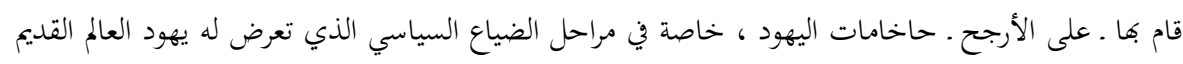

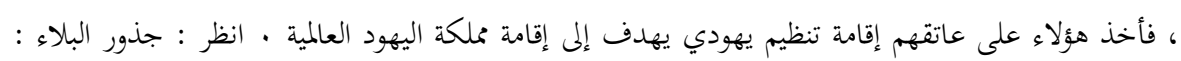

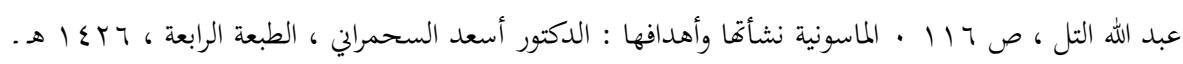

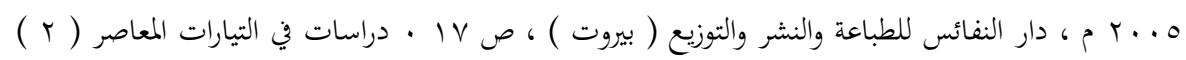

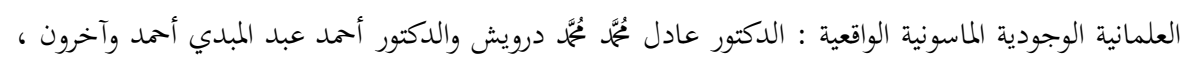
. $9 \cdot, \wedge 90$

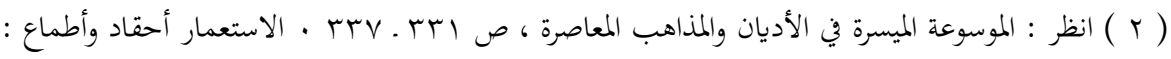

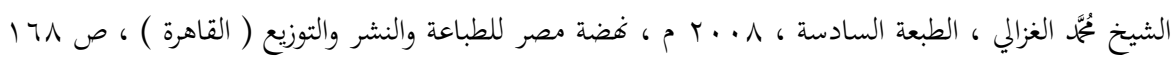

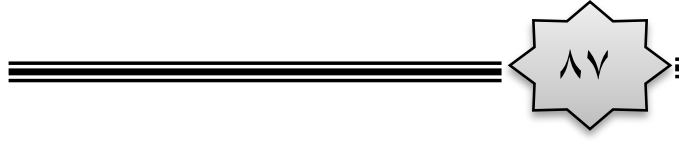


خاطفة على تعريف الصهيونية ، وجذورها التاريخية ، وأهم رجالاتها وأفكارها ب . صلة الصهيونية بالاستشراق :

لليهود والصهيونية العالمية أصابع وبصمات واضحة في مجال الاستشراق والتبشير ، هذين السلاحين الجبَّرين اللذين وُجِها ضد الإسلام والمسلمين في القرنين التاسع عشر والعشرين فين ولقد بدأت علاقة اليهود الصهاينة بالاستشراق منذ مولده في بلاد الأندلس ، حيث اطمأن اليهود إلى تسامح الحكام المسلمين بعد اضطهاد عنيف لهح ، فأقبلوا على اللغة العربية قواعد ومغردات وعروضا ، ينحون نحوها ويوازنون بها لغتهم لتحقيق تطورها التاريخي ، ويفيدون من علم الكلام في إرساء الدراسات التلمودية . والظاهر أن المستشرقين اليهود أقبلوا على الاستشراق لأسباب دينية ، وهي محاولة إضعاف الإسلام والتشكيك في قيمه بإثبات فضل اليهودية على

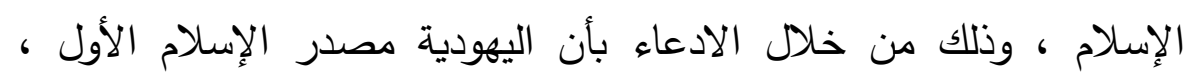
ولأسباب علمية تبغي إقناع غيرهم بإسقاط الأمة العربية من مكانها التاريخي

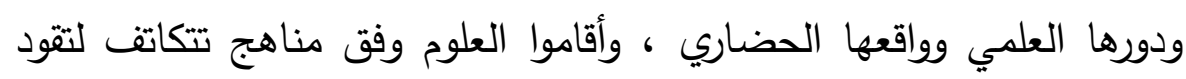

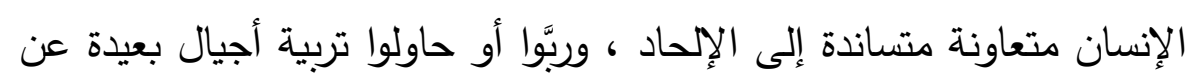
الإيمان ، ولأسباب سياسية تتصل بخدمة الصهيونية فكرة أولا ثم دولة ثانيا .

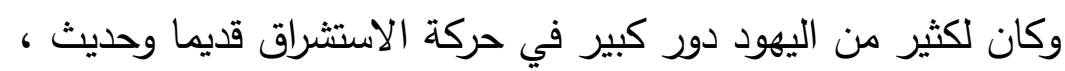
وليس من قبيل المصادفة أن يكون أكبر المستشرقين منذ أوائل القرن التاسع

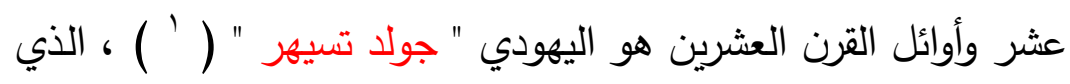
• المعجم الوسيط : بجمع اللغة العربية ، ج اص ص\&ه .

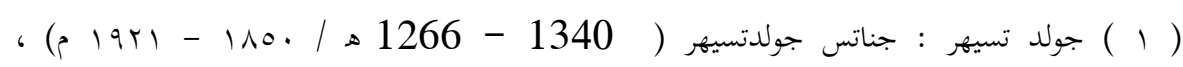

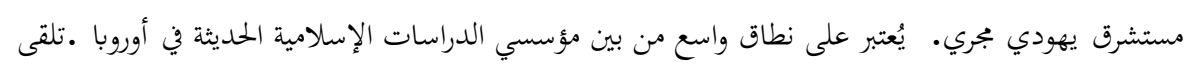

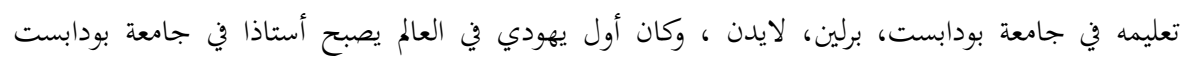

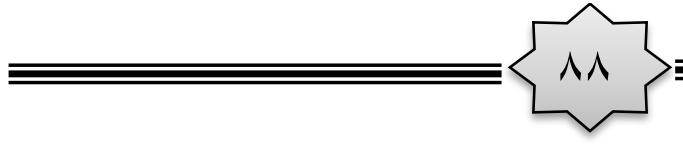


كرَّس حياته للطعن على الإسلام ونبيه وقرآنه ، بأسلوب تتبعث منه

أحقاد اليهود ومكرهم وخبثه * · مالمستشرق اليهودي العالمي " بروكلمان )

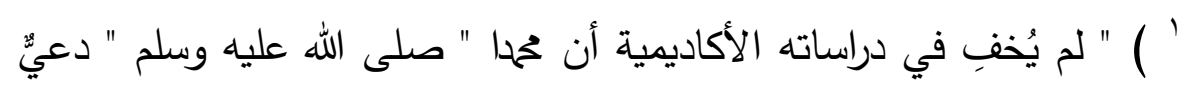
وليس بنبي ، وأن ما دعا إليه مقتبس من الأنبياء السابقين وعادات الأمم ، ويخرج بنتيجة هي أن حمدا " صلى الله عليه وسلم " لم يكن إلا شخصا عاديا ، وأن دينه لم يقم إلا بحد السيف · وكذلك يفعل المستثرق اليهودي " صدوئيل

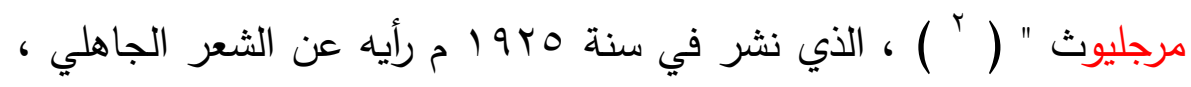

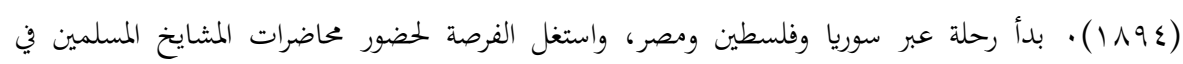

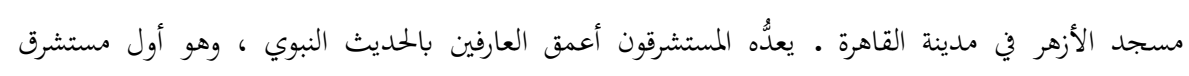
بمحاولة واسعة شاملة للتشكيك في الحديث النبوي ، حيث الَّف الكتب وكتب المقالات بهدف الطعن في السنة

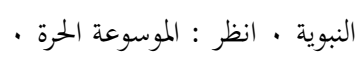

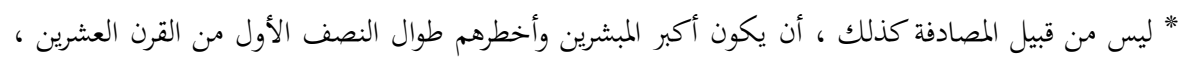

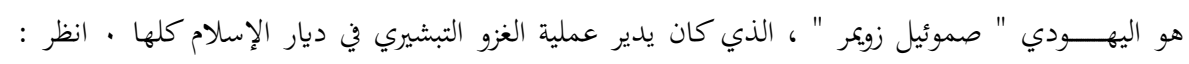

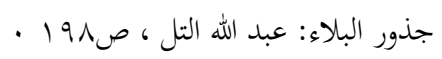

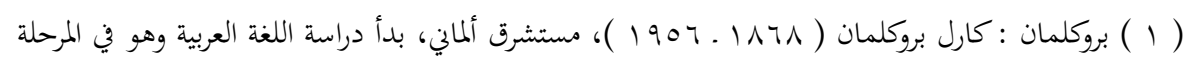

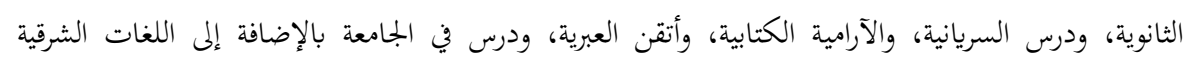

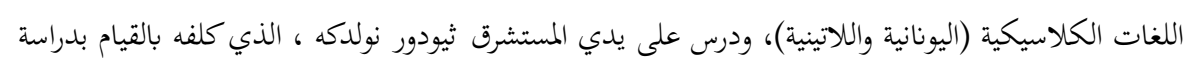

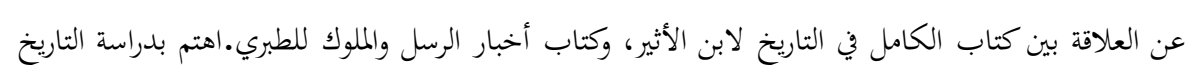
الإسلامي وله في هذا المجال كتاب مشهور (تاريخ الشعوب الإسلامية)، نقله إلى العربية نبيه أمين فارس ومنير

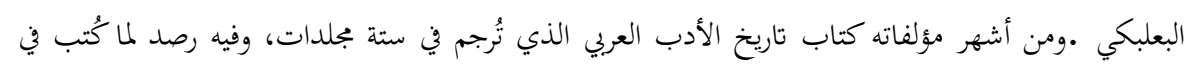

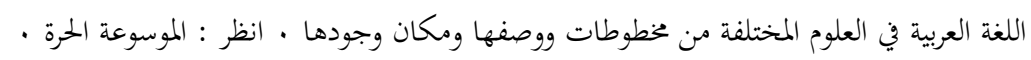

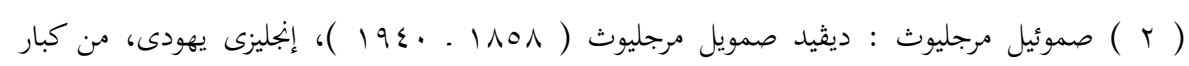

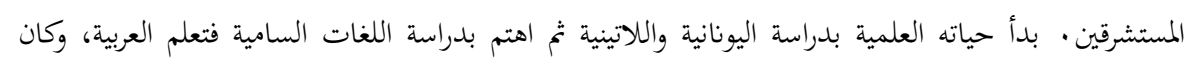

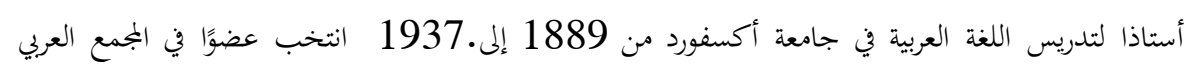

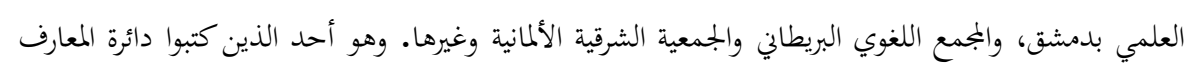

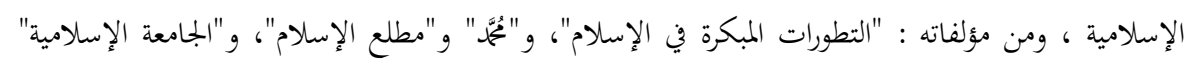

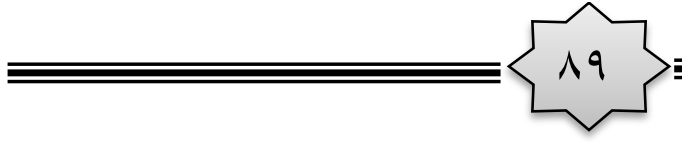


والتشكيك في مصادره ، وخرج برأي يشكك في إعجاز القرآن الكريم · ولا يقل

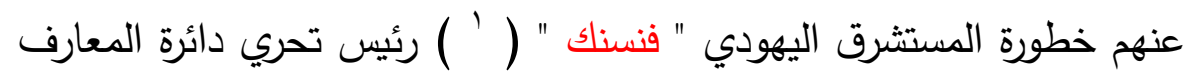
الإسلامية ، التي وُضعت بأقلام المستشرقين اليهود والمبشرين من أصل

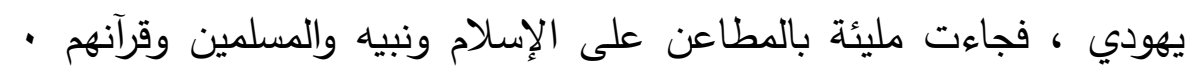

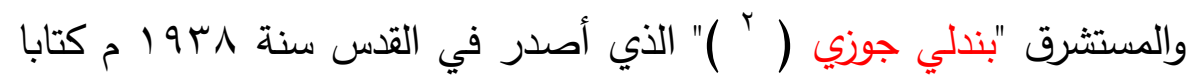
بعنوان "الحركات الفكرية في الإسـلام" ، ويمكن اعتبار هذا الكتاب أحدي

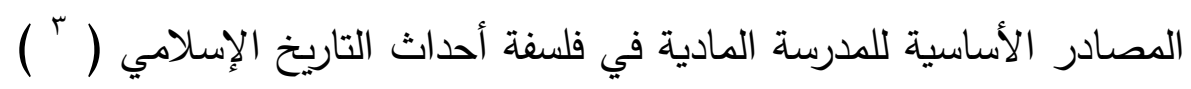
وعَمَلُ الكثير من اليهود في مجال الاستشراق ، إنما كان الهدف منه تحقيق

وكتابه عن الإسلام، والعلاقات بين العرب واليهود. ولكن هذه الكتابات اتسمت بالتعصب والتحيز وعدم

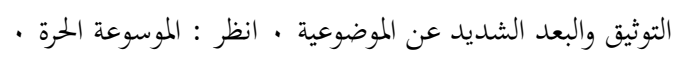

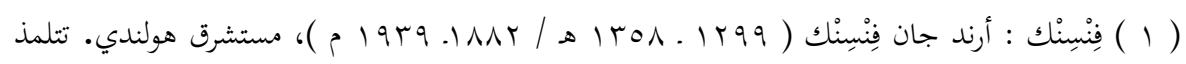

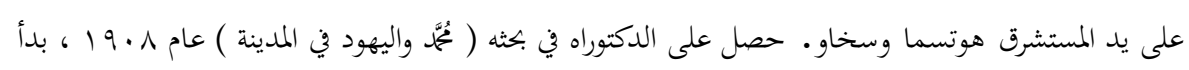
في عمل معجم مفهرس لألفاظ الحديث الشريف مستعيناً بعدد كبير من الباحثين وتمويل من أكاديمية العلوم في

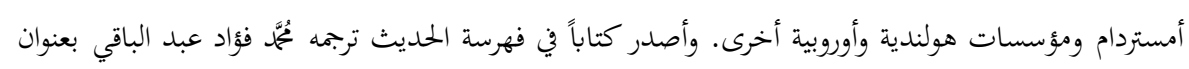

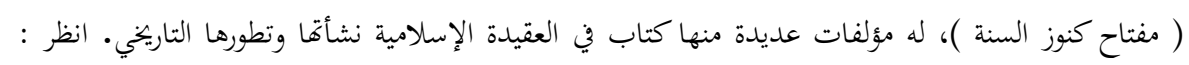

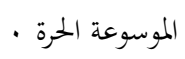

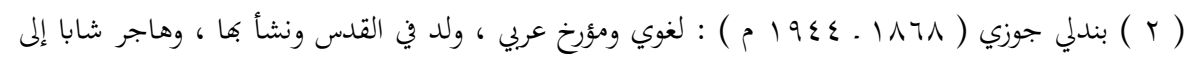

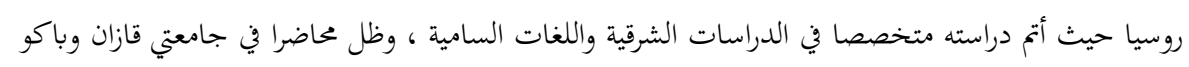

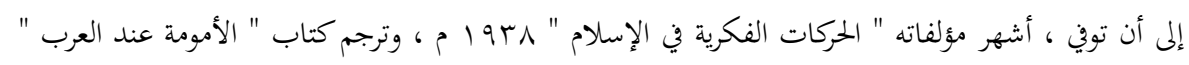

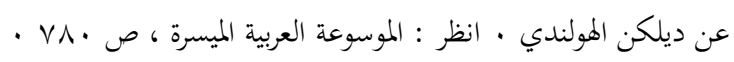

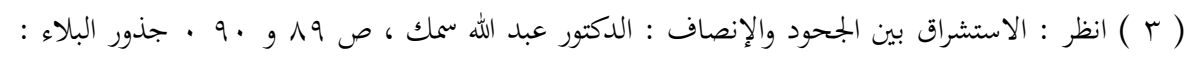

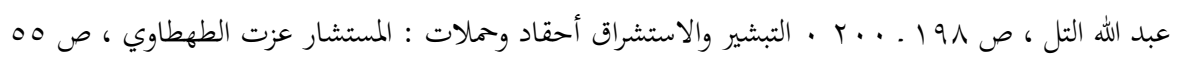

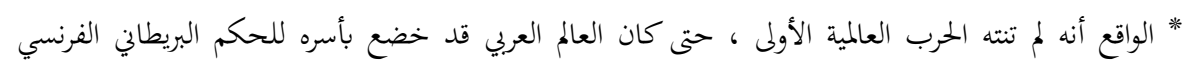

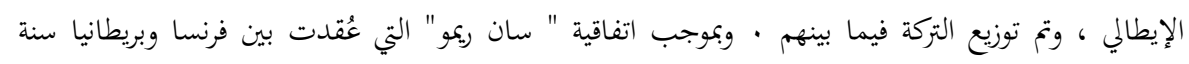

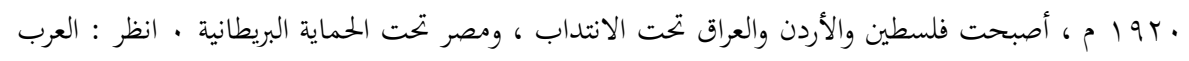

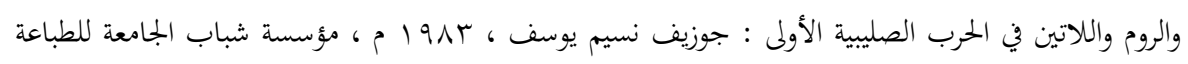

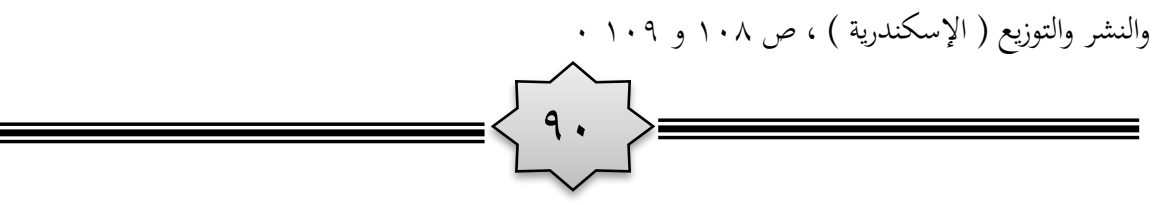


أحلامهم في إقامة دولتهم الصهيونية المزعومة من النيل إلى الفرات .

\section{ج · صلة الصهيونية بالتبشير :}

لقد أثبت التاريخ والواقع والأحداث التي كان مسرحها العالم العربي منذ القدم حتى يومنا هذا ، أن كلا من الحركة الصليبية والحركة الصهيونية في فلسطين ، إنما تُمثِلّ حلقة من حلقات الاستعمار الذي تعرضت لـه اله المنطقة العربية على مر العصور · وكانت التجربة الأولى هي التجربة الصليبية ، والتجربة الثانية هي التجربة الصهيونية ، وهذه حقيقة كثفت عنها البحوث - التاريخية

فالغربيون لم يتخلوا إطلاقا عن أطماعهم ، بل كانوا يتحينون الفرص والظروف المواتية لنشب أظفارهم من جديد في البلدان العربية ، والحلم القديم من أجل غزو فلسطين وتفتيت وحدة العرب ، ظل مطويا منذ الحروب

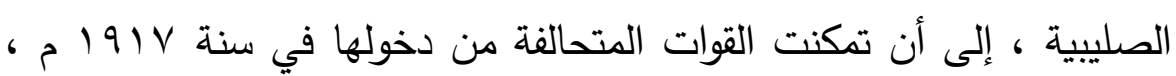
تلك السنة التي امتازت بوعد بلفور المشئوم بإنشاء وطن قومي لليهود في فلسطين ، فأحيت تلك القوات بذلك الروح الصليبية القديمة ولكن في ثوب جديد *

ولا نجافي الحق إذا قلنا إن إنشاء وطن قومي لليهود في فلسطين ،

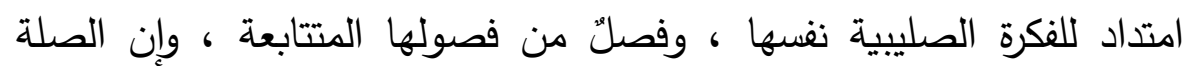
وثيقة بين الحركة الصليبية التي قامت منذ حوالي تسعمائة عام ، والاستعمار

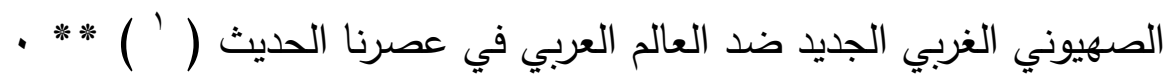

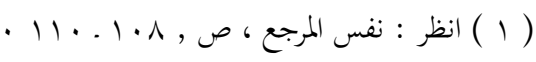

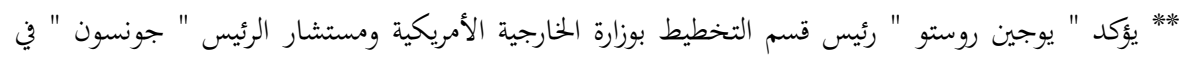

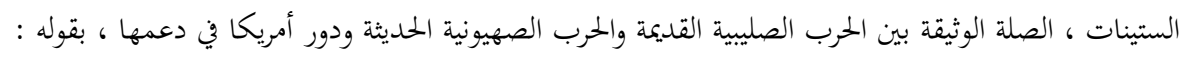
" لا تستطيع أمريكا إلا أن تقف في الصف المعادي للإسلام ، أي إلى جانب العالم الغربي والدولة الصهيونية ،

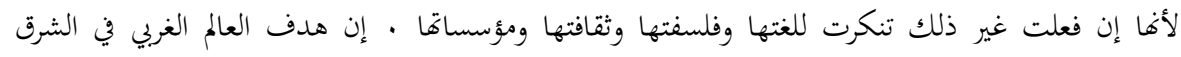

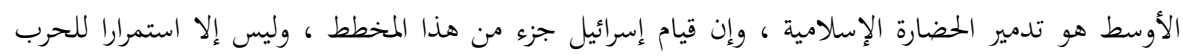

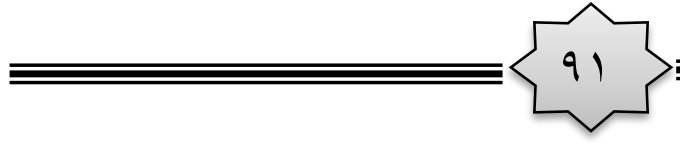


والصلة بين الصهيونية اليهودية والتبشير المسيحي وثيقة وقديمة ، ومنذ ظهور حركة الإصلاح الديني في القرن السادس عشر استطاعت الفكرة

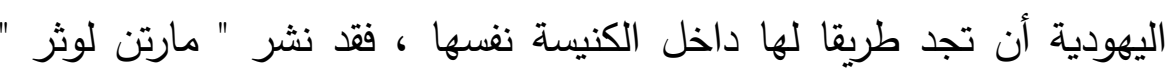
زعيم حركة الإصلاح الديني ، ورائد المذهب البروتستانتي كتابا في عام بror م باسم " عيسى ولد يهوديا " ، قال فيه : إن الروح القدس أنزل كل أسفار الكتاب المقد عن طريق اليهود وحدهم ، وإن اليهود هم أبناء الله ،

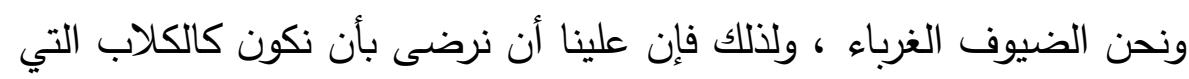

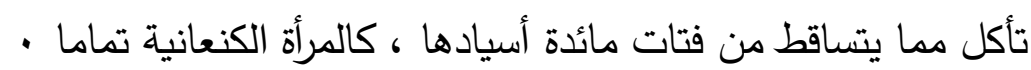
والأدبيات اليهودية التي تسربت إلى صميم العقيدة النصرانية آنذاك تدور حول أمور ثلاثة : الأول : أن اليهود هم شعب الله المختار ، الثاني الثي : أن

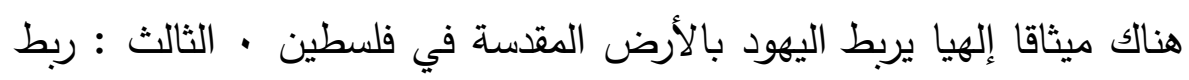

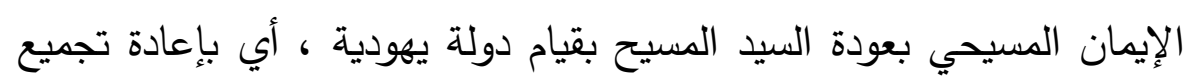
اليهود في فلسطين حتى يظهر المسيح فيهم · هذه المعتقدات الدينية المسيحية أصبحت جزءا من عقيدة الكنيسة البروتستانتية ومن جوهر طقوسها • ونجح اليهود في إقناع المسيحيين بأنهم أقرب الناس إليهم ، وتم الاتفاق على ضم التوراة إلى الإنجيل ، ويسمى الاثنان بالكتاب المقدس ، وبذلك أفلح

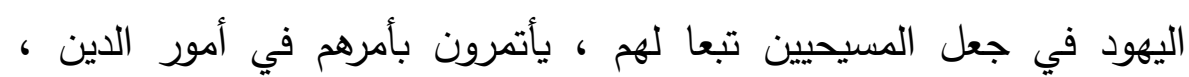
فتسلطوا عليهم في أمور الدنيا - جعائ. وكان أول تحالف رسمي بين اليهود والمسيحيين سنة 10.0 م ، وذلك بهدف القضاء على الكيان الإسلامي العدو المشترك لهما ، فقد كتب اليهودي " دافيد روبنس " مشروعا وقدمه إلى البابا ، فحواه : احتلال العالم الإسلامي ، وانتزاع الأرض المقدسة من المسلمين ، واحتلال اليهود لفلسطين

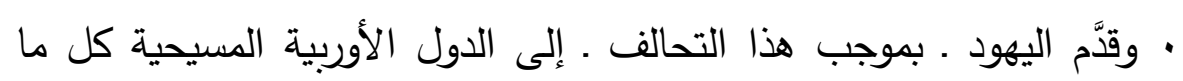

الصليبية " • انظر : الغزو الثقافي يمتد في فراغنا : الشيخ مُحّم الغزالي ، ص كع .

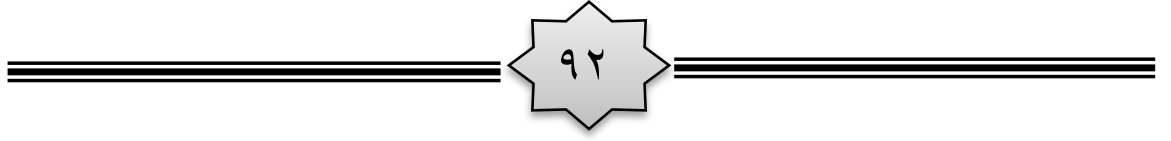


عرفوه عن المسلمين من مواطن القوة والضعف ، فسهل على الدول الأوربية بذلك ابتلاع الدول الإسلامية دولة بعد دولة .

ولا يفوتني بهذه المناسبة ، أن أذكر ما جرى في الفلبين ( ' ') من إبادة جماعية للمسلمين ، بفعل تحالف إسرائيلي مسيحي جمعته أهداف واحدة لإبادة المسلمين في تلك البلاد :

فلقد زارت " جولا مائير " ( ( ) ) جزر الفلبين سنة ع 19 ا م بوصفها وزيرة لخارجية إسرائيل ، واجتمعت بزعماء الفلبين المسيحيين ، وانتهت معهم إلى اتفاق موجز ، نصوصسه ما يلي : تقوم إسرائيل بمساعدة الفلبين بمعونات مادية ومعنوية ، وفي مقابل ذلك يعمل المسيحيون بكل طاقاتهم على امتلاكى الأراضي الإسلامية في جنوب البلاد ، والتي يغلب فيها العنصر الإسلامي ،

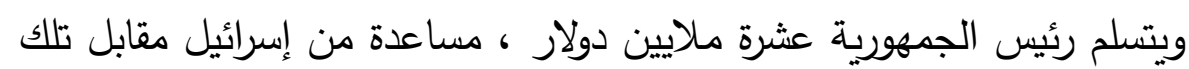

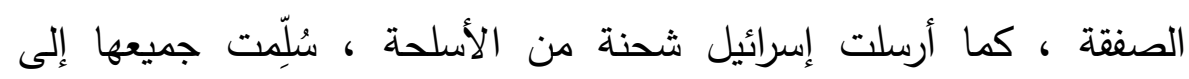
عصابة " إبلاجوس " التي تمارس قتل المسلمين بالجملة وتشريدهم ،

( 1 ) الفلبين : جمهورية الفلبين جمهورية دستورية تقع في جنوب شرق آسيا غرب الخيط الهادي .عبارة

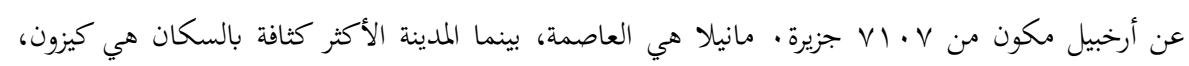

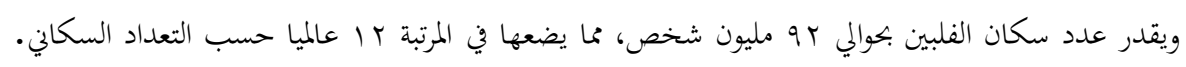

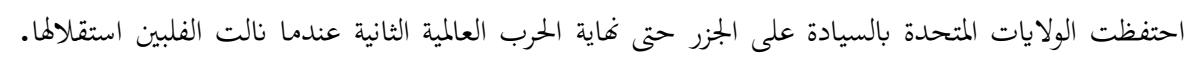

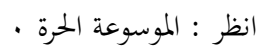

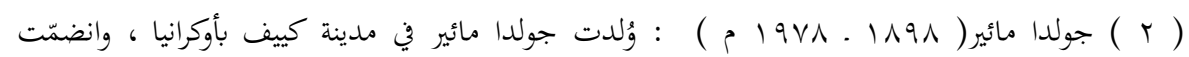

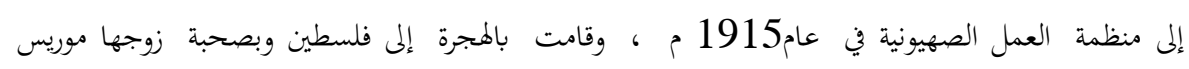

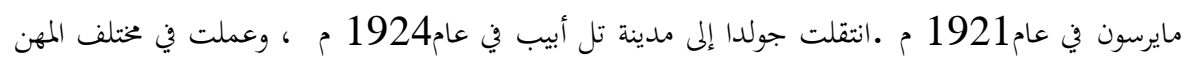

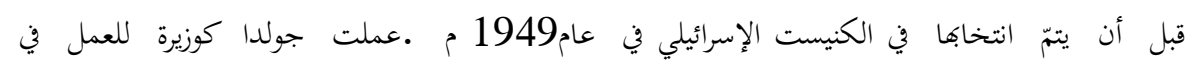

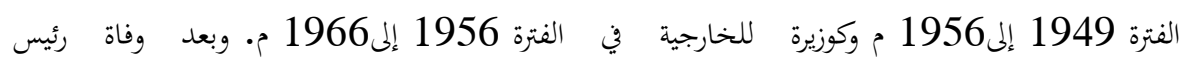

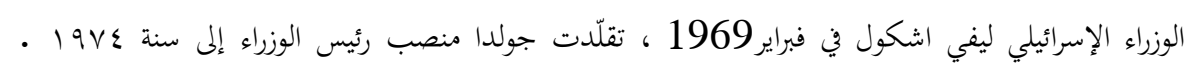

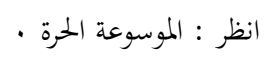

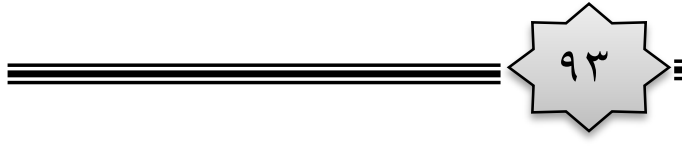


وكما حقق اليهود هدفهم الأكبر وهو الاستيلاء على فلسطين ، كان

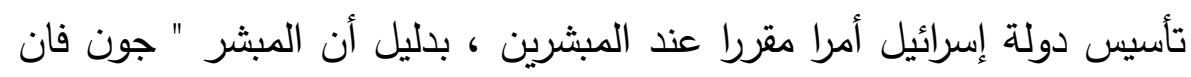

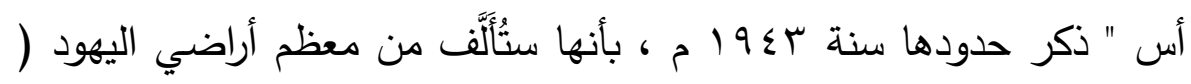

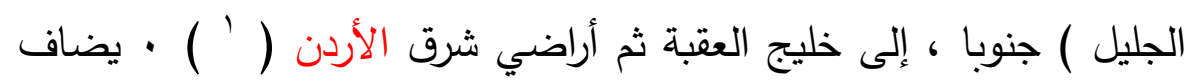

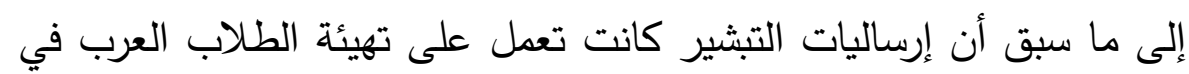

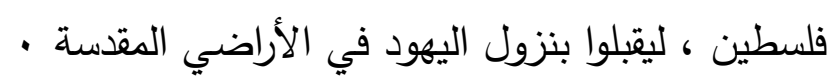
وقد أقر اليهود الصهاينة بفضل المبشرين والصليبيين ، فها هي " بربارة

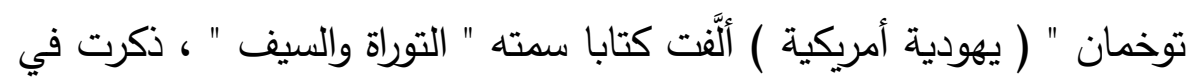

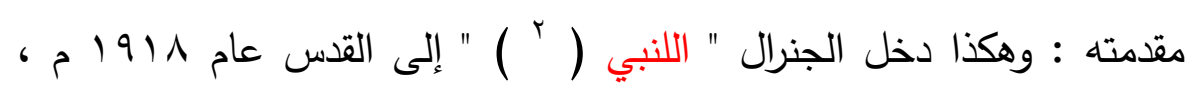
فنجح حيث كان " ريتشارد " قلب الأسد قد أخفق ، ولولا الانتصار من جانب إن وهن اللورد " اللنبي " ، لما كانت إعادة إسرائيل الآن ، وكذلك لم يكن بإمكان اللورد

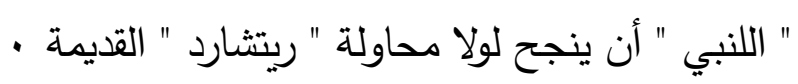
وحقد المبشرين على الإسلام ، دفع بهم إلى التجسس خدمة لإسرائيل ،

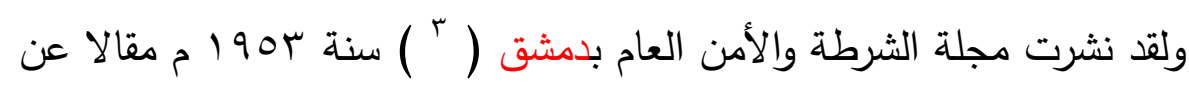

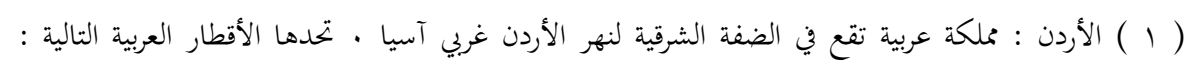

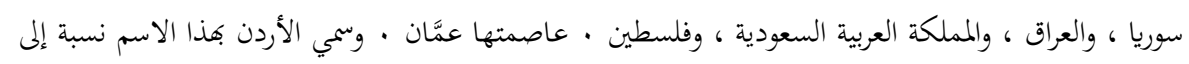

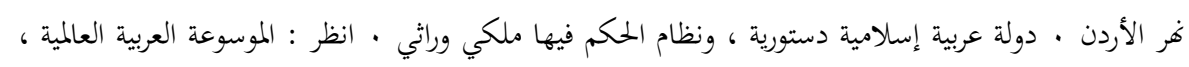

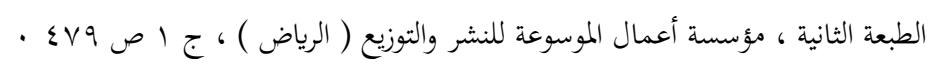

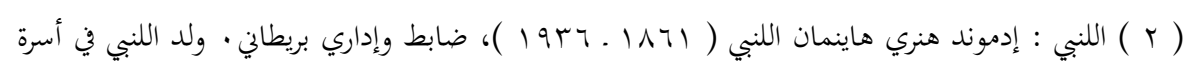
لها قدر من الثراء ذات ارتباط بالكنيسة الإنجيلية الشرقية ، وتخرج من الكلية العسكرية الملكية في ساندهيرست 1881 ، ثم التحق بعد ذلك بكلية الأركان في كامبرلي بانجلترا، واشتهر بدوره في الحرب العالمية

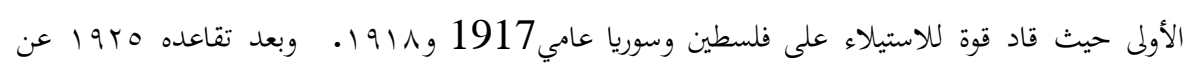

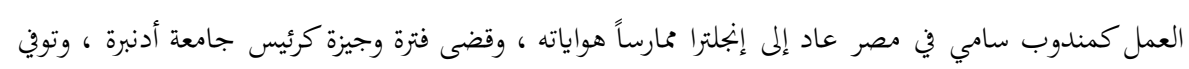

$$
\text { في } 14 \text { مايو } 1936 \text { عن عمر يناهز Vo سنة · انظر : الموسوعة الحرة . }
$$

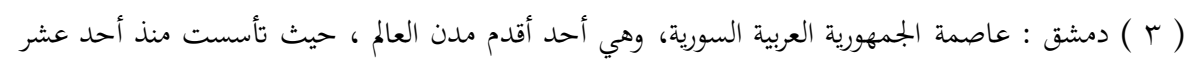

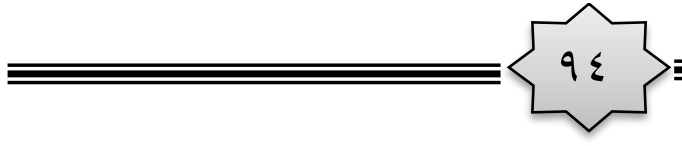


داعية ومبشر أمريكي ، اسمه " والف باني " يَدَّعي أنه يدير جمعية للتقارب

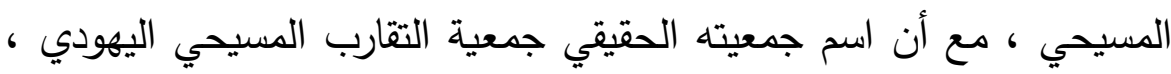
ويعمل على مساعدة اليهود والدسّ على العرب ، والتجسس عليهم وتثويها

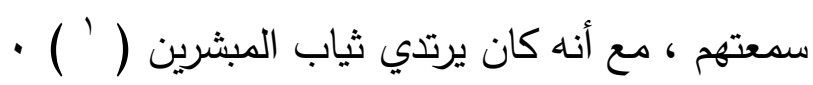
فإذا كان اليهود قد تمكنوا ـ. من خلال غزو الفكر المسيحي في الماضي . من العمل على إيجاد رؤى وأفكار تدعم هدفهم من منطلق ديني بحت ، فإن الحركة الاستشراقية منذ القرن الثامن عشر الميلادي كانت مجالا رحسبا

نفذ اليهود من خلاله بآراء تؤكد أحقية إسرائيل في البقاء في فلسطين

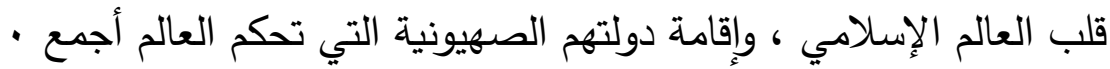
رابعا : صلة الاستشراق بالتغريب : أ ـ تعريف التغريب : أل

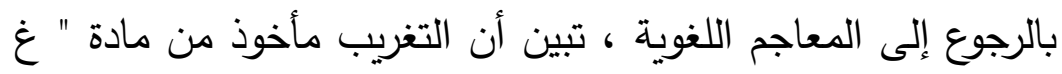
ر ب " ، وأفعالها في اللغة العربية تدور حول المعاني الآتية : غَرَب : غربت الثمس تغرب غروبا : غابت في المغرب ، وكذلك ألف عام تقريبًا، وأقدم مدينة عاصمة في العالم 0 أصبحت عاصمة منطقة سوريا منذ عام مباج م ـ تُعرف أيضًا بأسماء عديدة منها الشام ومدينة الياسمين؛ وقد احتلت مكانة إقليمية بارزة على صعيد الفنون،

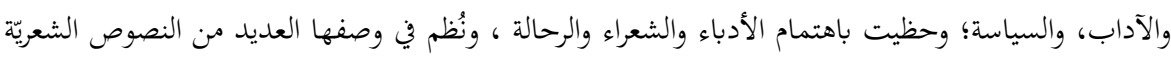
والأدبيّة، منها ما كتبه ياقوت الحموي : " ما وصفت الجنة بشيء ، إلا وفي دمشق مثله " • انظر : الموسوعة

( ) انظر : معركة التبشير والإسلام : حركات التبشير والإسلام في آسيا وأفريقيا وأوربا : الدكتور عبد الجليل

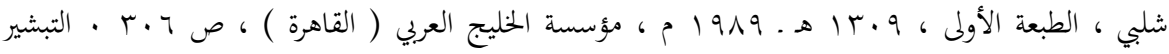

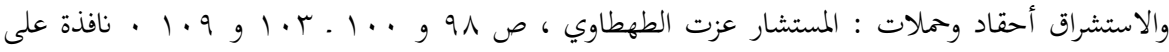

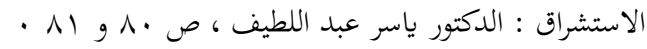

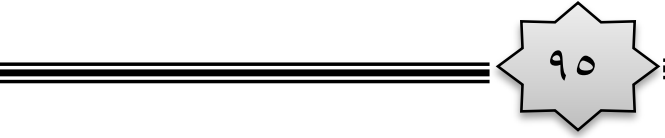


غرب النجم · غرب فلان : غاب · و . القومُ : ذهبوا · و . عنه : تنحَّى • و ـ فلانْ غربِا وغُربة : بَعُد عن وطنه · و ـ الكلامُ غرابة : غمض وخفي فهو

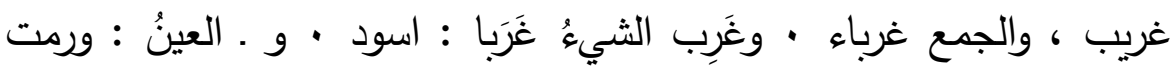
مآقيها

غَرَّب : غَرَّب القومُ : ذهبوا ناحية المغرب · و · في الأرض : أمعن فيها ، فسافر سفرا بعيدا · و . الكلابُ : أمعنت في طلب الصيد · • و ـ المرأةُ

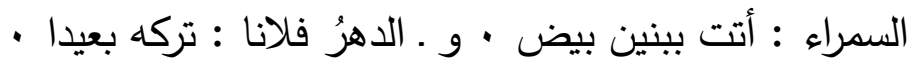

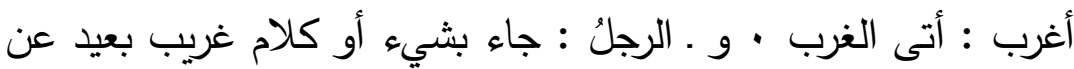

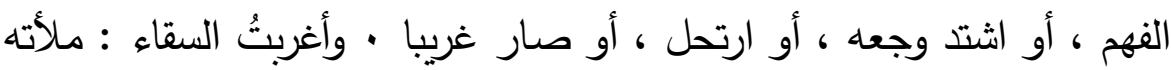

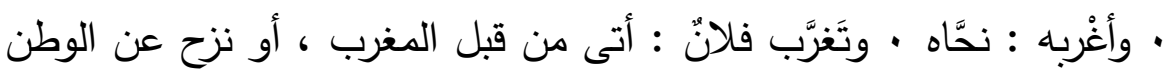
• واغترب الرجل : نكح في الغرائب ، وتزوج إلى غير أقاربه · واستغرب : أكثر من الضحك وبالغ فيه حتى تبدو غروب أسنانه · و . الدمعُ : سال · و و

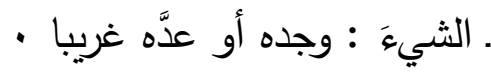

ومن معاني مشتقات هذه المادة في الأسماء : الغَرْب : خلاف الشرق

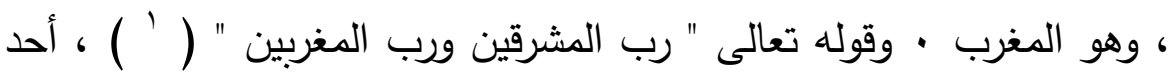
المغربين : ما تنتهي إليه الشمس في الصيف ، والآخر : أقصى ما تتتهي إليه في الشتاء • وقوله تعالى : " فلا أقسم برب المشارق والمغارب " ( ' ) ) معناه أنها تشرق كل يوم من موضع ، وتغرب في موضع ، إلى انتهاء السنة

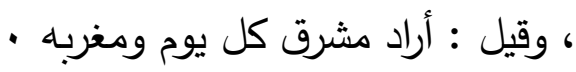

الغَرْب : جهة غروب الثمس ، والبلاد الواقعة فيه ، وهي ما تقابل بلاد الشرق · والذهاب والتتحي عن الناس · والنشاط والتمادي في الأمر · والحِدَّة من كل شيء · وفرس غَرْب : كثثر العَدْو · والغَرْب الذهاب والتتحي •

$$
\begin{aligned}
& \text { ( ) سورة الرمن : الآية VI ) }
\end{aligned}
$$

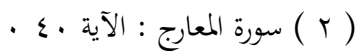


ويقال : أصابه سهم غَرْب : لا يدري راميه · والجمع غروب ، والغروب :

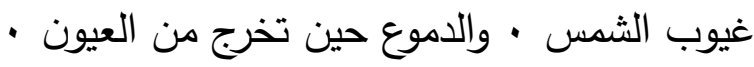

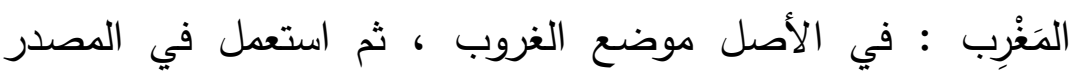
والزمان ، وقياسه الفتح ، ولكن استعمل بالكسر كالمشرق والمسجد · والمغرب

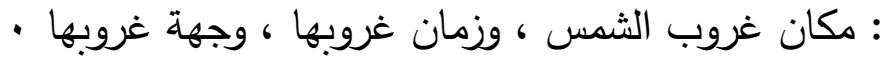

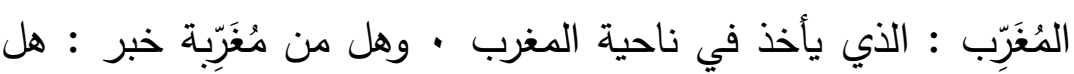
من خبر جديد جاء من بلد بعيد · والغَزْبة : البعد عن الوطن ، ومن هذا

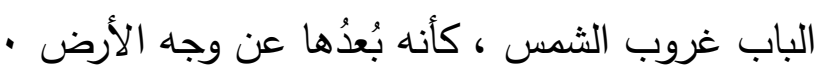

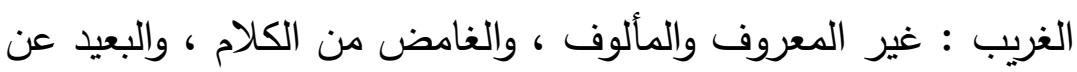
وطنه ، والرجل ليس من القوم ولا من البلد · والغُرْبة : النوى والبعد . والتغريب : البُعْد والنفي عن البلد ، وأن يأتي ببنين بيض وبنين سود .

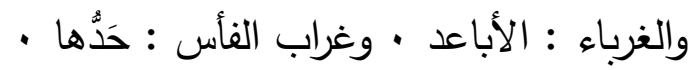

الغارب : ما بين العنق والسنام ، وهو الذي يلقي عليه خطام البعير إذا أرسل ليرعى حيث شاء ، ثم استعير للمرأة وجعل كناية عن طلاقها ، فقيل لها حبلك على غاربك ، أي اذهبي حيث شئت كما يذهب البعير · والغارب : أعلى كل شيء ، والكاهل · والإغراب : الإتيان بالغريب ، والمله ، وكثرة

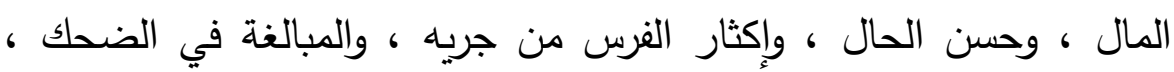
• والإمعان في البلاء وحنأ

الغَرَب : ضرب من الثجر تُسوَى منه السهام ، وداء يصيب الثاة

تتساقط منه شعر خطمها وعينها ، ويقال بعينيه غَرَب : إذا كانت تدمع ولا ينقطع دمعها · الغربيب : شديد السواد · الغربي : المنسوب إلى الغرب • وبلاد المغرب : البلاد الواقعة في شمال أفريقية وغرب مصر (') ، ') •

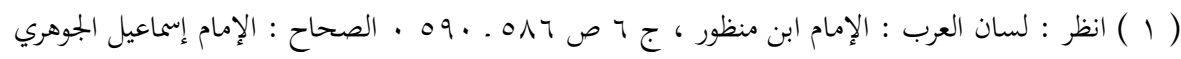

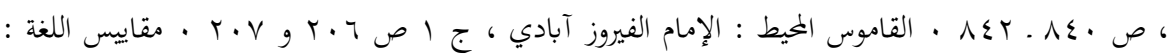
$\overline{\overline{ }}\{9 v\}$ 
فالتغريب في اللغة يدور حول المعاني الآتية : الغياب ، والذهاب ،

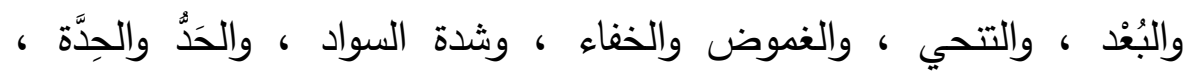
والمبالغة في الضحك ، وكثرة العَدْ ، وجريان الريق ، والامتلاء ، وزمان

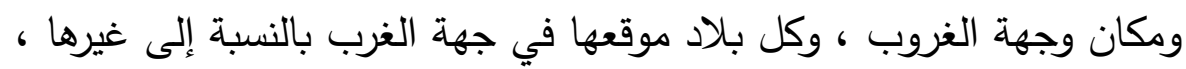

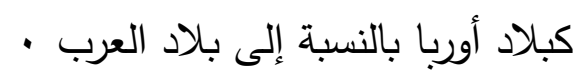

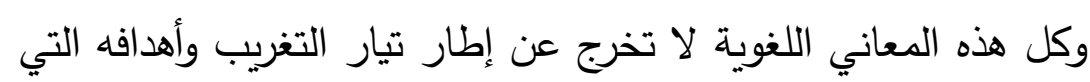

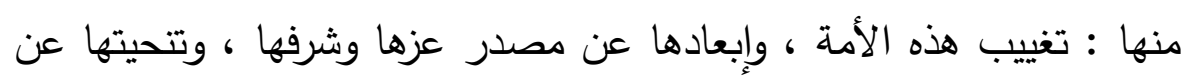

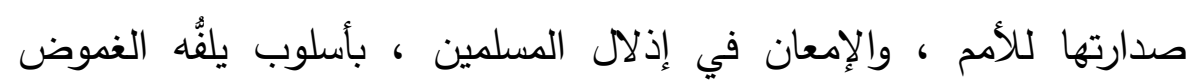
والسواد ، ويُكثر التغريب من العَدو نحو تحقيق هذا الهدف ، ويسيل لعابه ويبالغ في الضحك والسخرية عند تحققه ، وامتلاءِ الثرق الإسلامي بالثهوات

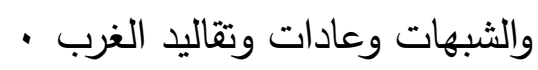
ولقد تعددت آراء الباحثين حول المفهوم العلمي لمصطلح التغريب ، وعاب ، منها :

ا ـ التغريب هو تيار كبير ذو أبعاد سياسية واجتماعية وثقافية وفنية ، يرمي إلى صبغ حياة الأمم عامة والمسلمين خاصة بالأسلوب الغربي ، وذلك

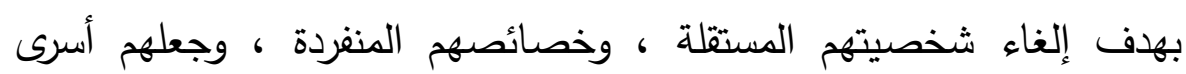
التبعية الكاملة للحضارة الغربية لُعاء r ـ التغريب هو محاولة طبع البلاد العربية بالقيم والعادات والتقاليد والحضارة الأوربية الغربية والأمريكية • أو هو محاول طبع المستعمرات

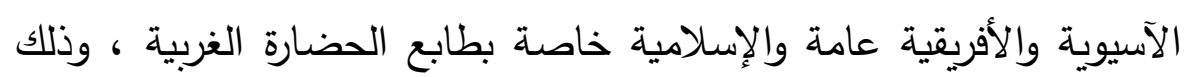

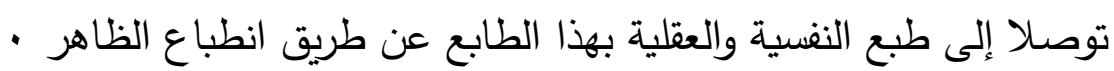

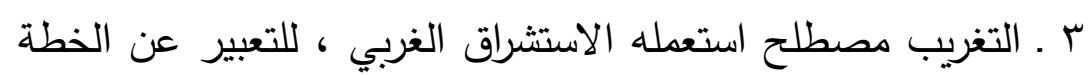

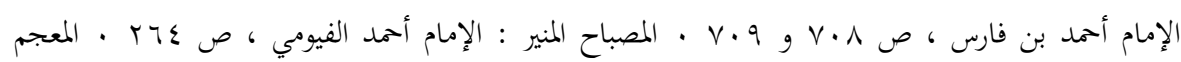

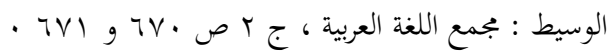


التي تقوم بها القوى ذات النفوذ السياسي الخارجي في حمل العالم الإسلامي على الانصهار في مفاهيم الغرب وحضارته ، والعمل على إخراج المسلمين مـن

هويتهم الإسلامية ، التي أقامها الإسلام من خلال مجتمعهم وكيانهر

ووجودهم السياسي والاقتصادي والاجتماعي ، وصهرهم في بوتقة الغرب • ع ـ التغريب هو حمل المسلمين والعرب على قبول ثقافة الغرب والخضوع لنفوذه وسلطانه ، وقبول الاحتواء في بوتقته ، بحيث لا يجد أية معارضة تحول دون غرس مبادئ التقبّلّ والولاء للغرب في نفوس المسلمين ، حتى يشُبُوا مستغربين في حياتهم وتفكيرهم ، وحتى تخف في أنفسهم موازين - القيم الإسلامية (') وخلاصة تعريف التغريب أنه طبع البلاد العربية والإسلامية بالقيم والعادات والتقاليد الأوربية ، وصبغ حياة المسلمين خاصة بالصبغة الغربية ، بقصد إبعاد المسلم عن تعاليم دينه ، المرتبطة بشئون حياته كلها -

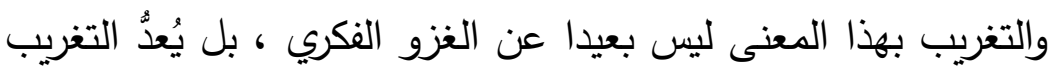

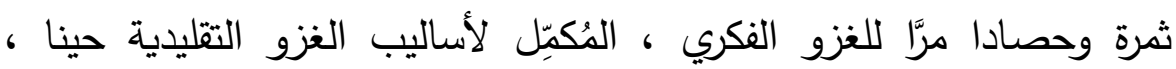

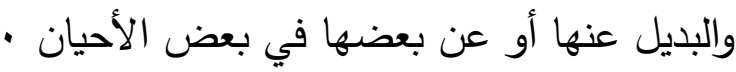

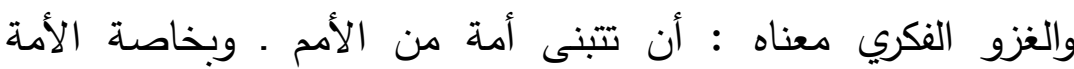

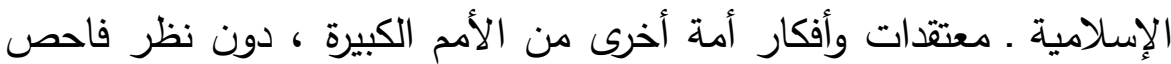
وتأمل دقيق لما يترتب على ذلك التبني من ضياعٍ لحاضر الأمة الإسلامية

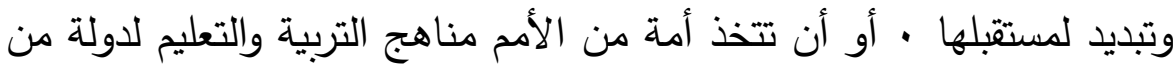
هذه الدول الكبرى ، فتطبقها على أبنائها وأجيالها ، فتشوه بذلك فكرهم وتمسخ التح

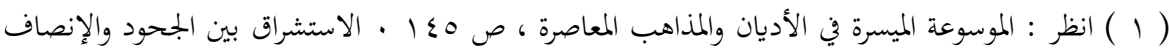

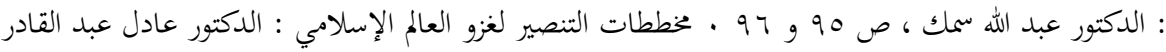


عقولهم ، وأن تزاحم لغة الغالب لغة المغلوب ، فضلا عن أن تحل محلها ، أو

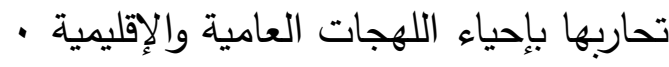
أو هو أن يحول العدو بين أمة من الأمم ـ وبخاصة الأمة الإسلامية . لماءلهيه

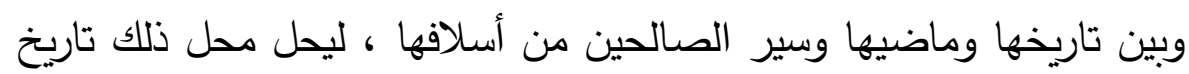

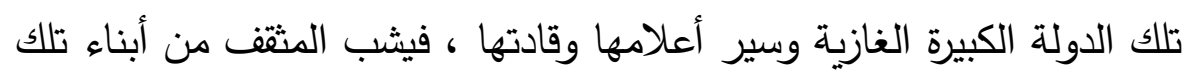
الأمة المقهورة وليس في نفسه مثل إلا ما يقرأ عنه في تاريخ الدولة الغازية .

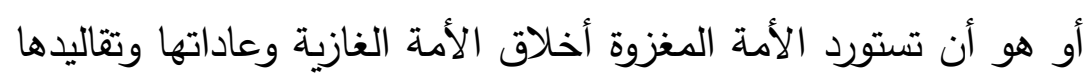

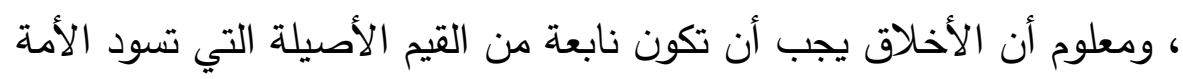

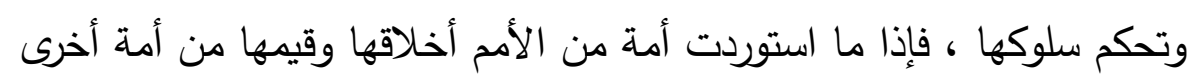

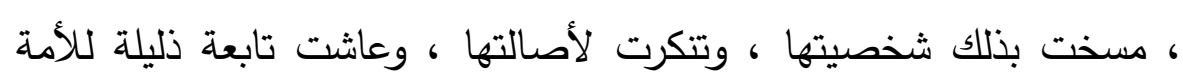

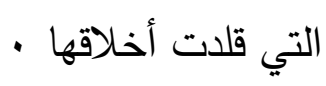
وسلاح هذا الغزو هو : الفكرة ، والكلمة ، والرأي ، والحيلة ، والثبهات ، وبراعة العرض ، وشدة الجدل ، وتحريف الكلام عن مواضعه ، فهو يتميز

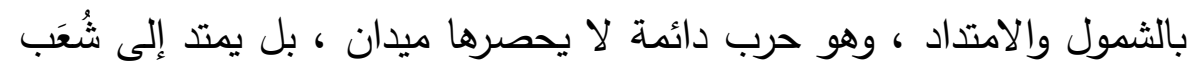
الحياة الإنسانية جميعا ، وتسبق حروبَ السلاح وتواكبها ، ثم تستمر بعدها لتحقيق ما عجز السلاح عن تحقيقه ( ' ) · فالتغريب والغزو الفكري وجهان لعملة واحدة ، والصلة بينهما وثيقة ، ويُغني أحدها عن الآخر ويسدُ مسده ، بل إن التغريب هدف أصيل للغزو الفكري •

$$
\text { ب · جذور التغريب : }
$$

لقد ارتدت الحملة الصليبية مهزومة بعد معركة حطين ، وفتح

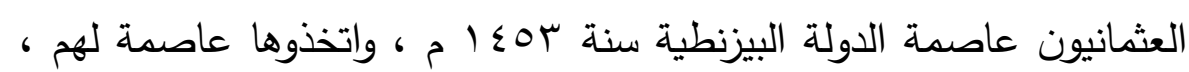
وغيروا اسمها إلى إسلامبول أي دار الإسلام ، بل وصلت الجيوش العثمانية

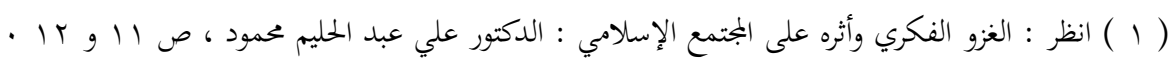

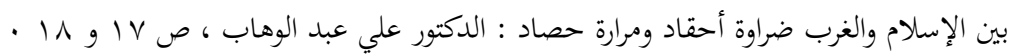

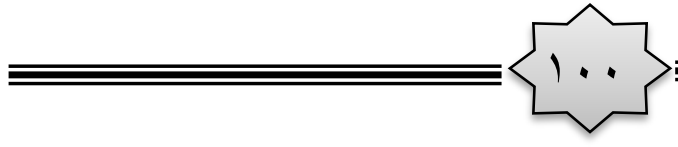


إلى أوربا ، وهددت فيينا سنة 9 و 10 م ، وظل هذا التهديد قائما حتى سنة

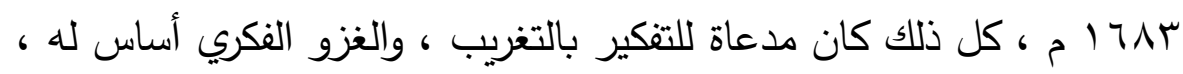

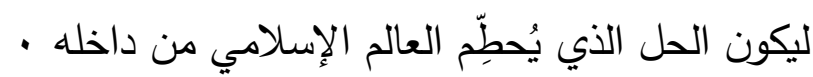

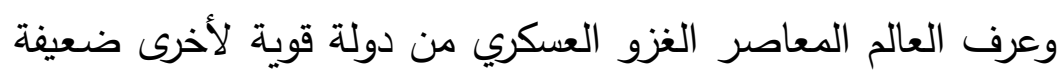
، وعانت الدول الضعيفة الويلات من هذا الغزو وقدَّمت التضحيات من أبنائها ، ونافحت من أجل حاضر مغنَصَب سيئ ، ومستقبل مهدد بما هو أسوأ .

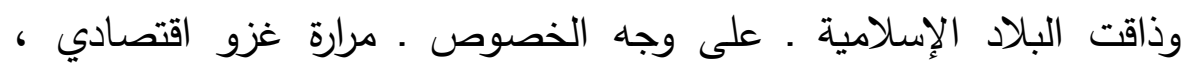
وتجرعت به كأس الحرمان والتجويع والإرهاب ، ودفعت راضية أو كارهة من خيراتها ومقدراتها ما هي في مسيس الحاجة إليه ، ووجدت نفسها عالة في كل شيء على الدول التي سرقت خيراتها واغتصبت حقوقها - ماتهي وإذا كان العالم الإسلادي ـ بخاصة ـ والعالم النامي قد عرف ذلك وعاش

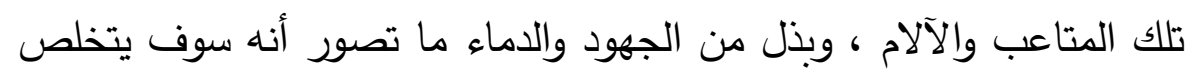

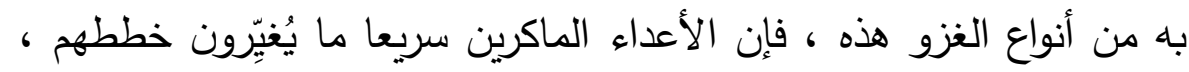
ويستبلون بأساليبهم العنيفة أساليب جديدة ، وبغزوهم العسكري غزوا تغريبيا وفكريا ، يكملون به أبعاد الصورة التي يرسمونها لاستغلال الثعوب ، ويصلون ونئن

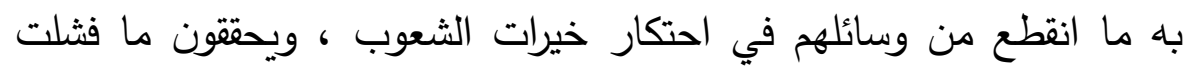

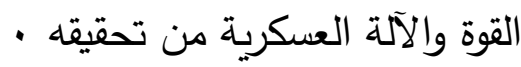
فالعالم الإسلامي يمر اليوم بمرحلة دقيقة من حياته ، تختلف اختلافا

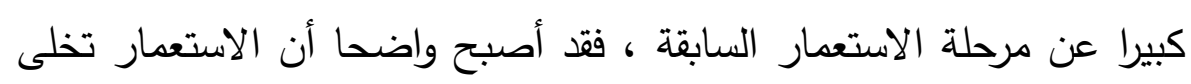

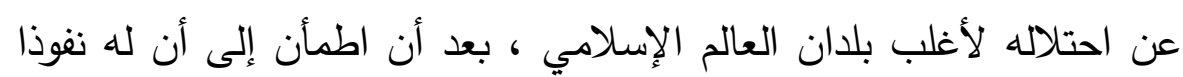

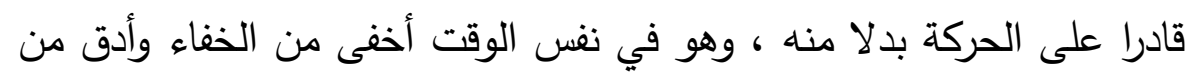

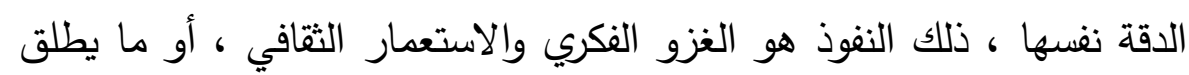
• عليه التغربب

لقد واجه العالم الإسلامي زحفا سياسيا واجتماعيا وثقافيا حاقدا طامعا

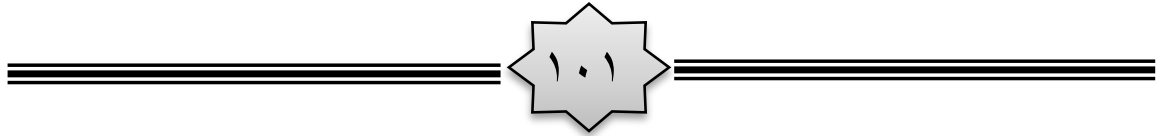


منظما ، فقاوم كثيرا ، ولكن كان هناك انحطاط عام في كل ميدان من ميادين

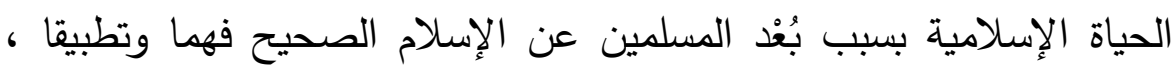
كان هناك تخلف في العلم ، وجمود في التفكير ، وركود في الفقه والتشريع ، وقصور في التربية والتوجيه ، وفساد في الإدارة والحكم ، وكان العدو الزاحف متفوقا في هذه المجالات ، فبهر أبصار الكثيرين ، وخلب ألبابهر ، فبدأوا يسيرون في دربه ، ويتبعون سنته ، شبرا بشبر وذراعا بذراع ،

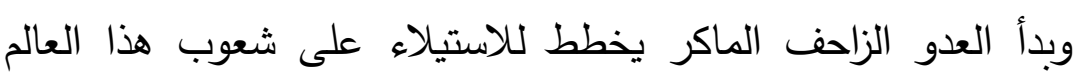

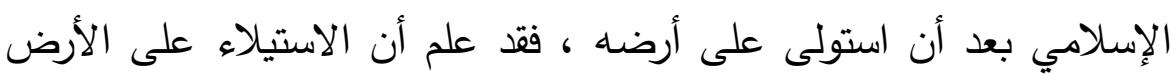

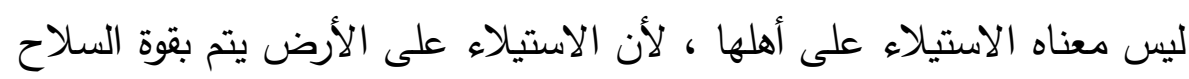

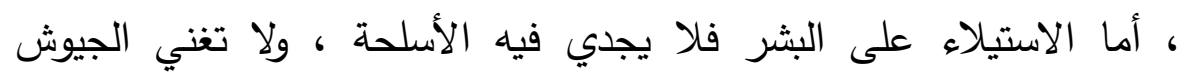
والأساطيل ، بل لابد من عمل منظم لتغريب العالم الإسلامي حتى يقبل الاستعمار الغربي ، ويهضم حضارته ويتتلمذ على أهله ، ولهذا رسم خطته لإنه بدهاء ومكر ، وشرع يُنِّْهُها بأناة وصبر ، ولم يصنع ما كان يصنع الفاتحون الأولون من تدمير المساجد ، أو تحريق المصاحف ، أو إلقاء الكتب في - الأنهار

لقد صمم الغرب الصليبي الزاحف أن يهدم ويدمر ، ولكن بأسلوب غير أسلوب التتار ( ' ) والصليبيين القدماء · لقد اتجه إلى تدمير العقائد والأفكار

( 1 ) التتار : التَّار أو التَّتر كلمة أطلقها العرب على مجموعة القبائل المغولية التي اجتاحت الشرق العربي

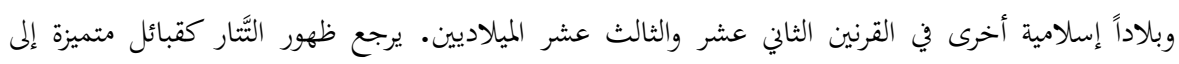

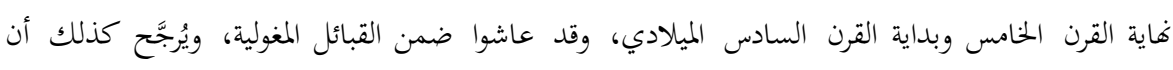

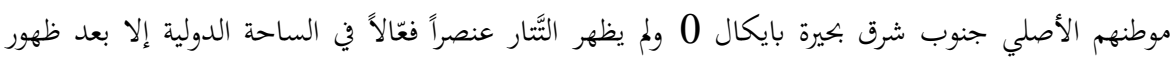

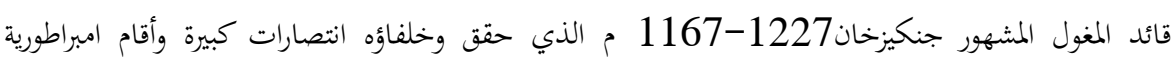

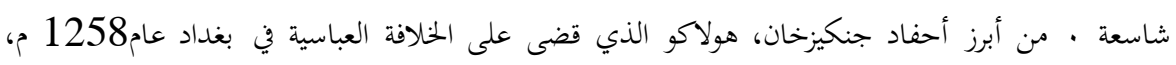

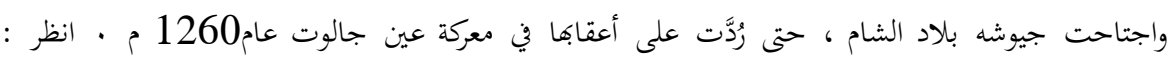
الموسوعة الحرة .

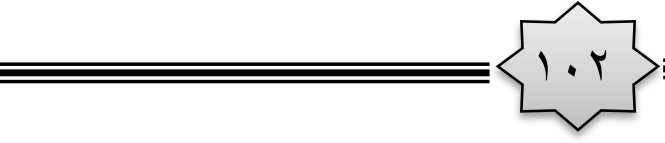


، وهدم القيم والأخلاق ، وتحطيم الآداب والتقاليد ، بمعاول خفية لا تراها

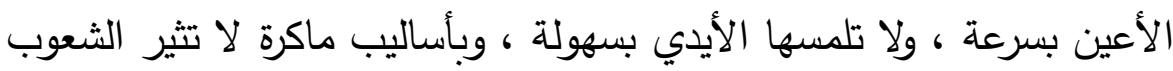
، ولا تغضب الجماهير ، ولهذا نجح في قتل الثعوب ، ولكن بغير إطلاق الرصاص ، وضرب السيوف ، بل بطريقة السم البطيء ، يوضع في الدسم

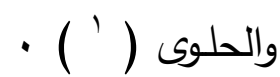

فجذور التغريب أو الغزو الفكري قديمة ، تمتد إلى الوقت الذي فثلت فيه الحروب الصليبية ، وعجزت عن تحقيق أهدافها ، فكان التغريب هو - السلاح البديل لتلك الحروب آلكابل ج · آثار التغريب وصلته بالاستشراق : كان للتغريب والغزو الفكري المنظم الذي استخدمت فيه كل الوسائل، وتسلح بالدهاء والمكر ، والعلم والمال ، واستند إلى سلطان القوة وقوة السلطان ، وامتلك أجهزة التعليم ووسائل الإعلام ، كان لهذا التغربب آثاره ونتائجه الخطيرة في حياة المسلمين ، تلك الآثار التي بدأت تبرز وتتسع يوما بعد يوم.

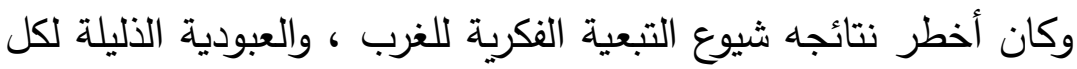
ما يصدر عنه من مبادئ وقيم ، ومفاهيم وأنظمة ، وأخلاق وتقاليد ، وأفكار ومفاهيم

ووجَّه التغريب أكبر همه إلى تكوين قادة للمستقبل ، قادة يصطنعهم لنفسه ، ويصنعهم على عينه ، ويربيهم في أحضانه ، ويغريهم بثقافته وأفكاره ، ويغرس فيهم الخضوع . عن طواعية . لنظمه وتقاليده ، والتقديس لمناهجه وفلسفته · إن صناعة هذا الجيل الذي سيقود السفينة فيما بعد ويقبض على زمام التوجيه والتثقيف والتربية والإدارة والسياسة والتشريع ، كانت أهم ما عُني لئي

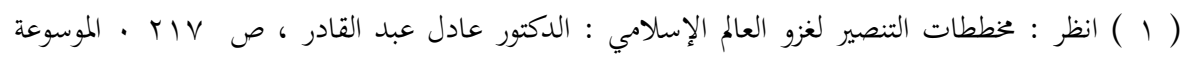

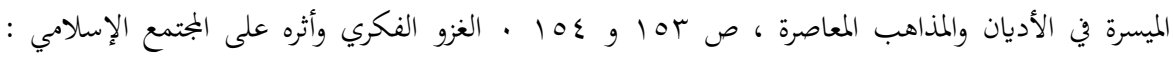

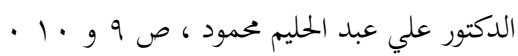

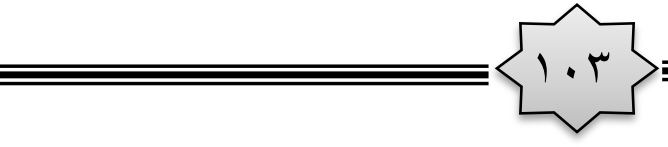


به الاستعمار الخبيث ، وكان النجاح في صناعته أعظم نصر حققه في المعركة بينه وبين الشرق الإسلامي · وبرز من هذا الجيل أناس يدعون إلى ، وهان

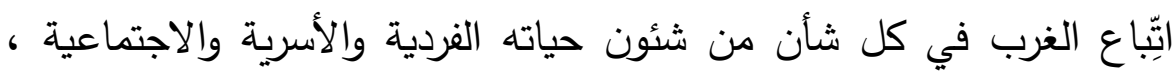

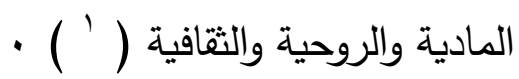
ومن أشهر من دعا في العالم العربي إلى تقليد الغرب واتِّبَاع مناهجهم في الخير والثر ، صاحب كتاب " مستقبل الثقافة في مصر " ، حيث بيَّن في كتابه هذا سبيل النهضة بقوله : " لكن السبيل إلى ذلك ليست في الكلام يرسل إرسالا، ولا في المظاهر الكاذبة ، والأوضاع الملفقة ، وإنما هي واضحة بينة مستقيمة ليس فيها اعوجاج ولا التواء ، وهي واحدة فذة ليس لها تعدد ، وهي : أن نسير سير الأوربيين ونسلك طريقه ، لنكون لهح أندادا ، ولنكون لهم شركاء في الحضارة ، خيرها وشرها ، حلوها ومرها ، وما يحب منها وما يكره

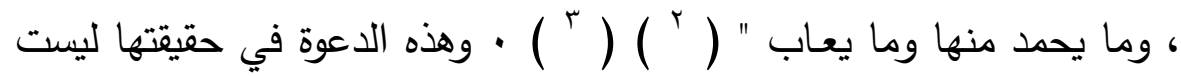

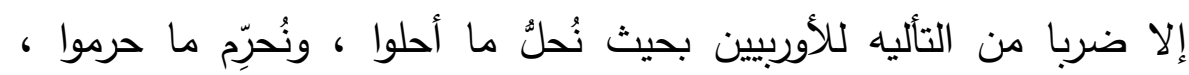

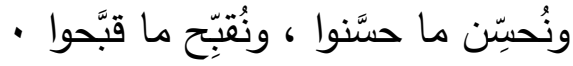

( 1 ) انظر : الحلول المستوردة وكيف جنت على أمتنا : الدكتور يوسف القرضاوي ، مكتبة وهبة ( القاهرة ) ، D

( ) مستقبل الثقافة في مصر : الدكتور طه حسين ، بو 199 م ، الهيئة المصرية العامة للكتاب ( القاهرة ) ،

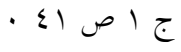

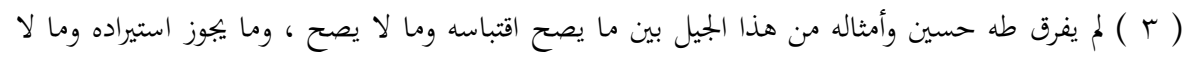

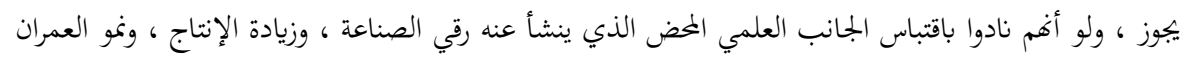

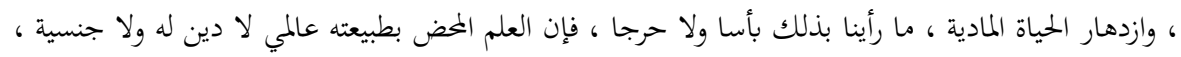

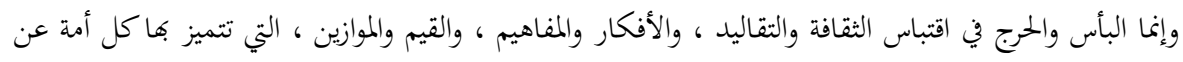

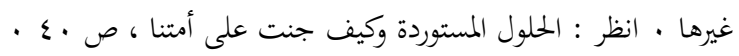
$\overline{\overline{1}}\{1, \varepsilon\}$ 
ولتحقيق هذا الهدف أنشأ كرومر (' ') كلية فيكتوريا بالإسكندرية ( (') ، لتربية جيل من أبناء الزعماء والوجهاء في محيط انجليزي ، ليكونوا أداة المستقبل في نقل ونشر الحضارة الغربية · وقاء المندوب المناء السامي البربطاني في مصر حينما افتتح هذه الكلية سنة بسو 19 م : كل هؤلاء لن يمضي عليهم وقت طويل ، حتى يتشبعوا بوجهة النظر البريطانية ، بفضل العشرة الوثيقة

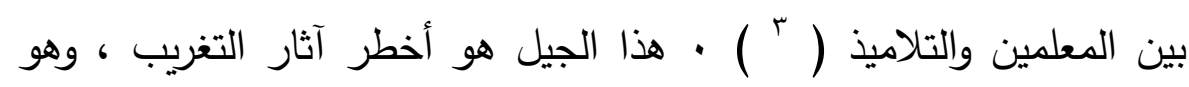
الذي حمل لواءه في العالم العربي والإسلامي ، وحقق ما لم يحققه أساتذته .

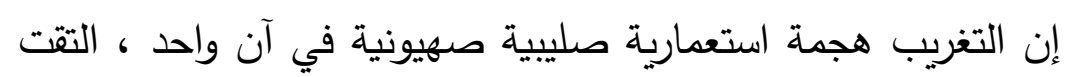

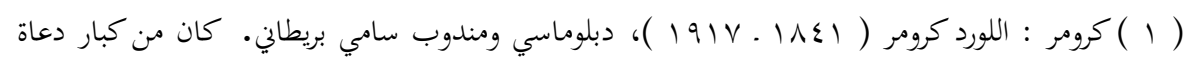

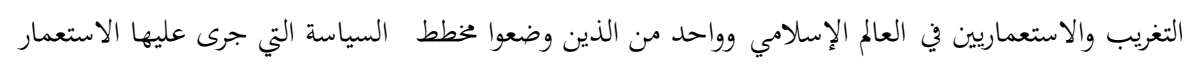

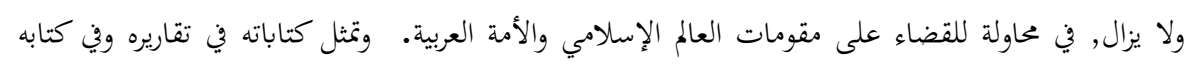

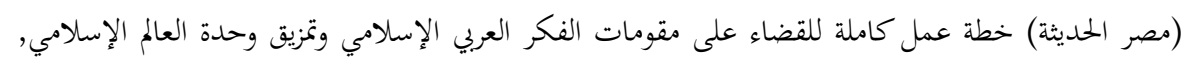

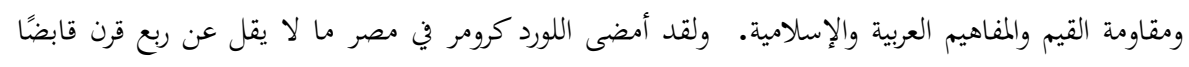

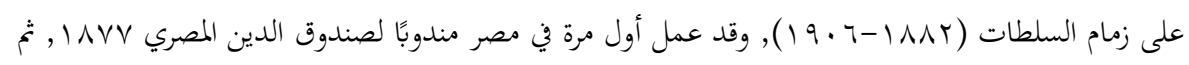

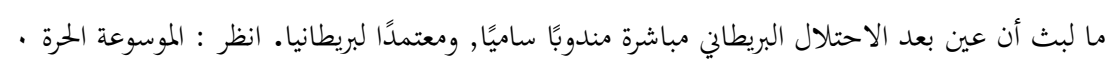

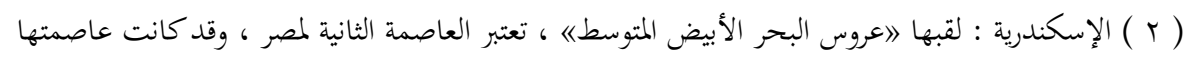

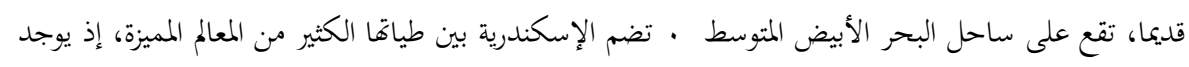

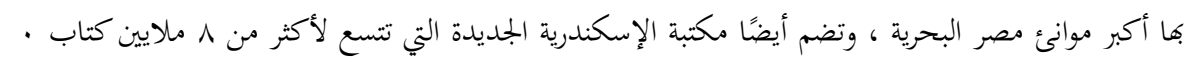

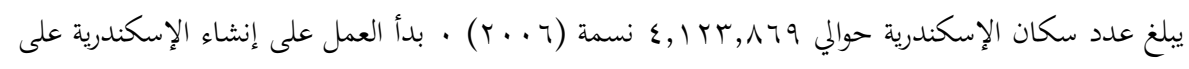

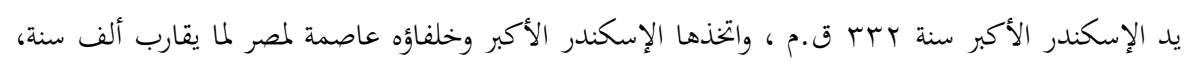

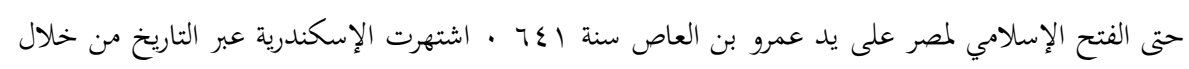

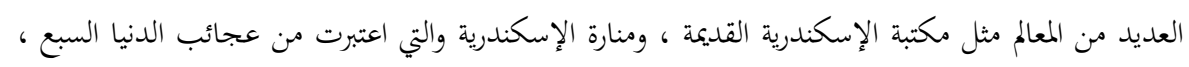

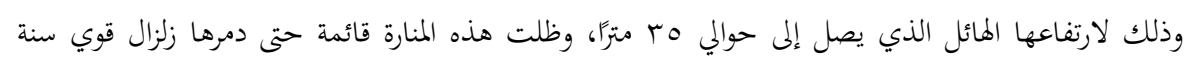

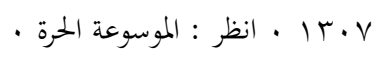

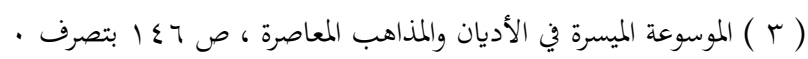

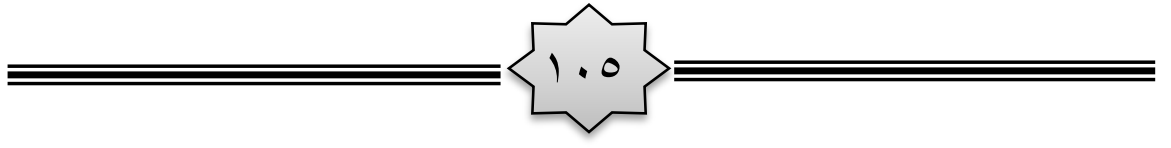


على هدف مشترك بينها ، ألا وهو طبع العالم الإسلامي بالطابع الغربي ،

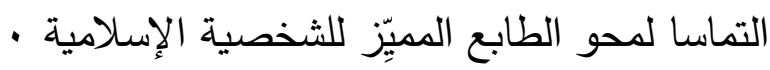
وقد حمل لواء التغريب وتحدياته الفكرية المبشرون والمستشرقون : فالمبشرون اعتُمدت لهم الميزانيات الضخمة ، والوسائل العديدة من معاهد علمية ، ومنشآت صحية واجتماعية ، إلى جانب المكتبات والصحافة والجمعيات الثقافية ، والإرساليات التبشيرية . وقام المستشرقون بدراسة الثقافة الإسلامية دراسة عميقة ، ليتصيدوا فيها

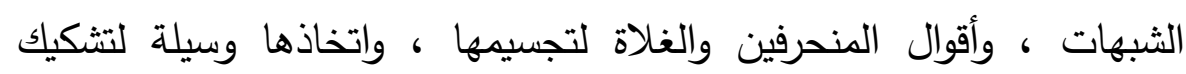

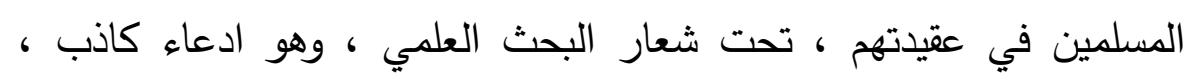
وبريق خادع في مجمله ، وذلك بهدف إخراج المسلمين من مقومات فكرهم ، وأهمها مقومات الإسلام ، ثم إخراج الإسلام من مقوماته أيضا ، وذلك بتفسيره

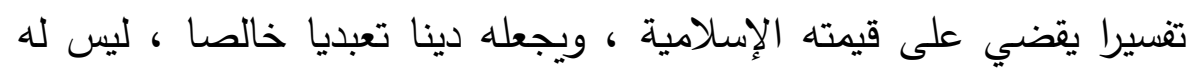

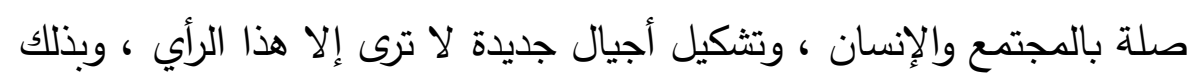

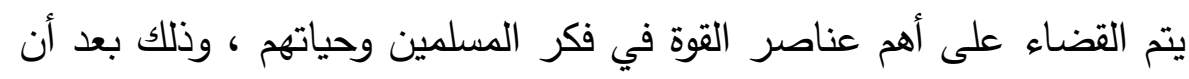
أدركوا أنه لا قِبَل لهم بمواجهة الإسلام كعقيدة ، فقرروا الهروب من هذه المواجهة إلى الالتفات حول الثغرات التي فتحتها الحضارة الغربية في جدار

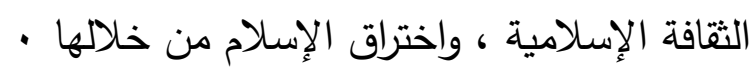

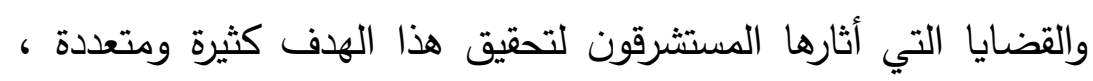
حتى يمكن القول بأنها شملت كل مجالات الفكر والبحث ، ولم تََعْ مسألة

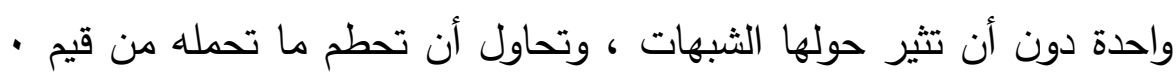
وأبرز هذه القضايا : الدعوة إلى عالمية الثقافة وتجزئة الإسلام ، والنظرية المادية ، وإقليمية الأدب ، ونقد النص القرآني ، وتزييف التاريخ ، وتدمير الإنيل

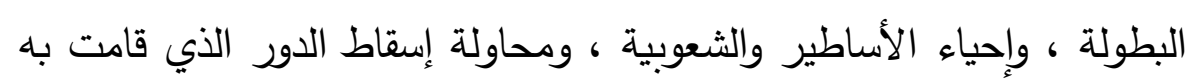

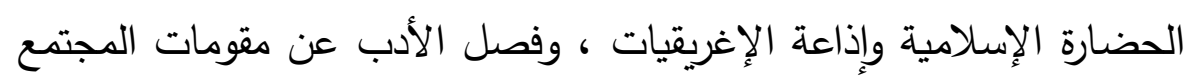

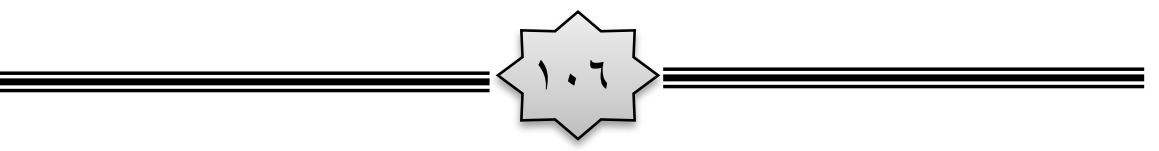


، وإذاعة الأدب المكثوف والإباحية والإقليمية الضيقة ، وتعظيم الغرب واتهام الأدب العربي ، وتغريب التربية والتعليم والجامعة ( ' ) • كل هذا يؤكد

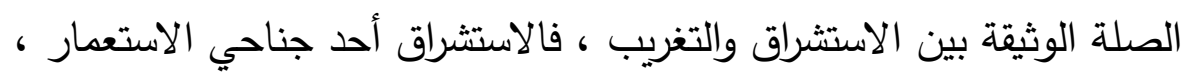

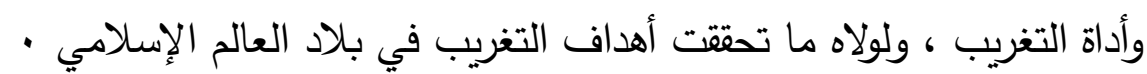

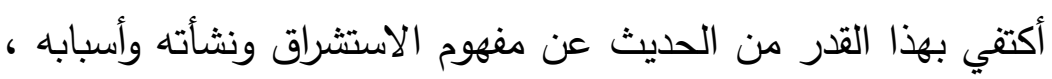

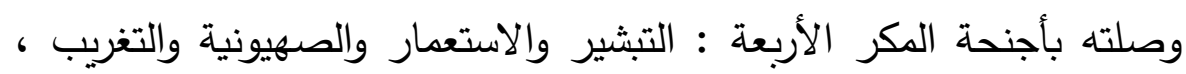
التي اتنَّتت فيما بينها على احتلال أرض المسلمين ، والسيطرة على خيراتها ، وتدمير الإسلام عقيدة وشريعة ، والنيل من رسول الله " صلى الله عليه وسلم "

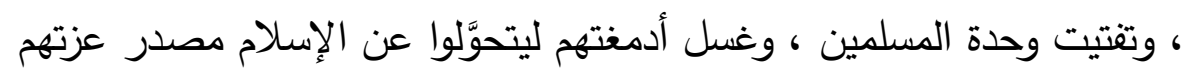
وقوتهم وسعادتهم ، واتَّبعوا . لأجل تحقيق تلك الأهداف ـ كل وسيلة ، سواء

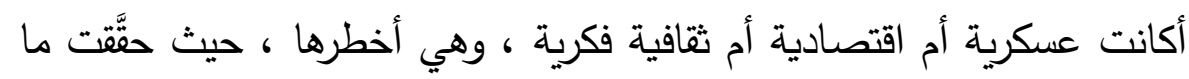
عجزت الوسائل السابقة عن تحقيقه ، وهي الحرب الباردة التي تقتل الإسلام

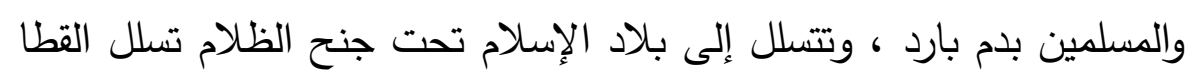

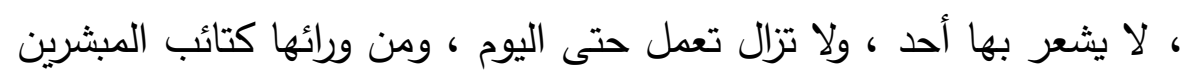

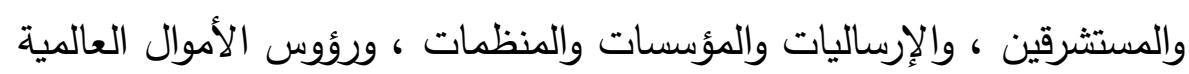
الضخمة التي رُصدت لنجاح هذه المهمة ، لكن الله من ورائهم محيط ، ويمكرون ويمكر الله والله خير الماكرين ، ويأبى الله إلا أن يتم نوره ولو كره

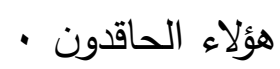

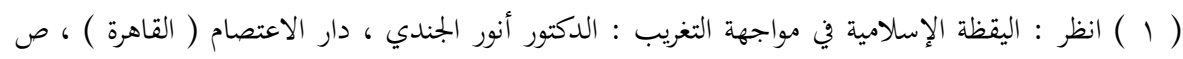

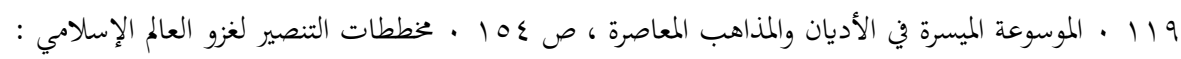

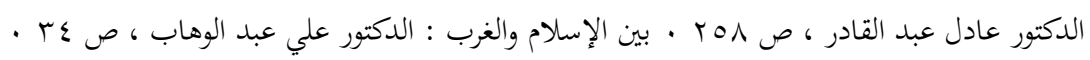
$\overline{\overline{ }}\{1 \cdot v\}$ 


\section{الخاثمـــة}

الحمد الله رب العالمين ، وأشهد أن لا إله إلا الله ولي الصالحين ،

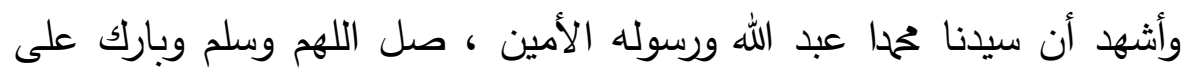
نبينا الكريم وعلى آله وصحبه أجمعين . . . أما بعد . . . .

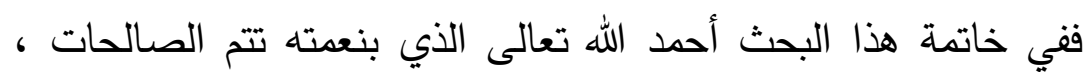
وأُقِّدم في هذه الخاتمة : أهم النتائج والتوصيات ، وترجمة لأهم الأعلام البلدان

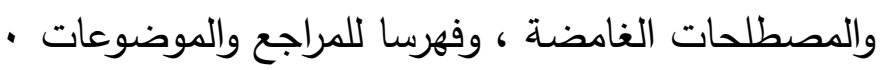
أولا : أهم النتائج والتوصيات :

$$
\text { أ ـ أهم النتائج : أولم }
$$

بعد هذه الدراسة لمفهوم الاستشراق وصلته بأجنحة المكر الأربعة ، خلص البحث بنتائج ، أهمها : ا ـ الاستشراق في اللغة العربية كلمة عصرية ، وهي كذلك في اللغات الأجنبية · والاستشراق في الاصطلاح يعني : دراسة حضارة الثرق عامة ،

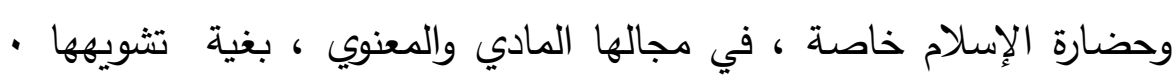

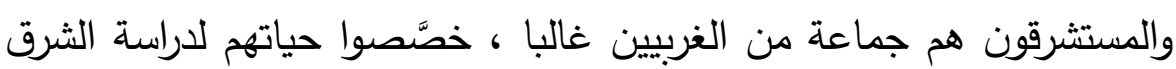
الإسلامي بأديانه وعلومه ، ولهم طبقات من حيث الزمن والاتجاه العام نحو

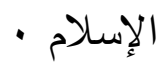

r ـ اختلف الباحثون حول بداية نشأة الاستشراق ، على النحو التالي :

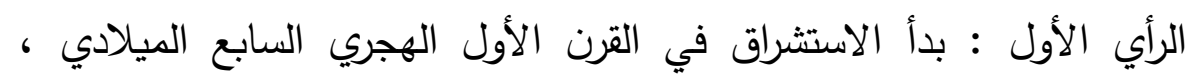
ويُستدل على ذلك بما فعله عبد الله بن سبأ الذي أبطن اليهودية وأظهر الأول الإسلام · الرأي الثاني : بدأ الاستشراق في القرن الثاني الهجري الثامن الميلادي ، ودليل ذلك ما فعله يوحنا الدمشقي ، المعروف بآثاره في الدراسات

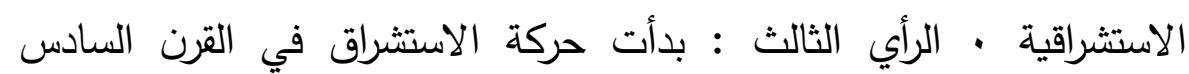

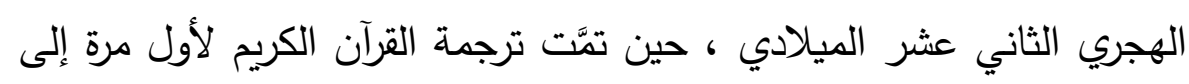

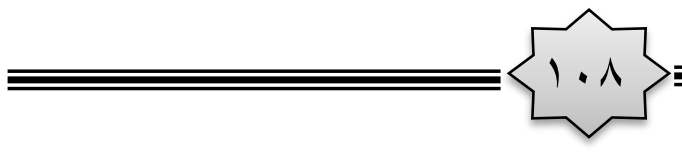


اللغة اللاتينية · الرأي الرابع : بداية الاستشراق القرن الثامن الهجري الرابع

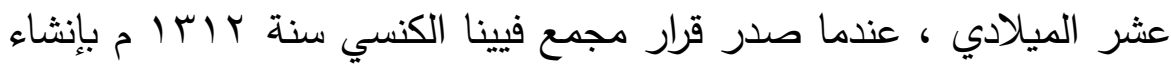

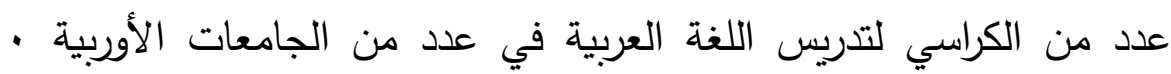
الرأي الخامس : بداية الاستشراق القرن العاشر الهجري السادس عشر لبن الميلادي ، الذي ظهر فيه الإصلاح الديني ، بسبب الاتصال الوثيق بين

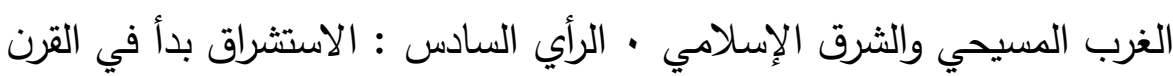
الثاني عشر الهجري الثامن عشر الميلادي ، وهو العصر الذي بدأ فيه الغرب استعمار العالم الإسلامي وسرقة مخطوطاته • ويمكن الجمع بين هذه الآراء

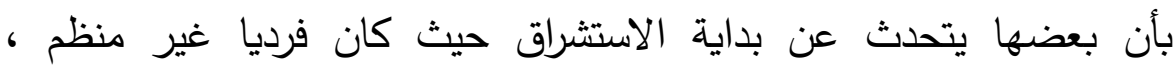
والبعض الآخر يتحدث عن الاستشراق حين اتسعت دائرته بعد الحروب الصليبية ، والبعض الأخير يتحدث عن الاستشراق في صورته الأخيرة - الجماعية المنظمة

r ـ مرت حركة الاستشراق بأطوار تاريخية ، أهمها : طور التكوين :

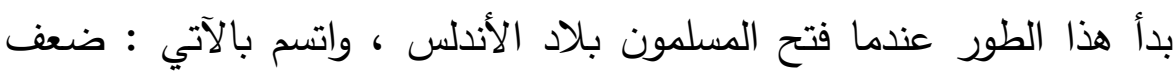
الحياة العلمية في الغرب ، ونشأة الاستشراق في كنف الكنيسة ، والحقد الأعمى على الإسلام · طور التقدم : بدأ هذا الطور بعد انتهاء الحروب

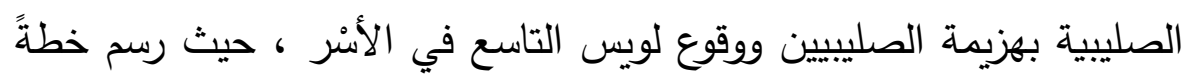
لغزو فكري بديل عن الغزو العسكري ، واتسم هذا الطور بالآتي : زيادة سلطة البابوات ورجال الدين ، واحتكاك الغربيين بالمسلمين ، وإنشاء كراسي للغات الثرقية في الجامعات الغربية ، والاهتمام بالترجمة ، وتتوع الدراسات - الاستشراقية

طور الانطلاق : بدأ هذا الطور في القرن الساد عشر والسابع عشر الميلادي حيث ظهرت الطباعة ، واهتم الغرب بطباعة نفائس العرب ومخطوطاتهم ، والعكوف على دراستها · وفي القرن الثامن عشر تأثرت حركة

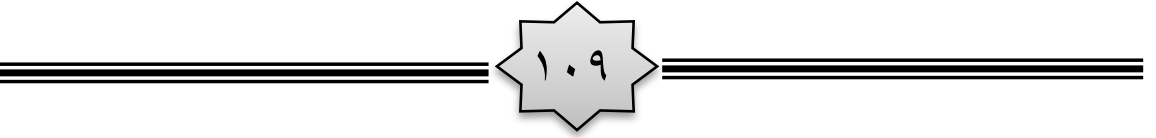


الاستشراق تأثرا كبيرا بالحملة الفرنسية على مصر ، والتي كانت مجهزة بعلماء في كل ضرب من ضروب ثقافة ذلك العصر · وفي القرن التاسع عشر وفي عهد محمد علي توافد عدد كبير من المستشرقين لبناء دولة عصرية في مصر ،

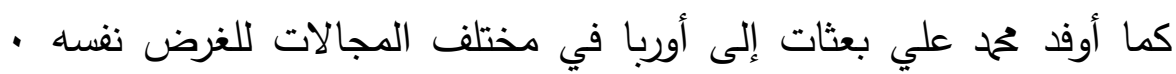
طور الازدهار : بدأ هذا الطور في القرن العشرين الذي احتل فيه العالم الغربي العالم الإسلامي ، وازداد اهتمام الدول الغربية بالدراسات الاستشراقية في جامعاتها ، وركزت تلك الدراسات على تثويه حقائق الإسلام ، وانتقاد

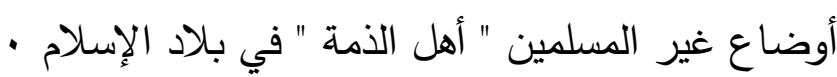
ع . بذل المستشرقون جهودا مضنية في تلك الدراسات لأسباب : دينية

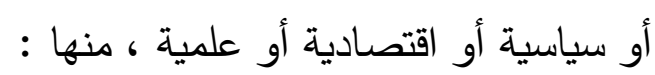
هناك الدافع الديني المتمثل في الكراهية والحقد المترسب في أعماق أهل الكتاب والمشركين منذ بزوغ فجر الإسلام ، والتنفيس عن الحروب الصليبية العسكرية بتلك الحروب التي تثوِه الإسلام ، ومواجهة حركات الإصلاح الديني المسيحية ، ووقف المد الإسلامي داخل أوربا ، والتتصير بدينهم بين

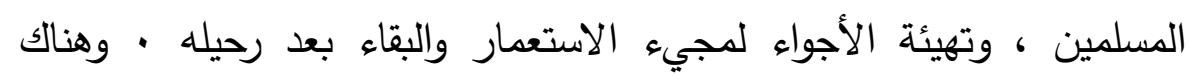

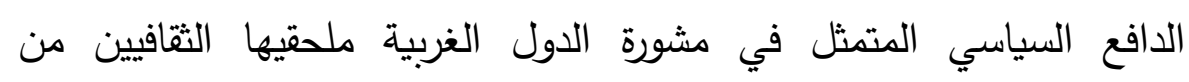
المستشرقين في الدول التي يريدون استعمارها · مهناك الدافع الاقتصادي حيث يهدف الاستشراق إلى السيطرة على الأسواق التجارية والمؤسسات المالية

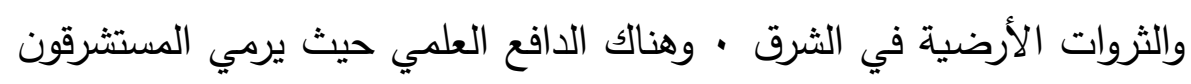
في دراساتهم إلى الانتقاص من تعاليم الإسلام ، وكانت تلك الدراسات بعيدة عن الحيدة والطابع العلمي ، بسبب الحقد الدفين الذي لازم المستشرقين طوال • تاريخهم

ه ـ الاستشراق والتبشير وجهان لعملة واحدة ، وتوأمان تجمعهما وحدة

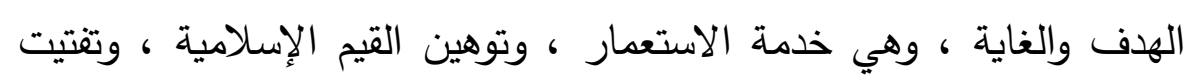

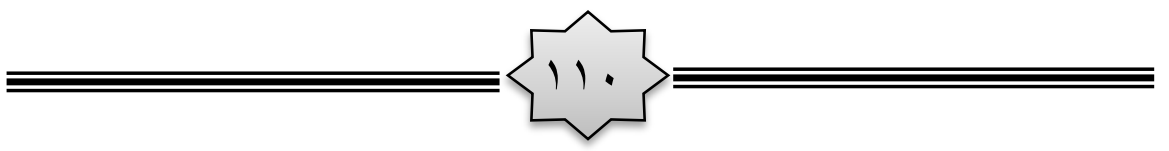


وحدة المسلمين ، وصرفهم عن الإسلام ، والتعاون والتسيق بينهما قائم ومستمر ، فالمستشرقون يقومون بتصنيع السموم ( الثبهات ) ، ويقوم المبشرون بترويجها ، وإن كان هناك فرق بينهما فإنما هو في أسلوب العمل فقط ، لتحقيق الهدف المشترك . 7 ـ ـ صلة الاستشراق بالاستعمار وثيقة ، فالدراسات الاستشراقية كانت بمثابة دليل للاستعمار في شعاب الثرق وأوديته ، من أجل فرض السيطرة عليه ، وتبرير تلك السيطرة الاستعمارية ، وضمان استمرارها بإضعاف روح المقاومة في نفوس المسلمين ، وفي المقابل أنشأ الاستعمار عدة مؤسسات في البلاد المستعمَرة لخدمة الاستشراق · وكذلك كانت صلة التبشير بالاستعمار ، وهذا ما أكده المبشرون والمستعمرون أنفسهم ، وما سجَّّه المفكرون الأحرار في بلاد الاستعمار ، فالتبشير يمثل الركيزة الأولى التي يعتمد عليها الاستعمار في بسط نفوذه على الشرق الإسلامي ، ولتحقيق هذا الهدف هيأت

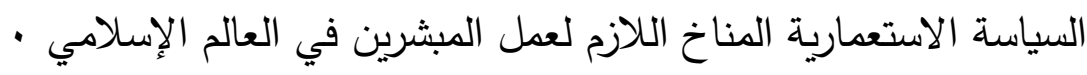

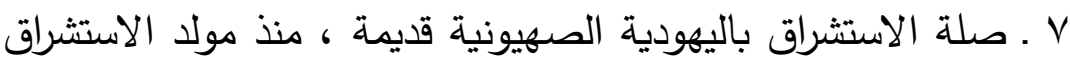
في بلاد الأندلس ، حيث اطمأن اليهود إلى تسامح المسلمين ، فأقبلوا على بلى دراسة العلوم العربية والإسلامية ، لمحاولة التشكيك في الإسلام ، وإسقاط الأمة العربية من مكانها التاريخي والعلمي والحضاري ، وخدمة الصهيونية فكرة أولا ثم دولة ثانيا ، وكان لكثير من اليهود دور كبير في هذه الحركة ونة ولهي · الاستشراقية قديما وحديثا ^ ـ التغريب هو صبغ الحياة الإسلامية بالصبغة الغربية ، وإبعاد المسلم عن تعاليم دينه المرتبطة بشئون حياته ، وهو ثمرة مرَّة من ثمار الغزو الفكري ، وجذوره ممتدة منذ فثل الحروب الصليبية · ومن أخطر آثار التغريب : شيوع التبعية الفكرية للغرب ، والعبودية الذليلة لكل ما يصدر عنه من مبادئ وقيم ، ومناهج وأنظمة ، وأخلاق وتقاليد ، وأفكار ومفاهيم · والصلة وثيقة ولهية

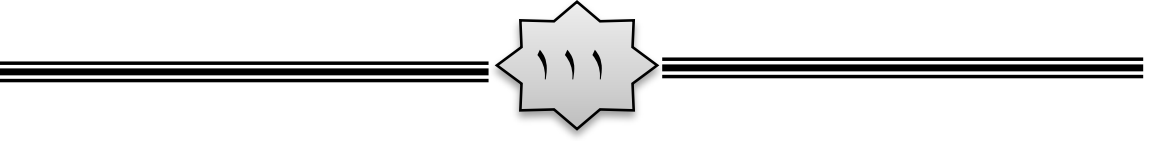


بين التبشير والاستشراق وبين التغريب ، حيث حمل المبشرون والمستشرقون لواء التغريب ، الذي هو هدف لهما ، واعتُمدت الميزانيات الضخمة والوسائل العديدة للمبشرين ، وقام المستشرقون بدراسة الثقافة الإسلامية دراسة عميقة

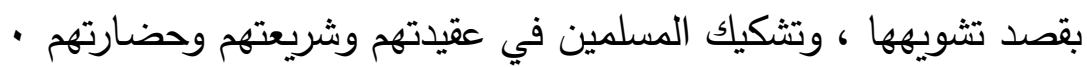

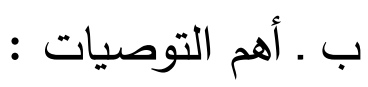
بعد هذه الجولة حول " مفهوم الاستشراق وصلته بأجنحة المكر الأربعة " يوصي البحث بالآتي : ا ـ كثف اللثام عن المصطلحات الخادعة التي يُخفي وراءها أعداء الإسلام ـ في الداخل والخارج . أهدافهم الخبيثة ، والرد على ما يثيرونه من

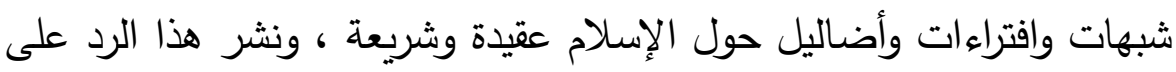
- العالمين r ـ تدريس مادة الاستشراق في كل كليات جامعة الأزهر ، وإنشاء أقسام علمية لهذا التخصص بالجامعات الإسلامية ، لتحصين الشباب المسلم من هذا الخطر الداهم ، وتثقيفه وتعريفه صحيح الإسلام وعظمته ووسطيته - مانه

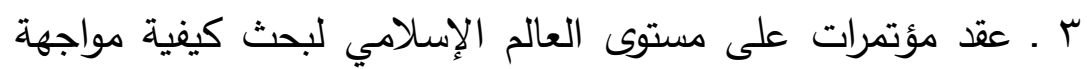
جناحي الاستعمار ( الاستشراق والتبشير ) بأساليب وطرق حديثة ، مع تقديم

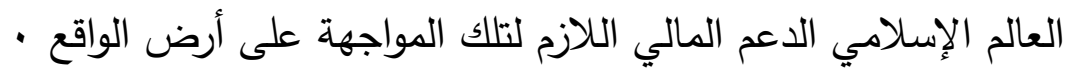

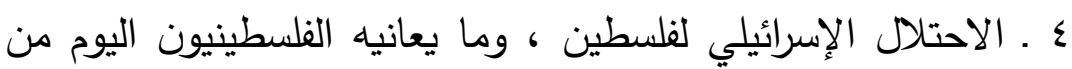
استيطان لأراضيهم وتشريد واستباحة لأنفسهم وأموالهم وأعراضهم وهتك لآدميتهم ، ما هو إلا ثرة مرة وحصاد أثيم لتعاون الصليبية الغربية

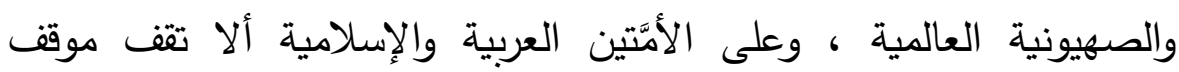
المتفرج أو المتابع ، بل يجب أن تقوم بواجبها وأن يكون لها دور في حل هذه وله

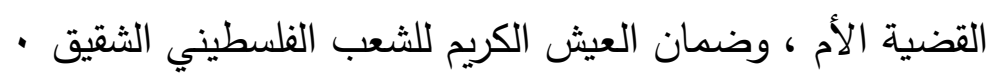
ه . إلقاء مزيد من البحث والدراسة حول الموضوعات الآتية : نشأة

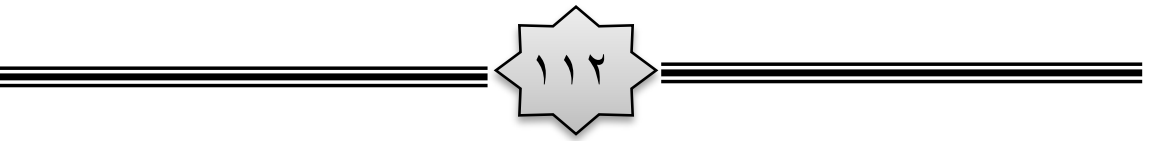


الاستشراق والأطوار التاريخية التي مر بها خاصة الاستشراق الحديث في القرنين التاسع عشر والعشرين ـ أوجه الاتفاق والاختلاف بين الاستشراق

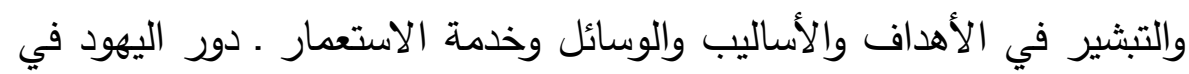
الحركة الاستشراقية قديما وحديثا . دور الاستشراق اليهودي في خدمة الصهيونية العالمية فكرة أولا ثم دولة ثانيا ـ آثار الاتصال الإيجابية والسلبية الإنئية بين المسلمين والمسيحيين في بلاد الأندلس وأثناء الحروب الصليبية .

ثانيا : فهرس الأعلام والبلدان والمصطلحات المتزجم لها

\begin{tabular}{|c|c|c|c|c|c|c|c|}
\hline ص & الإلـ أو . أو & ص & الإبل أو . أو & ص & البلد أو م . أبل & ص & البلد أو ال . \\
\hline 7 & اليهود & 0 & القــــرون & 10 & الحــروب الصليبية & rr & ابن خلدون \\
\hline 9 & اليهودية & 7 & القسيس & $\varepsilon q$ & دمشق & $\mu \wedge$ & أدنبرج \\
\hline 9 & يوحنــا الدمشقي & $r r$ & الكاثوليك & 11 & الدير & $\varepsilon q$ & الأردن \\
\hline- & & $1 \%$ & الكاهن . الكهنوت & $r V$ & دينيه & 9 & أريوس \\
\hline- & & or & كرومر & 7 & الراهب & $1 \varepsilon$ & أسبانيا \\
\hline- & & 19 & كمبردج & $1 \varepsilon$ & روما & $r$. & إسرائيل \\
\hline- & & 1. & الكنيسة & 11 & ريمونـــــد & $\Delta r$ & الإسكندرية \\
\hline- & & ro & لاهاي & rq & زويمر & Ir & الإدينيـــــلاح \\
\hline
\end{tabular}

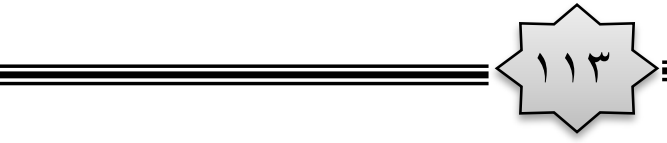




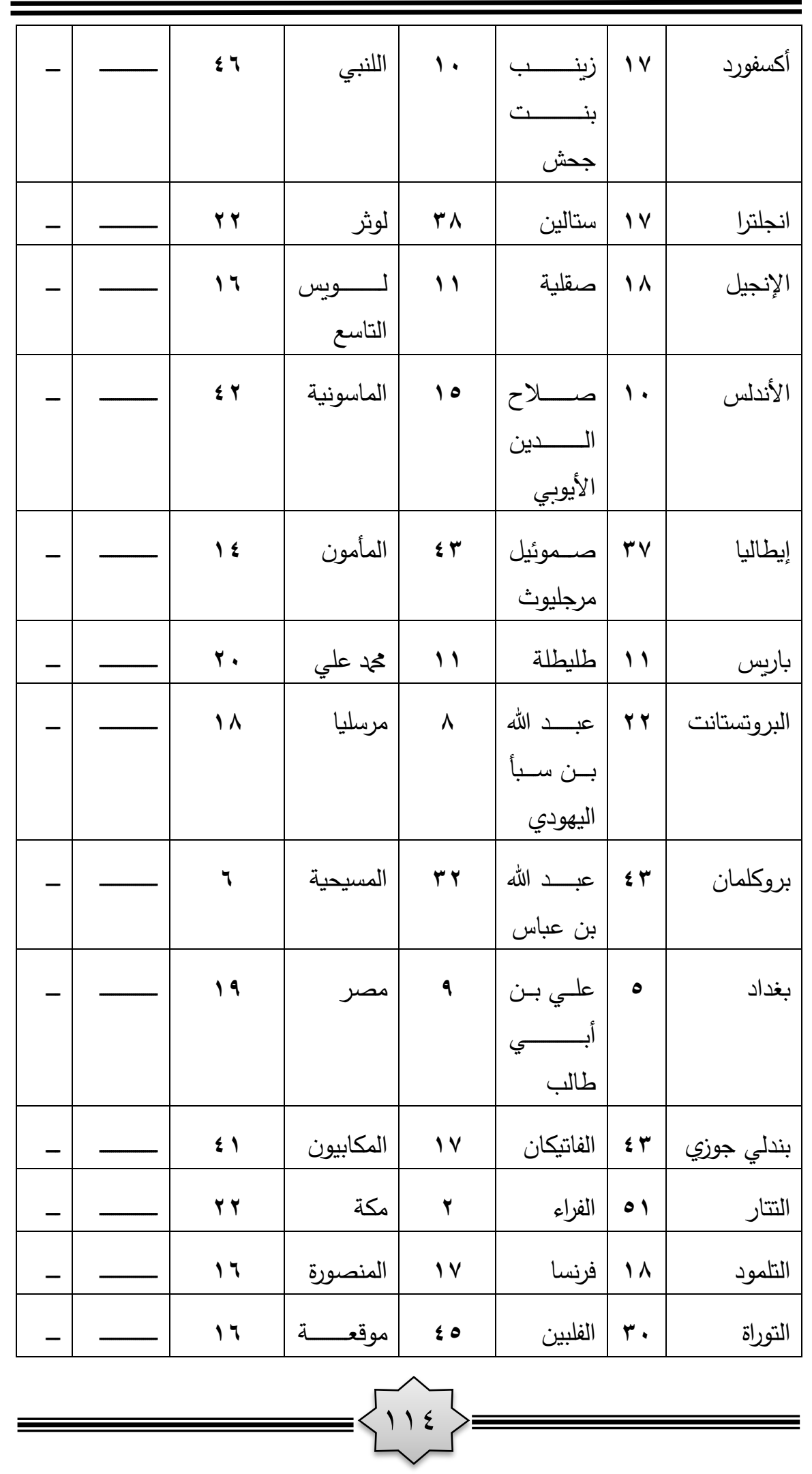




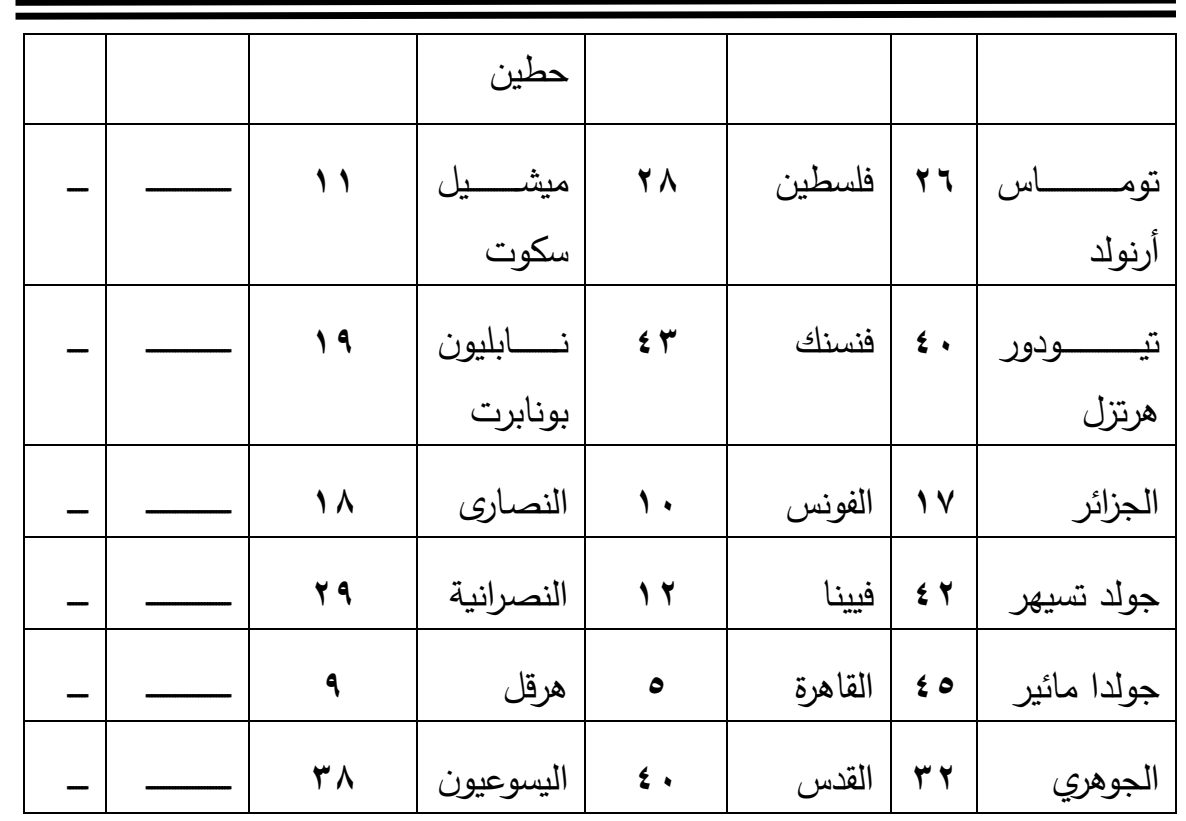

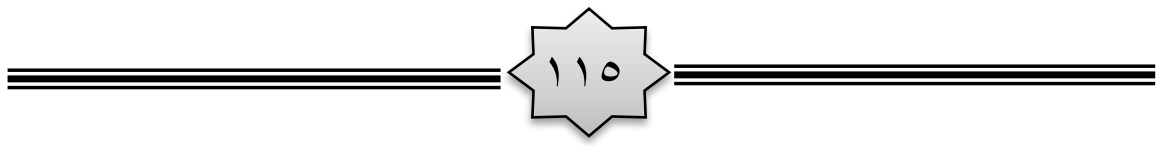




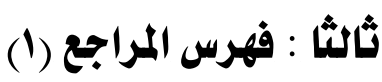

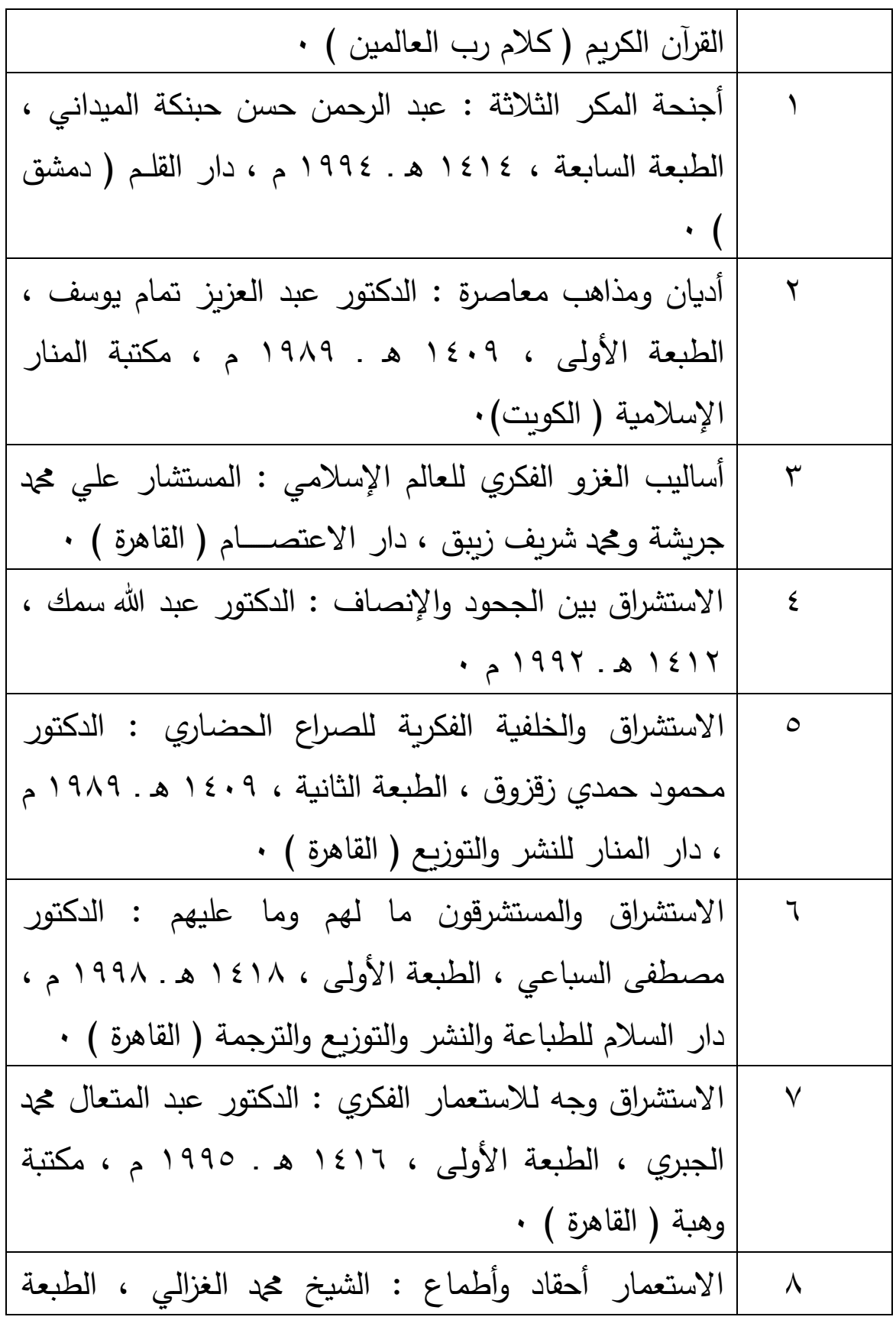

(1) صُّدِّت هذه المراجع بالقرآن الكريم ، الذي لا يأتيه الباطل من بين يديه ولا من خلفه ، ورئبّتِ باقي المراجع

• ترتيبا هجائيا 
السادسة ، ^ . . ץ م ، نهضة مصر للطباعة والنشر والتوزيع

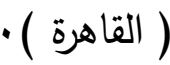

9 " ابن الأثير " ، دار الفكر للطباعة والنشر والتوزيع ( بيروت

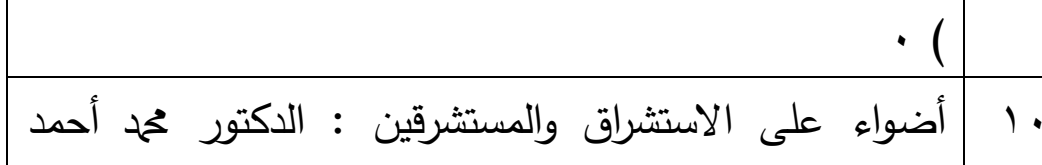

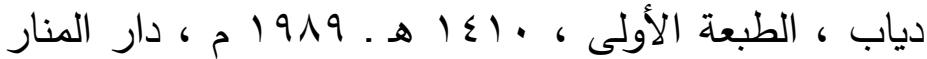

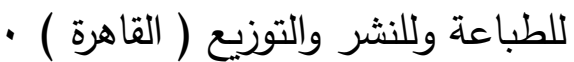

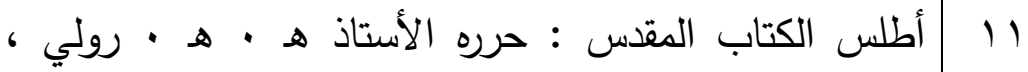

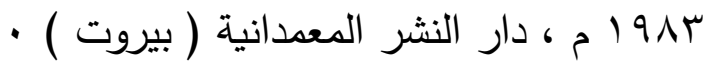
r ا البداية والنهاية : الإمام ابن كثير الدمشقي ، تحقيق أحمد أبو

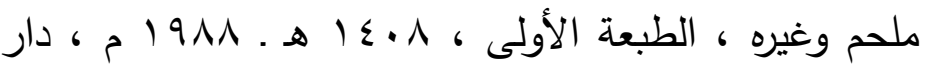

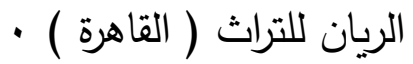

rا بين الإسلام والغرب ضراوة أحقاد ومرارة حصاد : الدكتور

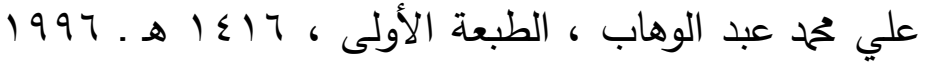

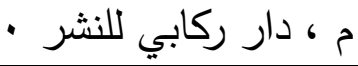

ع ا تاج العروس من جواهر القاموس : الإمام السيد محمد مرتضى

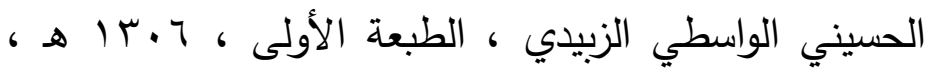
- المطبعة الخيرية المنشأة بجمالية مصر لوريطي

10 تاريخ المسيحية : المسيحية في العصور الوسطى : جاد

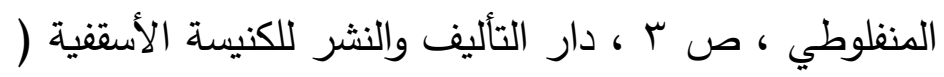
القاهرة ) •

17 |التبشير الخطر الداهم : الدكتور عبد الكريم حسن بلال ،

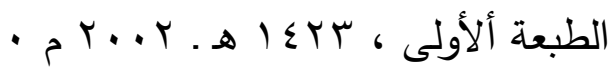




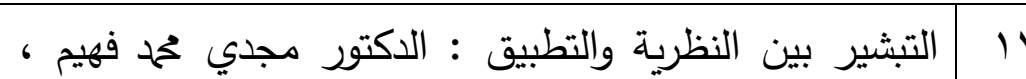

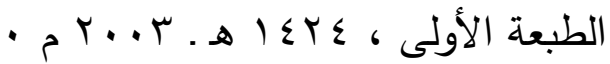

1 ا التبشير والاستشراق أحقاد وحملات على النبي محمد وبلاد

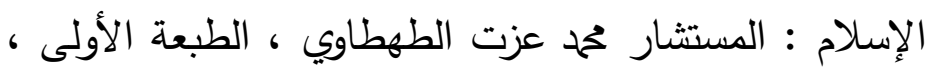

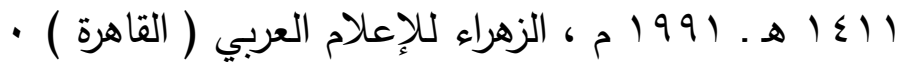
| 19 عبد الحميد ، 10 ب م ، كلية الدعوة الإسلامية بالقاهرة .

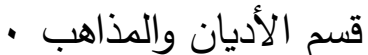
• r التصير بين الماضي والحاضر وكيفية مواجهته : الدكتور محمد زين العابدين تحمح والدكتور عادل محمد درويش ، الطبعة

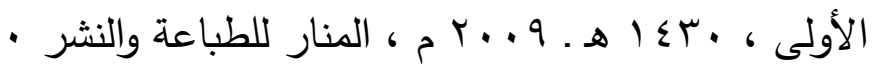

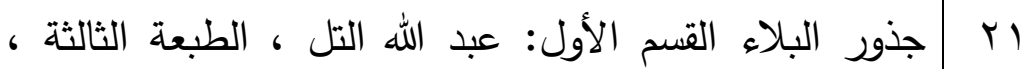
1 • ـ 1 هـ ـ 1911 م ، المكتب الإسلامي (بيروت) • T حقيقة التبشير بين الماضي والحاضر : اللواء أحمد عبد

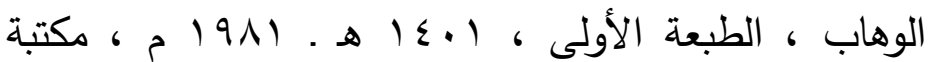

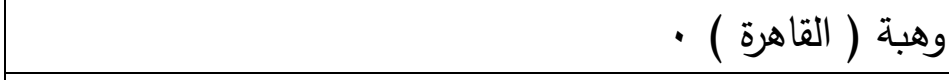
rr الحلول المستوردة وكيف جنت على أمتتا : الدكتور يوسف القرضاوي ، مكتبة وهبة ( القاهرة ) · دائرة المعارف الكتابية ، مجلس التحرير: القس صموئيل Yร حبيب وقساوسة آخرون ، المحرر وليم وهبة بباوي ، دار الثقافة ( القاهرة)

الاراسات العربية والإسلامية في الجامعات الألمانية : رودي بارت ، ترجمة مصطفى ماهر ، $197 V$ م ، دار الكتاب

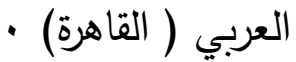

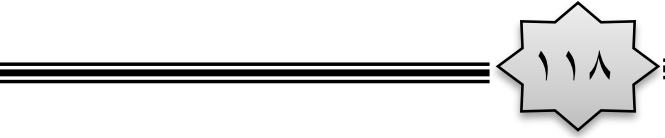




\begin{tabular}{|c|c|}
\hline 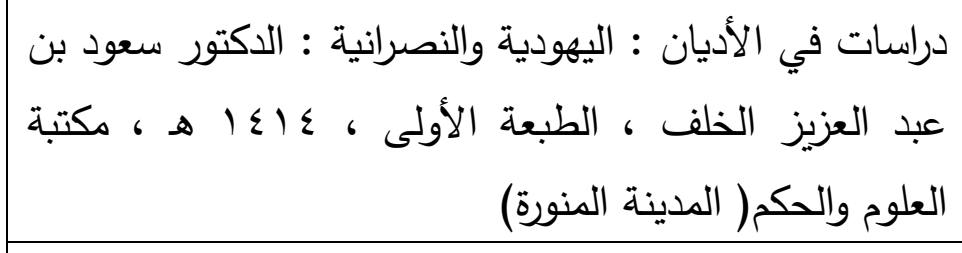 & Y \\
\hline 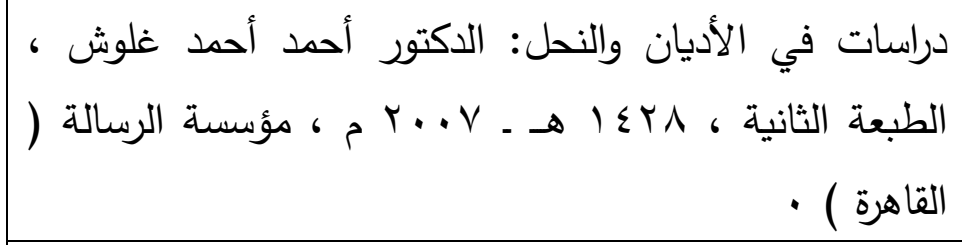 & $r V$ \\
\hline 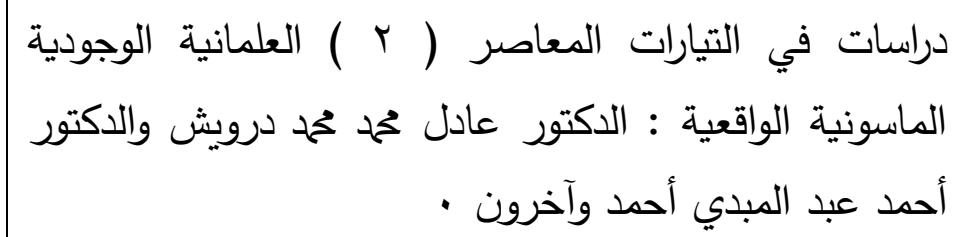 & rᄉ \\
\hline 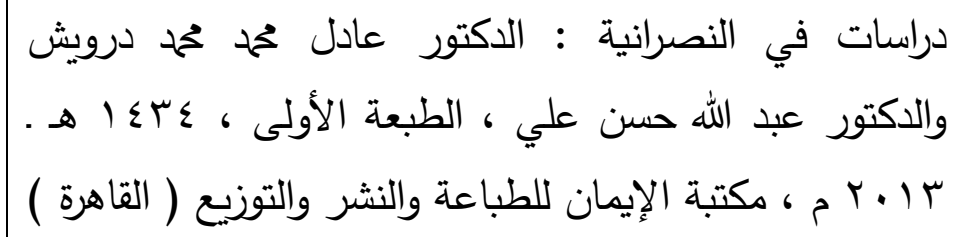 & rq \\
\hline لمفاع عن العقيدة والثريعة ضد مطاعن المستشرقين : الثيخ & . \\
\hline 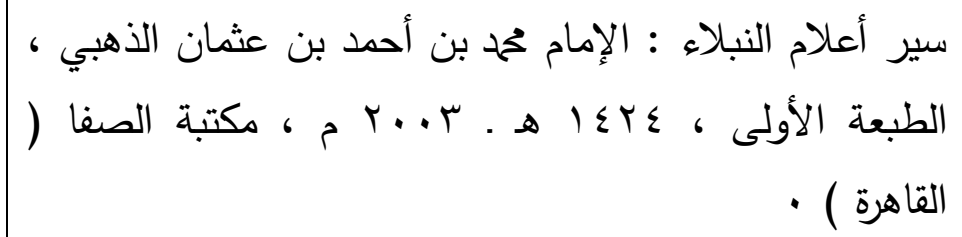 & ו \\
\hline 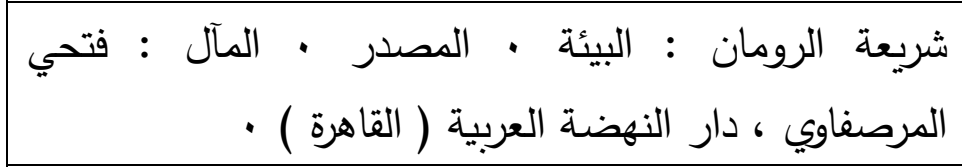 & r \\
\hline 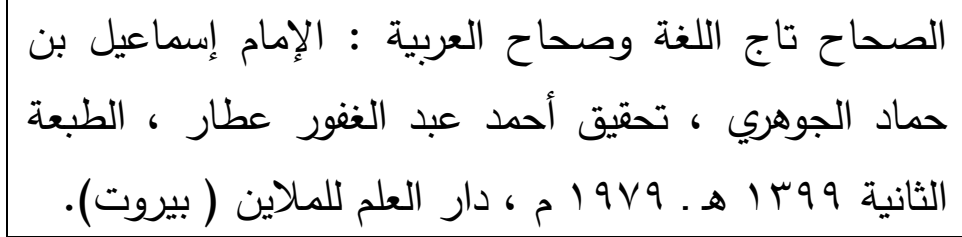 & س" \\
\hline
\end{tabular}


|الصراع بين الفكرة الإسلامية والفكرة الغربية : الأستاذ أبو

एร

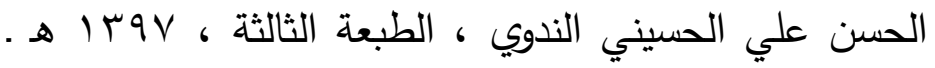
• 19VV

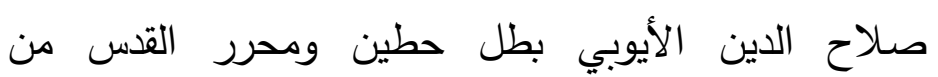
ro الصليبيين : الدكتور عبد الله ناصح علوان ، الطبعة السابعة

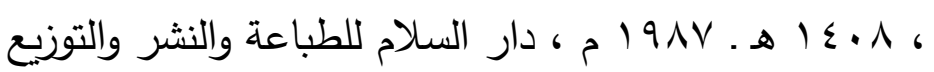

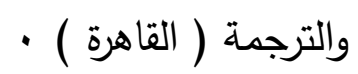

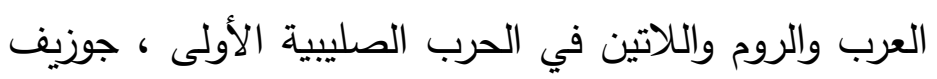
ru نسيم يوسف ، س 1911 م ، مؤسسة شباب الجامعة للطباعة

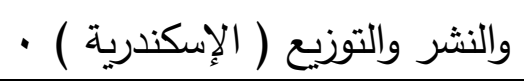

العلاقة بين الدين والدولة في اليهودية والنصرانية والإسلام rv

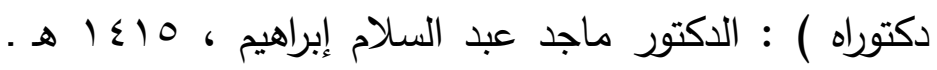
1990 م ، كلية الدعوة الإسلامية بالقاهرة . قدم الأديان

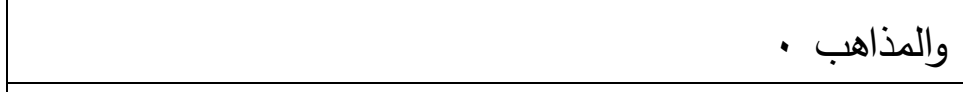

الغزو الثقافي يمتد في فراغنا : الثيخ محم الغزالي ، الطبعة r人

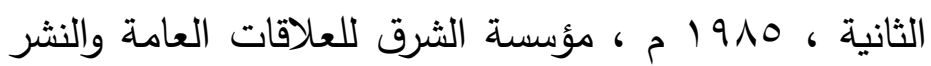
والترجمة • مألزو الفكري وأثره على المجتمع الإسلامي : الدكتور علي

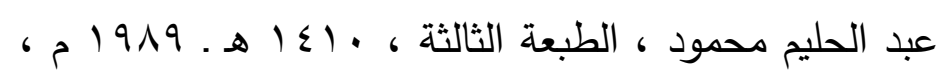

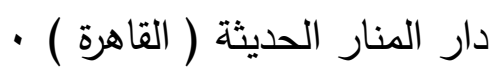

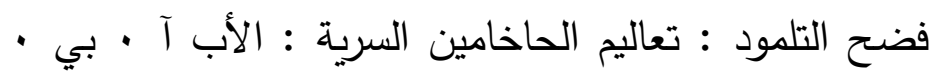
$\varepsilon$.

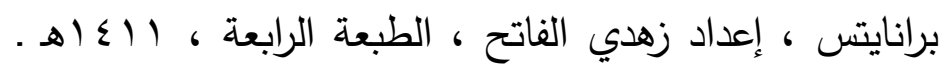
1991 م ، دار النفائس للطباعة والنشر والتوزيع (بيروت). الفكر الاستشراقي تاريخه وتقويمه : محمد الدسوقي ، الطبعة 


\begin{tabular}{|c|c|}
\hline والأولى ، 10 ألوز هـ . 1990 م ، دار الوفاء للطباعة والنشر & \\
\hline الفكر الإسلامي الحديث وصلته بالاستعمار الغربي : الدكتور & $\varepsilon r$ \\
\hline 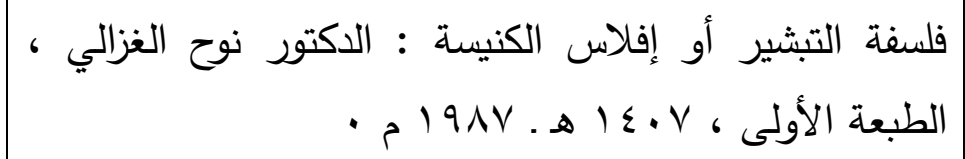 & r \\
\hline قاموس الكتاب المقدس ، نخبة من الأساتذة ذوي الاختصاص الطبعة التهبين ، هيئة التحرير بطرس عبد الملك وآخرون ، & $\varepsilon \varepsilon$ \\
\hline 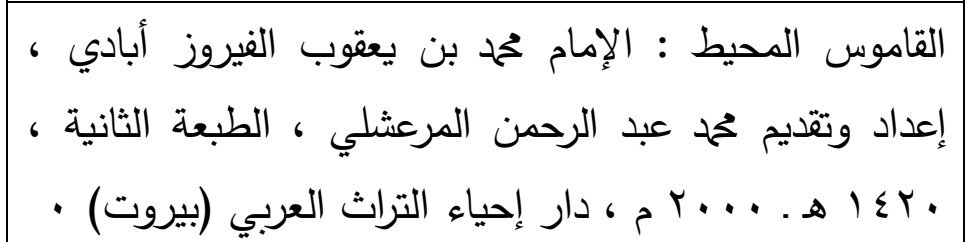 & $\leq 0$ \\
\hline قاموس المذاهب والأديان : حسين علي حمد ، الطبعة الأولى & $\leqslant 7$ \\
\hline وقى الشر المتحالفة : الاستشراق ، التبشير · الاستعمار & $\varepsilon V$ \\
\hline 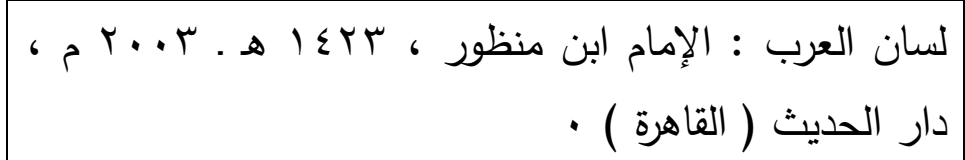 & $\varepsilon \wedge$ \\
\hline 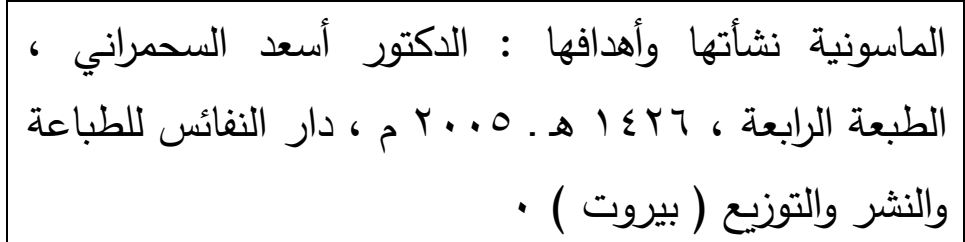 & $\leqslant 9$ \\
\hline
\end{tabular}




\begin{tabular}{|c|c|}
\hline متن اللغة : أحمد رضا ، IMN IN هـ . 1909 ) م ، مكتبة & 0. \\
\hline محاضرات في مفهوم الاستشراق : الاكتور حمد زين العابدين & 01 \\
\hline ، محاضرات في مفهوم التبشير : الدكتور محد زين العابدين كحم & or \\
\hline 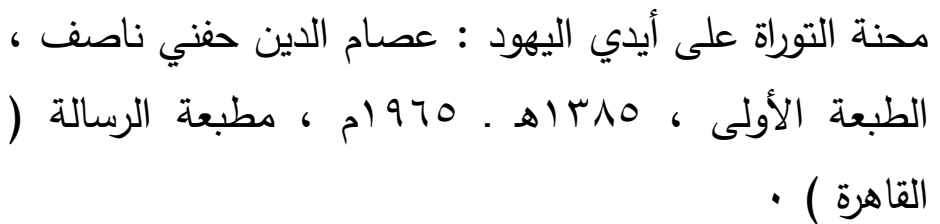 & س \\
\hline 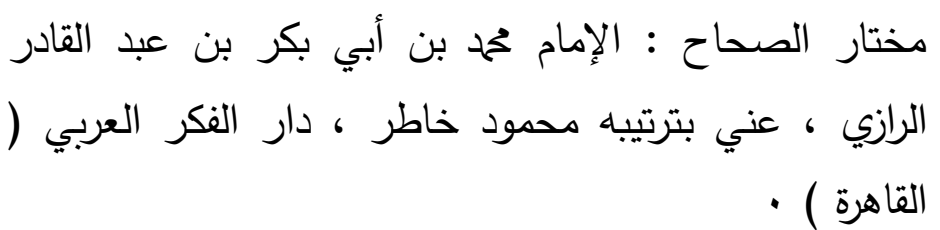 & O \{ \\
\hline 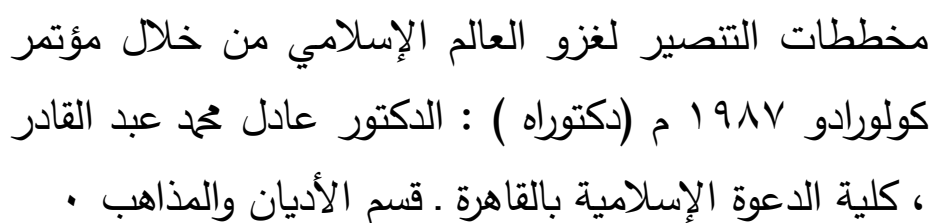 & 00 \\
\hline المستشرقون والتاريخ الإسلامي : علي حسني الخربوطلي ، الهيئة المصرية العامة للكتــاب ( القاهرة ) ، & 07 \\
\hline 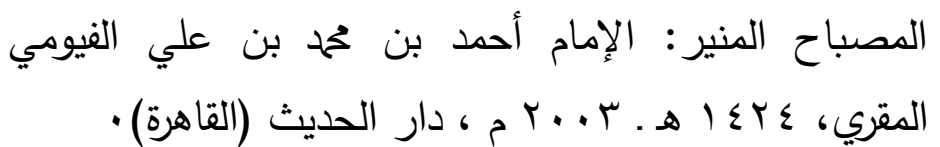 & ov \\
\hline 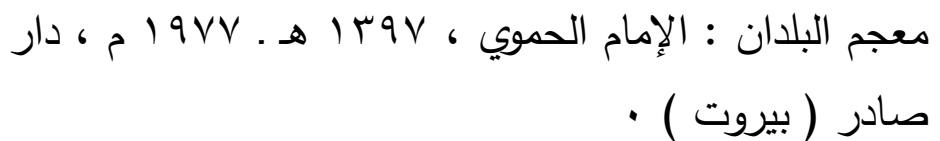 & $0 \wedge$ \\
\hline 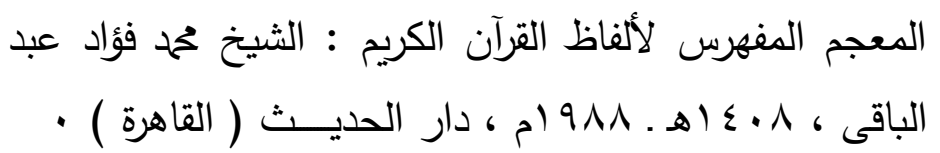 & 09 \\
\hline معجم المؤلفين : تراجم مصنفى الكتب العربية : عمر رضا & 7 . \\
\hline
\end{tabular}




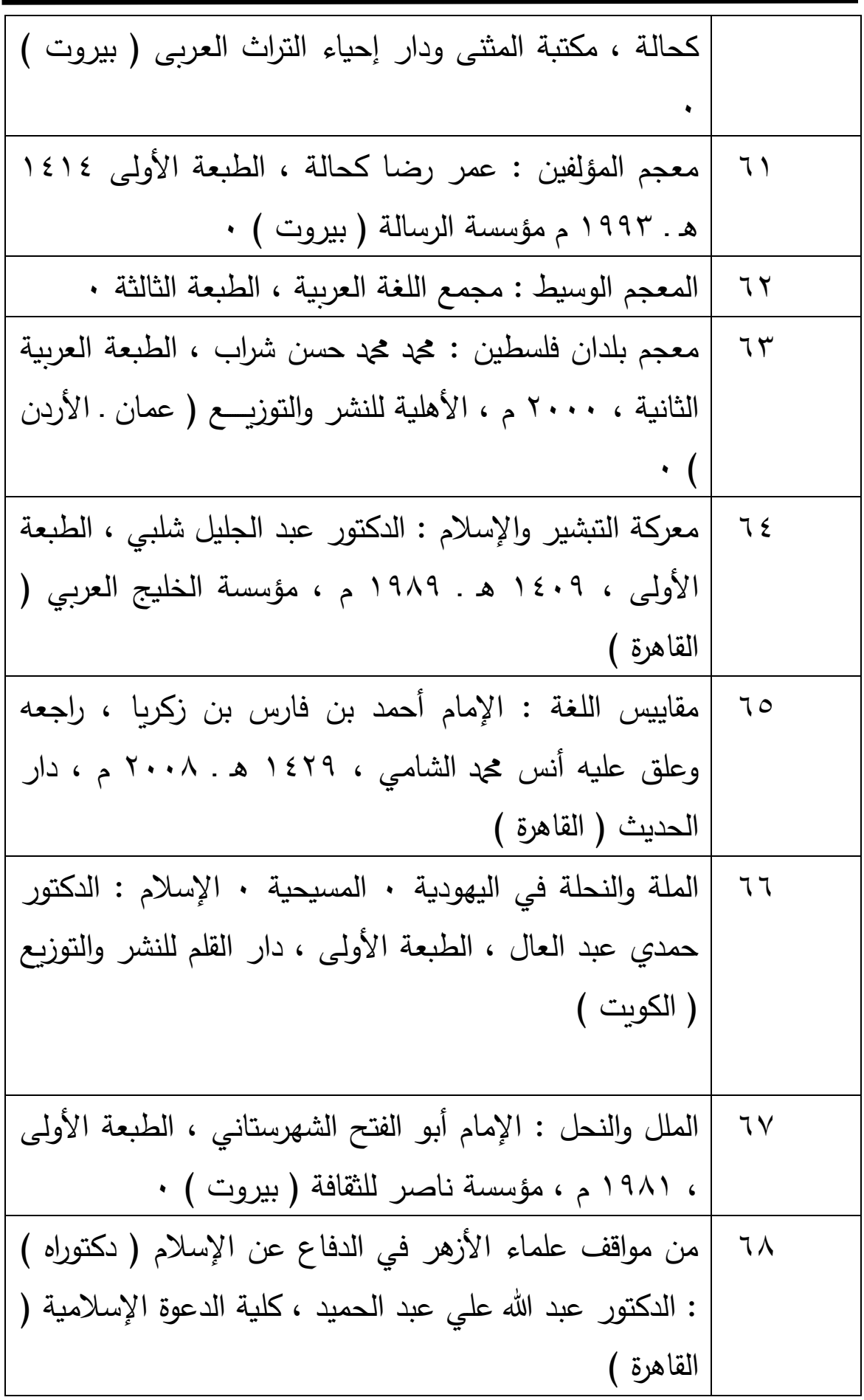

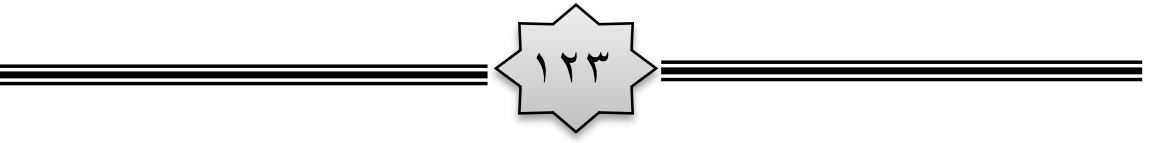




\begin{tabular}{|c|c|}
\hline 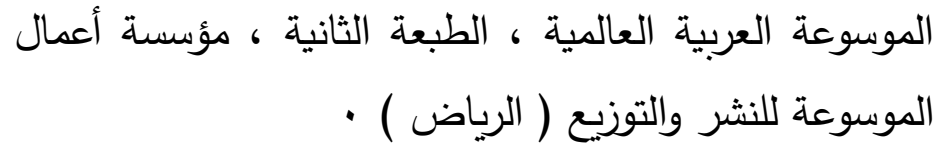 & 79 \\
\hline مالمديرين بإشراف المربية الميسرة : مجموعة من العلماء والخبراء & $V$. \\
\hline الموسوعة الميسرة في الأديان والمذاهب المعاصرة : الندوة & $V^{\prime}$ \\
\hline الموسوعة الميسرة في الأديان والمذاهب والأحزاب المعاصرة : & VY \\
\hline نافذة على الاستشراق النشأة والأهداف : الدكتور ياسر محهد & vr \\
\hline ويكيبيديا الموسوعة الحرة wikipediaOorg و & $\vee \leqslant$ \\
\hline 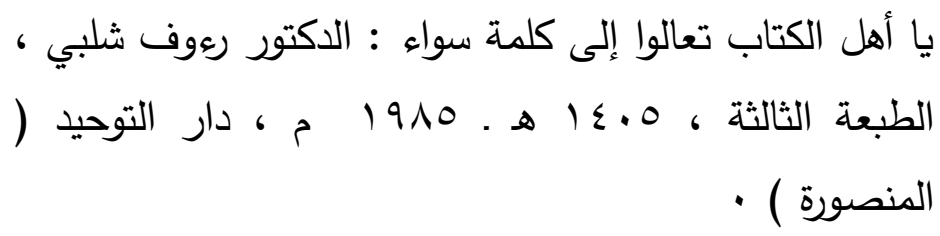 & Vo \\
\hline 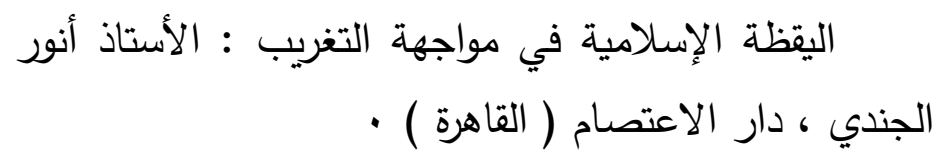 & VI \\
\hline 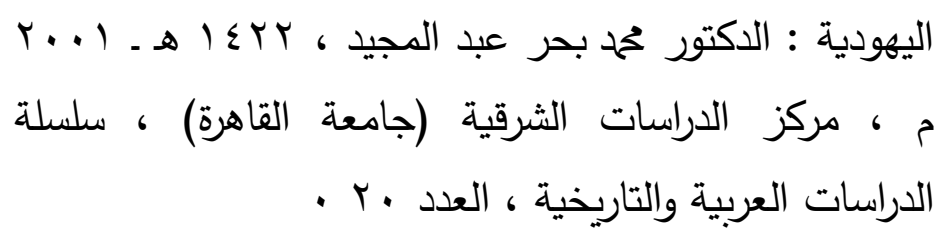 & $V V$ \\
\hline
\end{tabular}

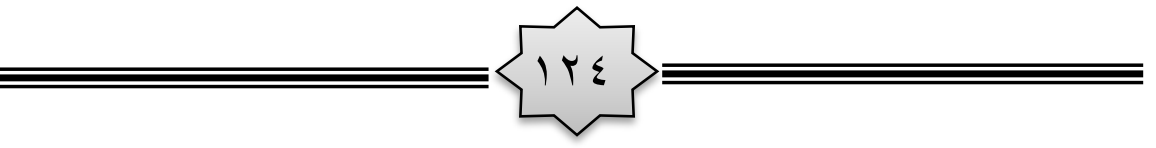




\section{رابعا : فهرس الموضوعات}

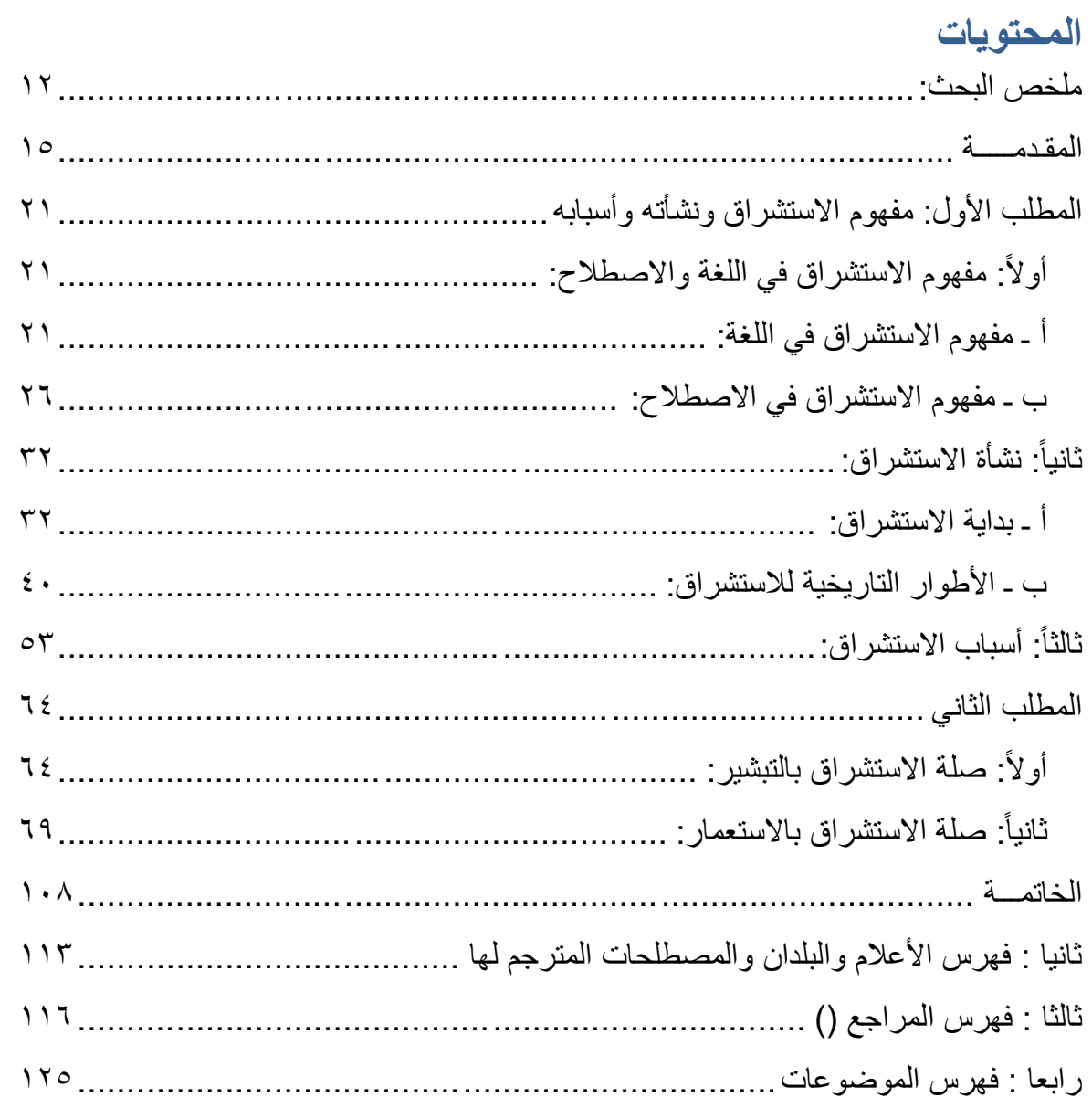

\footnotetext{
نتهى البحث

والله ولي التوفيق،، البق،
}

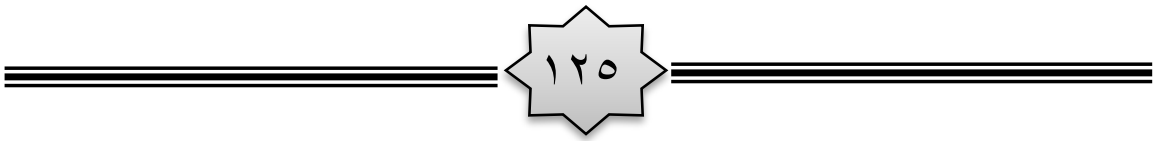

